

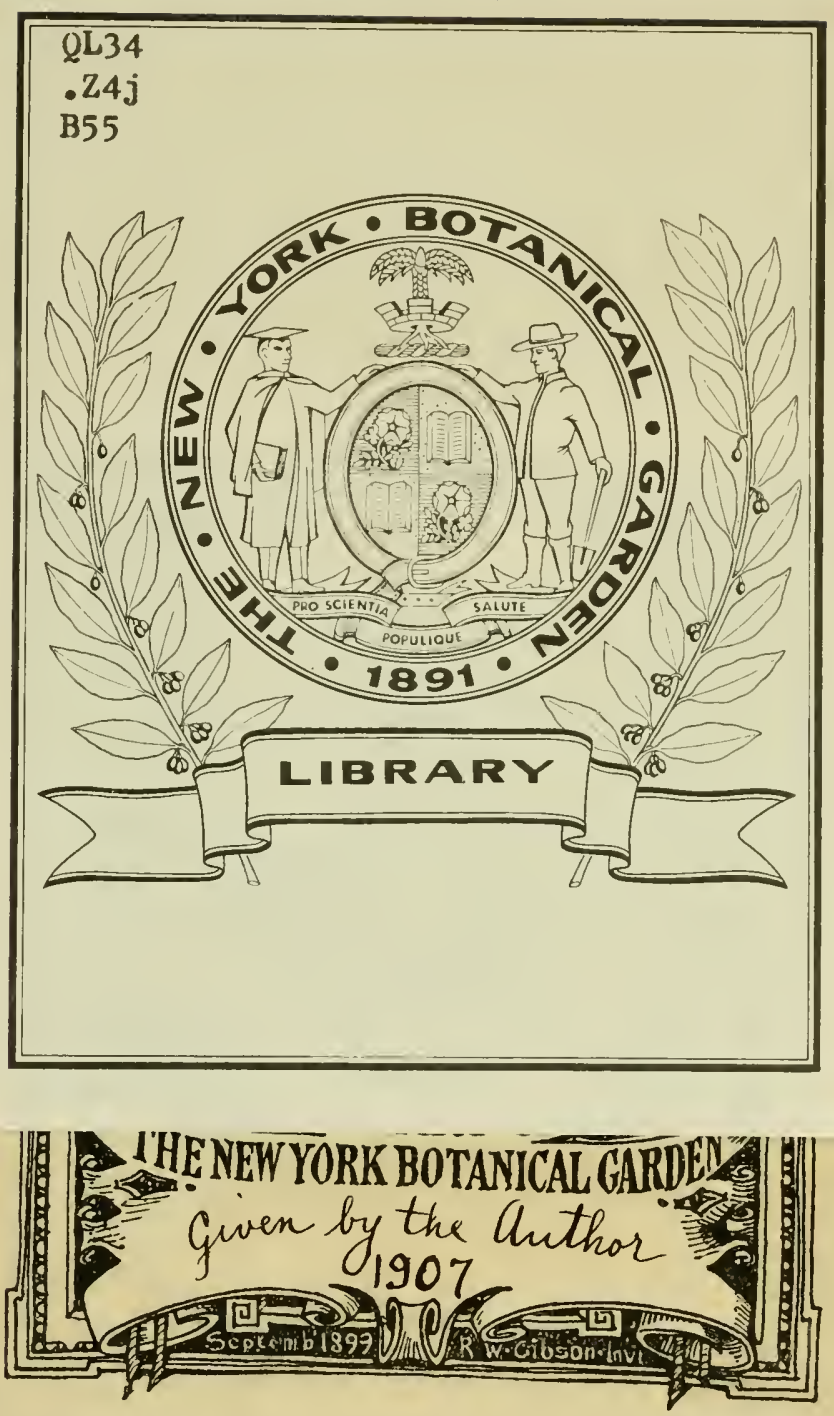





\section{BLARINGHEM}

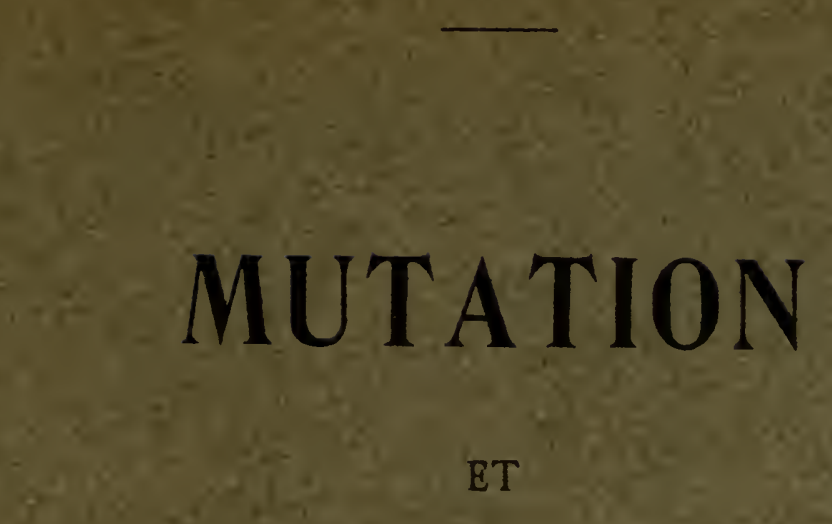

\section{TRAUMATISMES}

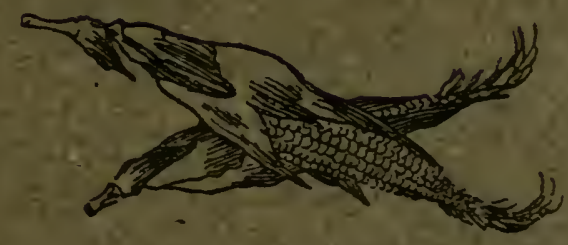

BLLLETIN SCIENTIFIQUE DE LA FRANCE ET DE LA BELGIQUE 1907

PARIS, 3, RUE D'ULAS 
L. BLARINGHEM

a b. Bbllothegue re

ivew youk totamcal

\section{MUTATION}

ET

\section{TRAUMATISMES}
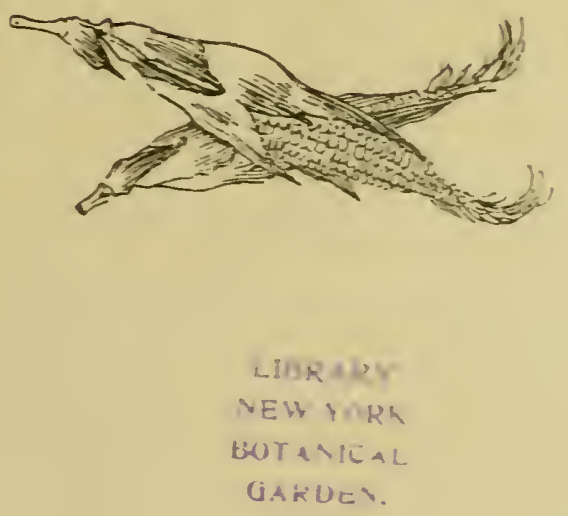

BLLLETIN SCIENTIFIQLE DE LA FRANCE ET DE LA BELGIQLE 1907

PARIS, 3, RLE D'ULM 



\section{वु}

\section{0̈onsien: GGugo de Pries.}

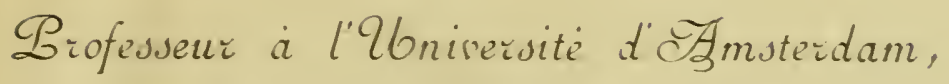
Directeur du Jaudin EBotanique. 



\section{AVANT-PROPOS}

Ce travail a été fait au Laboratoire de Botanique de l'École Normale Supérieure sous la direction de M. J. Costavtin, alors maître de Conférences à l'École Normale, puis de M. L. Matruchot, professeur adjoint à la Sorbonne. Je prie mes maîtres de vouloir bien agréer l'expression de ma profonde reconnaissance pour les encouragements et les conseils qu ills m'ont prodigués. Je tiens aussi à remercier tout particulièrement mon ami M. I. GallaUd qui a suivi mes essais arec une constante sollicitude.

J'ai trouvé au Muséum d'Histoire naturelle de Paris toutes les facilités de documentation et le matériel de plantes d'essais nécessaires pour accomplir mon travail. Je prie M. EdM. Perrier, directeur du Muséum et M. J. Costantin, professeur de Culture, d'agréer l'expression de mes sincères remerciements pour l'intérêt qu'ils n'ont cessé de me témoigner.

A la Sorbonne, M. G. Boxsikr, professeur de Botanique, a suivi arec une grande bienveillance mes études dont il a proroqué le développement et la généralisation. J'ai trouvé au Laboratoire de Biologie végétale de Fontainebleau qu'il dirige toutes les facilités pour l'étude des plantes sauvages, et j'espère pouvoir apporter sous peu, grâce à son extrême complaisance, de nouvelles preures à l'appui des conclusions de ce mémoire. J'ai souvent mis à contribution les connaissances approfondies que possède M. Molliard, maître de conférences à la Sorbonne, sur la Variation des formes végétales. Je suis heureux d'exprimer ici à ces maitres éminents ma reconnaissance pour le précieux concours qu'ils m'ont donné.

C'est à M. A. Giard que je dois l'orientation de mes recherches. J'ai suivi durant plusieurs années ses cours sur l'Évolution des êtres organisés; j’ai été initié par lui aux problèmes soulevés par 
la théorie de la Mutation, aux lois qui régissent la Sexualité et la Parthénogénèse, et plus tard j'ai constamment profité des ressources inépuisables de sa science des choses biologiques.

Avec une extrême complaisance, M. A. Giard et son élève M. J. Massart, professeur à l'Université de Bruxelles, m'ont familiarisé, sur le terrain, avec les méthodes d'observation et d'expérimentation; je conserve, des séjours que j'ai faits à leurs Laboratoires de Wimereux et de Coxyde, le meilleur souvenir. On trouvera souvent dans la lecture de ce mémoire l'influence de leurs conceptions fécondes sur la Variation et l'Adaptation des formes. Je les prie d'agréer l'expression de ma profonde gratitude.

Je dois à la lecture des remarquables travaux de M. Hugo DE VRIES, professeur à l'Université d'Amsterdam, la connaissance des lois et des méthodes de recherche qui m'ont permis de reconnaître et de vaincre les difficultés que présente l'étude de l'Hérédité. Je garde le précieux souvenir de l'agréable sẻjour que j'ai fait au Jardin botanique d'Amsterdain, où M. Hugo De Vries a eu l'extrême obligeance de me montrer en détail ses champs d'expériences, de me donner des conseils sur la technique des cultures, et de compléter les notions acquises par la lecture de ses œuvres. En lui faisant hommage de co livre, je tiens à lui témoigner ma reconnaissance pour ses précieux encouragements.

M. le professeur N. HJalmar Nilsson, directeur du Laboratoire d'Essai de Semences de Svalöf (Suède), m'a fait un accueil très bienveillant. Sous sa direction, j'ai pris connaissance des méthodes rigoureuses qui permettent de spécifier et de classer les formes de céréales cultivées; j’ai appris le maniement des appareils en usage dans son Laboratoire pour la détermination rapide des caractères de Sortes. Grâce aux renseignements ( $\left.{ }^{1}\right)$ nombreux que M. NiLsson et ses collaborateurs mont fournis sur les phénomènes de Mutation et d'Hybridation, j'ai pu donner à mes recherches une précision que je n'aurais pas atteinte sans leurs conseils.

Les ressources des Laboratoires scientifiques ne permettent pas de poursuivre sur une grande échelle les cultures nécessaires à l'analyse

(1) M. N. HJalmar Nilsson avait rédigé, lors de mon séjour au Laboratoire de Svalöf (février 1904), la première partie d'un ouvrage sur ses découvertes dont il m'a facilité la lecture. M. le professeur Costantin (1906) et moi-même, avons, avec le consentement de l'auteur, publié certains documents empruntés à ce travail encore inédit. 
complète et précise des phénomènes de l'Hérédité. J'ai pu les réaliser dans les champs d'Essais de la Société d'Encouragement de la culture des Orges de Brasserie en France. M. A. Kíreiss, président de la Sociêté, m'a encouragé à continuer sur direrses plantes et sur le Maïs les études qui m'ont conduit à la décourerte de lois que j'applique actuellement à l'amélioration des variétés d'Orges. Je rends hommage à la largeur de rues du Comité directeur de la Société d'Encouragement à la Culture des Orges de Brasserie, qui a consenti à mettre à ma disposition des champs d'essais situés dans le roisinage immédiat de Paris, le personnel et l'argent nécessaires à leur entretien.

Enfin je prie mes parents et amis qui ont facilité la culture isolée des porte-graines dans leurs champs et leurs jardins, et en particulier mon père qui a collaboré pour une bonne part à tous mes travaux, de croire à l'expression de mes vils et sincères remerciements.

Paris, le 10 janvier 1907.

\section{LoOIS BLARINGHEM.}




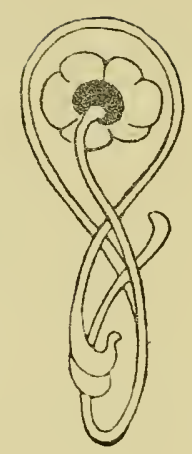




\section{TABLE DES MATIÈRES}

\section{INTRODUGTION}

Théorie de la Mutation. - Relations entre les traumatismes violents et les variations brusques et héréditaires............

PREMIÉRE PARTIE.

PRODUGTION EXPÉRIMENTALE DES ANOMALIES FLORALES DE MAÏS.

CHAPITRE 1.

MODE DE VÉGÉTATION DU MAÏS ET ANOMALIES DES INFLORESGENCES.

1. - Groissance et floraison du Maïs

2. - Relations entre la sexualité et le mode de nutrition des bourgeons................................

3. - Anomalies florales du Maïs: a) anomalies de la panicule terminale; b) anomalies de l'inflorescence latérale.................................

4. - Relation entre la taille des tiges et la nature de l'inflorescence terminale : tableau $I$...................

CHAPITRE II.

RECHERGHE DES CAUSES DES ANOMALIES ACCIDENTELLES DES INFLORESCENGES DU MAIIS.

5. - Conditions de recherche....................... 30

6. - Facteurs de Variation uniforme................... 31 
7. - Facteurs de Variation accidentelle, traumatismes: a) anomalies de la panicule; b) anomalies de l'inflorescence laterrale............................... 32

8. - Observations de K. Müller et de Krafft........... 35

CHAPITRE III.

PRODUCTION DES INFLORESGENGES ANORMALES DU MAÏS PAR DES MUTILATIONS.

9. - Expériences de 1903. Conditions de culture..........

10. - Section transversale de la tige : tableau II, tableau 'IIT,'tábleaii' TV ...........................................

11. - Section longitudinale de la tige : tableau $V$, tableau $V I$, tableau VII..............................

12. - Torsion de la tige autour de son axe : tableau VIII, tableau IX, tableau $X$...........................

CHAPITRE IV.

INFLUENGE DU DEGRÉ DE LA MUTILATION.

13. - Évaluation du degré de la mutilation ................. 55

14. - Relations entre le nombre de plantes mortes et le nombre des rejets des survivantes: tableau XI.....

15. - Relations entre le degré de la mutilation et le pourcentage des plantes anormales: tableau XII......... 58

16. - Évaluation de l'intensité de l'anomalie d'une panicule. 59

17. - Relations entre la taille des rejets, le degré de la mutilation et l'intensité de l'anomalie : tableau XIII... 60

18. - Élimination du bourgeonnement accessoire......... 62

CHAPITRE $V$.

INFLUENCE DE L'ÉPOQUE DE LA MUTILATION.

19. - Expériences de 1903 : tableau XIV, tableau XV ....

20. - Expériences de 1904 et 1905: tableau XVI, tableau XVII................................ 67

21. - Interprétation des résultats : tableau XVIII........ 68

22. - Conditions déterminantes de l'intensité de l'anomalie de la panicule................................ 
CHAPITRE 17.

MÉTAMORPHOSE DES ÉPIS LATÉRAUT FEMELLES EN INFLORESCENCES MALES.

23. - Allongement des pédoncules après la torsion des tiges :

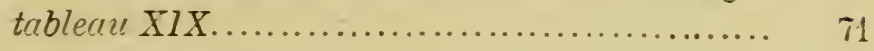

24. - Ramification des épis .....................

25. - Compression de la tige aux nœuds...............

26. - Torsion de l'épi latéral femelle................. 74

CHAPITRE III.

ACTION DES TRAUMATISMES SUR DIVERSES VARIÉTÉS DE MAÏS.

27. - Tariétés soumises à l'expérimentation............ 76

28. - Métamorphose des panicules terminales............ is

29. - Tendances rariables des diverses rariétés: tubleau X. 79

31). - Métamorphose des épis latéraux................ 81

Cojclusions de la Premiére partie.................... \$3

DEUYIĖME PARTIE.

ANOMALIES PROVOQḶEES PAR DES MUTILATIONS.

CHAPITRE IIII.

ANOMALIES DES TIGES. - FASCIES ET TORSIONS.

31. - Anomalies des tiges proroquées par des traumatismes: fascies, torsions, feuilles éparses, biroussins,

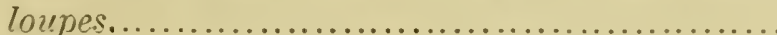

32. - Observations personnelles et Expériences ........... $\$$ \&?

33. - Influence de l'époque de la mutilation............. @3

34. - Relations entre les feuilles éparses et les fascies, les feuilles éparses et les torsions, les fascies et les torsions ............................... 94

35. - Culture des anomalies de tiges..................

36. - Exemples de plantes fasciées qui perdent ce caractère après mutilation $\ldots \ldots \ldots \ldots \ldots \ldots \ldots \ldots \ldots . . .6$ 
CHAPITRE IX.

ANOMALIES DES FEUILLES ET DES BRACTÉES.

37. - Relations entre les feuilles cohérentes et les tiges fasciées ou tordues .......................

38. - Feuilles cupulées ou Ascidies. Leurs relations avec les tiges fasciées ou tordues................. 101

39. - Feuilles découpées, à folioles surnuméraires ou avortées.................................... 103

40. - Relations entre les bractées et les feuilles

ANOMALIES DES GRAPPES FLORALES.

41 - Substitution des rosettes feuillẻes aux inflorescences. 108

42. - Compacité des grappes dont le cas extrême est l'état de fasciation ............................. 111

43. - Exemples de fasciation, de dissociation ef de substitution des parties des inflorescences ........... 113

44. - Régularité relative des inflorescences auormales.....

ANOMALIES DES FLEURS ET DES FRUITS.

45. - Indifférenciation primitive des pièces florales

46. - Relations entre les fascies de tiges et la multiplication des pièces florales .........................

47. - Anomalies de fleurs et de fruits. Anomalies des appareils reproducteurs des Cryptogames............ 119

48. - Duplicature des fleurs, prolifération et viviparité.....

49. - Polyembryonie. Dégénérescence.................

\section{CHAPITRE XII.}

CHANGEMENTS DE SEXUALITE்.

50. - Exemples connus de variation sexuelle après trauma-

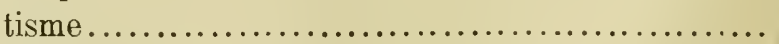

51. - Expériences de E. Bordage sur le Carica papaya 124 (1898) 
52. - Expériences sur le Mais (1903): Métamorphose des glumelles et leur passage aux feuilles; Epillets hermaphrorlites des inflorescences femelles et máles; Métamorphose desglumellulesen stigmates.

53. - Expériences de G. KLlebs sur le Sempervivurn (1904).

51. - Variation de la sexualité arec la nutrition. Relations entre l'abondance d'eau et le sexe fernelle.......

CBAPITRE XIII.

MÉCANISME DE L'HÉRÉDITÉ DES ANOMALIES.

55. - Les anomalies régétales dues aur traumatismes sont des cas particuliers d'Adaptation brusque..........

56. - Variations de structure, de nombre et de disposition des faisceaux rasculaires des rejets................

57. - Continuité des anomalies de tiges, de feuilles, de fleurs et de graines des rejets................ 140

5S. - Mécanisme morphologique et anatomique de l'hérédité des anomalies............................ 141

CoNCLCSIONS DE LA DECXIĖJE PARTIE.

\section{TROISIEMUE PARTIE.}

HÉRÉDITE DES ANOMALIES PROTOQLEES

PAR DES MUTILATIONS.

CHAPITRE XIV.

CULTURE ET HÉRE்DITÉ DES ANOOMALIES DE LA PANICULE

DU MAÏs.

59. - Arantages et inconrénients des plantes cultirées.

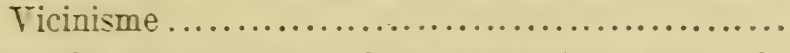

60. - Classification sommaire des espèces élémentaires du Mais......................................... 147

61. - Caractères du Maĩs de Pensylvanie............... 149

62. - Culture des anomalies de la panicule............. 152

63. - Hérédité des anomalies de la panicule (1903): tableau XXI .............................. 151

64. - Cultures des porte-graines et Cultares de Contrôle (1904-1906). 
VARIËTÉS INSTABLES OU «EVERSPORTING».

65. - Définition des Variétés instables.

66. - Famille I: Variètés à panicules fasciẻes, à panicules tordues, à feuilles tubulées, à plantes albines et panachées, à feuillage rouge et à épis ébréchés. Tableau récapitulatif...........................

67. - Famille II : Variètẻ de Mä̈s pleureur, Variẻtẻ à épis dissociés ....................................

68. - Famille III : Variètẻ hybride à grains acajou.......

VARIÉTÉS ET ESPĖGE ÉLÉMENTAIRE NOUVELLES.

69. - Famille I : Zea Mays var. pseudo-androryna; Zea Mays var. semi-praecox..................... 180)

70. - Origine de l'Espèce élémentaire Zea Mays praecox et de ses 'variétés. ................................ 187

71. - Étude biométrique des caractères qui définissent les formes nouvelles et stables : taille des tiges, nombre de feuilles, compacitè des panicules, nombre des rameaux des panicules, densité des rameaux des panicules, nombre de bractées d'enveloppe des épis, nombre des rangées de graines, compacité des épis...................................

CHAPITRE XVII.

MUTATION ET TRAUMATIŞMES.

72. - Résumé des variations héréditaires de la Famille I : tableau récapitulatif...........................

73. - Lois de la Mutation: Variation brusque, héréditaire, accidentelle, à multiples directions, donnant naissance d̀ des espèces élémentaires nouvelles...

74. - Discussion de la périodicité de la Mutation et du pourcentage des Mutantes...................... 
CHAPITRE XIIII.

CRĖATION DE FORMES PRÉCOCES CLLTIVĖES ET SALVAGES.

75. - Déreloppement rapide des rejets ................ 205

76. — La précocité résulte de l'Adaptation............... 206

77. - Dimorphisme saisonnier....................... 207

78. - Discussion des conclusions de Wettsten.......... 208

CHAPITRE XIX.

ÉVOLUTION DU GENRE $Z E A$.

79. - Création méthodique de formes nourelles: culture des anomalies, ébranlement du type spécifique, choix du groupement des caractères............. 210

80. - Etude de l'origine d'une espèce, le Zea Mays L......

81. - Comparaison du Zea Canina W. arec la variété nouvelle de Mais à épis dissociés de la Famille II...

82. - Origine des espèces du genre Mais : le Zea Mars est une forme fasciée de l'Euchlaena mexicana; naissance des espèces élémentaires el des variètès.

CONCLUSIONS GĖNÉRALES ET RĖSUMĖ............. શ્ય1

INDEX BIBLIOGR.APHIQUE..................... 229

INDEX ALPHABÉTIQUE .......................... 241

EXPLICATION DES PLANCHES.................... 249 


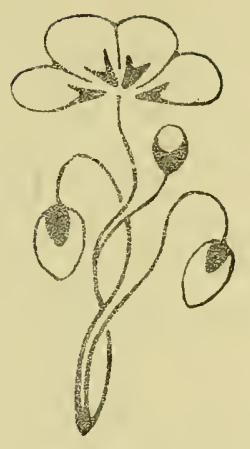




\section{INTRODUCTION.}

La naissance des espèces par Mutation consiste en la production, subite et sans transitions, de formes nouvelles et stables dans les lignées pures d'espèces bien définies. Le changement apparait comme une anomalie sur quelques individus. Les nombreuses expériences que DE VRIES a réalisées depuis vingt-cinq ans sur des formes régétales très différentes, les exemples signalés depuis quelques années par dirers auteurs montrent que ce processus est général et joue un ròle considérable dans l'Évolution des ètres vivants ( $\left.{ }^{1}\right)$.

Les causes de la Mutation ou de la Variation créatrice d'espèces sont inconnues. Hugo DE VRIES admet l'hypothèse d'une mutabilité périodique et rare; très peu d'espèces la présentent et il faut de nombreuses et patientes recherches pour obtenir le matériel expérimental qui permet de suivre l'érolution des formes.

Mes expériences sur la transmission héréditaire des diverses

(1) J'ai exposé les principaux traits de la théorie des Mutations dans divers articles publiés en français :

La Notion d'Espèce (Rerue des Idées, Paris, 15 mai 1905).

L'Origine des Espèces, Sélection et Mutation (Reoue des Idées, Paris, 15 novembre 1905).

La Notion d'Espèce et la théorie de la Mutation ( $L^{\prime}$ Année psychologique, tome XII, Paris, 1906).

De la Variation chez les Végétaux (Journal de la Société Vationale t'Horticulturc de France, Arril 1906).

Le Laboratoire d'Essai de Semences de Svalöf (Suède) (Bulletin du Muséum d'historre naturelle, 1904, n० 7 ). 
anomalies du Maïs me donnent la conviction que j'ai observé des phénomènes de mutation dans cette plante. Depuis 1903, j'ai obtenu un grand nombre de formes stables dont beaucoup sont tout à fait nouvelles en ce sens qu'on ne les avait pas signalées jusqu'ici et que la plupart montrent des caractères aberrants pour l'espèce, le genre et même la famille qui renferment la forme initiale. Les caractères anormaux sont apparus brusquement et leur fixation a été immédiate.

L'intérêt principal de mes recherches réside surtout dans la méthode qui m'a permis d' «affoler » le Maïs et de provoquer la période de mutation créatrice de formes nouvelles. La connaissance du mode particulier de végétation du Maĩs m'a fait découvrir que des mutilations violentes déterminent avec sûreté la métamorphose des fleurs mâles de la panicule en fleur's femelles fertiles ( $1^{\text {re }}$ partie).

Les traumatismes, faits à une époque convenable, provoquent non seulement des anomalies sexuelles mais beaucoup d'autres déviations cles caractères normaux de l'espèce qui seront étudiées dans la deuxième partie de ce mémoire. D'autre part des végétaux annuels ou vivaces, appartenant aux familles les plus diverses, montrent des variations analogues lorsqu'on les soumet au même traitement. Par l'ensemble des documents réunis sur cette question, je pense montrer la généralité de l'action des traumatismes pour la production des anomalies végétales.

Des cultures répétées des graines récoltées sur les individus déformés par les mutilations m'ont permis d'isoler de nombreuses lignées à caractères nouveaux, stables en totalité ou en partie. La description des formes nouvelles, cultivées sur de grandes parcelles, a été complétée par la détermination des caractères à l'aide de polygones de variation individuelle. Par cette méthode, j'ai essayé de préciser quelques points particuliers de la classification des formes, actuellement connues, du Maïs et de montrer comment on peut se représenter l'évolution de ce genre ( $3^{\ominus}$ partie).

Dans cette étude, j'ai pris soin de donner la description détaillée des expériences faites sur le Maïs, mais j’ai aussi cherché à mettre en évidence que la réussite des essais dépend bien plus de la connaissance exacte du mode de végétation de cette plante que des particularités morphologiques qui définissent ce genre de Graminées. Par là, j’ai voulu montrer la généralité des lois vérifiées dans un cas particulier et j'ai essayé d'esquisser un programme de recherches dont 
la réalisation aboutirait à la création raisonnée et expérimentale d'Espèces nourelles ( $\left.{ }^{1}\right)$.

(1) Ce mémoire renferme l'exposé d'observations et d'expériences faites de 1901 à 1906. Quelques-uns des résultats obtenus ont été signalés dans des notes qui sont par ordre de date :

1. Remarque sur du Mais tératologique dit a Maïs dégénéré v. (20 décembre 1902).

2. Production par traumatisme d'anomalies florales dont certaines sont heréditaires (28 juin 1904):

3. Sur une monstruosité du Zea . Kays tunicata D C. proroquée par un traumatisme (10 décembre 1907 ).

4. Hérédité d'anomalies florales présentées par le Zéa Mays tunicata D C. 17 décembre 190: .

5. Anomalies héréditaires proroquées par des traumatismes ( 6 férrier 1905 ;.

6. Action des traumatismes sur les plantes ligneuses ( 3 juin 1905;.

i. Action des traumatismes sur la Tariation et l'Hérédité 18 norembre 1905 :

8. Production de feuilles en cornet par traumatisme (25 juın 1906).

9. Production par traumatisme d'une espèce élémentaire nourelle de Maïs ( 23 juillet 1906.

10. Production par traumatisme et fixation diune variété nourelle de Maĩs, le Zea Jays rar. pseudo-androgyna (31 décembre 1906).

On trourera lindication des références à l’index bibliographique placé à la fin du rolume. 


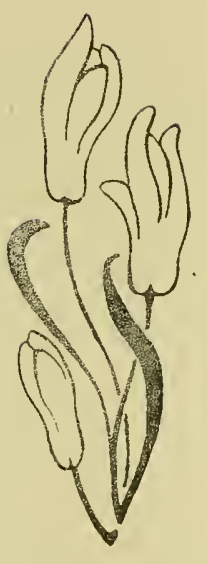


PRODUCTION EXPÉRIMENTALE

DES ANOMALIES FLORALES DU MAIIS.

CHAPITRE $I$.

MODE DE VÉGÉTATION DU MAÏS ET ANOMALIES DES INFLORESCENCES.

\section{1. - Croissance et floraison du maïs.}

Parmi les Graminées cultivées dans l'Europe centrale, le Maïs (Zea Mays L.) se distingue par sa grande vigueur et la rapidité de sa croissance. On en connaît de nombreuses variétés; les plus répandues dans le Nord de la France, la Belgique et l'Allemagne sont utilisées à l'état vert pour la nourriture du bétail. Les semailles ont lieu dans le cours du mois de mai; dans les sols légers et bien exposés, la levée s'effectue une quinzaine de jours plus tard. La plante est en pleine floraison dans la première moitié du mois d'août; si les circonstances atmosphériques sont convenables, elle atteint à cette époque deux et parfois trois mètres de hauteur. Sa tige épaisse et succulente, ses feuilles longues et larges, ses grappes de fleurs constituent, dans les périodes chaudes et sèches de l'année, une nourriture excellente pour les Ruminants.

Le Maïs doit être planté dans un sol riche et bien aéré par de profonds labours. Il demande beaucoup de chaleur et de lumière; d'ordinaire les pluies d'orage de l'été suffisent amplement à ses besoins d'eau. Il prend alors dans les mois de juillet et d'août un développement remarquable; il m'a été possible de voir certaines 
plantes s'allonger de 10 à 15 centimètres en 24 heures avant l'épanouissement de la grappe de fleurs mâles qui couronne la tige. Cette rapidité de croissance est évidemment anormale pour les plantes de nos régions et mérite d'être étudiée avec quelques détails.

Lorsque le Maïs germe, sa racine s'allonge rapidement de 5 à 8 centimètres. Elle s'enfonce jusqu'à ce qu'elle ait trouvé une zone suffisamment humide, puis se courbe et se ramifie pour s'étaler horizontalement. Cette première racine n'a qu'un rôle transitoire; elle ne tarde pas à être remplacée par des racines adventives qui font saillie dès la sortie de la plumule de part et d'autre du premier nœud visible sur l'embryon. Les racines adventives plus fortes et plus épaisses s'enfoncent, puis se ramifient à leur tour tandis que d'autres racines adventives se développent sur les nœuds plus élevés, même jusqu'à un mètre de hauteur dans les années humides; sans doute l'enfouissement convenable de la tige permettrait à ces racines de se ramifier et de remplir leur rôle fixateur et nourricier. Il m'est arrivé sourent de butter la base des tiges renversées par des orages violents et d'obtenir à l'automne des racines parfaitement ramifiées issues du quatrième nœud, à 15 centimètres au-dessus de la zone d'enfouissement du grain. Ainsi le Maïs a des racines de remplacement dont l'ensemble forme une touffe buissonnante; les plus anciennes sont centrales, les plus récentes périphériques. Elles se développent au fur et à mesure de la croissance de la tige à laquelle elles donnent une base solide et les aliments nécessaires.

La croissance de la tige est lente au début. Le premier organe visible au-dessus du sol est une gaine tubulée terminée en biseau, portant latéralement deux nervures saillantes. Cet organe ne joue qu'un rôle protecteur; d'ordinaire il est dépourvu de chlorophylle, mais il montre souvent un léger pigment rougeâtre. Les jeunes feuilles sont enroulées dans ce tube qu'elles déchirent en s'étalant. La première feuille fonctionnelle a une gaine courte et épaisse, un limbe ovale allongé à pointe arrondie dont la forme diffère beaucoup selon les variétés. Les feuilles suivantes qui ont la forme définitive de la feuille du Maïs adulte s'étalent dans un plan, s'écartant à la base pour permettre le développement du bourgeon central encore très petit. Un mois après la levée, la jeune plante de Maïs laisse voir 4 ou 5 feuilles; la plus jeune au centre est enroulée en cornet, les autres sont étalées et alternes distiques. A cette époque la tige est à peine visible; si on enlève avec soin les organes libres" on reconnaît 
que toutes les feuilles sont formées ainsi que la panicule, alors que la tige entière, à partir du premier nœud, ne dépasse pas un centimètre. Cestade correspond à celui de la rosette des plantes bisannuelles.

Nous sommes au commencement de juillet. Qu'une pluie d'orage survienne avec une température élevée, la plante croit á rue d'œil ; en moins d'un mois la tige s'allonge de près de deux métres, déployant ses feuilles longues et larges, étalant sa panicule abondamment ramifiée et chargée d'épillets mâles. La panicule était déjà esquissée dans le petit bouton central de la jeune plante; elle est complètement formée dès que la tige atteint sept centimètres. Tous les rameaux sont libres et serrés autour de l'axe principal. Au microscope, on distingue les glumes, les glumelles et les bourrelets qui seront les trois étamines de chaque fleur. La première période de croissance correspond donc à la formation définitive et à l'allongement de la grappe måle. J'ai pu récolter sourent, dans la première quinzaine de juillet, des panicules de 15 centimètres de longueur totale sur des tiges n'atteignant pas (1) centimètres.

Vient ensuite une période de repos pour l'allongement de la panicule; c'est maintenant que se produisent, sans laisser de traces visibles à l'extérieur, les modifications cellulaires dont la conséquence est la maturation du pollen fécondateur. Les rameaux durcissent, les enveloppes des fleurs prennent plus de consistance, l'are s'allonge légèrement, tandis que la tige croit en hauteur et en épaisseur jusqu'à l'épanouissement de la grrappe qui a eu lieu dans les premiers jours d'aoủt. Il faudra au moins 15 jours encore pour que le pollen seéchappe en minces filets, par les orifices en boutonnière situés à l'extrémité des étamines suspendues par leurs grẻles et longs filets.

On aperçoit alors, à l'aisselle des leuilles du milieu de la tige. les inflorescences latérales femelles entourées le leur épaisse enveloppe de bractées imbriquées et couronnées par les longs stigmates blancs ou rougeàtres. Le jeune bourgeon qui doit éroluer en épi est à peine formé au moment de l'allongement de la tige. Un lérer mamelon situé à l'aisselle de la feuille croit d'abord en diamétre: comprimé entre la feuille et la tige, il s'étale dans le sens transver'sal sans s'allonger sensiblement; les bractées se dérelopjent et pendant longtemps on ne peut distinguer que leur large surface d'attache à la périphérie du bourgeon. Les bractẻes prennent part à l'accroissement en épaisseur de la tige et leurs dimensions augmentent en même 
temps; il en résulte une compression des jeunes tissus à l'intérieur de la gaîne foliaire déjà épaisse et ferme, compression qui entraîne le renfoncement concave de la tige au-dessus des nœuds en des points de rupture facile. Le bourgeon central est encore rudimentaire lorsque les bractées ont pris leur taille définitive. C'est alors que les stigmates s'allongent; plus tard, après la fécondation, l'accroissement des bractées cesse, tandis que l'épi croît jusqu'à la période de maturation des graines qui correspond à la dessiccation de la plante entière.

\section{2. - Relations entre la Sexualité et LE mode De} NUTRITION DES BOURGEONS.

L'étude comparẻe de la morphologie et de l'évolution du bourgeon terminal et de l'un des bourgeons latéraux du Maïs est très suggestive. Les mêmes organès y sont présents. Au tube taillé en biseau qui apparaît à la germination correspond la bractée externe de l'épi à deux nervures saillantes qui embrassent la tige $\left({ }^{1}\right)$. On trouve, dans certaines lignées de Maïs mutilé expérimentalement, des cas de suture très nets des bords libres de cette bractée qui rendent l'analogie plus frappante encore.

La section de la jeune plante de Maïs à l'état de rosette par un plan vertical passant par les nervures des feuilles correspond à celle du jeune épi latéral, faite deux mois plus tard, par un plan vertical perpendiculaire an précédent. De part et d'autre des axes, les organes appendiculaires, souvent en nombre égal, ont la même disposition primitive ; leur forme seule diffère et ces diffẻrences, très accusées à l'état adulte, résultent seulement de la situation des bourgeons et surtout de leur mode de croissance.

Le bourgeon terminal a une base grêle ; il s'allonge et s'épaissit en même temps que se forment les racines, que s'étalent les feuilles à gaîne courte et à limbe étroit. La grappe florale qui le surmonte, développée à une époque où les racines sont peu abondantes, où les feuilles assimilent peu et pourvoient tout d'abord à leur propre croissance, est allongée et ramifiée à cause du manque de nourriture.

(1) Godron (1879) admet que la bractée exlerne de l'épi du Maïs est le résultat de.la suture de deux bractées à une scule nervure. J'ai observé plusieurs cas d'indépendance complèle de ces deux pièces, ce qui vérifie cette hypolhèse. 
Le bourgeon latéral apparait et croît sur une tige presque complètement développée, abondamment pourvue d'eau et de sels par une touffe épaisse de racines, d'hydrates de carbone par des feuilles longues et larges. La pléthore détermine l'épaississement, l'étalement du bourgeon et le raccourcissement des organes. Les bractées ont une large base d'attache; elles sont réduites à la gaîne surmontée rarement d'un limbe court; le rachis charnu augmente plus en diamètre qu'en longueur. De là résulte la diffẻrenciation extrêmement accusée des inflorescences qui entraine la séparation des seres.

L'examen des fleurs conduit aux mèmes conclusions. La distribution des parties est identique sur la panicule mâle et l'épi femelle. La forme et la nature des organes sont seules changées, mais à un degrẻ tel qu'il serait difficile d'en faire le rapprochement si l'on ne tenait compte de leur situation. Au rameau de la panicule màle correspond une double rangé de grraines de l'épi latéral. Les épillets, toujours groupés par deux, sont pédonculés sur la grappe et sessiles sur l'épi, au point de provoquer dans le rachis la formation de petites logettes où les graines sont enchâssées. La compression qui en résulte entraine l'arortement de l'un des deux épillets femelles et le rapprochement des points d'attache des graines sur le rachis.

Les épillets mâles ont deux glumes orales allongées, pointues, minces et poilues, à nervures parallèles, qui renferment deux fleurs composées chacune de deux glumelles, deux glumellules et trois étamines portées sur de minces filets; on ne peut y décourrir la trace d'un ovaire; les deux fleurs donnent à quelques jours d'intervalle un pollen abondant. Par contre, les épillets femelles n'ont le plus sourent qu'une seule fleur fertile sur les deux qui les composent. Leurs glumes sont courtes, évasées, ligneuses et dures; elles renforcent la cupule creusée dans le rachis de l'épi. A la loupe on roit deux groupes de deux glumelles menbraneuses renfermant chacun un ovaire dont un seul se développe comprimant tout le reste. On ne peut décourrir de traces d'étamines, mème à l'état de bourrelet, dans les coupes en série. Les sexes sont donc bien séparés dans le Maïs à l'état normal.

Cette étude nous montre que le Maīs est une Graminée vigourense, à léveloppement rapide, présentant des caractères très accusés de diffẻrenciation de bourgeons. Son appareil radiculaire, sa grappe terminale se forment tout d'abord dans la première période de croissance qui est relatirement lente. Sa haute tige puis ses inflores- 
cences latérales atteignent en moins d'un mois leurs fortes proportions. A la croissance lente en période de disette correspond la grappe de fleurs mâles, à la croissance rapide accompagnée de pléthore correspond l'épi femelle prêt à reçevoir le pollen au moment de sa chute liors des étamines.

Est-il possible de modifier le développement des inflorescences pour en changer le sexe? C'est ce qui semble résulter de l'existence lans la nature de grappes florales de Maïs présentant des fleurs de sexes différents.

\section{3. - Anomalies florales du Maïs.}

La séparation des sexes sur des grappes florales distinctes et diffẻremment situées n'est pas constante chez le Maïs. Très rarement et sans cause apparente, on trouve dans les champs et dans les jardins des grappes terminales couvertes de fleurs femelles évoluées en graines; plus rarement encore, on observe à l'intérieur des bractées qui enveloppent l'épi quelques épillets mâles serrés au milieu de nombreuses graines. Ces déviations insolites des caractères de l'espèce qui n’apparaissent que sur quelques plantes, dispersées parmi toutes les autres normales, sont désignées sous le nom d'anomalies ou encore de monstruosités.

Malgré l'impression d'irrégularité aux lois habituelles de la nature qu'éroquent ces dénominations, on sait maintenant que les anomalies sont soumises à des lois en tout point analogues à celles des variations les plus communes. Avant d'en faire l'étude approfondie, il est nécessaire de les décrire et de les classer.

\section{a. - Anomalies de la panigule terminale.}

Les anomalies de l'inflorescence terminale peuvent se subdiviser en trois catégories selon les degrés de la métamorphose plus ou moins complète des fleurs mâles en fleurs femelles ou hermaphrodites.

Au type A (Pl. I, fig. 1-5) correspondent les panicules qui montrent l'association de fleurs fertiles de sexes diflérents. On y fait rentrer', comme cas extrême, les grappes qui ont conservé l'apparence complète de la panicule normale mais qui possèdent quelques épillets à glumes allongées, étroites, d'où sort à la floraison un style 
filiforme. Des deux fleurs de l'épillet, l'une est mâle et complètement normale, l'autre est femelle et avorte par suite de la rupture précoce du strle secoué par le rent; en protégeant le stigmate par un tube de papier parcheminé, j’ai réussi à obtenir des grraines fertiles. J'ai rencontré aussi, mais très rarement, dans les épillets de ce type des fleurs véritablement hermaphrodites pourvues d'un verticille de 3 étamines et d'un oraire central. A l'opposé de cette panicule dont on ne peut découvrir les caractères anormaux que par un examen minutieux, on place aussi dans la même catégorie les grappes ramifiées dont la plupart des épillets mâles ont subi la métamorphose complète en épillets femelles. Le plus souvent l'axe central et la base des rameaux latéraux ne portent que des fleurs femelles. Seules les extrémités des rameaux latéraux présentent quelques épillets à fleurs mâles fertiles.

Le type B (Pl. I, fig. 6-7) renferme toutes les panicules ramifiẻes courertes de fleurs fertiles exclusirement femelles.

Enfin, le type C (Pl. I, fig. 8) correspond aux inflorescences rédluiles à un seul axe courert uniquement de fleurs femelles.

Cette classification est conventionnelle. Ayant eu l'occasion de récolter un nombre très considérable de ces anomalies, d'en faire le dénombrement et la désignation rapide à l'aide de symboles, il ma paru nécessaire d'avoir, avant tout, une méthode de classement immédiate et sùre. La présence ou l’absence de ramifications qui séparent les types B et C apparaît à première rue. La distinction des inflorescences At et B est plus délicate: jai toujours eu soin de choisir les épillets måles les mieux déreloppés pour faire l'examen des anthères et de leur contenu. En rẻalité l'absence mème d'autres caraclères morphologiques pour la séparation des groupes montre bien la continuité la plus complète dans les différentes étapes de la métamorphose. On trouve toutes les transitions entre les inflorescences màles, les inflorescences màles et femelles et les inflorescences purement femelles. Une telle sériation mavait paru inutile et mème trompeuse au début de mes recherches. Il existe en effet des inflorescences du type A-C réduites à l'axe principal dont la base est presque toujours couverte d'épillets femelles et le sommet d'épillets màles; au point de vue morphologique elles forment le passage entre les rares panicules mâles non ramifiees et les inflorescences femelles du Maïs (Pl. I, fig. 9-12).

Les différentes anomalies de la panicule peuvent donc ètre sériẻes 
L. BLARINGHEM.

de manière à former une chaîne ininterrompue de transitions entre les inflorescences mâles et les inflorescences femelles normales. Les liaisons qui les unissent sont représentées dans le tableau suivant :

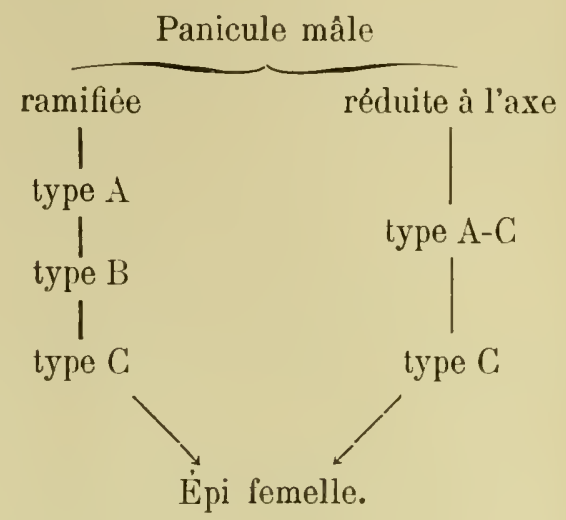

b. - Anomalies de l'inflorescence latérale.

Le rapprochement entre les inflorescences terminale et latérales du Maïs par la série continue des anomalies de la panicule peut être facilement établi par les modifications plus rares mais tout aussi accusées de l'épi femelle. On montre ainsi la réciprocité de la métamorphose et l'on fournit les preuves complètes de l'identité primitive des bourgeons que leur position fait évoluer en des organes différents par l'aspect, la structure et les fonctions.

Il n'est pas rare de trouver, dans la grande culture, des épis femelles présentant des indices de leur parentẻ avec les inflorescences mâles ; leurs caractères peuvent se grouper sous deux titres distincts : mitamorphose partielle des épillets femelles en épillets mâles, ramification plus ou moins accusée du bourgeon.

Les formes d'épi les plus arantageuses pour la production des graines, par conséquent celles qui sont choisies par le sélectionneur, ont le sommet arrondi et couvert de fleurs fertiles. Ce caractère est loin d'être constant; il suffit d'examiner quelques plantes dans un lot, même de choix, pour trouver des variations légères mais importantes pour le sujet qui nous occupe. Le plus souvent les épillets très voisins de l'extrémité de l'épi avortent et le rachis, au lieu d'être couvert d'alvéoles protectrices des graines, est nu sur une longueur 
de 5 à 10 millimètres. Les épillets qui se déreloppent sur la portion dénudée ne mentrent pas toujours lés caractères des épillets femelles. Réduits à leurs enreloppes, ils ont les glumes minces, allongées et striées, analogues à celles des épillets mâles de la panicule (Pl. I, fig. 14). L'absence complète d'étamines et parfois de glumelles ne permet pas de ranger ces épis dans la catégorie des anomalies. On peut seulement regarder ces particularités comme l'indice extérieur du caractèrc latent $\left(^{1}\right)$ que possèdent les inflorescences à donner des fleurs mâles au lieu de fleurs femelles. Leur présence sur des épis de lignées de Maīs en tout normales et n'ayant subi aucune mutilation montre que la métamorphose accidentelle des fleurs femelles en fleurs mâles n'est pas une qualité nouvelle, mais seulement une qualité cachée par le déreloppement abondant des épillets femelles. Des circonstances particulières peuvent permettre le développement . de cette tendance, sa fixation même; on ne peut leur attribuer un ròle créateur ni les regarder comme la cause directe de la production du caractère, puisqu'il existe, quoique très réduit, alors mème que ces circonstances n̈interviennent pas.

La métamorphose partielle des épillets femelles de l'inflorescence latérale en épillets mâles est une anomalie très rare surtout dans les variétés rigoureuses de Maĩs cultivées comme fourrage vert. On se l'expliquera facilement lorsque l'on aura examiné les circonstances difficiles à réaliser qui les provoquent. Néanmoins j’ai pu en obtenir une série complète, exposée ici dans l'ordre de la métamorphose croissante. On peut observer d'abord la présence de quelques épillets mâles à étamines fertiles dispersées sur l'épi latéral. En général, leur distribution est régulière et localisée à une seule rangée de fleurs femelles. Si les rangées sont spiralées (ce qui est le cas ordinaire lorsque leur nombre n'est pas multiple de 4), on peut suivre la torsion des parties qui constituent l'épi à la courbure que montre la rangée métamorphosée.

Vient ensuite la métamorphose des épillets mâles d'une zone de l'épi femelle. Cette zone, toujours plus ou moins allongée dans le sens de la plus grande dimension du rachis, peut ètre terminale ou médiane et couvrir le quart, la moitié ou même les trois quarts des rangées. Enfin toute une portion circulaire de l'épi peut subir la

(1) Le sens de l'expression caractère latent est celui qui est adopté par HicGo DE VRIEs dans Species and Varieties, p. 216. 
métamorphose. La pointe du rachis porte presque toujours des épillets mâles qui peuvent se substituer aux fleurs femelles sur le tiers, la moitié ou même la totalité de l'épi. Toutes ces formes d'inflorescences à mélange d'épillets de sexes différents correspondent exactement à la série des déformations décrites sur la panicule réduite à un axe:

Inflorescence latèrale

Épi femelle correspond au

Épi A-C

Épi mâle
Panicule terminale

type $\mathrm{C}$

type A-C

type uniaxe

La ramification de l'épi latéral est fréquente, et peut avoir lieu avec ou sans allongement de l'axe couvert de bractées (Pl. VIII, fig. 95-96). Sans allongement on possède des épis doubles et triples dont la ${ }^{\circ}$ ramification rappelle exactement les grappes terminales désignées sous le nom de type B. J'en ai observé accidentellement dans quelques lignées provenant de Maïs mutilé expérimentalement et j'ai constaté leur héréclité partielle. Les différentes races de Mais sont plus ou moins aptes à donner cette anomalie, et Bonafous, en 1816, signalait dans son Histoire générale du Maĩs une variété Polystachis qui présentait constamment ce caractère dans sa descendance. C'est aussi dans des espèces ou variétés de Maïs spéciales que j'ai trouvé la ramification de l'épi développée à son plus haut degré.

L'espèce élémentaire Zea Mays tunicala A. DE ST-Hilaire l'a donnée régulièrement dans certains lots isolés. Les variétés à grains blancs et rouges du Zea Mays oryzaeformis, qui présentent une tendance très accusée à l'aplatissement des épis, en ont offert les plus beaux échantillons.

On y trouve tous les stades de ramification avec apparition locale des épillets mâles dispersés au milieu des épillets femelles et, suivant le degré de la métamorphose, toutes les formes de transition observées entre la panicule terminale et l'épi latéral:

Inflorescence latérale

Épi femelle

Epi double, triple

Épi ramifié à épillets màles -
Panicule terminale

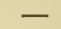

type $\mathrm{C}$

type $B$

type A 
Mais la métamorphose complète de l'inflorescence latérale en une panicule ramifiée et complètement màle entraine toujours l'allongement de l'axe et la production, à l'aisselle des bractées, d'épis secondaires normaux à fleurs exclusivement femelles. Les échantillons les plus remarquables de cette anomalie ont été donnés par une variété de Mais originaire de l’Algérie. Ils dérirent de la culture de graines récoltées sur un épi qui, après la torsion, s'est allongé de façon à présenter six épis secondaires qu il a été impossible de récolter mûrs. Seules les graines développées sur l'épi terminal du type A-C ont donnẻ des descendants, sur certains desquels j'ai trouré les inflorescences latérales composées, en tout analog̣es à une plante de Maïs complète arec panicule mâle et épis latéraux femelles.

En résumé, toutes les transitions entre les grappes florales trés différentes du Maĩs normal, obserrées dans les anomalies de la panicule, se retrourent dans les anomalies de l'épi latéral. L'identité primitive des bourgeons qui leur donnent naissance est donc démontrée. Il s'ag̣it maintenant de rechercher les conditions qui influent sur la mise en latence de l'une ou l'autre tendance par le développement exclusif de l'un des sexes.

\section{4. - Relation ENTRE LA TAILle DES tiges et LA Nature} DE L'NAFLORESCENCE TERMINALE.

On rient de roir que le cas extrème de la métamorphose de l'inflorescence latérale en une panicule abondamment ramifiée entrainait l'allongement du pédoncule et la formation d'épis latéraux de second ordre. Il serait facile, en étudiant dans le détail les déformations du Maĩs d'Algérie qui ont donné ces exemples remarquables, de montrer que la métamorphose est d'antant plus accusée que le pédoncule de l'ẹpi est plus allongé. Ayant surtout porté mes efforts sur l'ẻtude du Mais ordinaire cultivé comme fourrage dans le Norul de la France, je préfẻre me limiter à la démonstration de la mème loi pour les déformations de la panicule terminale. Cette loi résulte du releré de la taille des tiges correspondant à des anomalies de la panicule ayant porté des graines mùres à la fin du mois d'octobre. Dans ce tableau général figurent à la fois des anomalies proroquées expérimentalement par des mutilations ainsi que dautres obtenues par hérédité sans traitement particulier. Les tiges à panicules normales nont été comptées que parmi les rejets: 
L. BLARINGHEM.

TABLEAU I.

TAILLE DES REJETS A PANIGULE DÉFORMÉE OU NON, OBSERVÉS DE 1903 A 1905 INGLUS:

PANICULES

\begin{tabular}{|c|c|c|c|c|}
\hline TAILLE & & & & \\
\hline EN DÉCIMÉTRES & NORMALES & TYPE A & TYPE B & TYPE C \\
\hline 1 & 0 & 1 & 5 & 17 \\
\hline 2 & 1 & 1 & 7 & 33 \\
\hline 3 & 0 & 2 & 13 & 15 \\
\hline 4 & 1 & 2 & 18 & 18 \\
\hline 5 & 1 & 1 & 19 & 8 \\
\hline 6 & 2 & 2 & 14 & 10 \\
\hline 7 & 1 & 3 & 17 & 15 (1) $^{1}$ \\
\hline 8 & 3 & 5 & 16 & 11 \\
\hline 9 & 2 & 4 & 21 & 3 \\
\hline 10 & 2 & 7 & 17 & 7 \\
\hline 11 & 5 & 13 & 24 & 5 \\
\hline 12 & 11 & 17 & 22 & 0 \\
\hline 13 & 10 & 16 & 15 & 2 \\
\hline 14 & 18 & 19 & 4 & 0 \\
\hline 15 & 21 & 21 & 3 & 1 \\
\hline 16 & 27 & 20 & 1 & \\
\hline 17 & 23 & 29 & 2 & \\
\hline 18 & 28 & 23 & & \\
\hline 19 & 31 & 15 & & \\
\hline 20 & 39 & 9 & & \\
\hline 21 & 23 & 11 & & \\
\hline 22 & 18 & 4 & & \\
\hline 23 & 14 & 6 & & \\
\hline 24 & 19 & 2 & & \\
\hline 25 & 14 & & & \\
\hline 26 & 7 & & & \\
\hline 27 & 4 & & & \\
\hline 28 & 1 & & & \\
\hline TotaL & 326 & 233 & 218 & 145 \\
\hline
\end{tabular}

(1) Le chiffre 15 doit être choisi de préférence au chiffre 33 de la mème série, car ce dernier est fourni par les rejets dus au bourgeonnement accessoire (voir page 62). 
La loi qui régit la distribution de taille des rejets selon les degrés de la métamorphose des inflorescences terminales est frappante. Aux rejets très élevés, atteignant deux mètres et plus, correspondent les panicules mâles; la majeure partie des rejets á panicule du type $A$ atteignent 15-18 décimètres, ceux du type B 10-12 décimètres, ceux du type C $6-8$ décimètres.

On trouve donc une corrélation étroite entre les longueurs des supports et les formes des diverses grappes florales qui sont les termes de transition entre la panicule terminale et l'épi latéral du Maïs. 


\section{RECHERCHE DES CAUSES DES ANOMALIES ACCIDENTELLES DES INFLORESCENCES DU MAÏS.}

\section{5. - Conditions de REGherche.}

Mes observations sur le Maïs tératologique furent surtout faites dans une petite localité de la vallée de la Iys (Locon, Pas-de-Calais) où l'on a coutume d'utiliser cette céréale comme fourrage vert durant les mois d'août, de septembre et d'octobre. Les exploitations agricoles y sont petites et les parcelles cultivées en Maïs sont restreintes (5 à 50 ares). On en fait la récolte au fur et à mesure des besoins. Pour la commodité du transport, on plante en Mais les champs d'accès facile situés dans le voisinage immédiat de la ferme.

Le sol constitué par des alluvions argileuses d'origine récente est relativement humide. Pour l'irriguer, on a creusé des ruisseaux d'écoulement pendant l'hiver' et de réserves d'eau penciant l'été, qui sillonnent et séparent les propriétés, suivent les bords des routes et des sentiers. L'accès aux terres cultivées est rendu possible par la construction de nombreux ponts de terre jetés au-dessus des fossés. Il en résulte dans le voisinage même de ces ponts une zône de terrain sans cesse foulée où le Yaïs se développe moins bien. Le pourtour des parcelles, envahi par le chiendent et les mauvaises herbes des bords des ruisseaux, épuisé par les inondations de l'hiver fournit aussi des plantes de bordure moins vigoureuses et plus clairsemées que dans le milieu du champ.

La découverte, en 1901, de quelques inflorescences anormales de Maïs m'amena à interroger les agriculteurs du pays sur la fréquence de cette déformation. Ils la connaissaient tous et la désignaient sous le nom de «Mais dégénéré ». Ils avaient remarqué qu'elle était plus fréquente les années où des gelées tardives détruisaient le Naïs à la 
levée, surtout dans les sols humides et compacts ( $\left.{ }^{1}\right)$. Cette observation confirme les rues de Gallardo sur la cause d'une anomalie analogue de la panicule du Maïs dans certaines exploitations des environs de Buenos-Aires (1904).

Je me décidai à étudier la répartition de ces anomalies. Les résultats des observations faites en 1901 et 1902 ont été exposés à la Société de Biologie de Paris (Blaringhem, 1902).

\section{6. - Facteurs de Variation uniforme.}

Les plantes anormales trouvées dans les champs sont presque toujours localisées sur les bords des parcelles. Fréquentes sur les rangées limites, leur nombre diminue rapidement et devient nul, dès que l'on s'écarte du bord à une distance de 2 métres. On pourrait attribuer cette répartition d'une part à la vigueur moindre des plantes de bordure, d'autre part au moins grand nombre de plantes pour la mème surface de terrain couverte.

L'écartement des pieds favorise en effet l'apparition des anomalies sexuelles, mais d'une manière peu importante (²). J'ai fait à ce sujet des expériences précises en espaçant les graines à des distances duubles ou triples de la distance normale sans que les proportions de panicules déformées fussent sensiblement accrues. Les anomalies apparaissent d'ordinaire sur les suceurrs $\left({ }^{3}\right)$ qui dans les parcelles à pieds écartés se développent en mème temps que la tige principale; les suceurs prennent part à la croissance lente, puis rapide de la tige principale, ils évoluent alor's exactement comme elle et présentent une panicule normale. L'on conçoit toutefois que, dans certaines circonstances, surtout dans les terres froides et humides, les suceurs n’apparaissent et ne se développent que très tard, mais rapidement, à la suite de périodes de chaleur brusque suivies d’orages. En ce cas, la plantation clairsemée du Maiss peut entrainer la production de nombreuses anomalies.

(1) Gagiepain (1893) et Chatedu E. (1901) attribuent la métamorphose de la panicule du Maïs à des circonstances climatériques particulières sans d'ailleurs préciser le mode d'action de ce facteur complexe.

(2) Hoffurix en a fait l'étude pour plusieurs plantes dioïques (1885).

(3) On donne le nom de suceurs à des bourgeons qui d'ordinaire se développent à l'automne et sont insérés sous la touffe de racines adventives qui soutiennent la tige. 
J'ai voulu aussi déterminer par des recherches de statistique l'influence de l'éclairement sur la proportion des anomalies. Si ce facteur jouait un rôle important, on devait s'en apercevoir à la répartition des anomalies sur les bords des parcelles exposés à des orientations différentes; or leurs proportions restaient les mêmes quelle que fût l'orientation et j'en ai souvent récolté un grand nombre le long des haies qui formaient un écran à la lumière directe ou diffuse. L'anomalie se développe mieux pourtant dans les lignes de Maïs plantées, sur une épaisseur de 75 centimètres à un mètre, sur le pourtour des parcelles de tabac qu'elles protègent contre le vent. Faut-il y voir l'action d'une fumure intensive, d'une plantation précoce, d'un éclairement continu? Il se peut que tous ces facteurs agissent, surtout sur le degré de l'anomalie, mais leur action est bien faible et de l'ordre des erreurs d'expérimentation. Car il faut bien admettre que si l'action de toutes ces causes était réelle, elle s'accuserait uniformément sinon sur toutes les plantes, du moins sur un grand nombre d'entre elles placées dans les mêmes conditions. Or les déformations de la panicule du Maïs, quoique assez fréquentes, sont cependant des accidents, c'est-à-dire des modifications insolites et rares. Leurs proportions dans les champs de grande culture ne dépassent 5 pour 1.000 des plantes normales que dans des circonstances exceptionnelles. La cause déterminante ne peut donc résider parmi les facteurs de variation uniforme tels que la fumure, la chaleur, l'humidité, l'éclairement; elle doit être acci!lentelle et particulière aux quelques plantes anormales.

\section{7. - Facteurs de variation agcidentelde, traumatismes.}

Mes observations et mes expériences m'ont conduit à découvrir une cause (et ce n'est sans doute pas la seule) très importante des métamorphoses des panicules mâles et des épis femelles du Mä̈s. Je rappellerai ici quelques observations réunies dans une note publiée en 1902 et donnerai l'état de la question à la même époque.

\section{a. - Anomalies de la panicule.}

La localisation des pieds à panicule déformée le long des sentiers communaux, près des ponts de terre jetés sur les ruisseaux, dans le voisinage des cultures potagères qui entrainnent de fréquentes visites 
soit pour le sarclage, soit pour la récolte des produits, coinncide bien avec la fréqueuce des mutilations possibles dues à l'homme ou aux animaux. Assez sourent les traces de ces mutilations sont faciles á apercevoir ; cependant tous les pieds mutilès n'offrent point d'anomalies, et, d'autre part, on en trouve sur des plantes où la mutilation n'est pas très risible. La rupture de la jeune tige de Maïs a souvent lieu au ras du sol à une époque où l'épaisseur de la tige n'atteint pas un centimètre. Les rejets qui se développent dans la suite sont très vigoureux; ils recouvrent et cachent en totalité la surface de la plaie souillée par la terre. Pour un observateur prévenu, des anomalies en apparence inexplicables doivent ètre interprétées de cette façon. Il faut faire rentrer dans cette catégorie les cas oủ la tige jeune, couchée par terre, a pu se relever par suite du déreloppement unilatéral d'un nœud de base provoquant le redressement bien connu dans les céréales qui ont souffert de la rerse. On peut observer alors, à la base de la tige principale de ces pieds, une double courbure en forme d'S.

L'examen, fait en 1902, de deux champs où le nombre des anomalies dépassait en proportions toutes celles que j'avais observées jusque là, me permit d'attribuer aux mutilations un rôle capital. Dans l'une des parcelles bordée par un sentier de halage, le Naïs avait eu une levée irrégulière parce qu'il était planté dans un sol recouvert, pendant plusieurs années, par des dépôts de vase retirée du canal. Le nombre des plantes à plusieurs tiges était abondant, néanmoins les anomalies était rares sauf le long du sentier de halage où un tiers des pieds étaient déformés. La base d'un grand nombre d'entre eux portait encore les débris des jeunes tiges brisées puis desséchées et l'on trourait sur presque tous des traces nettes de mutilations. Dans le mème champ on pouvait aussi reconstituer le passage d'une brouette à la ligne faite par des anomalies développées, par exception, au milieu de la parcelle. Le véhicule chargé avait laissé des empreintes encore visibles, quoique pour la commodité de la traction, il faille admettre que cette mutilation ait été faite à une époque où le Maĩs était encore de taille peu élevée, environ un mois arant la floraison. Nulle part ailleurs, dans le même champ, je n'ai pu trouver d'anomalies.

La seconde parcelle, étudiée la mème année, était encore plus riche en panicules déformées. Le Maïs, très clairsemé, montrait plusieurs tiges par pied lorsqu'en fin de juillet le cultivateur en fit la récolte partielle pour la nourriture du bétail. Les tiges principales 
assez fortes furent enlevées pendant que les suceurs moins développés continuaient leur croissance. Il restait au début de septembre 27 tiges fleuries dont 12 présentaient des déformations de la grappe terminale. Ici, comme dans le cas précédent, les anomalies étaient, en majorité, des types B et $\mathrm{C}$.

Dans une expérience faite la même année dans un jardin, la mutilation de plantes tardives, faite en fin de juillet, avait donné trois inflorescences terminales du type A.

De ces observations je déduisais la technique qui devait me donner, dans les années suivantes, la réussite presque complète dans les essais de métamorphose de fleurs mâles du Maïs en fleurs femelles fertiles.

\section{b. - ANomalies de L'inflorescence latérale.}

Les anomalies de l'inflorescence latérale femelle sont très rares dans la grande culture et, dans mes nombreuses recherches faites dans le but de les découvrir, je n'ai eu l'occasion d'en observer que deux cas seulement. En 1902, sur la bordure d'une parcelle de Maïs, je récoltai un épi latéral femelle, le plus élevé sur la tige, presque complètement métamorphosé en un axe ligneux couvert d'épillets mâles. Au point d'attache de l'épi sur la tige principale on pouvait reconnaître une forte torsion du pédoncule, accompagnée d'un allongement qui écartait les bractées d'enveloppe externes de l'épi. Le rachis allongé faisait saillie hors des bractées et portait de nombreux épillets mâles entr'ouverts à étamines fertiles (Pl. I, fig. 13).

J'ai trouvé le second exemple, en 1903, dans des conditions très diffẻrentes. Un champ de Maïs englobant des meules de paille présentait, sur leur pourtour, de nombreuses traces de mutilation dues sans doute aux chevaux qui sont très friands de Maïs vert. Un des pieds avait la tige principale brisće au-dessus de la $5^{\text {e }}$ feuille comptée à partir de la base. L'épi situé à l'aisselle de la 4e feuille était porté sur un pédoncule allongé de 35 centimètres, et ses feuilles bractées, très analogues aux feuilles des tiges, étaient séparées par de longs entre-nœuds. Le rachis, épais à la base et couvert de nombreuses graines fertiles, s'amincissait à l'extrémité sur une longueur de 7 centimètres, et portait des épillets mâles. Le poids de l'épi avait dû provoquer la courbure du pédoncule, mais il faut attribuer au mode d'arrachement de la partie terminale de la tige la 
torsion de l'épi vers le tiers supérieur, torsion qui a entraîné l'amincissement du rachis et par suite la métamorphose, en épillets mâles, d'épillets destinés à ètre femelles.

\section{8. - Observations de K. Müller et de Krafft.}

Les ouvrages de Tératologie végétale abondent en exemples de métamorphose sexuelle rencontrés sur les plantes dioïques et monoïques. Pour le Maïs seul, on pourrait facilement trouver plus de cent notes relatives à la décourerte de ces anomalies dans des Ouvrages généraux ou dans des publications de Sociétés scientifiques. Il serait fastidieux et inutile de les énumérer toutes ici. La plupart des auteurs se sont contentés de signaler ces cas de variations. Un certain nombre les ont décrits avec soin. Bien peu ont réuni de nombreux exemples de cette métamorphose, et ont cherché, par cette méthode, à suivre les différents degrés de transition entre les deux types d'inflorescence du Maïs.

Les mémoires de K. Müller (185\$), de G. Krafft (1870) et de 0 . Penzig (1885̃ et 1894) sont les plus importants. K. MülLer décrit avec précision les transitions des épillets mâles aux épillets femelles et la métamorphose des bractées qui se gonflent, deviennent cornées, et renferment au lieu d'étamines un véritable ovaire qui arorte le plus souvent. Il signale les fleurs mâles à étamines bien conformées dont le voisinage des fleurs femelles a entraîné l'élargissement et l'épaississement des bractées. Il montre aussi la métamorphose de l'axe de la panicule en un véritable épi comparable à l'épi femelle et celle des rameaux en ares à symétrie bilatérale portant 4 rangées de graines. Il en résulte, selon lui, un passage indubitable de la fleur màle à la fleur femelle. «On se demande, ajoute-t-il, la cause de ces anomalies. On doit la trouver dans les pousses latérales du pied du Maïs. Car, lorsque je me fus suffisamment renseigné sur l'histoire du champ de Maïs, son propriétaire me raconta qu'il avait coupé et récolté les tiges principales déjả depuis longtemps et qu'ensuite les tiges latérales s'étaient développées ». MüLLER n’a point répété cette expérience et préféra trouver l'explication des faits qu'on lui présentait, en partie dans l'humidité du sol après les pluies abondantes de juillet et d'août et les fortes chaleurs du mois de septembre, en partie dans la copieuse fumure du terrain. Ce sont donc, d'après lui, des circonstances météréologiques spéciales qui ont provoqué le développement rapide de 
rejets, par suite d'un excès subit de nourriture favorisé par l'enlèvement de la tige principale des plantes.

On ne trouvera pas ailleurs une explication aussi nette des faits. G. Krafrt, dans son beau travail sur la Métamorphose normale et anormale du Maïs (1870), indique seulement, comme beaucoup d'autres auteurs, que les inflorescences anormales se rencontrent surtout sur les rejets qui se développent parfois au pied des tiges principales. Son analyse des causes est imparfaite mais la description des anomalies et leur figuration sur de belles planches ne laissent rien à désirer. Pour alléger ce travail qui doit être surtout l'exposé d'expériences et non la description morphologique des anomalies du Maïs, le lecteur est prié de recourir à l'examen du mémoire de Krafrt. Sur tous les points importants, mes observations concordent avec celles qu'il a décrites; pour le détail, je donnerai dans la seconde partie de ce mémoire les compléments qui m’ont paru nécessaires. On consultera aussi avec fruit l'ouvrage de O. Penzig, intitulé Planzenteratologie, vol. II, p. 458-463. Bon nombre de données bibliographiques y ont été réunies avec d'autant plus de sûreté que l'auteur avait lui-même étudié des cas analogues des diverses anomalies du Maïs dans un mémoire antérieur (1885). 


\section{CHAPITRE III.}

\section{PRODUCTION DES INFLORESCENCES}

\section{ANORMALES DU MAIIS PAR DES MUTILATIONS.}

\section{9. - Expériences faites en 1903. Conditions de} CULTURE.

J'ai utilisé dans ces essais le Maīs ordinaire à grains jaunes cultivé dans le nord de la France pour la production de fourrage rert. Au point de rue șstématique ce Mais correspond au Zce . Mays pensylvanica décrit et figuré par Boxafoos dans son Histoire naturelle du Mais (p. 33 et pl. VII, fig.4). KörNicke et WerNer (1S85) le rapportent à la forme Zea Mays vulgaris rar. vulgata $\left.{ }^{1}\right)$.

- Le Mais fut planté dans un enclos où il était impossible de pénétrer sans ètre remarqué; les mutilations dues à l'homme n'ont pu ètre produites que par moi-même, car j'ai fait seul les divers travaux de sarclag̣e et de binage nécessaires. Les accidents inéritables dans toute culture un peu étendue ont été notés arec soin et les plantes qui en ont souffert ou que jai dù repiquer sont éliminées des résultats.

Il était important de choisir le terrain de culture de façon à assurer l'isolement complet des parcelles; la fécondation du Yaīs par le rent rend cette précaution indispensable. Je me suis assuré qu aucune autre parcelle de Mais n'était cultivée dans un ravon de plus de 300 mètres; d'autre part les habitations qui entourent l'enclos au nord et à l'est, une haie haute de? mètres au sud et à l'ouest formaient des abris suffisants. A plusieurs reprises, j’ai cultivé dans un champ roisin des plantes de Yaĩs dont j’ai enlevé les panicules arant la floraison; je n'ai jamais obtenu de fécondation des épis. Enfin les lots de contròle m'ont permis de m'assurer de l'homogénéité et de la pureté de la semence.

(1) L'étude détaillée de celte rariété est farte dans la Troisième partie de ce mémoire. 
L'exposition du terrain d'expérience a été choisie de façon à permettre la plantation plus hâtive et par suite la maturité des graines. Alors que dans le voisinage les semailles ont lieu à la fin de mai, j'ai pu les faire dans la première quinzaine du même mois sans que les plantes aient subi aucun dommage des nuits encore froides à cette époque.
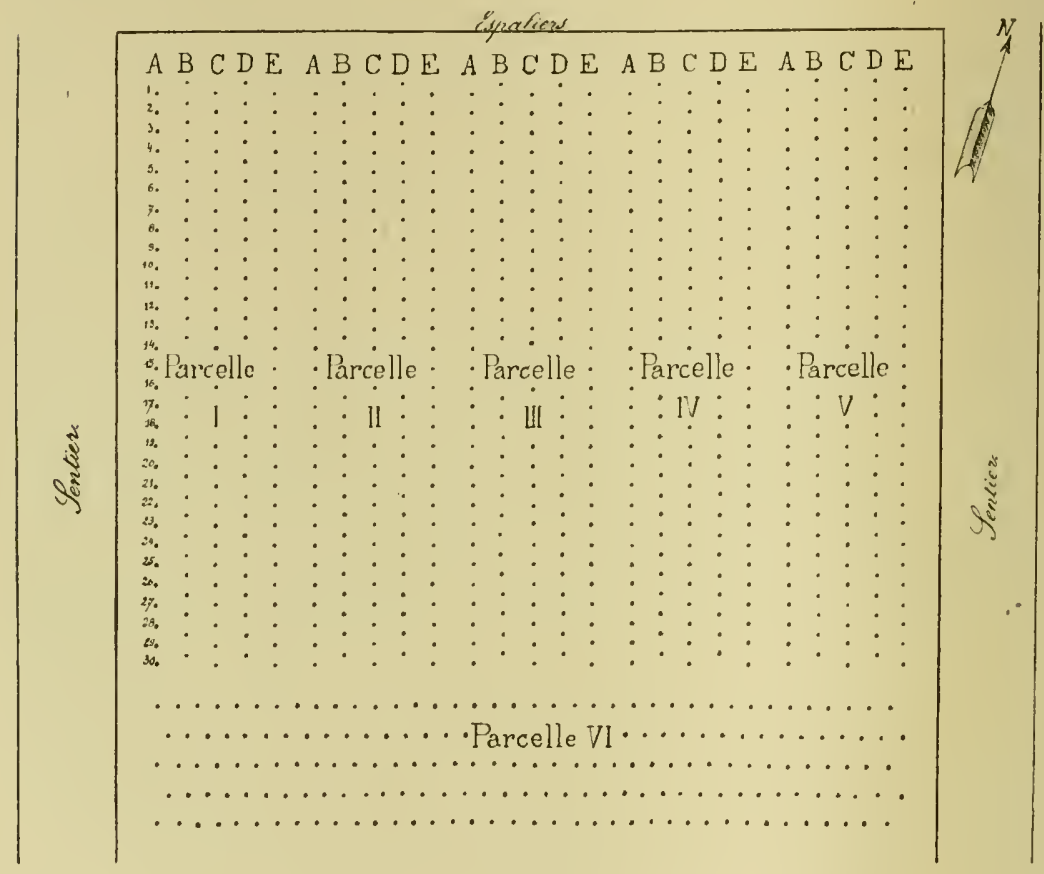

Fï. 1.

Le terrain a été divisé en 6 parcelles dont la disposition et l'orientation sont représentées dans la fig. 1.

Les diverses plates-bandes renferment chacune 5 lignes espacées de 30 centimètres et les graines y ont été plantées à 20 centimètres d'intervalle. Elles renferment donc 150 plantes, les absentes après la levée ayant été repiquées avec du plant pris dans la parcelke $V I$.

Les plantes des parcelles $I-V$ ont été soumises à des mutilations diver'ses à des époques différentes. Pour éliminer dans les résultats d'ensemble les causes d'erreur dues à l'exposition ou à la fumure, une même ligne de chaque parcelle et non une parcelle entière a été traitée de la même façon. Dans tout ce travail les lignes sont désignées 
par les premières lettres de l'alphabet et les plantes de chaque ligne par leur numéro d'ordre allant de 1 à 30 . Chaque plante porte son nom qui figure dans le livre des cultures. Les lignes $A$ des parcelles $I-V$ ont subi la section transrersale de la tige faite à la base de la plante: les lignes $B$, la section longitudinale; les lignes $D$. la torsion des tiges autour de leur axe ; les lignes $E$. la torsion des épis latéraux femelles. Dans chacune des parcelles les lignes $C$ médianes ont èté conserrẻes comme témoins.

Les rejets qui se déreloppent aprés la mutilation présentent parfois des panicules lont les épillets, mâles en apparence, ne renferment pas d'étamines fertiles. L'étude de cette anomalie oll're peu d'intérêt; il importe toutefois den tenir compte dans les tableaur récapitulatifs des expériences ou elle est dẻsignée sous le nom de panicule male acortie.

\section{0. - Section de la tigb principale.}

Le Mais planté le 15 mai était complètement levẻ le :99 mai. On fit 15 jours plus tard le repiquage de quelques plantes absentes et jusqu'à l'époque de la mutilation on le laissa se dérelopper sans binages, ni sarclages. Je fis ce trarail moi-mème. le 9 juillet, en prenant note de tous les pieds qui, à l'examen, semblaient aroir subi les dommages des Vers ou des Limaces et autres ennemis des jeunes plantules.

Le 10 juillet, c'est-à-dire 26 jours aprés les semailles, on pourait aperceroir, à l"intérieur du còne de feuilles qui termine la tiğe, lextrémité de l'axe principal et les rameaux de la panicule mâle complètement formée mais non étalẻe encore. C'est l'époque. nous l'arons ru, où la croissance de la tigge du Mais augmente rapidement arant de passer par son masimum. Elle fut choisie pour la date de mutilation des plantes. A une distance du sol rariant de 1 à 3 centimètres et toujours au premier nœul ne présentant pas de traces de racines adrentives, je fis la section transrersale des tiges à la base de toutes les plantes des lignes A appartenant aux parcelles $I$ : II et $I I I$. Quelques pieds présentaient des suceurs visibles quoique peu déreloppés. Ils furent laissés et il en est fait mention dans la colonne Obscrvations des tableaux donnant les résultats des expériences: 
TABLEAU II.

Parcelle $I$. Ligne $A$.

SEGTION TRANSVERSALE DE LA TIGE

faite le 10 juillet 1903.

Étude de Contrôle le 28 septembre.

Pieds morts : $A_{1}, A_{4}, A_{11}, A_{17}, A_{29}$; éliminés: $A_{2}, A_{19}$.

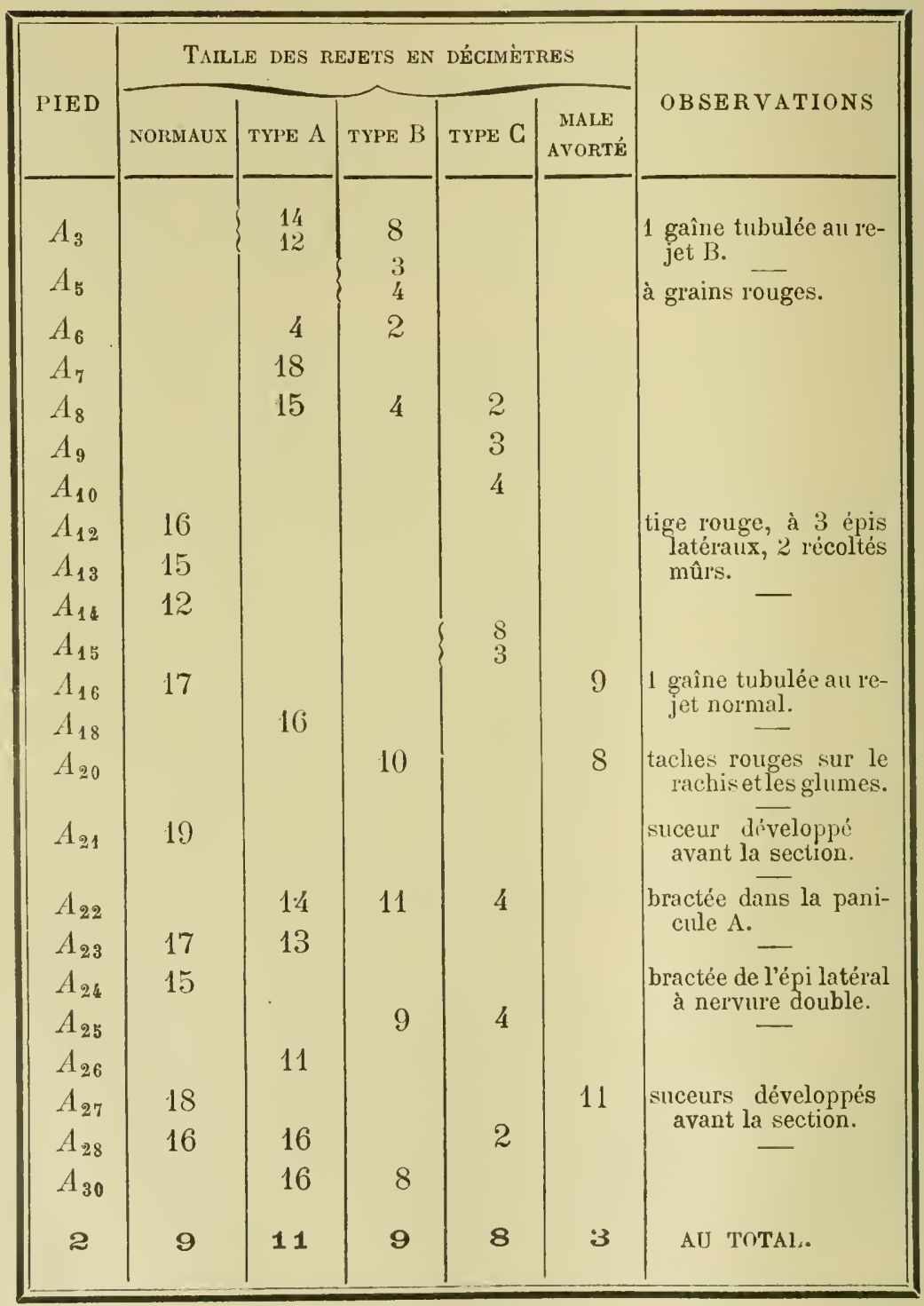




\section{TABLEAU III.}

\section{Parcelle $I I$. Ligne $A$.}

SECTION TRANSVERSALE DE LA TIGE

faite le 10 juillet 1903.

Etude de Contrôle le 28 septembre.

Pieds morts: $A_{2}, A_{9}, A_{11}, A_{19}, A_{29}, A_{23}, A_{30}$;

éliminés: $A_{3}, A_{17}, A_{29}$.

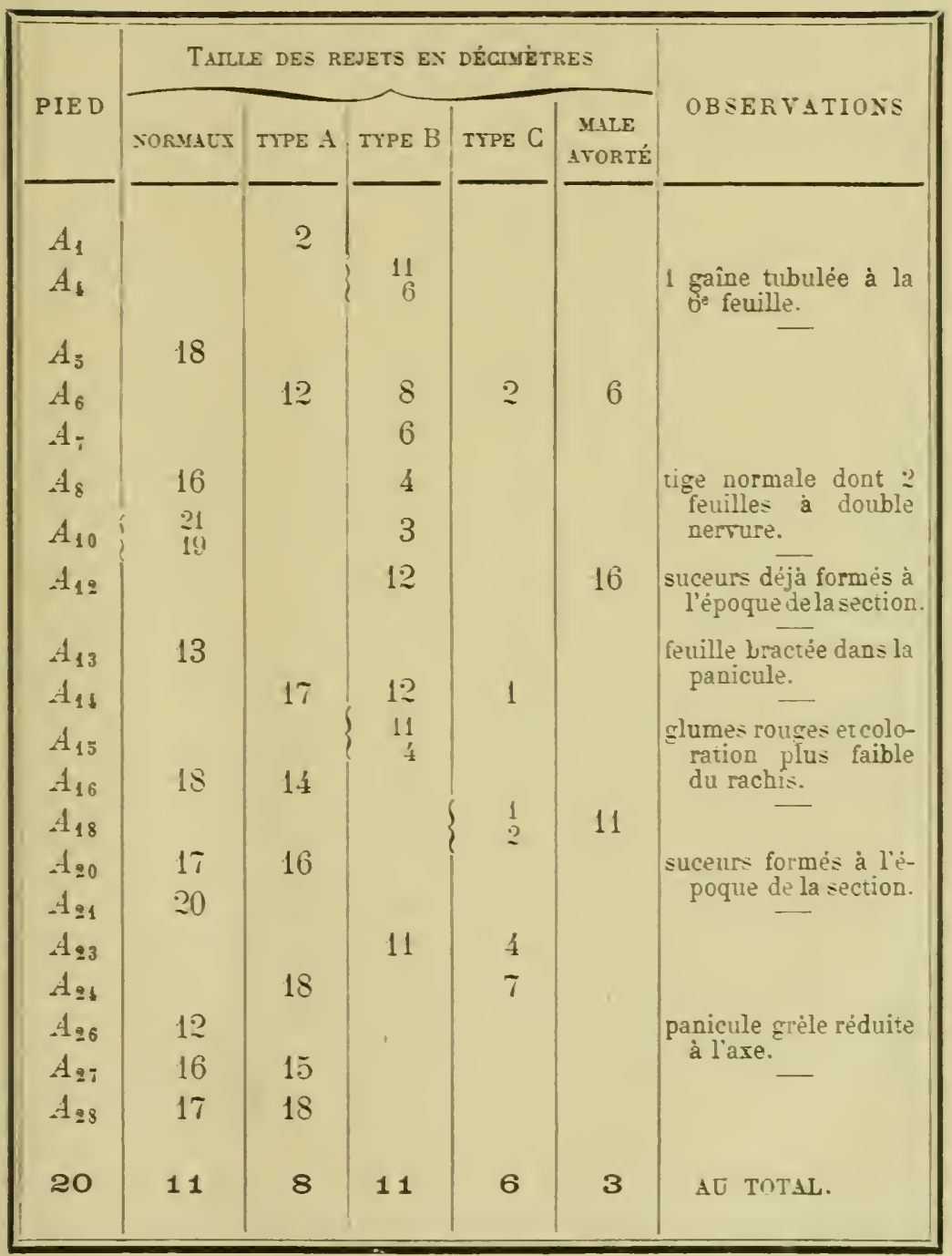




\section{TABLEAU IV.}

Pargelle $I I I$. Ligne $A$.

\section{SEGTION TRANSVERSALE DE LA TIGE}

faite le 10 juillet 1903.

Etude de contrôle le 28 septembre.

Pieds morts: $A_{1}, A_{2}, A_{9}, A_{18} A_{21}$; éliminés: $A_{3}, A_{22}, A_{26}, A_{30}$.

\begin{tabular}{|c|c|c|c|c|c|c|}
\hline \multirow{2}{*}{ PIED } & \multicolumn{5}{|c|}{ TAILLE DES REJETS EN DÉCIMÉTRES } & \multirow[b]{2}{*}{ OBSERVATIONS } \\
\hline & NORMAUX & TYPE A & TYPE B & TYPE $\mathrm{C}$ & $\begin{array}{l}\text { MALE } \\
\text { AVORTÉ }\end{array}$ & \\
\hline$A_{4}$ & & & $\begin{array}{l}11 \\
10\end{array}$ & & & \\
\hline$A_{5}$ & 16 & & 3 & 2 & & $\begin{array}{l}\text { panicule normale ar- } \\
\text { quée. }\end{array}$ \\
\hline$A_{6}$ & 18 & 14 & & & & $\begin{array}{l}\text { suceurs formés au mo- } \\
\text { ment de la section. }\end{array}$ \\
\hline$A_{7}$ & & 17 & & & & $\mathrm{~d}^{\circ}$ \\
\hline$A_{8}$ & & 4 & & & & 1 \\
\hline$A_{10}$ & & 14 & 8 & & & $\begin{array}{l}\text { plante complètement } \\
\text { rouge. }\end{array}$ \\
\hline $\begin{array}{l}A_{11} \\
A_{12}\end{array}$ & 18 & & 11 & & 6 & $\begin{array}{l}\text { bractée de l'épi femelle } \\
\text { à nervure double. }\end{array}$ \\
\hline$A_{13}$ & & & 8 & 6 & & \\
\hline$A_{14}$ & & & & $\begin{array}{l}0 \\
2 \\
1\end{array}$ & & \\
\hline$A_{15}$ & 8 & & & & & \\
\hline$A_{16}$ & & & 4 & & 7 & \\
\hline$A_{17}$ & 18 & & & & & $\begin{array}{l}\text { rejet formé à l'époque } \\
\text { de la section. }\end{array}$ \\
\hline $\begin{array}{l}A_{19} \\
A_{20}\end{array}$ & 21 & 18 & 7 & & 10 & $\begin{array}{l}\text { épillets mâles à glu- } \\
\text { mes larges. }\end{array}$ \\
\hline $\mathrm{A}_{23}$ & 19 & 15 & & 4 & & rejet normal avec \\
\hline$A_{24}$ & 13 & & & & & Iennes a nervures. \\
\hline$A_{25}$ & & 16 & 12 & & & \\
\hline$A_{27}$ & & 11 & & 3 & & \\
\hline$A_{28}$ & 18 & 16 & & & & $\begin{array}{l}\text { plante très rouge peu } \\
\text { fertile. Epislaterraux }\end{array}$ \\
\hline$A_{29}$ & 19 & & & & & avecquelques grains \\
\hline 21 & 10 & 9 & 9 & 6 & 3 & AU TOTAL. \\
\hline
\end{tabular}




\section{1. - Section losgitudinale de la tige.}

La section a été faite dans le plan rertical qui sépare la tige du Maïs en deux portions symétriques laissant intactes les nervures principales les feuilles alternes-distiques. Un scalpel bien effilé était enfoncé à travers la tige à une hauteur de 3 à 5 centimètres au-dessus du sol et toujours all $4^{\mathrm{e}}$ nœud de la jeune plante. Une traction rerticale régulière séparait la tige en deux parties sensiblement égales que je rapprochais à l'aide d'un fil de coton après avoir enleré la jeune panicule. Dans beaucoup de cas j'ai obtenu la suture ultérieure des lèvres de la plaie sur une longueur de 10 et même 23 centimètres; sourent aussi les deux parties des tiges s'enroulèrent en crosse. Enfin des pieds, cependant très vigoureux à l'époque de la section, sont morts des suites de cette mutilation violente.

Sur toutes les portions de tiges soudées ou libres, droites ou enroulées, je n’ai récolté que des épis mal conformés, tordus ou impartiellement fécondés. Toutefois l'avortement ou plutôt la mauvaise venue des graines ne semblait pas due à une nutrition défectueuse des bourgeons latéraux. Car les plantes ainsi mutilées m'ont donné un très grand nombre d'épis ramifiés, c'est-à-dire des épis ordinaires dont les bractées d'enveloppe, quoique serrées, présentaient à leur aisselle de nombreux épis latéraux secondaires. Aucun d'eux n'a porté, même en fin d'octobre, des graines mûres ou voisines de la maturité.

Un autre caractère général de ces tiges coupées dans le sens de la hauteur est leur couleur rouge-pourpre $\left({ }^{1}\right)$. La production très abondante d'anthocyanine est remarquable ; elle s'est présentée aussi, comme nous le verrons dans d'autres cas de mutilation, sur tous les organes végétatifs et mème dans les fleurs et les fruits.

La section longitudinale, de mème que la section transversale de la tige, a provoqué le développement de rejets dont bon nombre présentent des anomalies de la panicule. Les résultats obtenus dans les parcelles $I, I I$ et $I I I$ sont résumés dans les tableaux suirants :

(1) Voir les récentes communications de MIRANde (1906) et GautieR (1906) sur co sujet. 
L. BLARINGHEM.

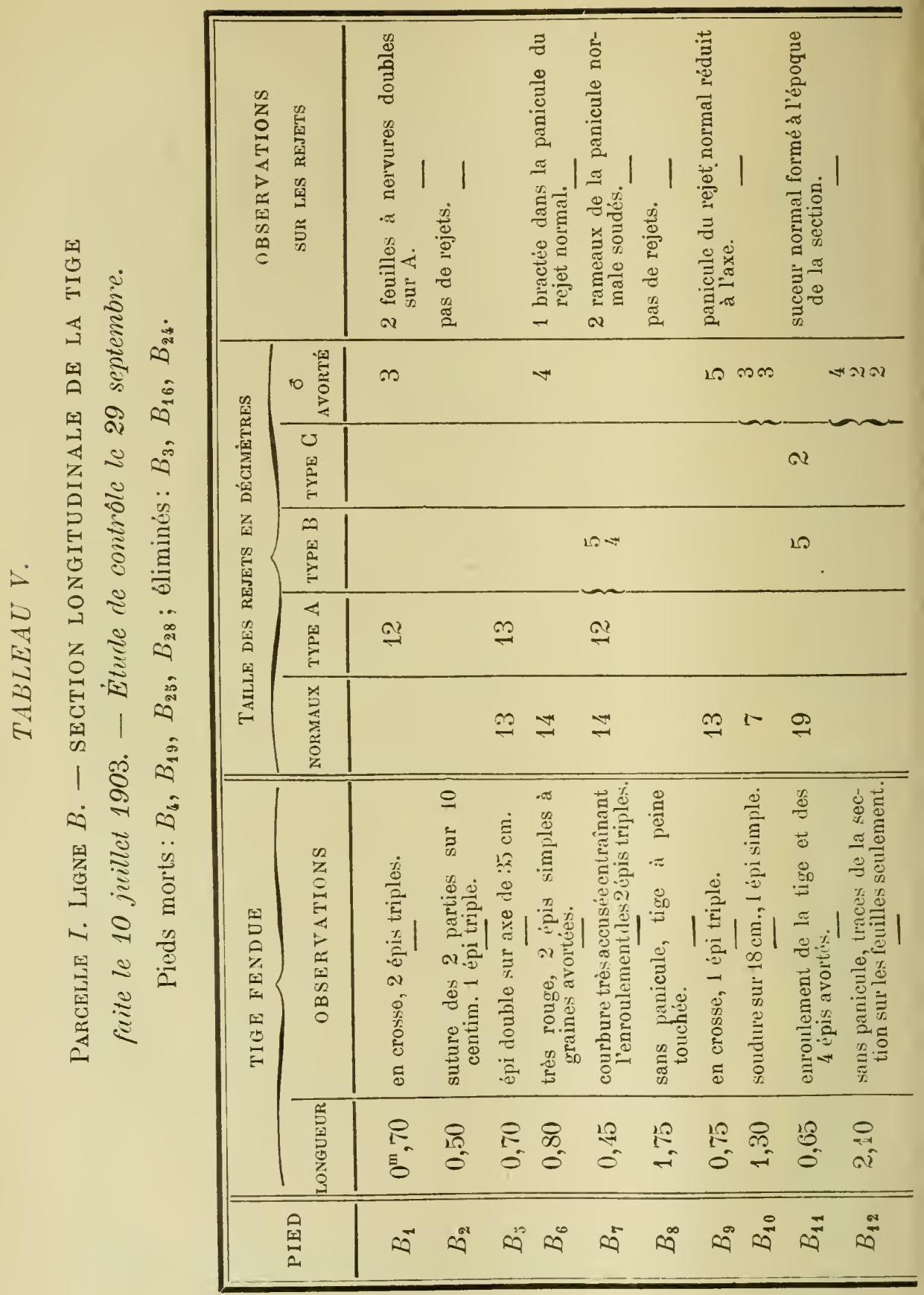




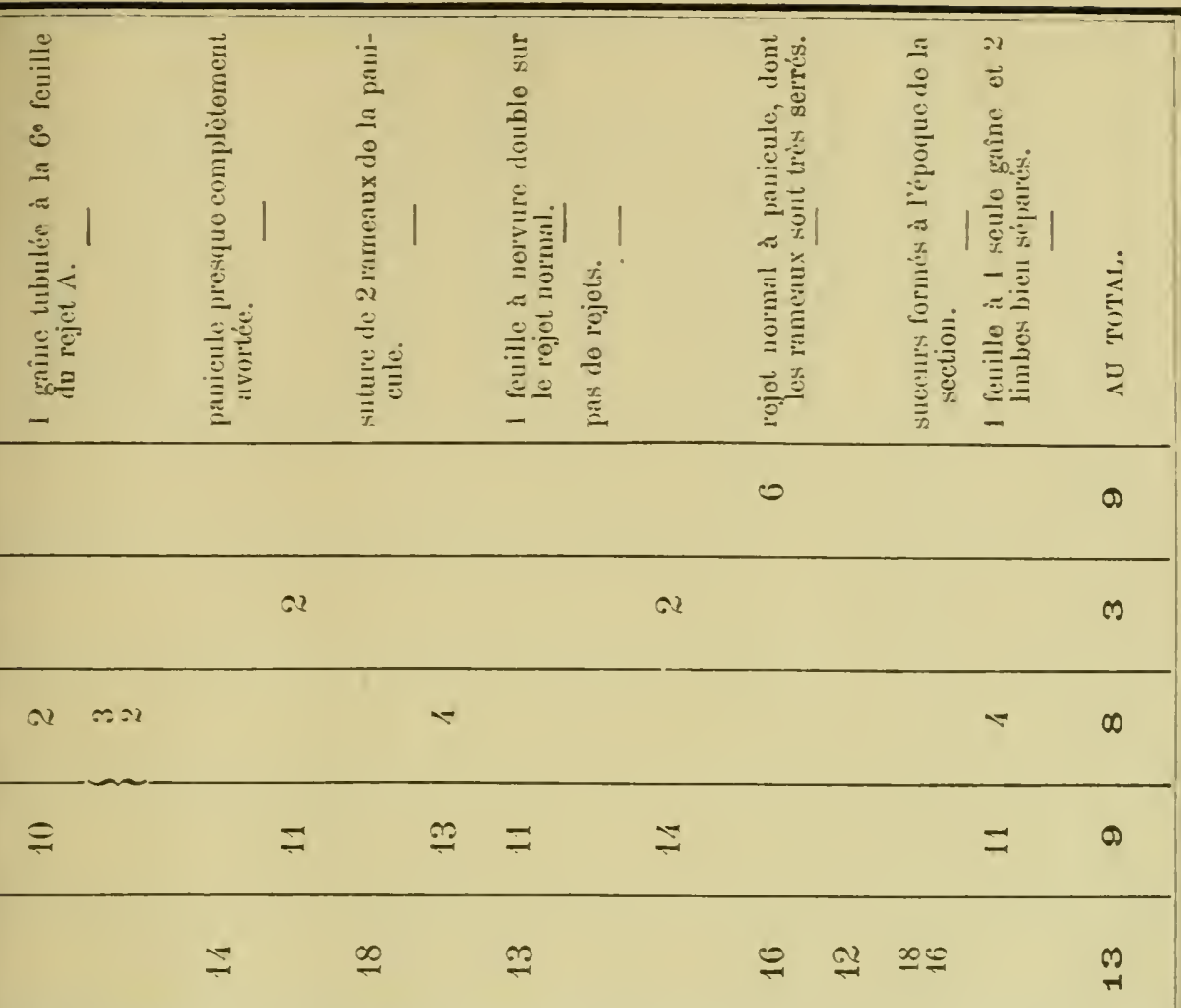

\begin{tabular}{|c|c|c|c|c|c|c|c|c|c|c|c|c|}
\hline 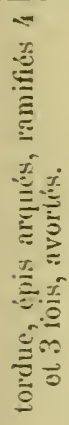 & 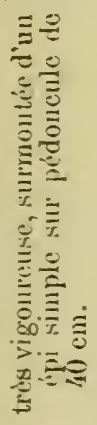 & 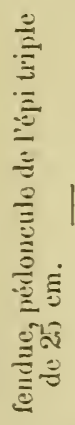 & 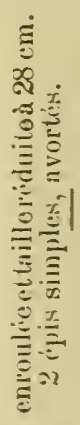 & 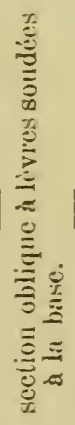 &  & 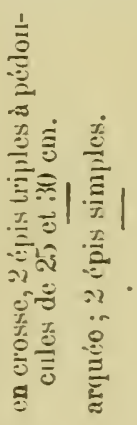 & 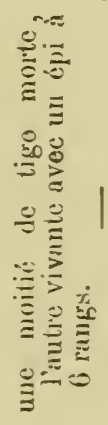 & 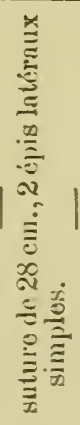 & 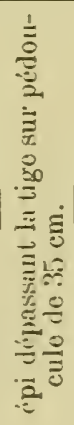 & 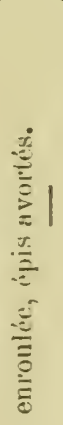 & 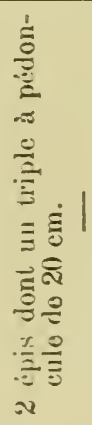 & \\
\hline$\stackrel{\Leftrightarrow}{=}$ & ळ. & $\begin{array}{l}20 \\
0 \\
0\end{array}$ & $\stackrel{10}{0}$ & $\stackrel{29}{=}$ & مू. & $\begin{array}{ll}20 & \infty \\
0 & 0\end{array}$ & ڤू & 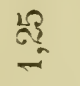 & की & ڤ్ & $\stackrel{10}{=}$ & \\
\hline$\cong$ & $\cong$ & 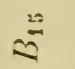 & 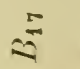 & $\underbrace{\infty}$ & $\stackrel{\circ}{=}$ & 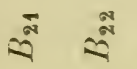 & $\approx \tilde{\theta}$ & $\stackrel{\ddot{\Psi}}{\sim}$ & $\stackrel{0}{5}$ & जิ & $\stackrel{\circ}{=}$ & \\
\hline
\end{tabular}


L. BLARINGHEM.

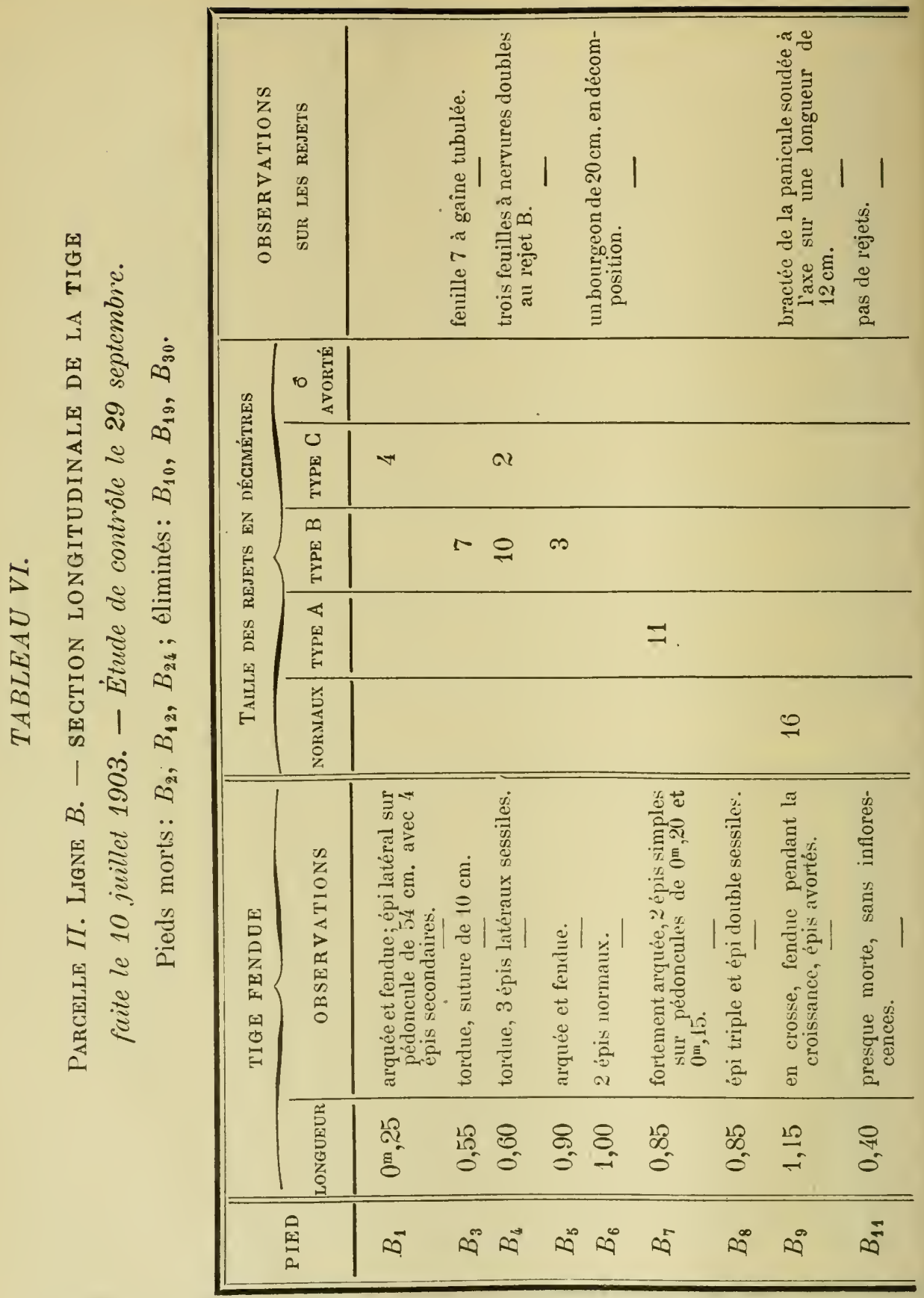


L. BLARINGHEM.

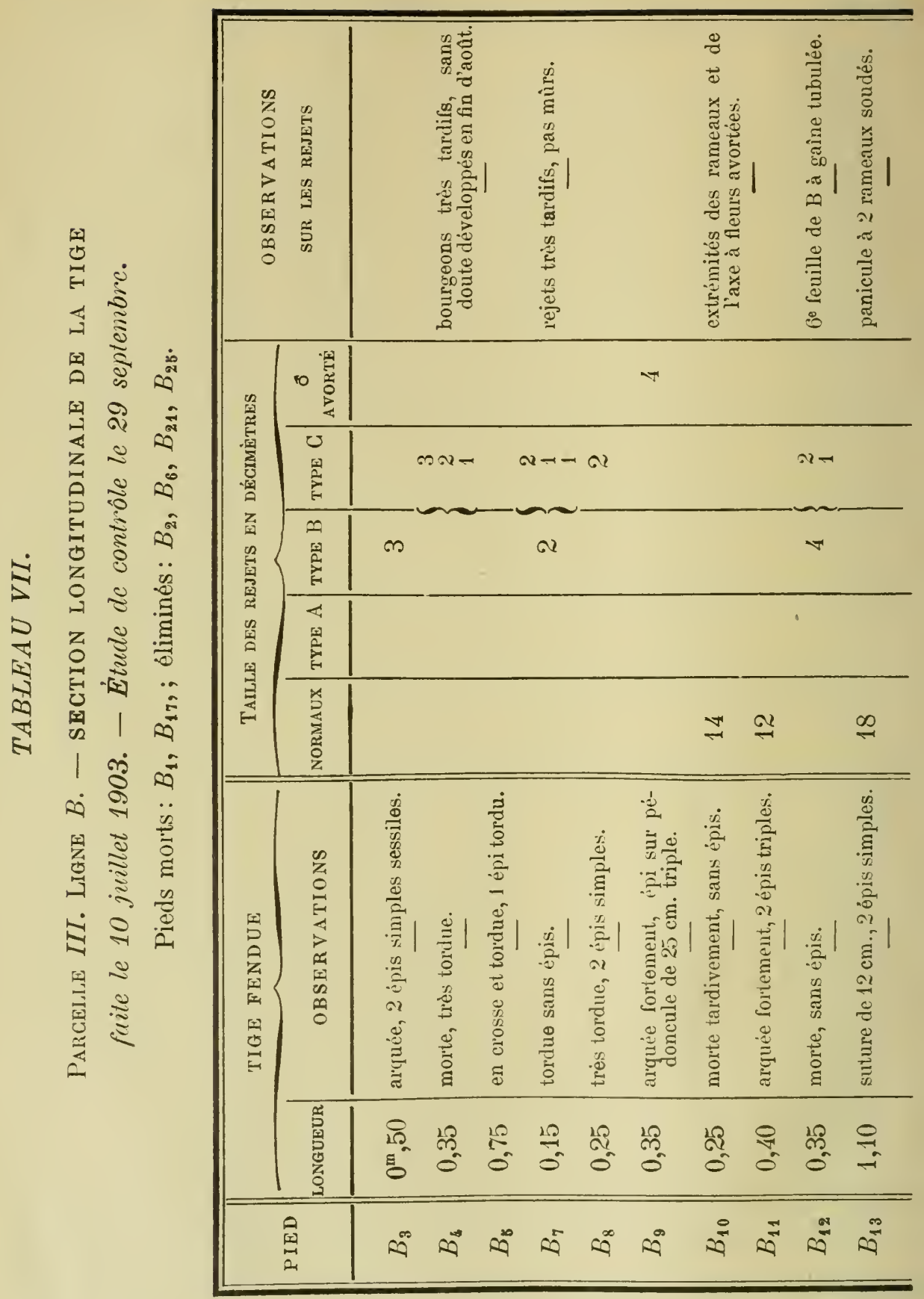




\section{2. - Torsion De la tige aUtour DE SON AXe.}

A l'époque où fut faite celte mutilation, le 10 juillet 1903, les trois ou quatre premières feuilles du Maïs étaient étalées, les suivantes à demi déroulées s'écartaient sans effort; seules, les feuilles supérieures enveloppant la panicule ne pouvaient se séparer sans dommage. Pendant que la main droite maintenait la base de la tige au point d'insertion de la quatrième feuille, la main gauche placée à la hauteur du huitième nœud imprimait un mouvement de torsion de $360^{\circ}$ dont l'effet portait par conséquent entre la quatrième et la huitième feuille. C'est dans cette région que sont situés les jeunes épis femelles et cette opération faite lentement avait pour objet de provoquer le déplacement latéral des bourgeons sans les briser. Le résultat de ces essais fut non seulement la déformation des épis latéraux femelles, mais aussi l'arrêt momentané de croissance de la tige et par suite le développernent rapide de rejets. La torsion était faite dans le sens inverse du déplacement des aiguilles d'une montre, par conséquent dans le sens opposé au déroulement des feuilles. Il en résultait un léger déplacement des gaînes qui n'enveloppaient plus complètement la tige, et, en même temps, l'élargissement de l'espace libre toujours très étroit compris entre la tige et la base de la feuille.

En provoquant artificiellement et de très bonne heure le déplacement des parties sans en entraîner la rupture, j’ai facilité le développement des épis latéraux dont les pédoncules se sont fortement allongés et ont donné à leur tour des inflorescences secondaires. Cies circonstances favorisent la métamorphose partielle des épillets fémelles en épillets mâles.

Mlais, ce qui nous importe le plus en ce moment, c'est l'éveil de la tendance à donner de bonne heure des rejets qui présentent les anomalies de la panicule. Par la torsion on supprime momentanément l'excitution inhibitoire, selon le mot très juste de L. ErRERa (1904), que le bourgeon terminal transmet aux bourgeons de base pour en limiter ou en modifier la croissance. Il suffit d'une suspension de courte durée de cette inhibition pour assister à la sortie rapide de rejets dont lo développement ultérieur ne peut être arrêté. On obtient par ce procédé deux ou plusieurs cimes sur une plante qui n'en présente d'ordinaire qu'une seule.

Les résultats des expériences sont résumés dans les tableaux suivants : 


\section{TABLEAU VIII.}

Parcelle $I$. Ligne $D$. - torsion des tiges faite le 10 juillet 190́3. - Étude de cantrôle le 29 septembre. Plantes mortes: 0; éliminées: $D_{4}, D_{12}, D_{17}, D_{19}, D_{22}, D_{25}, D_{27}$.

\begin{tabular}{|c|c|c|c|c|c|c|c|c|c|c|c|c|}
\hline \multirow{3}{*}{ PIED } & \multicolumn{7}{|c|}{ Tige PRINCIPALE TOKDUE } & \multicolumn{5}{|c|}{ TAILLE DES REJETS EN DÉCINĖTRES } \\
\hline & \multirow[t]{2}{*}{ TAILLE } & \multicolumn{3}{|c|}{$\begin{array}{c}\text { Ramifications } \\
\text { des épis }\end{array}$} & \multicolumn{3}{|c|}{$\begin{array}{c}\text { Pédoncules } \\
\text { en centimètres }\end{array}$} & \multirow{2}{*}{$\begin{array}{l}\text { nor- } \\
\text { maux }\end{array}$} & \multirow{2}{*}{$\begin{array}{l}\text { type } \\
\text { A }\end{array}$} & \multirow{2}{*}{$\begin{array}{l}\text { type } \\
\text { B }\end{array}$} & \multirow{2}{*}{$\begin{array}{l}\text { type } \\
\mathrm{C}\end{array}$} & \multirow{2}{*}{ avort } \\
\hline & & 1 & 2 & 3 & 1 & 2 & 3 & & & & & \\
\hline$D_{1}$ & $1^{\mathrm{m}}, 80$ & 3 & 2 & 2 & 40 & 21 & 18 & & 15 & 1 & & \\
\hline$D_{2}$ & 1,85 & 0 & 0 & $\gg$ & 3 & 7 & $\gg$ & 12 & & & & \\
\hline$D_{3}$ & 1,60 & 2 & 0 & $\gg$ & 20 & 18 & $\gg$ & & & & & \\
\hline$D_{5}$ & 2,10 & 1 & 1 & 0 & 15 & 10 & 5 & & & & & \\
\hline$D_{6}$ & 2,0 & 0 & 0 & $\gg$ & 3 & 5 & $\gg$ & & & 2 & & 6 \\
\hline$D_{7}$ & 1,80 & 4 & 4 & 3 & 37 & 35 & 23 & & & & & $\begin{array}{l}3 \\
2\end{array}$ \\
\hline$D_{8}$ & 2,10 & 2 & 0 & $\gg$ & 10 & 4 & $\gg$ & & & & & 3 \\
\hline$D_{9}$ & 2,0 & 3 & 1 & $\gg$ & 22 & 18 & $\gg$ & & & & & 2 \\
\hline$D_{10}$ & 1,90 & 0 & 0 & $\gg$ & 3 & 8 & $\gg$ & & & & & \\
\hline$D_{11}$ & 1,75 & 0 & 0 & 0 & 3 & 7 & 12 & & & & & \\
\hline$D_{13}$ & 2,10 & 1 & 2 & 0 & 19 & 23 & 6 & & & $\begin{array}{l}3 \\
2\end{array}$ & & . \\
\hline$D_{14}$ & 1,80 & 0 & 0 & $\gg$ & 3 & 5 & $\gg$ & $\begin{array}{l}11 \\
10\end{array}$ & & & & วั \\
\hline$D_{15}$ & 2,0 & 0 & 0 & 3 & 12 & 14 & 17 & & & & & \\
\hline$D_{16}$ & 2,30 & 1 & 0 & 0 & 10 & $\bar{\partial}$ & 5 & 12 & & 3 & & \\
\hline$D_{18}$ & 2,25 & 3 & 2 & 0 & 24 & 10 & 6 & & & & & 9 \\
\hline$D_{20}$ & 2,10 & 0 & 0 & $\gg$ & 3 & 7 & $\gg$ & & & & 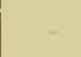 & S \\
\hline$D_{21}$ & 1,95 & 0 & 0 & 0 & 3 & 4 & 9 & & & & & \\
\hline$D_{23}$ & $1,6.5$ & 0 & 0 & $\gg$ & 5 & 4 & $\gg$ & & & 4 & & 11 \\
\hline$D_{21}$ & 1,80 & 0 & 0 & $\gg$ & 2 & 3 & $\gg$ & 14 & & & & \\
\hline$D_{26}$ & 2,0 & 2 & 3 & 3 & 12 & 18 & 14 & 16 & & & & \\
\hline$D_{28}$ & 1,75 & 4 & 3 & $\gg$ & 35 & 13 & $\gg$ & & & 4 & 1 & \\
\hline$D_{29}$ & 1,90 & 0 & 0 & 0 & 2 & 5 & 6 & & & & & \\
\hline$D_{30}$ & 2,25 & 3 & 2 & 0 & 32 & 17 & 7 & & & & & \\
\hline 23 & & & & & 23 & 23 & 12 & 6 & 1 & $y$ & 1 & 9 \\
\hline
\end{tabular}




\section{TABLEAU IX.}

Parcelle $I I$. Ligne $D$. - TORSion Des tiges faite le 10 juillet 1903. - Étude de contrôle le 29 septembre. Plantes mortes: 0 ; éliminées: $D_{2}, D_{6}, D_{17}, D_{19}, D_{21}, D_{27}, D_{29}$.

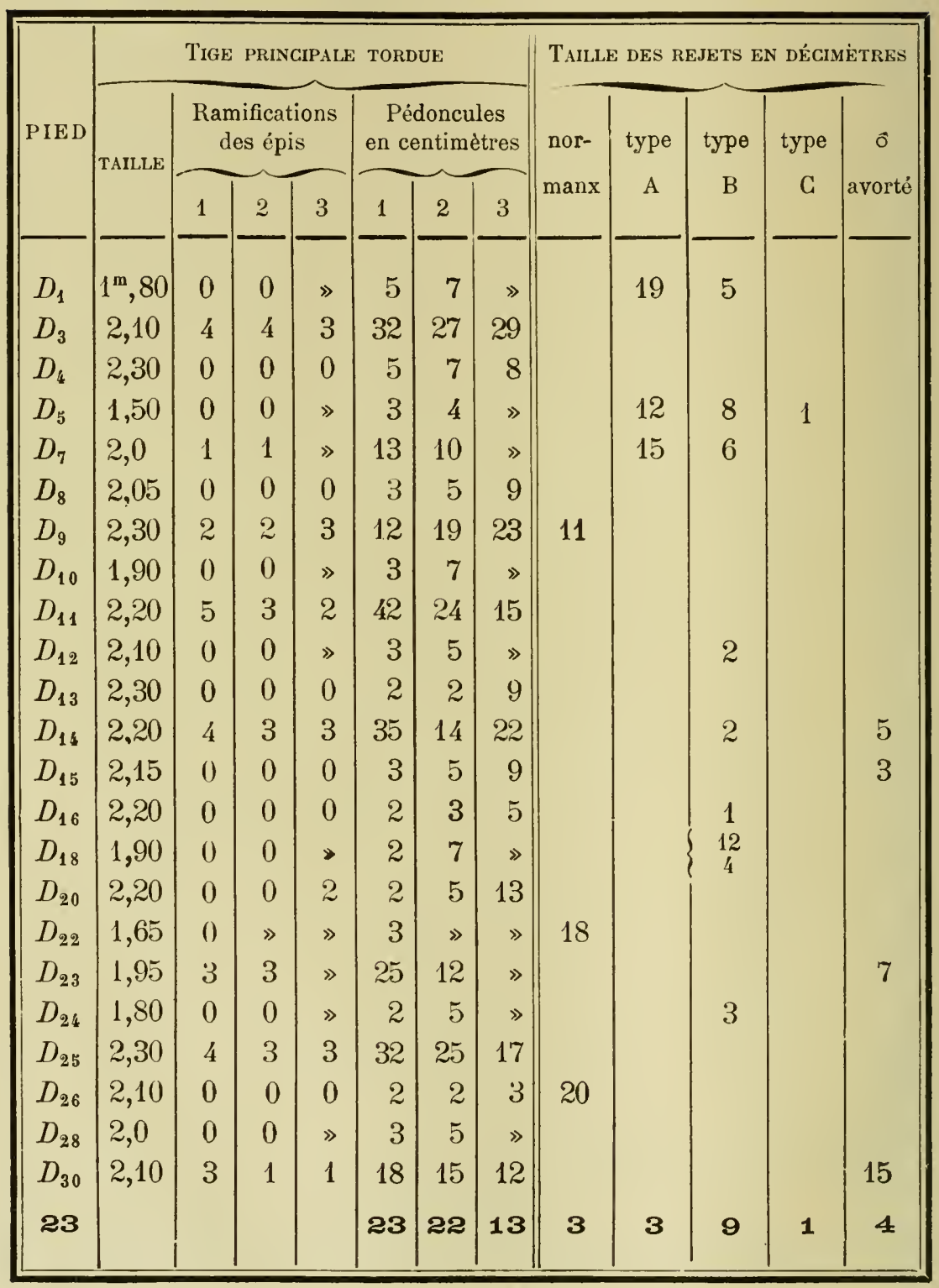




\section{TABLEAU X.}

Parcelle $I I I$. Ligre $D$. - torsion Des tiges

faite le 10 juillet 1903. - Etude de contrôle le 29 septembre.

Plantes mortes: 0 ; éliminées: $D_{3}, D_{5}, D_{8}, D_{9}, D_{14} . D_{17}, D_{23}, D_{96}$.

\begin{tabular}{|c|c|c|c|c|c|c|c|c|c|c|c|c|}
\hline \multirow{3}{*}{ PIED } & \multicolumn{7}{|c|}{ TIGE PRLNCIPALE TORDUE } & \multicolumn{5}{|c|}{ TAILLE DES REJETS EN DÉCNIE TRES } \\
\hline & \multirow{2}{*}{ TALLE } & \multicolumn{3}{|c|}{$\begin{array}{l}\text { Ramifications } \\
\text { des épis }\end{array}$} & \multicolumn{3}{|c|}{$\begin{array}{c}\text { Pédoncules } \\
\text { en centimètres }\end{array}$} & \multirow{2}{*}{$\begin{array}{l}\text { nor- } \\
\text { maux }\end{array}$} & \multirow{2}{*}{$\begin{array}{l}\text { type } \\
\mathrm{A}\end{array}$} & \multirow{2}{*}{$\begin{array}{c}\text { type } \\
\text { B }\end{array}$} & \multirow{2}{*}{$\begin{array}{c}\text { type } \\
\text { C }\end{array}$} & \multirow{2}{*}{$\begin{array}{c}0 \\
\text { avorte }\end{array}$} \\
\hline & & 1 & 2 & 3 & 1 & 2 & 3 & & & & & \\
\hline$D_{1}$ & $2 \mathrm{~m}, 0$ & 3 & 2 & 2 & 25 & 18 & 12 & & & & & \\
\hline$D_{\Xi}$ & $1, \pi 0$ & $\gg$ & $\gg$ & $\gg$ & $\gg$ & $\gg$ & $\gg$ & & & & $\begin{array}{l}2 \\
1\end{array}$ & \\
\hline$D_{\downarrow}$ & 1,95 & 0 & 0 & 》 & 3 & วั & $\gg$ & & & & & \\
\hline$D_{6}$ & 1,90 & 0 & 0 & 0 & う & $\tau$ & 8 & 17 & & & & \\
\hline$D_{7}$ & 2,30 & 3 & 2 & 2 & 24 & 17 & 22 & & & $\begin{array}{l}3 \\
2\end{array}$ & & 10 \\
\hline$D_{10}$ & 2,10 & 0 & 0 & 0 & 2 & 2 & 5 & & & & & \\
\hline$D_{11}$ & $1, \geq 0$ & $\gg$ & $\gg$ & $\gg$ & $》$ & $》$ & $》$ & & & 3 & & \\
\hline$D_{12}$ & 2,05 & 0 & 0 & 0 & 2 & 3 & 7 & & & & & \\
\hline$D_{13}$ & 1,85 & 3 & 3 & 》 & 29 & 17 & 》 & & & & & \\
\hline$D_{15}$ & 1,95 & 0 & 0 & $\gg$ & 2 & 3 & 》 & & & & & \\
\hline$D_{16}$ & 1,60 & 0 & 0 & $\gg$ & 2 & う & $》$ & & & & & 11 \\
\hline$D_{18}$ & 1,90 & 2 & 1 & $\gg$ & 19 & 11 & 》 & & & & & \\
\hline$D_{19}$ & 2,20 & 0 & 0 & 0 & 3 & う & 9 & 17 & & & & \\
\hline$D_{20}$ & 1,65 & 0 & 》 & $\gg$ & 4 & $\gg$ & $\gg$ & & & 4 & 1 & \\
\hline$D_{21}$ & 1,95 & 4 & 1 & 2 & 32 & 5 & 9 & & & & & \\
\hline$D_{22}$ & 2,25 & 0 & 0 & 9 & 3 & 3 & 7 & 14 & & & & \\
\hline$D_{24}$ & 2,30 & 3 & 3 & 4 & 26 & 12 & 19 & & & & & 8 \\
\hline$D_{25}$ & 1,80 & 0 & 0 & 》 & 2 & 4 & $》$ & 18 & & & & \\
\hline$D_{27}$ & 2,10 & 0 & 0 & 0 & 2 & 5 & 9 & & & & & \\
\hline$D_{28}$ & 2,25 & 0 & 0 & $\gg$ & 4 & $\check{~}$ & 》 & & 20 & & & \\
\hline$D_{29}$ & 2,25 & 1 & 1 & 3 & 15 & 13 & 25 & & & & & \\
\hline$D_{30}$ & 2,30 & 0 & 0 & 0 & 2 & 2 & 4 & 19 & & & & \\
\hline 22 & & & & & 20 & 19 & 12 & 5 & 1 & 5 & 3 & 3 \\
\hline
\end{tabular}


Il faut signaler la vigueur des plantes qui ont subi la torsion: leur poids est souvent le double de celles dont la croissance en hauteur n'a pas été entravée. En moyenne leur taille est inférieure de 20 et même 30 centimètres à celle des plantes témoins, mais l'épaississement des tiges, l'allongement des pédoncules, la métamorphose dës bractées en feuilles véritables pourvues d'un limbe allongé, la multiplication des épis de second ordre, la production des rejets sont à l'avantage de celles dont la torsion a entravé la croissance. Le roulage des céréales, qui est d'un usage courant en agriculture, augmente lui aussi le tallage, fortifie l'appareil radiculaire, épaissit et égalise les chaumes. Il faut bien reconnaitre cependant que ce rapprochement n'est pas une explication et que nos connaissances sur les procédés courants d'arrêt ou de forcage des plantes sont très imparfaites.

Dans les tableaux récapitulatifs des expériences j'ai supprimé les plantes dont les tiges ont été brisées par le vent avant l'épanouissement complet des panicules. Leur nombre assez considérable s'explique par le défaut de solidité des axes partiellement dégagés des gaînes qui d'ordinaire les soutiennent. 


\section{INFLUENCE DU DEGRÉ DE LA MUTILATION.}

Les différentes mutilations de la tige principale du Maïs qui viennent d'être exposées ont cu pour effet de provoquer le développement rapide des rejets présentant fréquemment des anomalies de la panicule terminale. Le seul examen des tableaux montre que la inéthode employée est très féconde en rẻsultats probants et suffirait à établir le rôle important des traumatismes dans la production des anomalies végétales. Il est possible de creuser davantage le problème et d'en tirer des conséquences plus importantes.

\section{3. - Évaluation du DEgré de la iutilation.}

L'importance d'une mutilation est chose difficile à définir arec précision. Un traumatisme violent entraîne la morl des plantes qui le subissent, un traumatisme faible ne semble modifier en rien leur croissance. L'incertitude qui règne dans l'appréciation des résultats tient pour une bonne part à la variabilité fluctuante des individus en expérience qui sont vigoureux ou chétifs, précoces ou tardifs, et réagissent par suite différemment à la même mutilation. On ne peut obvier à cet inconvénient que par l'emploi des grands nombres. Les opérations multiples faites sur une population aussi homogène que possible donnent, si l'on examine l'ensemble des résultats, l'impression nette des conséquences d'une opération précise sur un matériel idéal.

Pour apprécier l'importance des traumatismes violents, qui parfois entrainent la mort des individus, on peut utiliser le pourcentage même des morts. La mutilation sera d'autant plus forte qu'elle laissera moins de plantes vivantes.

Si l'expérience est faite sur un nombre élevé d'individus, une centaine par emple, il est évident que le nombre des survivants sera d'autant moins élevé que la mutilation aura été plus forte. 
Cette méthode de mesure est insuffisante pour suivre les différents ermes de mutilations graduées et, en particulier, elle ne permet pas l'étude des mutilations faibles qui n'entrainent point la mort, même celle des individus chétifs. Il faut la compléter par un autre procédé de mesure et j’ai adopté le nombre des rejets qui se développent sur les plantes ayant survécu à la mutilation $\left({ }^{1}\right)$.

\section{4. - ReLations ENTRE LE NOMBRE DES PLANTES MORTES} ET LE NOMBRE DES REJETS DES SURVIVANTES.

Avant tout il importe que ces deux méthodes de mesure soient concordantes, sinon elles ne pourraient se compléter. Or les expériences, résumées dans les tableaux précédents et faites sur un nombre assez considérable d'individus, donnent les résultats suivants :

\section{Voir Tableau XI (page 57).}

La lecture des résultats est plus commode si l'on ne trent compte que des pourcentages, et le rapprochement de la mortalité et du nombre des rejets donne la justification de la méthode employée. Une mortalité de 21, 12, 0, 0 pour 100 plantes mutilées correspond au développement de 181, 148, 91, 21 rejets sur celles qui survivent. I) en résulte bien que la section transversale, puis la section longitudinale et enfin la torsion des tiges, auxquelles correspondent ces chiffres, sont des mutilations rangées par ordre d'importance décroissante.

(1) Une inntilation légère, faite à une tige en voie de croissance, peut entraîner plusieurs conséquences; l'une d'elles est la suspension plus ou moins forte de l'exeitation inhibitoire du bourgeon terminal sur les bourgeons adventifs. Il est naturel d'admettre qu'à une mutilation croissante correspond un arrêt de plus longue durée de l'excitation inhibitoire et par suite le développenent d'un plus grand nombre de rejets. Tout se passe dans le Maïs comme s'il en était ainsi (page 50) et c'est la raison qui m'a fait adopter ce procédé de mesure des mutilations légères. 
TABLEAU XI.

RELATIONS ENTRE LES NOMBRES DES PLANTES MORTES APRES UNE MUTILATION ET LES NOMBRES DE REJETS DÉVELOPPÉS SUR LES SURVIVANTES:

Mutilations faitesle 10 juillet 1903. - Contrôle le 29 septembre.

$1^{\circ}$ Section transversale de la tige (Ligne $A$ ).

\begin{tabular}{|c|c|c|c|c|c|c|}
\hline Parcelle & $\begin{array}{l}\text { Plantes } \\
\text { opérées }\end{array}$ & $\begin{array}{l}\text { Plantes } \\
\text { mortes }\end{array}$ & $\begin{array}{l}\text { Plantes } \\
\text { vivantes }\end{array}$ & Rejets & $\begin{array}{l}\text { Mortalité } \\
\text { pour } 100\end{array}$ & $\begin{array}{c}\text { Rejets } \\
\text { pour } 100\end{array}$ \\
\hline- & - & - & - & - & - & - \\
\hline$I$ & 28 & う & 23 & 40 & 17,9 & 175 \\
\hline$I I$ & 27 & 7 & 20 & 39 & 29 & 195 \\
\hline$I I I$ & 26 & 5 & 21 & 37 & 19,2 & 181,5 \\
\hline nsemble & 81 & 17 & 64 & 116 & 21 & 181 \\
\hline
\end{tabular}

$2^{\circ}$ Section longitudinale de la tige (Ligne $B$ ).

\begin{tabular}{|c|c|c|c|c|c|c|}
\hline Parcelle & $\begin{array}{l}\text { Plantes } \\
\text { opérées }\end{array}$ & $\begin{array}{l}\text { Plantes } \\
\text { mortes }\end{array}$ & $\begin{array}{c}\text { Plantes } \\
\text { vivantes }\end{array}$ & Rejets & $\begin{array}{l}\text { Mortalité } \\
\text { pour } 100\end{array}$ & $\begin{array}{l}\text { Rejets } \\
\text { pour } 100\end{array}$ \\
\hline - & - & - & - & 一 & - & - \\
\hline$I$ & 27 & 4 & 23 & 42 & 14,8 & 183 \\
\hline$I I$ & 27 & 3 & 24 & 29 & 11,2 & 121 \\
\hline$I I I$ & 26 & 2 & 24 & 34 & 7,7 & 148 \\
\hline nsemble & 80 & 9 & 71 & 105 & 12,5 & 148 \\
\hline
\end{tabular}

$3^{0}$ Torsiox de la tige $\left({ }^{1}\right.$ ) (Ligne $D$ ).

\begin{tabular}{|c|c|c|c|c|c|c|}
\hline $\begin{array}{c}\text { Parcelle } \\
-\end{array}$ & $\begin{array}{l}\text { Plantes } \\
\text { opérées }\end{array}$ & $\begin{array}{l}\text { Plantes } \\
\text { mortes } \\
\text { - }\end{array}$ & $\begin{array}{l}\text { Plantes } \\
\text { virantes }\end{array}$ & $\begin{array}{c}\text { Rejets } \\
-\end{array}$ & $\begin{array}{l}\text { Mortalité } \\
\text { pour } 100\end{array}$ & $\begin{array}{l}\text { Rejets } \\
\text { pour } 100\end{array}$ \\
\hline$I$ & 23 & 0 & 23 & 24 & 0 & 104,2 \\
\hline$I I$ & 23 & 0 & 23 & 20 & 0 & 87 \\
\hline$I I I$ & 22 & 0 & 22 & 17 & 0 & 77 \\
\hline Ensemble & 68 & o & 68 & 61 & 0 & 91 \\
\hline \multicolumn{7}{|c|}{$4^{0}$ Lignes de CoNTrôle (Ligne $C$ ). } \\
\hline $\begin{array}{c}\text { Parcelle } \\
-\end{array}$ & $\begin{array}{l}\text { Plantes } \\
\text { vivantes (2 } \\
\text { - }\end{array}$ & & ejets & $\begin{array}{l}\text { Rejets } \\
\text { pour } 100 \\
-\end{array}$ & & \\
\hline$I$ & 27 & & 9 & 22,3 & & \\
\hline$I I$ & 28 & & 4 & 14,3 & & \\
\hline$I I I$ & 25 & & 7 & 28 & & \\
\hline Ensemble & 80 & & 17 & 21,3 & & \\
\hline
\end{tabular}

(1) On n'a pas compté les pieds brisés.

(2) Déduction faite des pieds repiqués. 
15. - Rellations entre le degré de la mutilation ét LE POURGENTAGE DES PLANTES ANORMALES.

Les mutilations décroissantes entrainent des proportions correspondantes de plantes à panicules ayant subi la métamorphose des épillets mâles en épillets femelles, comme on peut le voir par le tableau résumant les expériences antérieurement décrites.

\section{TABLEAU XII.}

RELATIONS ENTRE LES DEGRÉS DE LA MUTILATION ET LES NOMBRES DE PLANTES ANORMALES OBTENUES:

MUTILATION

Mortalité
pour
100 plantes
opérées

Section transversale.
Parcelle $I$; ligne $A$

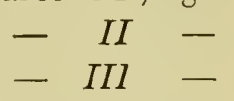

Ensemble ....

SECTION LONGitudinale.

Parcelle $I$; ligne $B$

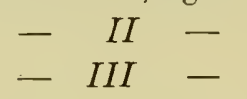

Ensemble ....

TORSION.

Parcelle $I$; ligne $D$

$$
\begin{array}{lcl}
- & I I & - \\
- & I I I & -
\end{array}
$$

Ensemble ....

Plantes tÉmoins.

Parcelle $I$; ligne $C$

$$
\begin{array}{lll}
- & I I & - \\
- & I I I & -
\end{array}
$$

Ensemble ....

$$
17,9
$$$$
26,0
$$

19,2

$\approx 1$

$\begin{array}{rr}14,8 & 183 \\ 11,2 & 121 \\ 7,7 & 142 \\ 12,5 & \mathbf{1 4 8}\end{array}$

\begin{tabular}{lll}
12 & & 11 \\
13 & & 11 \\
14 & & 10 \\
\cline { 1 - 1 } & &
\end{tabular}

47,9

46

41,7

45

\section{4}

80

76

76,5 
En résumé la section transversale de la tige, puis la section longitudinale et enfin la torsion des tiges sont des mutilations qui permettent d'obtenir la métamorphose partielle ou totale de la panicule mâle du Maīs en inflorescences femelles. Leur action est d'autant plus violente qu'elles entrainent la mort d'un nombre plus considérable de plantes ou encore le déreloppement d'un plus grand nombre de rejets sur les survivantes. Aux divers degrés de l'importance de la mutilation correspondent des nombres plus ou moins élevés de cas de déformation.

\section{6. - Évaluation de l'intensité de l'anomalie d'une} PANICULE.

Une des grandes difficultés qui a fait négliger les recherches de tératologie, si importantes au point de vue de la Systématique et de l'Evolution, est à n'en pas douter la rareté du matériel d'étude. Les mutilations permettent d'obtenir sans grands frais un nombre considérable d'anomalies; leur étude montre que les variations accidentelles peurent, comme les variations individuelles, être groupées en séries continues qui facilitent la décourerte des lois de corrélation.

J'ai déjả insisté sur le caractère artificiel de la classification des panicules anormales du Maïs en catégories: type $A$, type B, trpe C, montrant que dans chacune d'elles il y avait des degrés et que ces degrés permettraient de passer insensiblement de l'une à l'autre. On troure arantage à les conserver en les assimilant aux séries en usage dans les études de Biométrique. De même que l'on emploie la longueur du décimètre comme unité commode pour l'évaluation de la fluctuation de la taille des tiges du Maïs, de même il est permis, en première approximation, d'utiliser les catégories, panicules normales, panicules du type $\mathrm{A}$, panicules du type $\mathrm{B}$, panicules du type $\mathrm{C}$, à la condition que ces catégories soient relatives à des caractères de mème nature et que la continuité de la variation soit traduite par l'ordre dans lequel elles sont assemblées. Les photographies des anomalies de la panicule décrites dans le premier chapitre montrent la continuité que beaucoup d'auteurs avait d'ailleurs établie avant moi. Leur production simultanée sur les mêmes plantes, soumises aux mêmes traitements, prouve bien qu'elles sont la traduction d'un 
même caractère : l'indétermination du sexe au début de la formation des bourgeons. On peut donc considérer les mots panicules du type $A$, panicules du type $B$, panicules du type $C$; comme représentant des différences d'intensité d'un même phénomène et chercher ensuite les conditions nécessaires pour obtenir une intensitẻ d'anomalie déterminée.

17. - Relations entre la tallle des Rejets, Le Degré DE LA MUTILATION ET L'INTENSITÉ DE L'ANOMALIE.

Quelque probants que soient les chiffres qui résument les expériences exposées au chapitre IV, ils ne donnent cependant pas la véritable impression que produit la vue des cultures. Le dénombrement précis des pieds anormaux exige que l'on fasse figurer sous le même titre une métamorphose précoce de la panicule mâle en inflorescence ramifiée femelle couverte á l'époque de la récolte de nombreuses graines bien conformées, et, d'autre part, la même anomalie tardive et peu visible. Pour l'observateur, les deux cas sont sensiblement différents ; c'est pour donner une impression plus exacte des faits que je vais rapidement étudier les rapports étroits qui lient l'intensité de la métamorphose et la taille des rejets.

Le relevé des tableaux d'expériences $I I-X$ donne, pour la taille des rejets comptée de 2 en 2 décimètres, les séries de chiffres suivants :

Tableau XIII (page 61).

La taille moyenne en décimètres des:

$\begin{array}{rrrr}\text { rejets normaux est comprise entre........ } & 12 \text { et } 18 \\ - \text { du type A } & - & \ldots \ldots \ldots & 10 \text { et } 18 \\ - \text { du type B } & - & \ldots \ldots \ldots & 2 \text { et } 4 \\ - \text { du type C } & - & \ldots \ldots \ldots & 0 \text { et } 2\end{array}$

Nous retrouvons les relations établies déjà en examinant l'ensemble de tontes les anomalies récoltées durant plusieurs années (page 29). Leur décroissance régulière à partir de l'inflorescence mâle ramifiée pour aboutir à l'inflorescence femelle uniaxe confirme la règle déjà énoncée. 
MUTATION ET TRAUMATISMES.

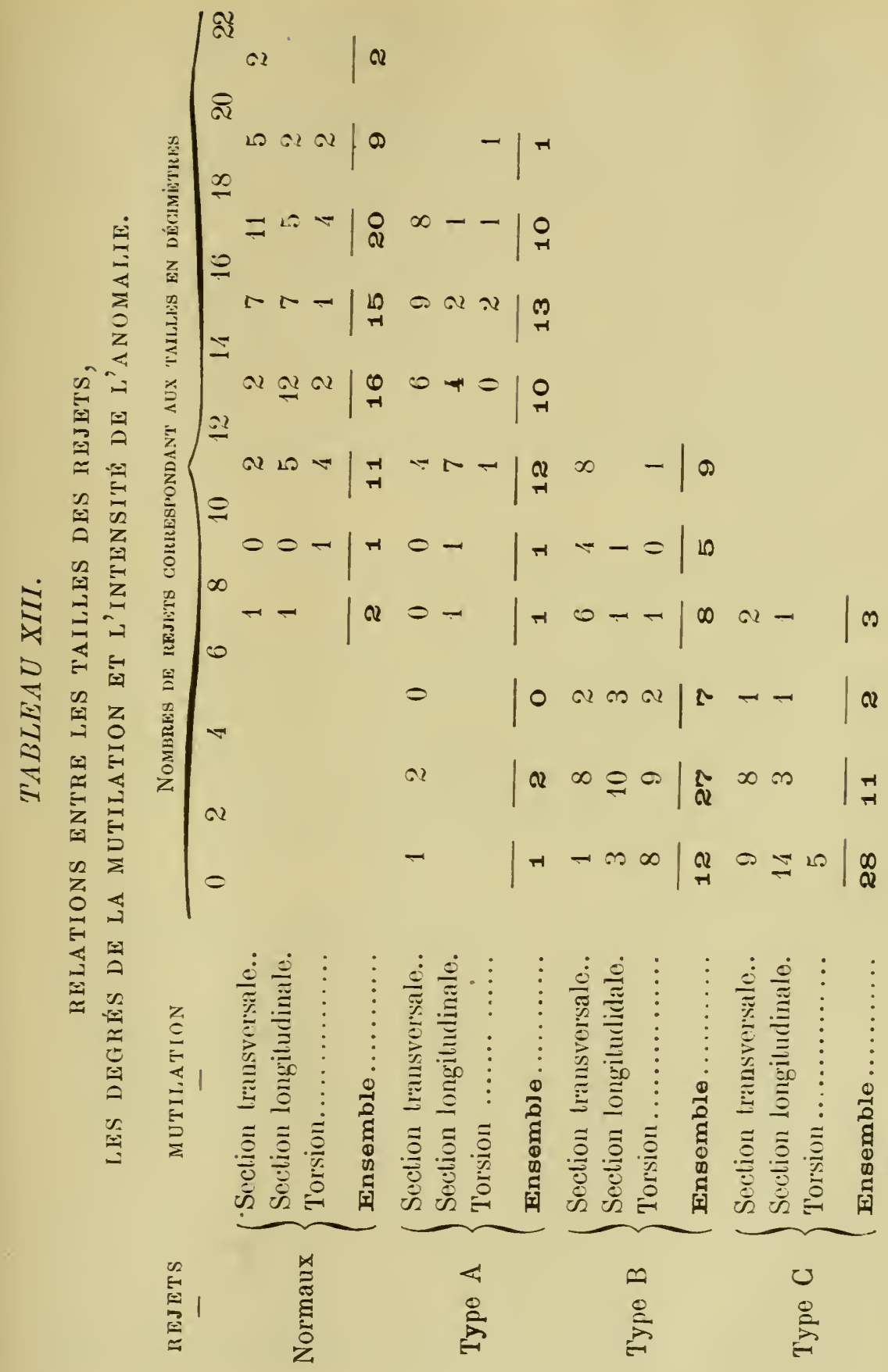


On peut en faire l'examen plus approfondi. Les données du tableau $I$ sont relatives à un grand nombre d'anomalies; elles donnent par l'application de la loi des grands nombres la taille moyenne correspondant à une anomalie déterminée. Or ces tailles moyennes diffèrent sensiblement de celles qui viennent d'être calculées d'après les résultats des mutilations faites le 10 juillet 1903.

\begin{tabular}{|c|c|c|}
\hline \multirow[b]{2}{*}{$\begin{array}{c}\text { REJETS } \\
-\end{array}$} & \multicolumn{2}{|c|}{ Taille moyenne en décimètres des rejets rẻcoltés } \\
\hline & $\begin{array}{c}\text { de } 1903 \text { à } 1905 \\
-\quad\end{array}$ & $\begin{array}{l}\text { après mutilation } \\
\text { faite le } 10 \text { juillet } 1903\end{array}$ \\
\hline Normaux..... & 18 à 20 & 12 à 18 \\
\hline Type A............ & 15 à 18 & 10 à 18 \\
\hline Type B............ & 10 à 12 & 2 à 4 \\
\hline Type C............ & 6 à 8 & $0 \grave{\mathrm{a}} 2$ \\
\hline
\end{tabular}

La taille moyenne de l'ensemble des rejets est toujours supérieure à celle des rejets récoltés après mutilation.

Une grande partie du matériel examiné dans le premier cas provenait de cultures faites en vue de l'hérédité de l'anomalie. Toujours les rejets ou les tiges principales déformées sont apparues de bonne heure et peu de temps après la levée. Au contraire les rejets provoqués par traumatisme apparurent assez tard dans l'évolution de la plante. C'est pourquoi leur taille est réduite.

\section{8. - Élimination du bourgeonnement aGGessoire.}

Il est d'autre part facile de prouver que la nature de la mutilation ou plutôt le degré de la mutilation a une influence sur la rapidité de la sortie des rejets, c'est-à-dire sur leur taille au moment de la récolte. La distribution des rejets dans la série de tailles croissantes de 2 en 2 décimètres est:

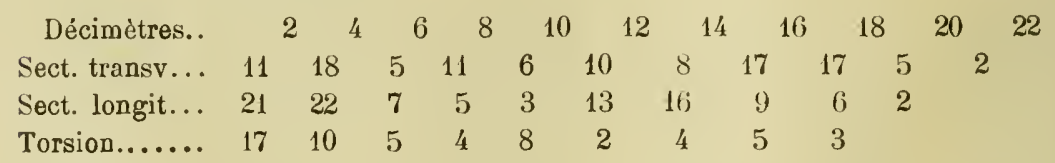

Il est plus commode de comparer les séries de tailles ramenées à 
100 individus pour chaque opération. Elles sont:

$\begin{array}{llllllllllll}\text { Décimètres. } & 2 & 4 & 6 & 8 & 10 & 12 & 14 & 16 & 18 & 20 & 22\end{array}$

$\begin{array}{llllllllllll}\text { Sect. transv. } & 9,5 & 15,5 & 4,3 & 9,5 & 5,2 & 13,5 & 6,9 & 14,5 & 14,5 & 4,8 & 1,8\end{array}$

$\begin{array}{llllllllll}\text { Sect. longit. } 20,2 & 21,1 & 6,7 & 4,8 & 2,9 & 12,5 & 15,5 & 8,6 & 5,8 & 1,9\end{array}$

$\begin{array}{llllllllll}\text { Torsion. ... 27,5 } & 16,4 & 8,3 & 6,6 & 5,0 & 13,1 & 3,3 & 6,6 & 8,3 & 4,9\end{array}$

Plus de la moitié des rejets développés après la section transversale dépasse un mètre de hauteur. Les autres, et ils sont nombreux surtout entre 0 et 4 décimètres, sont des rejets de second ordre développés (comme on peut s'en rendre compte facilement sur les tableaux d'expériences $I I-X)$ tard dans la saison et après l'érolution déjà complète des premiers sortis. Les polygones de variations de taille que l'on peut tracer à l'aide des chiffres (fig. 2) montrent en

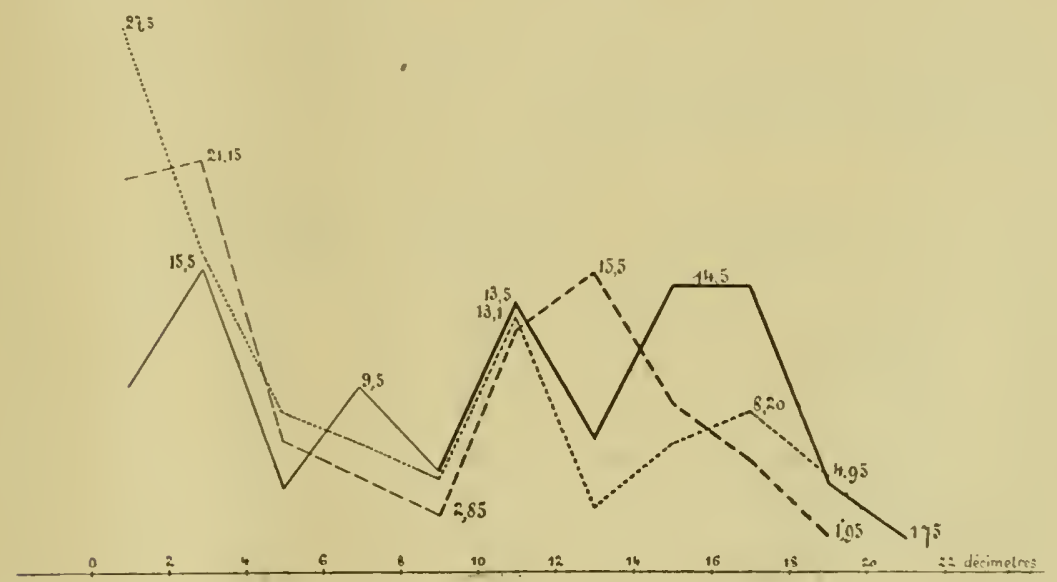

FIg. ?. Section transversale, Section longitudinale, Torsion.

effet deux sommets principaux l'un correspondant à 16 décimètres pour les premiers rejets développés, l'autre à $2-4$ décimètres pour les derniers. Les nombres donnés par la section longitudinale sont encore plus faciles à interpréter. Les deux sommets du polygone de variation sont nettement séparés par une vallée profonde et correspondent à 1:-14 décimètres et à 2-4 décimètres. Seuls les résultats donnés par la torsion des tiges sont moins faciles à grouper, ce qui tient, d'une part, au nombre restreint de rejets développés après cette opération, et surtout, à la difficulté que présente l'opération elle- 
même. Ils montrent seulement que la torsion, qui n'entraine la mort d'aucune plante, est une méthode peu précise pour déterminer des anomalies de la panicule.

Les polygones de variation permettent d'èliminer le bourgeonnement accessoire et tardif que trahit la présence de nombreux rejets de taille peu élevée; on voit alors que la section transversale des tiges de Maïs provoque le développement immédiat de rejets atteignant à maturité 16-18 décimètres, et la section longitudinale celui des rejets de 12-14 décimètres. Puisque les deux opérations ont été faites à la même époque, on peut en conclure que la section transversale, mutilation plus grave que la section longitudinale, détermine le développement plus précoce ou plus rapide des rejets.

D'autre part, puisqu'il existe une loi de corrélation entre la taille des rejets et le degré de l'anomalie, il semblerait que la section transversale dût donner surtout des rejets du type A et la section longitudinale des rejets du type B. L'examen des tableaux $I I-V I I$ ne confirme pas cette déduction:

\begin{tabular}{|c|c|c|}
\hline PANICULES & $\begin{array}{l}\text { SECTION } \\
\text { LONGITUDINALE } \\
-\end{array}$ & $\begin{array}{c}\text { SECTION } \\
\text { TRANSVERSALE } \\
-\end{array}$ \\
\hline Normales............. & 32 & 30 \\
\hline Type A............. & 16 & 28 \\
\hline Type B.............. & 18 & 29 \\
\hline Type C............... & 19 & 20 \\
\hline Mâle avorté........... & 19 & 9 \\
\hline Total.......... & 104 & 116 \\
\hline
\end{tabular}

Il ne paraît donc pas possible, dans les conditions de l'expérience, d'obtenir une intensité d'anomalie donnée par une mutılation appropriée. Pour y aboutir, il est nécessaire de tenir compte d'un facteur négligé jusqu'ici qui est l'époque de la mutilation. 
INFLLENCE IE L'ÉPOQUE IE LA MUTILATION.

\section{9. - ExpÉRIEXces DE 1903.}

Deux parcelles des cultures de 1903 a vaient été réservées pour ces essais. Comme elles ont donné des résultats concordants pour toutes les mutilations employeées, je n'étudierai ici que les elfets de la plus violente, la section transversale:

\section{TABLEAU XIV. \\ Parcelle $I V$. Ligie A.}

SEGTION TRANSTERSALE DE LA TIGE

faite le 14 aouit 1903. - Etude de contiôle le 2 octobre. Pieds éliminés: $A_{10}, A_{16}, A_{23}, A_{25}$; Pieds morts : 12 sur $26: A_{1}$, $A_{2}, A_{6}, A_{9}, A_{11}, A_{12}, A_{16}, A_{17}, A_{20}, A_{22}, A_{26}, A_{29}$.

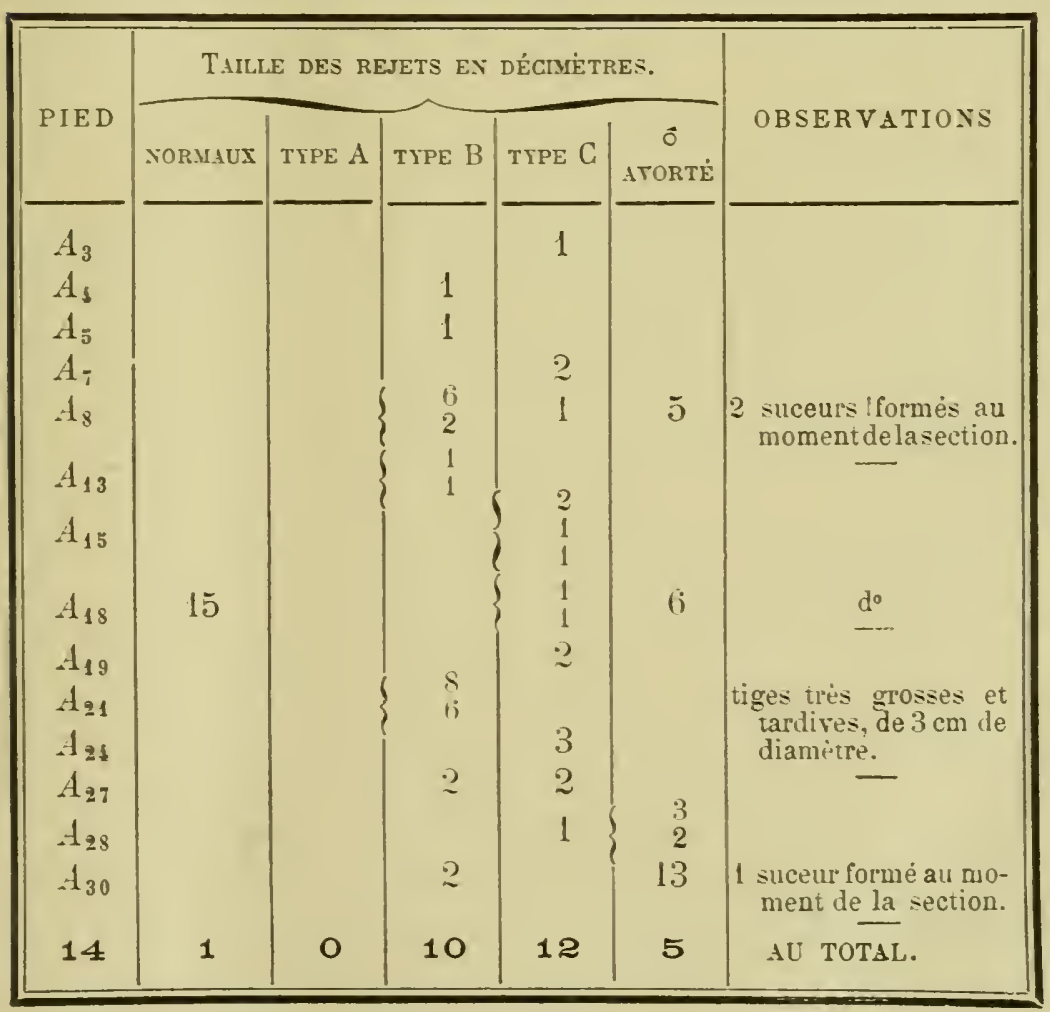




\section{TABLEAU XV.}

\section{Pargelle $V$. Ligne $A$.}

SEGTION TRANSVERSALE DE LA TIGE

faite le 14 uoût 1903. - Etude de contrôle le 2 octobre.

Pieds élinninés: $A_{6}, A_{11}, A_{13}, A_{17}, A_{24}$; Pieds morts: 13 sur 25: $A_{1}, A_{4}, A_{5}, A_{9}, A_{12}, A_{14}, A_{19}, A_{20}, A_{23}, A_{25}, A_{27}, A_{29}, A_{30}$.

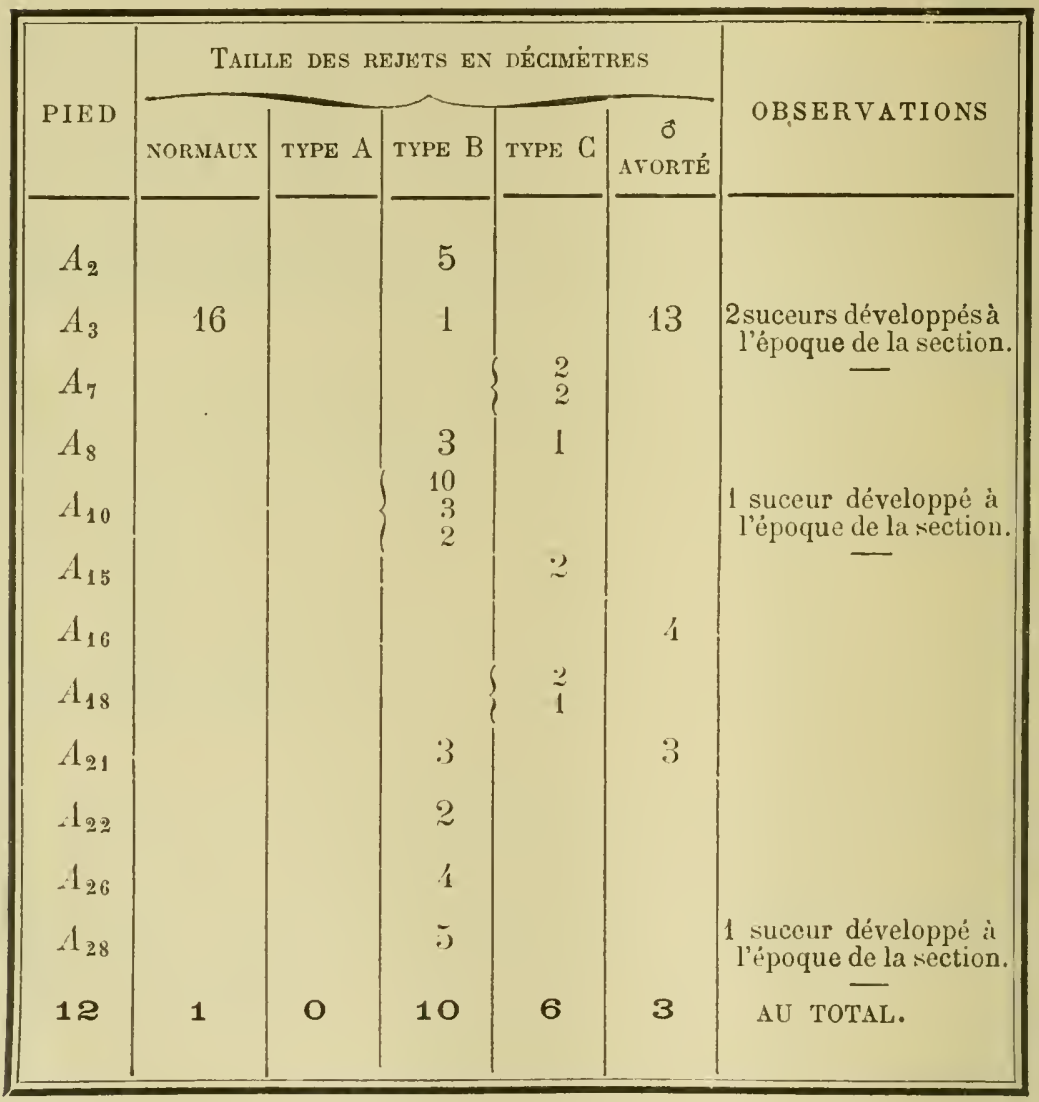

En ne tenant pas compte des rejets déjà formés au moment de la section de la tige principale, on constate que les anomalies sont nombreuses sans doute, mais portées toules sur de courts pédoncules. 
Elles sont d'ailleurs apparues trés tard et la majeure partie n'a pas pu mùrir ses graines. Au 23 octobre, date de la récolte, une seule panicule du trpe B appartenant au pied $A_{2}$ de la parcelle $V$ pourait ètre conservée. Troi rameaux latéraux et l'axe principal portaient ensemble une cinquantaine de graines presque mùres et capables de germer comme j'ai pu m'en assurer dans la suite. D'autre part, nombre de grappes florales, formées après la disparition complète du pollen hors des ètamines flétries, n’ont pu ètre fécondẻes.

La mutilation a entrainé la mort d'un grand nombre dindividus: 12 sur 26 dans la parcelle $I V$ et 13 sur 25 dans la parcelle $V$, soit la moitié des plantes mutilées; la proportion eût èté plus forte encore sil'on arait supprimé les suceurs.

Le nombre des pieds déformés (35 sur 36 survirants), très considérable, est bien encore en rapport arec le haut pourcentage de la mortalité ; mais il est érident que cette époque est trop tardire pour donner des résultats intéressants pour la culture, puisque la récolte de graines mùres sur les panicules anormales est presque impossible.

\section{0. - EXPÉRIENCES DE 1904 ET 1905.}

Afin de donner une solution plus complète á cette question trés importante de la date convenable pour déterminer la métamorphose sexuelle des fleur's màles suivie de fécondité, jai repris ces essais en 190 á à Chaville (Seine-et-Oise), et en 1905 à Bourợ-la-Reine (Seine), sous un climat plus farorable à la maturité du Mais. Il serait trop long de reproduire en détail toutes les mesures faites; il suffit de donner les résultats d'ensemble.

Les graines emplorées ont été réioltées sur des pieds exempts d'anomalies et á une seule tige. Jarais eu soin le faire l'autoféconlation pour éviter l'influence du pollen de plantes amormales, car les porte-graines ont été choisis parmi les plantes témoins de la pareelle TI des cultures de 1903. La seule mutilation employée fut la section transversale de la tige, qui, dans les expériences précédentes, arait été la plus fẻconde en déformations de la grappe terminale. Les lignes 1 et 8 , limites des pareelles, ont été laissées intactes ainsi que la ligne $t$ conservée comme témoin. Chaque ligne comprenait 's plantes dont il faut éliminer les plantes repiquées ou mutilées par accident. Les études de contrôle ont été faites dans les deux cas à la fin du mois d'octobre : 
TABLEAU XVI.

EXPÉRIENGES FAITES EN 1904 a CHAVILle (Seine-et-Oise).

\begin{tabular}{|c|c|c|c|c|c|c|c|}
\hline \multirow[b]{2}{*}{$\begin{array}{c}\text { SECTION } \\
\text { TRANSvERsale } \\
\text { de la tige faite le }\end{array}$} & \multirow[b]{2}{*}{$\begin{array}{c}\text { Nonbre } \\
\text { de } \\
\text { plantes } \\
-\end{array}$} & \multirow[b]{2}{*}{$\begin{array}{c}\text { Morites } \\
-\end{array}$} & \multicolumn{5}{|c|}{ NoMbre DE REJETS } \\
\hline & & & $\begin{array}{l}\text { nor- } \\
\text { maux } \\
-\end{array}$ & $\begin{array}{c}\text { type A } \\
-\end{array}$ & $\begin{array}{c}\text { type B } \\
-\end{array}$ & $\begin{array}{c}\text { type } \mathrm{C} \\
-\end{array}$ & $\begin{array}{c}\hat{\sigma} \\
\text { avorté } \\
-\end{array}$ \\
\hline $1^{\text {er }}$ juillet........ & 19 & 2 & 21 & 4 & 5 & 3 & 3 \\
\hline 18 juillet........ & 21 & 5 & 13 & 7 & 3 & 2 & 3 \\
\hline 2 août........... & 20 & 9 & 4 & 2 & 8 & 5 & 1 \\
\hline 17 août .......... & 21 & 14 & 0 & 0 & 12 & 9 & 0 \\
\hline 19 septembre... & 20 & 17 & 0 & 0 & 6 & 4 & 0 \\
\hline Plantes témoins. & 22 & 0 & 1 & 0 & 0 & 2 & 1 \\
\hline
\end{tabular}

TABLEAU XVII.

EXPÉRIENGES FaItes EN 1905 a BoURG-LA-REINE (Seine).

\begin{tabular}{|c|c|c|c|c|c|c|c|}
\hline \multirow[b]{2}{*}{$\begin{array}{c}\text { Section } \\
\text { Transversale } \\
\text { de la tige faite le }\end{array}$} & \multirow[b]{2}{*}{$\begin{array}{c}\text { Nombre } \\
\text { de } \\
\text { plantes } \\
-\end{array}$} & \multirow[b]{2}{*}{ Mortes } & \multicolumn{5}{|c|}{ NOMBRE DE REJETS } \\
\hline & & & $\begin{array}{l}\text { nor- } \\
\text { maux } \\
-\end{array}$ & $\begin{array}{c}\text { type A } \\
-\end{array}$ & $\begin{array}{c}\text { type B } \\
-\end{array}$ & $\begin{array}{c}\text { type } \mathrm{C} \\
-\end{array}$ & $\begin{array}{c}\text { ô } \\
\text { avorté }\end{array}$ \\
\hline 24 juin... & 23 & 2 & 19 & 7 & 6 & 4 & 2 \\
\hline 12 juillet........ & 21 & 3 & 14 & 12 & 11 & 5 & 4 \\
\hline 29 juillet........ & 22 & 8 & 3 & $\tau$ & 13 & 9 & 6 \\
\hline 12 août......... & 23 & 12 & 0 & 1 & 10 & 8 & 1 \\
\hline 27 septembre... & 22 & 18 & $1\left({ }^{1}\right)$ & 0 & 4 & $\eta$ & 0 \\
\hline Plantes témoins. & 20 & 0 & 2 & 0 & 3 & 2 & () \\
\hline
\end{tabular}

\section{1. - Interprétation Des RÉSultats.}

Exception faite des pieds témoins, dont la tenue a été indiquée pour donner une idée exacte des erreurs produites par l'irrégularité du

(1) Suceur développé avant la section. 
développement due aux plantes mêmes, on roit immédiatement que plus le traumatisme est fait tardivement, plus il entraîne une mortalité élevée et plus le nombre des rejets anormaux est considérable.

Les sections faites le 17 août et le 19 septembre 1904, le 27 septembre 1905 entraînent la mort d'un grand nombre de plantes et les rejets des survivantes sont tous déformés. Par contre le déreloppement des rejets, rapide peu de temps après la section, se ralentit bientòt, et il est impossible de récolter sur eux des graines bien mûres.

Dans cette série, seules quelques inflorescences ont pu ètre conserrées pour l'essai de germination. Les autres, succulentes encore, se sont décomposées; leur taille petite permet de les ranger dans la catégorie des bourgeons accessoires dont les polygones de variation le taille ont décelé la présence. On peut donc les éliminer et ne conserver que les rejets dont les grappes ont mùri au moins quelques graines :

TABLEAU XVIII.

INFLUENCE DE L'ÉPOQUE DE LA SEGTION TRANSV゙ERSALE SUR L'INTENSITÉ DE L'ANOMALIE DES PANICULES.

\begin{tabular}{|c|c|c|c|c|c|}
\hline \multirow[b]{2}{*}{ SEctrox faite le } & \multirow{2}{*}{$\begin{array}{c}\text { Nombre } \\
\text { de plantes } \\
\text { vivantes } \\
-\end{array}$} & \multicolumn{4}{|c|}{ REJETS A GRAPPE MŮRE } \\
\hline & & $\begin{array}{c}\text { normale } \\
-\end{array}$ & $\begin{array}{c}\text { type A } \\
-\end{array}$ & $\begin{array}{c}\text { type B } \\
-\end{array}$ & type C \\
\hline $1^{\text {er juillet } 1904 . . . . . .}$ & 17 & 21 & 4 & 2 & 1) \\
\hline 18 juillet 1904 ........ & 16 & 13 & 7 & 2 & 1 \\
\hline 2 août $1904 \ldots . . . .$. . & 11 & 4 & 2 & 6 & 3 \\
\hline 17 août $1904 \ldots . . . . .$. & 7 & 0 & 0 & 7 & 4 \\
\hline 2 '́ juin $1905 \ldots . . . \ldots$. & 21 & 19 & 7 & 3 & 2 \\
\hline 12 juillet $1905 \ldots . .$. & is & 14 & 12 & 5 & 1 \\
\hline 29 juillet 1905 ........ & $1 \cdot t$ & 3 & 7 & 9 & う̆ \\
\hline 12 août $1905 . . . \ldots \ldots$ & 11 & 0 & 1 & 3 & 5 \\
\hline
\end{tabular}

Les résultats sont très différents de ceux qui figurent dans les tableaux XVI et XVII; ils sont aussi plus précis. Exiger des rejets qu'ils donnent des graines mûres pour les faire entrer en ligne de compte, c'est limiter l'examen à ceux qui se sont déreloppés de très bonne heure et immédiatement aprés la section ; c'est par conséquent limiter l'étude aux phẻnomènes qui se produisent immédiatement 
après la mutilation et laisser de côté la gemmation accessoire qui l'accompagne toujours en troublant la netteté des résultats.

Dans ces conditions, il est facile d'énoncer les lois qui régissent la production des anomalies de la panicule terminale des tiges du Maïs.

\section{2. - Conditions DÉterminantes dE líntensité DE} L'ANOMALIE DE ILA PANICULE.

La section transrersale de la tige faite an ras du sol détermine la mort d'un nombre considérable d'indiviclus. Elle entraîne la production de nombreux rejets dont la plupart présentent des cas de métamorphose des fleurs màles en flcurs femelles fertiles.

La métamorphose est plus ou moins accusée. L'époque à laquelle est faite la mutilation joue un ròle, plus important peut-être que le mode rle mutilation employé, pour déterminer avec précision l'intensité de l'anomalie. La section transversale des tiges faite de bonne heure entraine surtout la production de panicules normales; faite plus tåd, quelıues épillets mâles se métamorphosent en épillets femelles (type A) ; lorsque le tıaumatisme a lieu peu de temps arant la période de maximum d'allongement de la tige, bon nombre de rejets montrent la métamorphose complète des épillets mâles on épillets femelles (type B). Tous la montrent, si la mutilation est laite pendant ou après là floraison, et même, daus ce dernier cas, la ramification des inflorescences disparaît à son tour (type $\mathrm{C}$ ). On passe ainsi de la panicule mâle ordinaire à l'épi fernelle latéral. 


\section{MÉTAMORPHOSE DES ÉPIS LATERAUX FEMELLES EX INFLORESCENCES MÂLES.}

L'examen des deux cas de métamorphose des épis décrits précédemment (page 34́) montre une relation entre cette anomalie of l'allongement du pédoncule que l'on peut proroquer par la torsion le la tige. D'autre part, la portion du rachis couverte d'épillets mâles wst toujnurs moins épaisse que celle qui porte les épillets femelles et la torsion de l'épi permet de déterminer l'amineissement du rachis au dela de la zone de torsion. Les lignes $D$ et $E$ des 5 jarcelles: l'expériences de 1903 furent réserrées pour des essais de mutilation des inflorescences latérales, la ligne $D$ pour l'allongement des péduncules réalisé par la torsion de la tige principale (tableaux $\checkmark I I I-X)$, la ligne $E$ pour la torsion de l'épi lui-mème.

\section{3. - Allongemext des pédonclles apres lat torsiox} DES TIGES.

Les résultats des expériences faites sur la ligne $D$ des parcelles I-II-III sont exposés aux tableaux VIII, $I X$ et $X$. La torsion de la tige faite le 10 juillet 1903 a eu pour effet d'entrainer, outre le déreloppement des rejets, l'allongement des pédoncules et la production d'épis de second ordre. Ces deux dernières anomalies ne sont pas extrèmement rares dans les champs de grande culture; elles sont toutefois exceptionnelles; il y a donc un certain intérèt à connaitre une méthode qui les provoque.

Les pédoncules des épis de Maïs sont d'ordinaire très courts ; l'épi supérieur, inséré le plus sourent au troisième nœud compté à partir de la panicule, est complètement sessile; les autres, qui se déreloppent a l'aisselle des feuilles immédiatement inférieures, sont plus longs de 1 à 3 centimètres et en général ils présentent un nombre plus éleré de bractées d'enveloppe. Il importe donc d'examiner ensemble les épis de même situation sur la tige que je désigne, en commençant 
par le haut: Épi d'ordre 1 on Épi 1, Épi 2, Épi 3.... Le relevé des tableaux VIII, $I X$ et $X$ donne, pour la distribution de la longueur des pédoncules comptée de 5 en 5 centimètres, les séries de chiffres suivantes :

TABLEAU XIX.

ALLONGEMENT DES PÉDONGULES DES ÉPIS

APRES LA TORSION DE LA TIGE,

fuite le 10 juillet 1903. - Contrôle le 29 septembre.

$\begin{array}{cccc}\begin{array}{c}\text { I.ONGUEUR } \\ \text { des pédloncules } \\ \text { en centimètres }\end{array} & \text { ÉPI 1 } & \text { ÉPI 2 } & \text { ĖPI 3 } \\ - & - & - & - \\ 5 & 38 & 30 & 6 \\ 10 & 2 & 12 & 15 \\ 15 & 5 & 8 & 6 \\ 20 & 5 & 8 & 4 \\ 25 & 5 & 3 & 5 \\ 30 & 2 & 2 & 1 \\ 35 & 6 & 1 & \\ 40 & 2 & & \\ 45 & 1 & & \end{array}$

Contrairement i ce qui se passe lorsque la tige se développe sans mutilations, ce sont les épis supérieurs ou épis 1 dont le pédoncule s'allonge le plus après la torsion de la tige. Ce résultat peut être interprété de la manière suivante. Lat torsion de la partie supérieure d'une tige a pour effet d'en limiter la croissance et, comme nous l'avons vu pour les rejets, de suspendre momentanément l'excitation inhibitoire que le bourgeon terminal transmet aux autres bourgeons de la lige. Tous les bourgeons ne profitent pas de la mème façon de la faculté de s'allonger rapidement. L'épi d'ordre 1 voisin du bourgeon terminal est celui qui souffre le plus de la présence de ce dernier et qui est favorisé au maximum par son arrêt de croissance momentané.

\section{4. - RaMification DES ÉPIS.}

Les épis 1 qui ont les pédoncules les plus allongés donnent aussi naissance aux nombres les plus élevés d'épis secondaires, développés 
à l'aisselle de leur's feuilles bractées, comme le montre le relevé des chiffres inscrits aux mèmes tableaux VIII, IX et $X$ :

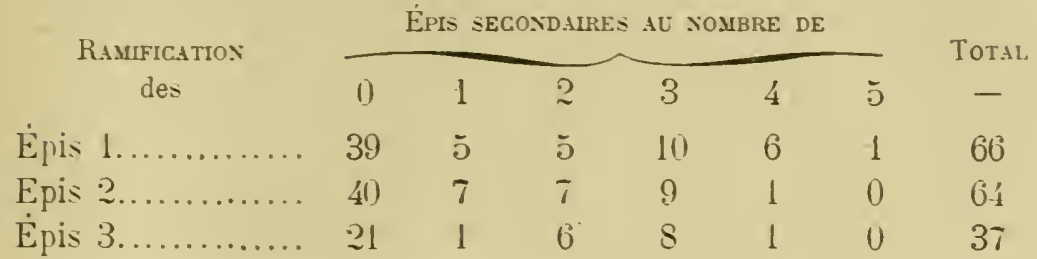

On remarquera la tendance plus accusée des épis d'ordre 3 à donner des épis secondaires en nombre élerẻ. Cela tient sans doute au déreloppement tardif de res épis d'ordre 3 qui ne mùrissent jamais. Les nuits froides et brumeuses de l'automne entrainent un ralentissement dre croissance qui proroque leur ramification aux dépens de leur maturation.

La métamorphose des fleurs femelles en fleurs miles ne s'observe que sur les épis terminaux pourrus de pédoncules trés allongés et d'épis secondaires nombreux. Elle est toujour's très réduite, n’affecte que quelques épillets et n'est que l'exagération do la tendance latente signalée plus haut. Dans les expériences de torsion de la tige principale je n'ai pu obserrer que deur cas, pen nets d'ailleurs, de la substitution des épillets màles aux épillets femelles le l'extrémité des épis ; ils ont été fournis par les pieds $D_{3}$ et $D_{11}$ de la parcelle $I I$ (tableau II). La pointe du rachis, amincie sur une longueur de? ou 3 centimètres, portait une vingtaine d'épillets måles à étamines fertiles et sans aucune trace d'ovaire.

\section{0̈. - Coupression de la tige aUd nđeuds.}

Faite le 14 a aut, la compression arait pour but de suppléer à la torsion de la tige principale rendue impraticable par la taille élerée qu'arait le Maiss à cette date. Elle consistait en l'écrisement le la tiq̣e, de la gaine et de l’épi déjà risible, à l'aide de pinces clont les extrémités étaient munies le bouchons de liège. La base du jeune épi était ainsi mutilée sans que la feuille et la portion de tige qui l'enveloppaient eussent à soulfrir. J'espérais obtenir quelques ėpis en bon état mais modifiés par laarrèt de croissance momentané que derait apporter cette mutilation. Je n'ai pu obtenir ancun cas de métamorphose des fleurs femelles en fleurs màles. 


\section{6. - TORSION DE L'ÉPI LATÉRAL FEMELLE.}

Les lignes $E$ des parcelles $I, I I$ et $I I I$ des cultures de 1903 furent réservées pour ces essais faits le 14 août. Leur réalisation est très délicate. Il faut tont d'abord dégager la tige et l'épi de la gaîne de la feuille qui les embrasse; la tige succulente se rompt avec une grande facilité et entraîne la perte d'un nombre considérable des plantes en expérience. Souvent le jeune épi se détache arec la tige; lorsqu'il n'a point souffert, son pédoncule s'allonge et les bractées espacées se développent en véritables feuilles caulinaires portant à leur aisselle des épis secondaires. Aucune métamorphose des fleur's femelles en fleurs màles ne s'est présentée sur les 12 plantes qui ont végèté de cette laçon.

Lorsqu'il fut possible d'écarter la tige et la gaine de la feuille sams entrainer de rupture, je tordis l'épi de 180 degrés afin d'amener la première bractée à deux nervures, primitivement accolèe à la tige, contre la surface interne de la gaîne; je replaçai la tige daus la gaûne et maintins le tout avec un lien de coton. Malgré ces précautions bon nombre de bractées reprirent les jours suivants leur position normale et les épis ne montrèrent, à l'étude de contrôle, dans les premiers jours d'octobre, aucune modification. Ces difficultés ont lortement réduit le nombre des épis ayant subi la torsion. Sur les 8:? plantes en expérience, il en restait 47 seulement n'ayant subi ni rupture de tige ni rupture d'épis. On ne trouvait, au moment de la récolte, de traces de mutilations que sur 1.1 épis:

9 épis aviient leurs rangées de graines tordues en spirales très serrées les unes contre les autres, et sur ce nombre, 7 portaient huit rangées. Ces 7 épis avaient certainement subi la torsion de l'axe car je n'ai jamais pu observer une disposition spiralée des rangées sur des épis à 8 rangs et non mutilés.

2 épis laissaient des espaces libres très larges entre leurs 4 rangẻes doubles de graines accolées, particularité très rare sur les plantes témoins.

Enfin les 3 derniers montraient la métamorphose partielle des fleurs femelles en fleurs mâles.

Deux de ces épis étaient analogues à celui déjà décrit comme rencontré accidentellement dans les cultures. Ils montraient l'amineissement du rachis dont l'épaisseur passait subitement de 20 á 
j millimètres. Seules les feurs de la base de l'épi mont donnẻ des graines que jai pu récolter múres. Les épillets màles, en tout comparables a cen de la panizule, renfermaient des étamines

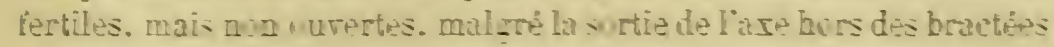
denteloppe de liepi. On n'y trouvait aucune trate diovire.

Le troisiéme épi. I plus intéressant peut-être élatit le moins déformé. Les rangeses de graines étaient tondus of lon purvait

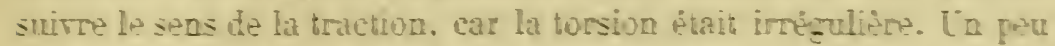
au-dessus du milieu de lépi, un léger étranglement correspondait à

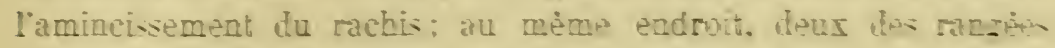

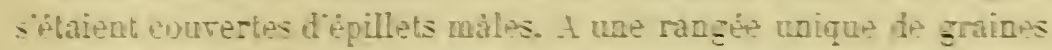

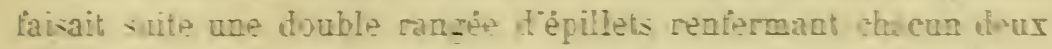

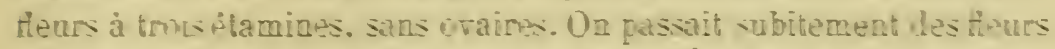

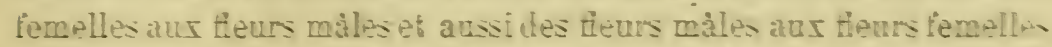
car le ranhis reprenait son épaisseur normale at lak pointe of se

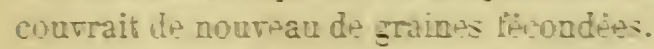

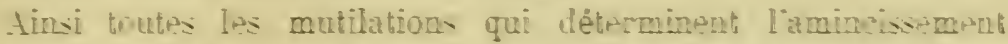

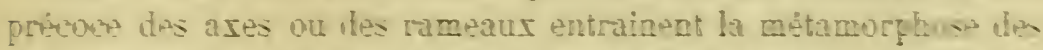
Hipurs femelles en teurs måles. On peur pe conchere que lanomalin résulte diune diminution dans la nutrition des jeunes bourgenes fioratur. Il esiste certainement une epuque plus farorable que in autres peur la proroquer. Al point te ne exporimental il y aturit lieu de la déterminer arec procision comme on la hat pour los intorescrners malps molitipes en grappes à seres mélangés on à seres femelles. Les diftedtés de lexpérience do mont pas parmis de faire cet essai. On pourmil lentreprendre atree dizutres variétes de Mais arec de plus gramdes chan des de suces. 


\section{ACTION IIES TRAUMATISMES}

\section{SUR DIVERSES VARIÉTÉS I)E MAÏS.}

\section{7. - VÁRiétés SOUMiSES a L’Expérinentation.}

les graines ont été achetées, ou reçues d'amis qui connaissaient mon désir de cultiver diverses variétés de Maïs. Les lots homogènes et suffisamment abondants pour en permettre la culture immédiate sur une assez grande échelle sont désignés ici sous leurs noms de ratalogue ou d'origine. Ce sont:

1. Maïs cinquantino, YiLMorin.

2. Maïs blanc des Landes, Vilmorin.

3. Maïs sucré ridé nain hâtif, ViLmoris.

4. Maïs sucré ridé, tardif, Vilmorin.

5. Maïs dent de cheval, Vilmorin.

6. Maïs Cusco blanc et rouge, Thmorin.

7. Maïs panaché, Tilmorin (japonica foliis variegatis).

8. Maïs d'Algérie (M. Launay).

9. Maïs d'Afrique (M. Chevalier. Mission au Lac Tchad, 1903).

10. Maïs de Chine (M. Rouaud. Muséum, Paris).

l)'autre part j'ai pu me procurer, grâce à la bienveillance de M. J. Costantin, professeur de Culture an Muséum d'Histoire naturelle, les nombreuses variétés envoyées par les jardins botaniques d'Europe. Mais, il faul remarepuer que les lots où l'hybridation était manifeste formaient la grande majorité; j'ai dù me résigner à n'en cultiver (qu'un petit nombre, purs en apparence. Quant aux autres, il a fallu d'abord les purifier et les récoller après autofécondation. Ces essais, commencés en 1904, n'étaient pas complètement terminés en 1906 ; il m'est naturellement impossible d'en parler ici. J'ai obtenu, d'autre part, des plantes désignées sous un nom diffẻrant totalement des diagnoses connues; quelques-unes d'entre elles sont intéressantes par leur pureté et li netteté de leur's caractères, mais leur description 
et par conséquent la justesse de leur désignation n’a pas été rérifiée. Parce qu'ils présentent quelque intérèt, je donnerai rapilement quelques résultats des essais faits sur ces plantes. Pour ne rien préjuger je les désignerai sous les noms qu’elles portent dans les catalogues d'échange des Jardins Botaniques en indiquant le lieu d'origine et la date de l'enroi:

11. Zea Mays rar. alba, VARSOVIE, 1904.

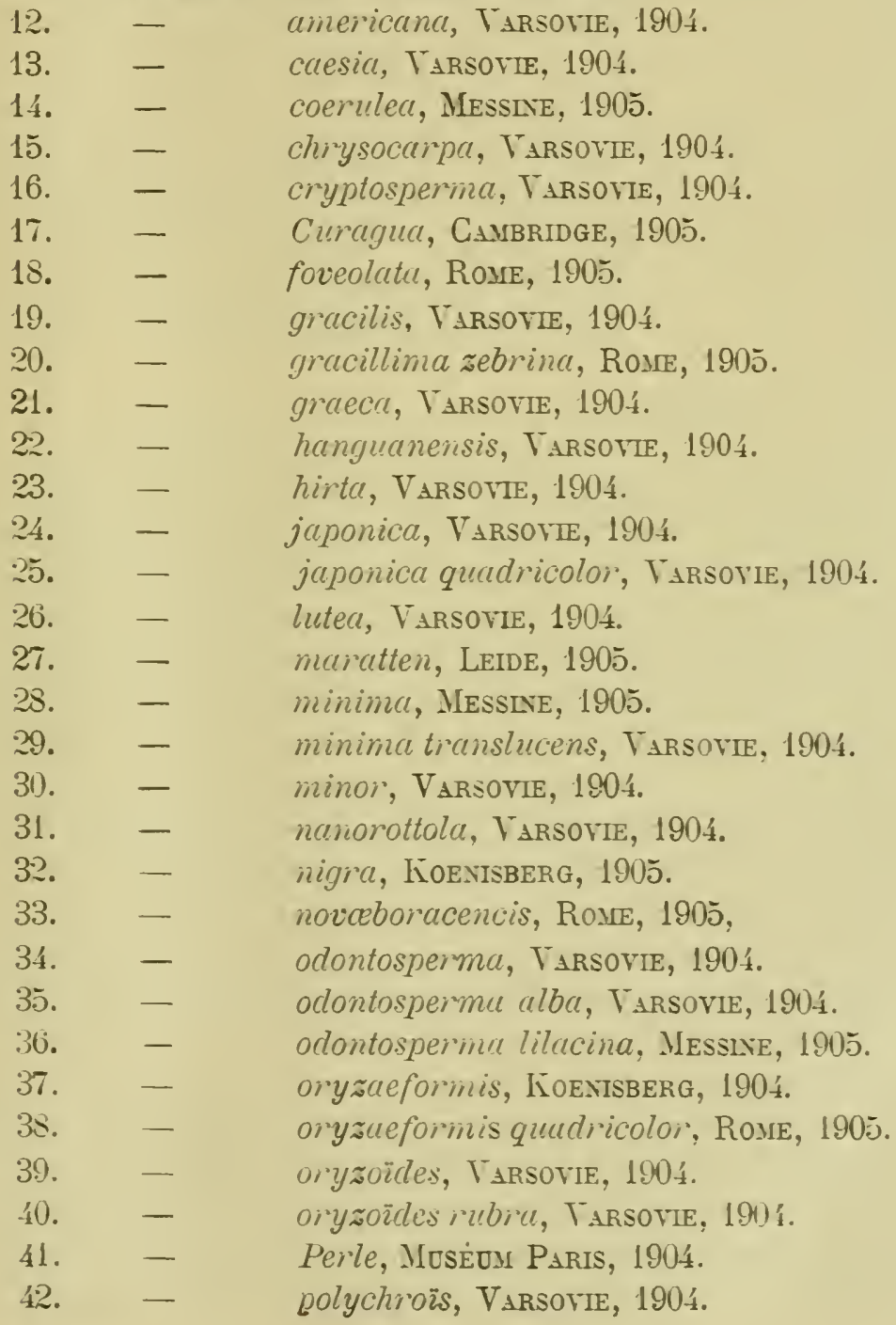


43. Zea. Mays var. racemosa, VArsovie, 1904.

$\begin{array}{ll}\text { 44. } & - \\ 45 . & - \\ 46 . & - \\ 47 . & - \\ 48 . & - \\ 49 . & - \\ 50 . & - \\ 51 . & - \\ 52 . & - \\ 53 . & - \\ 54 . & - \\ 55 . & - \\ 56 . & - \\ 57 . & - \\ 58 . & -\end{array}$ Reuteri, VARSOVIE, 1904. rossica, VARSOVIE, 1904. rostrata odontospema, VARsovie, 1904. rubra, Muséum, Paris, 1904. rubra dulcis, Rome, 1905. saccharata lilacino, Rome, 1905. saccharata mbra, VARSOVIE, 1904. translucens crispa, BudAPESTH, 190 כ. tricolor, BALE, 1905. tunicata blanc et rouge, MusÉum,PARIs, 1904. van Rels, VArsovie, 1904. vulgate var. ambre, WVAGENINGEN, 1905. vulgaris var. nova, Strasbourg, 1905. violacel, Dublany, 1905. aunthornis, KöNISBERG, 1905.

\section{8. - MÉtamorphose DES PANICUI.ES TERMinales.}

Les essais dont il est question ici ont été faits sur 30 plantes formant des lots homogènes et provenant toutes les fois qu il a été possible d'un mêmr épi. Les lots de 1905 dérivent en partie de plantes autofécondées en 1904 sur lesquelles on n'a pu observer les caractéres de disjonction des hybrides si nets dans le Maïs. J'y joins les cultures de 190 í et 1905 faites avec des lots de semence dont la pureté a pu être contròlée à la récolte. Sur les 30 plantes, 10 ont été conservées comme témoins, 10 ont subi la section transversale de la tige à la base dans le cours du mois de juillet, et, les autres unt été mutilées de diffẻrentes façons pour provoquer la déformation des inflorescences latérales.

Les résultats de ces essais montrent que les variations provoquées par les mutilations sont régies, non pas surlout par les caractéres essentiels qui distinguent les variétés, mais bien plus par leur mode de végétation.

En règle générale, les anomalies de la panicule terminale sont rares ou totalement absentes dans les parcelles plantées en variétés tres tardives, par contre les anomalies des inflorescences latérales y sont nombreuses. Le contraire a lieu pour toutes les variétés précoces. Toutefois certaines variétés très précoces présentent à la fois de nombreuses métamorphoses des fleurs de la panicule et des épis. 
Malgré les essais répétés durant deux années, un certain nombre de variétés n'ont pas montré de métamorphose sexuelle des fleurs. Ce sont, pour la plupart, des variétés très tardives dont il est impossible sous le climat de Paris de récolter des graines mûres; on ne peut mème que rarement assister à l'épanouissement de la panicule. Le Maïs dent de cheval, les variétés blanches et rouges du Maïs Cusco, les formes très spéciales et regardées par dirers auteurs comme des espèces linnéennes véritables Zea Cuiarnu MoLIsa, Zea graeca Boxafous, Zeı hirta Boxafous rentrent dans cette catégorie. J'ai d'ailleurs quelques doutes sur la véritable diagnose des deux dernières formes car les exemplaires que $\mathrm{j}$ ai eus en culture ne répondaient pas aux caractères donnés par Boxafoús dans son Histoire naturelle du Mä̈s. De mème, le Zea Mays japonica quadricolor et la forme tricolor de Bâle, qui en est très roisine, n'ont pas mùri leurs graines et leurs panicules ont pu à peine s'étaler' avant l'arrivée des premiers froids.

\section{9. - TENDANGES VARIABLES DES DIFFÉRENTES VARIÉTÉS.}

Tout d'abord viennent les variétés qui ont montré dans mes cultures, aussi bien sur les plantes témoins que sur les plantes mutilécs, la métamorphose partielle de la panicule mâle en une inflorescence femelle. Les variétés gracilis, marutten, nanorottola, oryzoürles, rucemosa sont des formes peu vigoureuses, sourent très prẻcoces qui présentent à un haut degré ce caractèrc. Il est probable que les graines que jai reçues prorenaient déjả d'individus anormaux, reconnus ou non dans les Jardins botaniques qui en ont fait l'enroi. Je crois plutôt que ces caractères aberrants sont intimement liés à la particularité qui a permis de spécifier ces formes. Elles ont toujours un grain de petite taille, et les individus qui en dérivent sont les plantes naines. D'autre part, ces variétés sont très précoces; nous verrons plus loin que la culture de plantes anormales de variétés tardives a conduit à l'obtention d'espèces naines ot précoces. Il sera sans doute impossible de reconstituer l'histoire de ces formes: toutefois les indications relatives à l'origine de la variété Mü̈s suci e $e^{\prime}$ ride muin hätif de Tilvorix pourraient infirmer ou confirmer cette hỵpothèse, car elle présente aussi à un haut degré la propriété de donner des anomalies sans mutilations. Toutefois, mème dans ces variétés, les traumatismes jouent encore un rôle. Le pourcentige 
des pieds anormaux en moyenne de 20 à $60 \%$ parmi les témoins oscille entre 80 et $100 \%$ pour les plantes mutilées.

Toutes les autres variétés se comportent comme la forme de Mä̈s de Pensylvanie qui a servi pour mes expériences de 1903. Les plantes non mutilées se développent normalement, arec séparation des sexes; la mutilation donne des plantes anormales en quantité plus ou moins considérable; pour bon nombre d'entre elles, le pourcentage des pieds déformés est moins élevé que dans le Mä̈s de Pensylvanie ainsi que le montre le tableau suivant:

\section{TABLEAU XX.}

SECTION TRANSVERSALE DE LA TIGE faite en juillet 1904 et 1905.

\section{Zea Mays var.}

alba

americana

caesia

chrysocarpa

coerulea..................

cryptosperma............

gracillima zebrina.......

hanguanensi. ............

japonica..................

lutea.....................

minima translucens. ....

minor.....................

novaeboracensis..........

nigra ....................

odontosperma.............

Perle......................

polychroüs................

Reuteri...................

rossica...................

mbra ....................

tunicate ..................

santhornis...............

van Rels...................

Pieds
MUTILÉS

DÉFORMÉS

12

18

13

17

8

12

10

17

14

11

16

13

6

$\begin{array}{ll}- & - \\ 5 & 4 \\ 9 & 2 \\ 4 & 5 \\ 3 & 9 \\ 4 & 3 \\ 2 & 9 \\ 3 & 2 \\ 5 & 8 \\ 2 & 5 \\ 3 & 1 \\ 2 & 7 \\ 4 & 9 \\ 2 & 1 \\ 1 & 1 \\ 3 & 8 \\ 2 & 1 \\ 3 & 5 \\ 2 & 7 \\ 5 & 3 \\ 4 & 6 \\ 1 & 9 \\ 2 & 1 \\ 3 & 3\end{array}$


Les différences de détails tiennent certainement à la difficulté que présente la reconnaissance exacte du mode de régétation particulier à chacune de ces variétés. Certaines ont une rapidité de croissance surprenante qui m’a empêché de faire la mutilation à une époque convenable; d'autres ont un déreloppement lent et il eût été préférable de faire, pour ces dernières, la section des tiges à la fin et non au début du mois de juillet. Il ne faut donc pas attribuer une trop grande valeur aux chiffres donnés dans le tableau précédent, mais les regarder comme le minimum de ce que peut fournir la méthode appliquée en temps opportun.

La section transversale faite à la base des tiges des variétés de Maïs homogènes, cultivées en 1904 en parcelles de 50 plantes, a donné des résultats analogues. Les formes Mä̈s cinquantino, blanc des Landes, Laïs d'A frique, de précocité comparable, donnent des anomalies de la panicule màle en très grand nombre. Le Maïs de Chine et le Mä̈s panaché n'ont pas inùri leurs graines et par suite n'ont pu être cultivés qu'en 1904. Ils donnent peu d'anomalies véritables, par suite de leur régétation lente, mais, spontanément, beaucoup de suceurs se développent à la base des tiges, tous terminés par une grappe florale femelle du type C. Les stigmates font à peine saillie hor's des feuilles, au mois d'octobre. Cette particularité s'applique à toutes les formes à feuillage panaché de blanc, le rouge ou de jaune, dont j'ai fait l'essai pendant plusieurs années. La panachure est plus accusée sur les rejets que sur la tige principale, et très souvent les rejets tardifs sont complètement dépourrus de chlorophylle, l'où leur croissance très lente.

I a variété de Mä̈s sucré ridé tardif de VILMonix, comme les variétés oryzoürles et oryzaeformis, présente sourent, après la section transversale des tiges, des inflorescences latérales fasciées. Leur culture a montré l'hérédité partielle de l'anomalie. Ies caractères plus aberrants encore, apparus sur les épis des rejets déformés du Zea Mays tunicata, ontété décrits ailleurs (p. 122 et BLARINGHeN, $1904 c, 1904 d)$.

\section{0. - MÉTAMorphose DES Épis latéraux.}

Elle a été observée, à la fois sur les plantes témoins et sur les plantes mutilées, pour un certain nombre de variétés très précoces 
telles que Zea Mays maratten, nanorottola, gracilis et les variétés à graines rouges et blanches de Zea Mays oryzö̈des.

J'ai déjà signalé la tendance très accusée de ees derniers à donner des épis latéraux à pointe aplatie en fourche à deux ou plusieurs branches. Ce caractère est partiellement héréditaire. Dans les lots de contrôle cultivés en 1905 et en 1906, j’ai obtenu des épis dont la dissociation était encore plus accusée et accompagnée de la métamorphose partielle des épillets femelles en épillets mâles.

Certaines variétés n'ont montré l'anomalie qu'après la torsion de l'épi. Celles qui l'ont présentée avec le maximum de netteté sont les formes chrysocarpa, japonica, Perle, Reuteri, van Rels, xanthornis. Le Mä̈s du centre de l'Afrique, dont un épi m'a éte remis par M. Chevalier au retour de son expédition au lac Tchad, donne aussi la métamorphose fréquente des épillets femelles en épillets mâles. Peut-être retrouve-t-on dans cette forme la variété de Maïs du Sénégal que signale BeLhomme (1862)? La métamorphose partielle des épillets femelles en épillets mâles, reconnue sur tous les épis, l'a fait signaler sous le nom de Zea androrynua.

Enfin, le Maïs d'Algeirie, qui malheureusement mûrit mal ses graines dans les environs de Paris, donne les meilleurs résultats. En 1904, j’ai soumis à la torsion 20 épis d'ordre 1 de cette variété ; 11 m'ont fourni la transformation partielle des épillets femelles en épillets màles. Les épis, repris en 1905 , ont donné des résultats analogues. Enfin les graines récoltées sur les épis métamorphosés partiellement donnent des plantes qui montrent l'hérédité partielle du caractère.

Cette variété serait à mon avis la plus appropriẻe à l'élude expérimentale complète de la métamorphose des épis latéraus en panicules terminales. La recherche de la mutilation la plus convenable, puis la détermination de l'époque favorable pour la réussite complète, pourraient être entrepris avec cette variété sous un climat oú elle mûrit facilement ses graines. Il ne faut pas y songer dans nos régions où très souvent la fécondation est à peine faite au début du mois d'octobre. 


\section{CONCLUSION DE LA PREMIÉRE PARTIE.}

Toutes les espèces et variétés de Maïs connues présentent les mèmes caractères de végétation. Elles ne renferment que des plantes annuelles dont le bourģeon terminal, à croissance lente, se déreloppe en panicule abondamment ramifiée dès les premiers mois qui suirent la germination. Plus tard, lorsque les racines sont fortes et abondantes et que les feuilles se sont étalées, la tige sallonge rapidement et seépaissit pour renfermer les nombreuses réserves élaborées. C'est à cette époque qu'apparaissent et se développent les bourgeons latéraux uniaxes, épais et courts, que protègent de nombreuses bractées. Les inflorescences terminales, formées lentement dans une période de disette pour la plante tout entière, ne portent que des fleurs mâles: les inflorescences latérales, nées et développées dans dans la période de pléthore, sont couvertes seulement de fleurs femelles. La séparation des sexes, due seulement au mode très spécial de régétation du Maïs, est si générale qu’elle a été considérée a vec raison comme le meilleur caractère du genre $Z e a$.

Il est possible de modifier expérimentalement ce caractère et d'obtenir', par des mutilations violentes faites aux époques convenables, toutes les formes de grappes florales qui sont des termes de transition entre les panicules màles et les épis femelles du Maïs.

La section transversale, puis la section longitudinale, enfin la torsion de la tige principale du Maïs sont des mutilations classẻes dans l'ordre d'importance décroissante. La première donne surtout des rejets à inflorescences terminales ramifiées et à sexes mélangés, la dernière des inflorescences uniaxes et presque exclusivement femelles. Toutefois la seule considération du degré de la mutilation laisse de grandes incertitudes pour la détermination de l'intensité de l'anomalie.

On peut décomposer l'action du traumatisme en deux parties. Tout d'abord la mutilation de la tige détruit l'inhibition que le bourgeon terminal transmet aux bourgeons de base, ou bourgeons dormants, qui ne pouraient se développer. La destruction de linfluence inhibitoire du bourgeon terminal est complète lorsqu'on le supprime par 
la section transversale; elle n'est que partielle ou momentanée lorsqu'on effectue la section longitudinale ou la torsion de la tige. Il en résulte que les rejets se développent beaucoup plus rapidement dans le premier cas que dans le second.

Mais le facteur le plus important de la métamorphose sexuelle est la quantité de nourriture fournie subitement aux bourgeons de base par la suppression ou l'arrêt momentané de croissance du bourgeon terminal. L'appareil radiculaire, non endommagé, est utilisé en totalité pour la nutrition et la croissance des rejets dans le cas de la section transversale de la tige. L'eau et les sels pris au sol servent à la fois à la nutrition de la tige mutilée et des rejets, après la section longitudinale et la torsion, puisque la tige mutilée continue à croître. La section transversale de la tige du Maïs donne donc les plus beaux exemples de métamorphose sexuelle de la grappe terminale des rejets.

Puisque la nutrition des grappes est le facteur qui détermine l'évolution sexuelle des fleurs, il est bien évident que l'époque à laquelle est faite la mutilation joue un rôle important pour la détermination des anomalies. Les rejets, dont la sortie est provoquée de bonne heure, avant que les racines aient atteint leur croissance complète, évolueront comme les bourgeons terminaux du Maïs; ceux qu'on fera développer plus tard auront avec les épis femelles des analogies d'autant plus grandes que la plante sera plus forte à l'époque de la mutilation. Si l'on réussit à bien connaître le mode de végétation des nombreuses variétés de Maïs en expérience, il est possible pour chacune d'elles de déterminer, par un choix convenable de la date du traumatisme, la nature et le degré de la déformation des grappes florales terminant les rejets dont on provoque le développement.

Les rejets ne portent pas seulement des fleurs, ils présentent des feuilles, des bractées dont la situation et la forme dépendent beaucoup des conditions de croissance. Aussi faut-il nous attendre à rencontrer, a vec les anomalies de grappes florales, de nombreuses déviations aux caractères de tiges, de feuilles et de fleurs du Maïs.

D'autre part, les circonstances particulières qui rendent le Maïs très approprié aux recherches de Tératologie expérimentale, dépendent non pas uniquement des caractères spéciaux à ce genre, mais surtout des modes de croissance et de nutrition des bourgeons. Il est naturel de penser que les méthodes qui ont donné des résultats 
pour le Maïs pourront être appliquées arec succès à d'autres végétaux.

Dans la seconde partie de ce mémoire, je vais essayer de montrer la généralité des lois établies ici pour le cas particulier de la production expérimentale des inflorescences anormales du Maïs. 


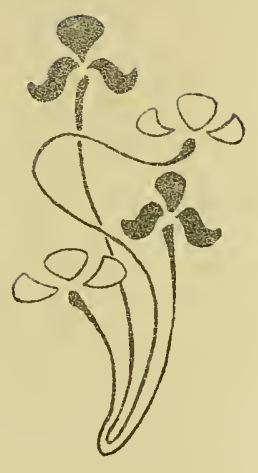




\section{ANOMALIES PROTOQUÉES}

\section{PAR DES MUTILATIONS.}

\& Les botanistes philosophes, dit Moquzi TAIDos; considèrent le végétal comme un ètre collectil, comme un agrégat d'individus ». En groupant les résultats établis par GøтHE (1790) dans sa Théorie de la Métamorphose, puis par Gacdichacd (183.5), auteur do la Theimie des Phytons, et. tout récemment, par G. Boxiser (1900). conduit par des études anatomiques à * considérer la tige comme lensemble des prolongements des bases des feuilles $»$; il faut admettre que les individus élémentaires qui composent le végétal sont des feuilles ou des organes analogues aux feuilles.

Le: différents urganes d'un individu présentent entre eux, à une époque quelconque de la vie. des rapports de taille. de vigueur et de dimensions désignés depuis longtemps par Geoffror St-HiLatre et Curier sous le nom de loi de Corrélation des Organes. Ces auteurs ont mis ainsi en éridence les rapports des parties d'un même ètre: à une tig̣e forte et élevée correspondent des racines abondantes, des rameaux vicoureur, des feuilles, des fleurs et des fruits nombreux.

L'effet des mutilations violentes est de détruire l'équilibre des organes. La section transtersale des tiges, faite au ras du sol, supprime toutes les parties aériennes de l'individu sans pöter dommage aus racines. Il en résulte ou la mort de l'indiridu, ou le déreloppement rapide et inattendu de bourgeons adrentifs dont l'érolution diffère de celle des bourgeons ordinaires. Le déséquilibre se traduit par des rariations importantes dans la forme et les fonctions des organes. Il affecte toutes les parties des plantes mutilées, les ares comme les feuilles, les fleurs et les fruits.

Ies expériences ont porté exclusirement sur les parties aériennes des plantes : jen expose les résultats en décrivant successirement les anomalies des tiges, des feuilles, puis des inflorescences et des fleurs. Mais il importe de bien connaitre les théories rappelées briẻvement ci-dessus, pour suirre l'enchainement des faits qui mettent en relief le mécanisme de l'hérédité des anomalies. 


\section{ANOMALIES DES TIGES. - FASCIES ET TORSIONS.}

\section{1. - Anomalies des tiges provoquées par des trauma-} TISMES : FASGIES, TORSIONS, FEUILLES ÉPARSES, BROUSSINS, LOUPES.

Le premier essai précis de Tératologie expérimentale date d'un demi-siècle. J. Saciss (1856) a déterminé la fascie des rameaux nés à l'aisselle des cotylédons de Phaseolus multiflorus par la section de la jeune tige principale. K. Goebel, dans son livre remarquable: Oryanographie der Pflanzen (1898, page 164) a montré l'importance de cette belle expérience et a conclu : «La suppression du bourgeon terminal d'une plante a pour effet de provoquer des fasciations par ce fait que la sève est amenée rapidement et avec une plus grande intensité à un bourgeon latéral qui auparavant n'en recevait qu'une faible partie ». Il est curieux qu'après cette interprétation, reprise récemment par ḰLEBS, on n'ait point cherché à produire artificiellement des fasciations puisque leur importance au point de vue de l'étude morphologique des végétaux ne fait aucun doute. Les expériences de GÉNEAU dE LAMARLiĖRE (1901) qui réussit à déterminer la fascie des rameaux de second ordre d'une Composée, Barkhausia taraxacifoliu, sur un seul individu mutilé à deux reprises différentes, restent un cas isolé. On ne peut attribuer la valeur d'expériences à des observations accidentelles de fascies accompagnées de la description de circonstances particulières qui laissent supposer que les traumatismes jouent un rôle plus ou moins important dans leur déterminisme [(Hinciss (1853), W. Russel (1894), Masters (1902), De Vries (1903), Kilein (1891), Gowerts (1893), Souny (1905), Muтн (1906)] $\left({ }^{1}\right)$.

(1) Tout récemment, Lopriore (1903-04) et Coniglio (1903) ont mis en évidence des phénomènes analogues à la suite d'observations faites en étudiant la régénération des racines de jeunes plantules cultivées sur des solutions salines. La production artificielle de racines fasciées après la suppression de la racine principale montre la généralité de la loi que je vais m'efforcer d'établir pour les organes aériens. 
La rariation de la disposition des feuilles sur les rameaux à la suite de la section des tiges a été entrerue pour le Noisetier (Corrylus Avellana) par IKrry (1898) sur les conseils de qui cette étude a été reprise par A. WeIsse (IS99 et 1904). Les traraux de ces auteurs ont montré la production de feuilles éparses à la suite de la section des tiges sur le Populus tremula, Coinglus Avellana, Tilia platyphyllos, Syringa vulgaris, Fraximus excelsior, Aesculus Hippocastanum. Des observations antérieures de VIAUd GrandMarais (1S60) sont relatives à des phénomènes analogues produits par la taille répétée du Carpinus Betulus.

Dans la littérature, on troure peu d'exemples de tiges tordues proroquées par des mutilations seules. La torsion, observée après la section des tiges, a été signalée par Hשgo dE TrRIEs sur les indiridus atariques de la race Dipsacus silvestris rar. torsus (1S59) qu il a isolée. On pourrait y voir comme l'auteur la réapparition d'un caractère conserré à l'état latent, mais. dans des expériences faites sur une population normale de Dipsucus silvestris, j’ai réussi à faire apparaitre la torsion des rameaur ou des rejets après la section partielle ou complète des tiges (1905 $a)$.

Le déreloppement des broussins et des loupes sur les Ironcs mutilés et les souches des Chènes, Tilleuls, Hètres, Charmes, Saules, etc. est aussi très connu. Il est possible qu'en certains cas des maladies parasitaires proroquent ces déformations, mais. le plus sourent, elles sont la conséquence de mutilations purement accidentelles comme ladmettent Tréccl (I\$5̄3), Fraik (1880), Hartig (18S9): SnRauer (18S6) et Tines Tayes (1904), qui se sont occupés spécialement de ces anomalies régétales. Citons enfin la curieuse observation de KLes (1891) qui a reconnu, dans la mutilation, la cause de l'origine d'une variété à rameaux pleureurs d'Eleagnus.

\section{2. - Observations personnelles et Expériences.}

Après aroir établi le ròle des traumatismes dans la production les anomalies de la panicule du Maīs, jai cherché à suirre les mèmes effets sur les arbres et arbustes des forêts, des pépinières ou des haies soumis à une taille récente ou à la coupe.

Il est peu de régétaux ligneux qui ne montrent point de dériations considérables aux caractères normaux à la suite de mutilations violentes. Le Chène est le seul arbre commun de nos bois qui n’ait 
point fourni de matériel important pour la démonstration de la loi présentée par les autres végétaux, et, cette exception tient sans doute à sa croissance relativement lente, ou encore, à la difficulté que l'on rencontre à observer des rejets de cet arbre qui ne soient point attaqués par des insectes. J'ai rejeté toutes les anomalies qui pouvaient être considérées comme des exemples de Cécidies, et je me propose d'en reprendre l'étude ultérieurement, pour établir la part de la déviation qui doit être attribuée soit an parasite, soit à la mutilation; il en est de même des variations dues à la greffe.

La variation est rarement limitée à la seule modification de la divergence foliaire. Les Conifères ne m'ont pas montré de fascies à la suite de la section, mais il est fréquent de trouver des ramilles de Pinus silvestris et de Pinus maritima portant 3, 4 et 5 aiguilles alors qu'elles sont d'ordinaire groupées par 2.

Les arbres el arbustes à feuilles opposées montrent souvent des rejets à feuilles éparses ${ }^{(}{ }^{1}$ ) (Syringa vulgaris, Fraxinus excelsior, Ligustrum vulgare, Cornus sanguinea, Evonymus europacus et juponicus, etc...) mais ils offrent aussi bon nombre de pousses à feuilles ternées (Syringa vulgaris, Fraxinus excelsior, Acer pseudo-Platanus, Ligustrum vulgare. Cormus sanguinea, Viburmum Opulus, Sambucus nigra, etc...) ou encore rapprochẻes au point de former des verticilles de 4, 5 et 6 feuilles. Ils donnent alors des torsions ou des fascies locales.

Les vẻgétaux à feuilles alternes montrent aussi, après des mutilations violentes, tous les termes de disposition irrégulière des feuilles. Les exemples les plus fréquents sont trouvés sur le Tilia silvestris, Ulmuscampestris, Pipulus alba, Carpinus Betulus, Betula alba, Corylus Avellana, Castanea vulgaris, Robinia Pseudacacia, de nombreuses espèces de Sulix, diverses variétés d'Hibiscus, etc...

Pour toutes ces formes, sauf pour le Chêne et les Conifères, j’ai trouvé, dans les mêmes conditions et en proportions plus ou moins considérables, des rejets lasciés ou torlus. Les fascies sont de beaucoup les anomalies les plus fréquentes dans les Evonymus, Fraximus, Acer, Populus, Robinia, Hibiscus... Elles sont associées

(1) A. P. DE Gandolle réserve le nom de feuilles éparses pour les cas accidentels où la symétrie de disposition n'est plus visible. Les exemples qu'il en donne sont relatifs à des tiges fasciées (Organographie végétale, tome I, p. 328). 
aux torsions sur les rejets de Fraxinus, Tilia. Salix, Corylus, Viburnum, Sambucus.

Dans mes expériences sur des végétaux herbacés annuels ou rivaces: appartenant aux familles les plus différentes, jaai pu obtenir aussi de nombreux exemples de toutes sortes de déformations diases. On peut reconnaitre des espèces donnant, après la mutilation, seulement des rariations dans la dirergence foliaire; d'autres, des fascies ou des torsions; dautres enfin, des rameaux pendants ou pleureurs: il est des espèces très stables, analogues au Chène ( $\left.{ }^{1}\right)$, et d'autres, où les monstruosités sont plus fréquentes. comparables au Frène, au Tilleul, à l'Orme.

Les exemples de variation de dirergence foliaire, résultant de la section partielle ou totale des tiges, sont très visibles sur le Tournesol (Helianthus annuus, le Lin (Linum usitntissinum), le Sarrasin (Fugopyium esculent!mi). la Moutardelle (Sinnjis alba). Toutes ces plantes m'ont donné de nombreuses rariations. arec entrencuds courts et allongés. feuilles rapprochées au point de se souder. et, comme déformations extrèmes, des fascies plus ou moins déreloppées. Ces fascies sont terminales pour le Tournesol et se caractérisent par le groupement de plusieurs capitules soudés plus ou moins complètement à lestrémitó des tiges. Elles affectent les rejets sur toute leur longueur dans le Lin et le Sarrasin. Enfin jaai réussi, après deux sections répétées des tiges, à provoquer la fascie de quelques bourgeons de Sinapis alba. Pour cette dernière, les graines récoltées en 190 a sur l'une des fascies, ont donné 3 plantes fasciées sur is déreloppées. Jamais les plantes témoins n’ont présenté cette anomalie, qui doit ètre extrèmement rare, puisqu'elle n'est signalée dans l'ourrage de Pevzig (Pfanien-Teratologie, I, page 263) pour aucune des espèces du même genre.

La divergence foliaire modifiée est rare sur les individus de Mercurialis aninu que j'ai mutilés; par contre les fascies et les torsions proprement dites sont très communes et parfois réunies en touffes sur la mème plante. Pour cette espèce, l'opération la plus féconde en anomalies consiste en la section de la tige principale. arant l'apparition des fleurs et au-dessus des rameaur de base, puis en la

(1) Les expèces de Ricin (Rieinus communis et $R$. sangwirea) ne mont pas fourni de fascies malggré mes essais rẹpétés. 
section, faite quinze jours plus tard, des rameaux eux-mêmes. La section simultanée de tout l'appareil aérien entraîne d'ordinaire la mort de la plante, surtout par un temps sec et chaud.

Les modes particuliers de végétation des plantes bisannuelles telle que la Betterave (Beta vulgaris), l'Enothère (Fnothera biemnis), la Chicorée (Cichorium Intybus) demanderaient aussi à être décrits pour permettre d'indiquer avec précision le moyen d'obtenir des tiges fasciées qui naissent avec une grande facilité. Enfin la mutilation des plantes vivaces de Herucleum Sphondylium, Angelica silvestris, Valeriana dioüca a fourni de fréquentes variations dans la disposition des feuilles comme aussi de belles fascies et des torsions très accusées des tiges.

Les anomalies proprement dites de la tige sont relativement rares dans le Maïs; je crois être le premier à les signaler. Les rejets développés après la section, ou les plantes qui dérivent de graines récoltées sur ces rejets, présentent parfois plusieurs feuilles réunies à un même nœud. Le plus souvent, ces feuilles sont groupées par deux ou trois à l'extrémité de la tige, et, si la condensation des organes s'accentue, il se forme sous les panicules de véritables touffes de feuilles serrées (Pl. III, fig. 31-39).

Si la disposition alterne-distique des feuilles n'est plus conservée, on observe la torsion de la tige. Parfois la torsion se remarque sur toute la longueur de l'axe, les feuilles insérées obliquement se soudent par leurs gaines et leurs limbes, et l'on obtient des tiges tordues comparables aux plus belles torsions du Dipsacus silvestris var. torsıs. Mais cette anomalie entraîne un ralentissement dans la croissance de la plante et l'avortement partiel ou complet des graines; il ne m'a pas été possible d'en étudier l'hérédité.

J’ai trouvé aussi dans les cultures d'anomalies du Maïs de Pensylvanie des pieds dont toutes les feuilles étaient groupées par verticilles de $3\left({ }^{1}\right)$. L'une de ces plantes, dont les graines mûres en 190 '́ ont été cultivées en 1905, a donné naissance à une variété nouvelle de Maïs, que le port de la tige, arquée durant toute la végétation, la chute des feuilles et la courbure de la panicule me font désigner sous le nom de Mä̈s pleureur (Pl. T, fig. 52).

(1) LOBSENER (1903) en a décrit un exemple. 


\section{3. - Influence de l'Époque de lat mutilation.}

L’importance de l'Époque de la mutilation pour la détermination des anomalies des tiges est considérable. On a ru dans la première partie de ce mémoire que la section transversale des tiges de Mais, faite peu de temps après la germination, provoque le déreloppement de plusieurs rejets qui tous présentent une panicule terminale à rameaux non fasciés. Lèrolution des bourceons adventils, nés dans une période de disette, est identique à celle du bourgeon terminal de la tige non mutilée. De mème la section de la jeune tige principale du Sarrasin ou du Sinapis albu, au stade ou $\dot{f}$ et う feuilles seulement sont déreloppées, détermine la formation de branches grèles, ou volubiles (Sarrasin), trés ditérentes par l'aspect et le port des fascies qu'on peut réussir à proroquer sur les mèmes plantes par des sections tardires et lorsque la floraison commence. Labondance des anomalies des rejets, en certains points des forèts et bois rẻcemment coupés, s’explique aussi par la date de la coupe : si on la fait pendant lhirer ou tard à l'automne. les rejets qui se déreloppent au début du printemp̣s sont presque tous normaux; au contraire la coupe faite en avril détermine la production d'un nombre très éleré de monstruosités. J'ai pu m'assurer de la raleur de cette loi, soit par le contròle des indications fournies par les gardes lorestiers sur la date de la coupe des bois, soit par des tailles de haies ou d'arbustes qui ont été faites, sur mes indications, à la fin de l'hiver.

D'ailleurs, la méconnaissance de l'Époque de la mutilation farorable pour la dètermination des anomalies résulte d'une interprètation incomplète des faits tels que sichs les a exposés (1850, p. 86). Il ajoute, en effet, à la description de la production des fascies de Phuseolus imultiflorus, que l'époque de la section joue un róle capital. Il faut enlever la tigelle du Haricot au moment où plle est encore renfermée entre les cotylédons; plus tard la mème opération ne détermine plus de fascies mais bien la formation de rameaux vigoureux à feuilles ternées. Enfin, SAchs n’a jamais obserté d’anomalies lorsqu'il a enlevé la tige principale au-dessus des feuilles primordiales de la jeune plante. Les rameaux qui se déreloppent soit à l'aisselle des cotrlèdons, soit à l'aisselle des feuilles, portent des feuilles alternes différant peu, mème par la taille, des feuilles normales. 


\section{4. - Relations entre LeS FEUILLES ÉPARSES ET LES} TORSIONS, ENTRE LES FASCIES ET LES TORSIONS.

On retrouve donc dans les belles expériences de Sachs tous les éléments qui ont permis de provoquer à volonté la formation des inflorescences anormales du Maïs; on peut en déduire aussi une interprétation plus générale des fascies et réunir, dans une même étude, l'examen des anomalies connues sous le nom de ferilles éparses, fasciations et torsions parce qu'elles sont des stades particuliers d'un même phénomène: la modification de la divergence normale des feuilles.

Sachs a constaté que des rameaux fasciés, ou à feuilles ternées, ou normaux se dẻveloppent à l'aisselle des cotylédons, selon l'époque plus ou moins précoce de la section de la tige principale. La différenciation des rameaux dépend donc, à la fois, de l'état de développement des jeunes bourgeons et de l'épuisement plus ou moins complet des rẻserves accumulées dans les cotylédons. Le déséquilibre est d'autant plus accusé que les bourgeons sont plus jeunes et leur. surnutrition accidentelle plus considérable. De même Kítein (1891) insiste sur l'époque particulière de la mutilation qui a donné naissance aux déviations multiples qu'il a observées sur diverses plantes et en particulier à l'Eleagnus à port pleureur.

Des nombreuses observations et expériences faites jusqu'ici, il résulte d'une manière évidente que les accidents dus à la taille ou à la coupe des plantes ligneuses sont multiples et peuvent même entraîner la mort des individus qui les subissent lorsqu'on les effectue à une période de grande circulation de la sève. Le petit nombre des anomalies trouvées dans les pépinières, malgré l'emploi fréquent des mutilations en arboriculture, tient à l'application précise de règles empiriques établies par la longue pratique des horticulteurs. D’autre part, les tailles peuvent être faibles et la surnutrition des bourgeons adventifs provoquée brusquement peut être insuffisante pour en déterminer la déviation. En particulier le fait que Weisse (1899) dans ses expériences n'a pas trouvé ni signalé de fascies s'explique par l'utilisation de sujets très jeunes et peu développés. Seule la divergence foliaire a été modifiée, mais cette anomalie n'est, pour moi, qu'un cas particulier de l'état de fasciation.

Mes nombreuses observations sur les vieilles haies, sur les arbres 
et arbustes des jardins, des bois et des forêts soumis à la coupe récente mont en effet permis de récolter un nombre considérable de rejets à dirergence foliaire modifiée dont l'ensemble prouve l'origine commune des tiges à feuilles éparses, des fascies et des tursions (1905). Sourent des pousses normales à la base, puis à divergence foliaire variable, se terminent par des fascies étalées en balais par suite d'une dissociation tardive. Le seul examen de ces rejets, dont quelques-uns sont représentés par les figures 21) à 30 (Pl. II . montre bien que,contrairement aur rues de nombreus auteurs [Hichs(1553), Masters (1869)]. la fascie ne rẻsulte pas de la suture de bourreons roisins, mais bien de la dissociation tardire d'un seul bourgeon terminal qư un nutrition exagérée a hypertrophié. Cette dernière opinion, soutenue par Moecr-T_xdos (18il). est justifie par les exemples, et ils se comptent par centaines, que jai pu olserrer sur les plantes les plus communes de nos forets et de nos jardins.

Il n'est pas rare de trourer assuciées les fascies et les torsions. Je ne veux pas seulement parler ici de lenroulement les crètes en forme de crosse, du à un développement inégral des diverses partie de l'axe, mais las torsions véritables affectant parfois une tige entiére. Laxe lascié. au point où il est le plus étalé, se dissocie en branches indérendantes que lon troure sourent complètement tordues ou spiralées dans le Sumbucus nipra, le Tiburnum opulus, le Titin silecestris (PI. II, fig. 23). Parlots aussi le rejet. tordu à la base et parfaitement rond. se termine au sommet par une créte: ce mode de régétation est fréquent sur certains individus d' Enotheru biennis: les multiples transitions observees entre la tige tordue et la fascie proprement dite, sont la meilleure preure de liidentité des deus déformations.

\section{3.. - Culture des anomalies de tiges.}

Il est possible de prétoir, dés le commencement de la régétation. que les pousses dont on a proroqué le déreloppement par la section de la tige principale seront anormales. Dès que l'allongement des rejets permet de roir la situation des bourgeons latéraus, on constate que bon nombre d'entre eus ne présentent pas la dirergence foliaire normale: si ces rejets sont suffisamment nourris, ils érolueront en fascies ou en torsions, bien que l'on ne puisse que rarement déterminer laquelle des deur anomalies fera son apparition. 
L'examen de la situation respective des premières feuilles des rejets est analogue à la méthode de séparation des plantules tricotylées ou hemi-tricotylées qui a permis à Hugo DE VRIEs de reconnaitre de bonne heure, lans les semis, les plantes qui donneront plus tard les belles tiges tordues du Dipsacus silvestris (1892, 1894) ou les fascies du Picris hieracioüdes et du Crepis biennis fasciutu (1895). Les dispositions relatives des premiers organes trahissent l'anomalie visible seulement beaucoup plus tard. La fascie ou la torsion existent donc à l'état latent lorsque l'on peut reconnaître, dès les débuts de végétation des rejets, le changement de situation des bourgeons latéraux; mais la bonne nutrition est nécessaire pour les mettre en évidence.

De même que l'horticulteur, pour obtenir de belles Crêtes de coq, fait des semis de Celosia cristata en conches chaudes, sur un sol parfaitement fumé et abondamment pourvu d'eau, qu'il sarcle et éclaircit les plantules au lur et à mesure de leur développement, de même, on n'obtiendra de belles fascies sur les souches d'arbres et d'arbustes que si, accidentellement ou à dessein, on supprime bon nombre des rejets, et si l'on fournit l'eau et les aliments nécessaires à une végé-. tation rapide. On ne peut prétendre que les conditions favorables à une nutrition active aient seules contribué à fournir les crètes fasciées de la Célosie ; cette tendance existe déjà dans la graine au moment du semis, comme le prouve la présence des embryons tricotylés.

La section des tiges principales développe une tendance à la fasciation et aussi à de nombreuses déviations distinctes, même opposées en apparence. La mutilation détermine le déséquilibre dans la végétation et produit «l'affolement » des bourgeons. Selon qu'ils seront plus ou moins bien nourris, ils donneront des rejets fasciés, tordus ou grèles, enroulés en tire-bouchon ou mème filiformes. Le traumatisme violent a seulement pour effet de faire apparaître des bourgeons à développement hâtif et irrégulier que les bonnes ou les mauvaises conditions de nutrition font évoluer en fascies ou en ramilles.

36. - Exemples de plantes fasciées Qui perdent Ge Garactìre aprés la Mutilation.

Si l'on peut considérer comme établi que les sections de tiges, faites à une époque appropriée, déterminent les monstruosités de 
eroissance connues sous le nom de fascies et de torsion, il est important l'opposer à ces phénomènes de surnutrition lev bourgeons. les eremples de perte le leétat de fasciation, acquis depuis longtemps. a la suite de mutilations qui ont eu pour effet de réduir" brusquement l'ẻlaboration normale des aliments. Fiard en a fiecrit un exemple trés démonstratil en 1886. L'après de nombreux documents empruntés à la littérature horticole. il faut admettre que larbuste ornemental Biotu orientalis est une forme fasciée et plus ou moins stable par roie de semis du Retinospoin dubiu. Or' GLARD a observé, en 1STS. un magnifique Biota grievitalis l'une vingtaine d'années, dont toutes les feuilles furent mangẻes par des insectes. «Bientòt, dit-il, de nouvelles pousses se produisirent, mais. à mon grand étonnement. l'aspect de l'arbre était complètement changé. Au lieu de ramilles aplaties, courertes de feuilles squamiformes imbriquées, l'arbre présentait des rameaur cylinulriques. garnis de feuilles en aiguilles rappelant le facies du Genérrier. En un mot le Biotr était devenu un Retinospora».

Cette variation est. par tous ses caractères, analogue à celle que proroque, chez le Jais, la torsion des tiges principales. Les intlorescences latérales femelles du Maĩs, qui unt tous les caractères dinflorescences latérales fasciées d'Euchlaena mexiruna. se ramifient et donnent des épis multiples chargés de quatre rangées de graines, variation qui peut ètre partiellement fixée. Il en résulte un retour à un état primitif lù certainement, clans le cas du Maĭs, à une insulfisance ou un ralentissemeut de nutrition, car la sère brute fournie par la toulfe des racines est répartie, aprés la tursion de la tige principale, entre les rejets léreluppés à la suite te la mutilation et la tige principale elle-mème.

On désigne sous le nom d'Atarisme la réapparition accidentelle d'un état ancestral de l'espéce. Ca mut nest pas une explication. Il est très intéresiant de constater. ut linsstr (18911) laa établi en particulier pour les rariations des feuilles, que les mutilations, qui déterminent un affaiblissement le lindividu, constituent un moren commode et peu connu pour proroquer la réapparition les furmes ancestrales, et permettre lia reconstitution de la phylozénie des

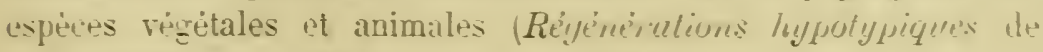

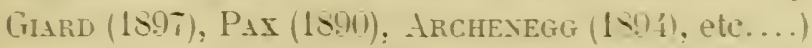

En résumé. les mutilations cléterminent l'apparition des anomalies de tiges les plus variées: ramilles et fascies, soulures et 
disjonctions, multiplication ou disparition des bourgeons. Suivant la nature de la mutilation, l'époque où elle est laite, et suivant les tendances particulières des sujets, on peut faire naître les formes les plus diverses et les plus inattendues. La méthode ne peut donner de résultats définis que si l'on a pris connaisšlnce, par une longue culture, des phénomènes de nutrition, de dépôt et d'utilisation des réserves, variables selon les espèces et parfois selon les individus. 
CHAPITRE IX.

\section{ANOMALIES DES FELILLES ET DES BRACTEES.}

\section{7. - Relations eNtre LES Feuilles cohérextes ET}

\section{LES TIGES FASCIÉES OU TORDUES.}

Les mutilations riolentes, qui proroquent l'augmentation en nombre des bourgeons en même temps que des variations considérables dans. leur situation normale, entrainent le rapprochement des feuilles et par suite leur soudure fréquente. Il est rare que les fascies nen présentent pas des exemples remarquahles: on sait aussi, par les belles experiences de Hugo de Tries sur le Dijjsocs silvest, is rar. toisus, que fréquemment la torsion des tiges est la conséquence immédiate de la suture de la base des feuilles dans les bourceons encore jeunes (1sঃ9-1s94). De même, toutes les plantes ligneases ou herbacées, qui ont donné des rejets fasciés ou tordus aprés la mutilation, ont fourni en même temps de nombreux exemples de feuilles cohérentes $\left({ }^{1}\right)$.

La suture peut être complète. Le limbe est alors parfaitement r'égulier et diffère à peine, par ses dimensions plus fortes, d'une feuille normale de la même plante. On reconnait la trace de la suture à la forme de la section du pétiole ereusé à la fois sur sa face inférieure etsur sa face supérieure et aussi à la présence le deux bourceon: accolés latéralement à l'aisselle de la feuille simple en apparence. Le rameau unique qui s'y déreloppe est fascié à la bast et se dissucie en fourche. Les exemples les plus fréinuents corresfondent à la cuhérence incomplète des limbes qui se traduit par lat présence de deux pointes, pour les feuilles simples, et d'un pétiole bifurqué pour les feuilles composées. En général. on troure tous les

(1) Jüriche (1891) montre leur Jocalisation au point des rejets où la dirergence foliaire change nulablement, en particulier pour les Wrigola, au point où les feuilles ternées sunt remplacees par des feuilles opposées. 
passages entre le rapprochement de la base des pétioles et la suture complète en un organe unique.

Il est remarquable que bon nombre de rejets présentent la suture des feuilles sur une même génératrice de leur surface. Des rejels d'Orme, de Maïs et de presque toutes les plantes á feuilles alternes distiques offrent ce caractère. Il semble que la tige anormale se compose de deux ou de plusieur's secteur's, les uns complètement normaux, les autres caractérisés par la cohérence des feuilles et des bourgeons secondaires situés à leur aisselle. Ces faits, s'ils n'étaient point l'exception, seraient un argument très démonstratif en laveur de la théorie des phytons soutenue par Gaudichaud, en 1835, et reprise dernièrement par G. Bonsier, qui a donné de nombreuses preures anatomiques à l'appui de son hypothèse (1900).

lílein (1891) a insisté à plusieur's reprises sur la fréquence des anomalies foliaires sur les rejets des arbres et des arbustes $\left.{ }^{1}\right)$; il remarque qu'on trouve des feuilles doubles ou à deux pointes aussi bien sur les plantes à feuilles disposées en verticille (Nerium oleander, ITeigela rosea, Lonicera fragrantissina, Syoinga vulgaris, Philadelphus coronurines, Calycunthus floridus, Cormus albu) que sur celles ou les bourgeons ont une insertion spiralée (Mornes alba et nigra, Ficus australis, Cydonia vulguris, Pyrus amygduliformis, Robinia Psendacaciu, etc.....). Il croit que les mutilations, qui ont souvent fourni aux jardiniers de nouvelles formes, mériteraient une élude scientifique sérieuse «car la question, dit-il, n'est pas éluciclée, puisque beaucoup de chercheurs doutent que les actions extérieures puissent provoquer l'apparition de nouvelles formes ». Les mémoires de KLEIN passèrent inaperçus et c'est par une itude détaillée des anomalies foliaires connues que j'ai pu les décourrir et apporter ainsi un document nouveau à l'appui de ma thèse.

La suture rles fenilles voisines ne se fait pas toujours par les bords; elle s'opère parfois face à face et tout le long d'une nerrure, comme on le voit sur les rejets d'Acer platanoüdes, Tilia silvestris. Les deux pédoncules soudés forment une curette profonde, presque une gaine tubulée qui comprime le bourgeon terminal et en arrête le développement. Les limbes peuvent être soudés sur toute leur

(1) V. Borbas (1893) donne une classificalion sommaire des feuilles cohérentes dont il attribue la cause à une nutrilion exagérée des pousses et particulièrement des rejets. 
longueur et former un organe à symétrie axiale, ayant 4 ailes, dont la section ressemble au signe $x$; ou bien la nervure centrale se dissocie en nombreuses nervures rayonnantes et le limbe forme une surface représentée par deux cônes de mème sommet et tangents le long d'une génératrice qui est le pétiole. Enfin trois el mème quatre feuilles peuvent être groupées en une houppe terminale. Les extrémités des rejets examinés à l'automne, ou encore les points de dissociation des fascies fourchues, fournissent beaucoup de cas de ces anomalies très curieuses.

Le Mais déformé par des mutilations, ou obtenu par la culture de graines récoltées sur les panicules mâles, donne aussi de nombreuses feuilles anormales. Un cas particulier au Maïs est la dissociation de la nervure centrale du limbe en deux ou trois nervures blanchâtres qui s'atténuent à la pointe et n'entrainent pas la division de la surface du limbe. Les feuilles à limbes doubles noffrent sourent qu ime seule gaine, mais on rencontre aussi deux gaines, accolées ainsi que le: limbes, par leurs faces en contact. La mème anomalie s'observe plus rarement sur les bractées des épis.

Les exemples de suture des feuilles ou de dissociation des nervures sont rarement isolés; on en trouve dordinaire plusieurs sur la mème plante et souvent ils sont accompagnés d'ascidies.

\section{8. - Feullles cupulées ou Ascidies. Leurs relations} AVEG LES TIGES FASGIÉES OU TORDUES.

La déformation cupulée des feuilles est une des plus rares dont il suit question dans les Traités de Tératologie régétale. Aussi, est-il improtant de signaler une méthode de production expérimentale de ces anomalies et d'indiquel les circonstances dans lesquelles il est permis d'en récolter rapidement un grand nombre. Les ascidies que l'on obtient en abondance sur les rejets de Tilleul (Tilia silvest, is), d'Orme (Ulmus campestris), de Noisetier (Comylus Avellum), d'Epinard (Spinacin olerecen) of de Maïs (Zeu Mays), elc.. ne montrent plus la alistinction nette du limbe du pétiole ot de la gaiñe. Les feuilles cupulées présentent, en effet, wue hase et une pointe analogues, en genẻral, aux feuilles normales, mais, dans l'intervallr, au lieu de la différenciation brusque des parties en pétiole et limbe, on observe le passage graduel d'un axe à une surface conique. 
On est conduit à rapprocher les ascidies des anomalies de tiges connues sous le nom de fascies annulaires qui sont signalées seulement pour Turaxacum officinale, Peperomiu maculosa, par Hugo de Vries (1891), et Veronica lonyifolia par Nestler (1894). Parmi les rejets développés sur les souches de Robinia Pseudacacir, on trouve souvent des fascies terminées par un pinceau de branches plus ou moins étalées dans un plan. Il est plus rare d'observer des fascies à section triangulaire, dissociées en rameaux et offrant la disposition particulière des arêtes d'une pyramide triangulaire dont la pointe serait dirigée vers le sol. La multiplication des arêtes conduit à la formation d'un spadice tubuleux. De même que les fascies annulaires sont rares parmi les fascies connues, de même les ascirlies sont des cas particuliers et peu fréquents parmi les multiples exmples observés de feuilles cohérentes ou à nervures dissociẻes.

L'assimilation des ascidies aux feuilles cohérentes est justifiée par des considérations diverses. On les observe le plus souvent sur les rejets tordus ou fasciés ou à feuilles éparses ( $\left.{ }^{1}\right)$; j’en ai récolté de nombreux exemples sur les Tilia sylvestris, Ulmus campestris, Corylus Avellana, Fraxinus excelsior, Spinacia oleracea où ces anomalies sont tellement fréquentes après la mutilation qu'on pourrait croire, avec Vunllemin (1906), à la mise en évidence d'un caractère latent. Mais elles sont purement accidentelles et doivent être regardées comme des cas particuliers d'un mode de dissociation sprecial des nervures lorsqu'on les observe sur Acer pseudoPlutanus, Fruxinus excelsior, Hibiscus Rosa Sinensis, Trifolium pratense, Fagopyrum esculentum, Zeu Mays.

Non seulement les feuilles en cornet doivent être comparées aux feuilles cohérentes, mais souvent, il est nécessaire de les considérer comme équivalentes pour satisfaire à la loi de périodicité dans l'apprarition de l'anomalie, loi établie sur de nombreux exemples (H. DE Vries, 1895 et 1899). J'ai décrit un de ces exemples offert en 1905 par une variété de Maïs de mes cultures; la périodicité est aussi très nette sur beaucoup de rejets d'Ulmus campestris, Tiliu silvestris, Spinacia oleracea, et parfois, pour les mêmes plantes, il est nécessaire d'assimiler les feuilles à deux pointes aux ascidies pour retrouver la loi (Pl. II, fig. 22, 29).

(1) G. de Gandolle (1905) insiste sur leur fréquence sur les arbres émondés et LENEGEK (1894), sur des arbres vivant dans des conditions très spéciales d'humidité. 
La justification de cette méthode est d'ailleurs fournie par la présence sur lês mèmes échantillons d'ascidies à deux pointes (Pl. II, fig. 25). En particulier, une plante de Maïs, observée en 1906 dans un lot de descendants de la variété instable à feuilles tubulẻes née après mutilation, a présenté l'anomalie ả un degré tel que la tige et la panicule, comprimées dans les tubes à deux nervures principales, n’ont pu se développer malgré la rupture partielle des feuilles (Pl. $r$, fig. 42). Sur cette plante, jai noté 2 feuilles à deux nervures et 4 feuilles à gaines tubulées, dont 2 présentaient la suture des bords sur la plus grande partie du limbe et avaient deux nervures principales. Cn rejet du type C développé à la base du pied montrait aussi deux feuilles à nervures dissociées.

Enfin. il est fréquent de trourer des ascidies, soit à la pointe des folioles de Légumineuses, soit substituées aux folioles ellesmèmes, lorsqu on examine les rejets déreloppés après la mutilation (LLARINGHEM, 1905 (u). Les transitions que l'on observe entre les feuilles à folioles soudées, les feuilles à folioles cupulées et les feuilles à folioles surnuméraires montrent bien que toutes ces anomalies sont l'expression d'un mème phẻnomène, c'est-à-dire, la réaction à une mème cause déviatrice, la mutilation violente.

\section{9. - Feuilles découpées, a folioles surnumératres}

\section{OC AVORTÉES.}

Par suite de l'ébranlement consilérable proroqué par un traumatisme violent et subit, les nervures et le limbe des feuilles subissent de nombreuses fluctuations dans leur déreloppement. Les feuilles des rejets de Chène, de Hètre, de Châtaignier et, d'une manière génerale, de la plupart des arbres et des arbustes prennent des caractères aberrants parfois atariques [(KRASAr, 1891)), vox ARCHENEGG, 189.1)] dont l'étude détaillée ménerait trop loin (1). Qu'il suffise de signaler ici les feuilles découpées du Mais (Pl. III, fig. 34 et 35) qui apparaissent sourent en grand nombre sur le mème pied. Les rejets de

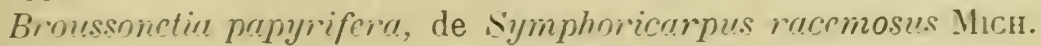
offrent des exemples trés connus de dimorphisme foliaire qu'on peut

(1) Les obserrations de KR.ssıx (1890) s'appliquenl aussi aux particularités décriles par Gripfox (1897) sur les pousses développées après une gelée tardive. 
faire apparaître à volonté par des tailles appropriées ; von WIDENMANN (1893) en a décrit beaucoup d'autres cas.

Il est plus intéressant peut-être, quoi que ce ne soit que l'exagération du même caractère, de signaler comme dues à la même cause, les feuilles à folioles surnuméraires de nombreuses Papilionacées (diverses espèces de Trifolinm et de Medicnyo, Onobrychis sativa, Robina Pseudacacia), la ramification du limbe de Ulmus campestris qui présente des feuilles composées [Marty (1899), Vunlamin $(1902)]$, el la ramificalion répétée des feuilles de Sumbucus niry a, Fruxinus cxcclsior qui offrent la division des folioles en folioles secondaires.

Ces anomalies résultent sans doute d'un excès momentané de nutrition ayant pour effet de doubler et même quadrupler la surface des limbes des fenilles ou folioles. Plus tard, l'insuffisance de nutrition, consécutive à un excès, détermine l'atrophie et l'avortement de cerlaines parties du limbe; ce phénomène est analogue à celui qui entraîne la dissociation des fascies en rameaux disposés en éventail.

On peut encore regarder comme une conséquence de l'irrégularité de la nutrition des parties constituant les organes, les nombreuses variations dans la consistance et l’épaississement des tissus, on les inégalités de croissance qui déterminent les feuilles enroulées (Maïs pleureur (1'l. IV, fig. 41-42), diverses espèces de Saules) les feuilles onrlulées ou crispérs (Zea Muys, Fraxinus excclsior, Tilia silvestris) ou enfin les déchirules multiples et localisées des appendices caulinaires (feuilles de Maïs, feuilles et bractées de Populus alba, Salix vimimulis, Acer pseudo-Platanus, Fraximus excelsior, Helirnthus ammus, ete. $\left.{ }^{1}\right)$.

Toutes les anomalies présentées par les feuilles proprement dites peuvent êtro observées sur les bractées ou les modification spéciales des leuilles. La substitution des organes les uns aux autres à la suite de mutilations violentes a été reconnue par de nombreux auteurs et les ohservations de Giard (1886 et 1897), de Krrasan (1890) ne sont que des cas particuliers d'une rígle générale. Ledoux (1903) a cherchó à la mettre en évidence par des essais sur la Régénération

(1) Bucheneau (1891) a signalé la métamorphose de feuilles de Charme en feuilles lobées analogues à celles du Chêne à la suite de mauvaises conditions de nutrilion. Le phénomène s'est maintenu pendant plusieurs années. 
expérimentale des feuilles de Légumineuses. Bon nombre des résultats signalés par cet auteur peurent être interprétées en faveur de la thèse soutenu dans ce travail. Si les anomalies de végétation qu'il a obtenues semblent peu variẻes c'est que l'auteur s'est localisé dans les traumatismes faits à des plantes jeunes et trop peu vigoureuses pour donner naissance à des anomalies multiples. En particulier la conclusion qu'il énonce à la page 392 de son mémoire: «La forme des feuilles séminales ou de celles qui les suivent immédiatement ne réapparaît jamais par suite des blessures faites sur les rameaux de remplacement ou sur l'axe principal »n'est pas applicable aux pieds vigoureux de trèfle ou de luzerne qui donnent très souvent après la seconde coupe des feuilles primordiales à une seule foliole. On les observe principalement à la base des rejets à feuilles ne portant pas de folioles surnuméraires. Il existe en effet une relation entre la multiplication des folioles des feuilles du trèfle et la présence de bractées plurinerviées à la base des mêmes rameaux, relation analogue à celle que DE TrRifs a établie pour les jeunes plantules de la race Trifolium prutense quinquefolium qu'il a isolée (Mututionstheorie, I, p. 435).

Pour la grande majorité des plantes expérimentées et observées, j'ai pu mettre en évidence, à l'aide de mutilations appropriẻes, la métamorphose possible des bractées en feuilles ou des feuilles en bractées. Il me suffira ici de l'établir pour le Maïs.

\section{0. - Relations entre les BRactées et les feullles.}

Les feuilles et les bractées du Maĩs différent beaucoup l'aspect et fonctions, suivan! qu'elles sont insérées sur l'axe firincippal ou sur les bourgeons latéraux. Les feuilles jouent deux rôles importants : elles consolident la tige par leurs gaines cylindriques fendues sur toute leur longueur; elles assimilent par leurs limbes allongés et pourvus d'une seule nervure médiane. La longueur de la feuille entière atteint souvent 70 centimetres, dont 20) environ pour la gaîne. Les bractées des épis latéraux n'ont d'ordinaire qu'un ròle protecteur; elles sont réduites à la gaîne, enroulée de manière à présenter une surface conique qui, étalée, a une forme triangulaire; elles sont courtes et larges et ne présentent point de nervures.

L'avortement du limbe des bractées n'est pas constant. Les plantes 
vigoureuses de Maïs permettent de le reconnaitre dans un petit appendice triangulaire, pourvu d'une nervure médiane; il est la trace du caractère latent que possèdent les bractées à développer un limbe en tout comparable à celui des feuilles.

D'autre part, il arrive fréquemment de rencontrer des individus dont les bractées sont munies d'un limbe véritable. LiRsFFt en signale et en décrit (187i, p. 37, Taf. II, fig. 8) dont le limbe atteint $8 \mathrm{~cm}$. Le Maïs de Pensylvanic des champs de grande culture ou de mes parcelles d'expérience en ont souvent donné de 20 et $30 \mathrm{~cm}$. Toutes les opérations qui ont pour but de faciliter la ramification des épis et l'allongement des pédoncules favorisent le développement du limbe des bractées, et, on obtient même fréquemment la métamorphose de la bractée en une feuille véritable. Lans la plupart de mes lots tardifs provenant de plantes mutilées et cultivées pour l'étude de la transmission héréditaire de diverses anomalies, il ne m’arrive plus d'obtenir des épis qui ne présentent point ce caractère à un haut degré. Je n'ai pourtant jamais fait le choix des portegraines dans cette direction, car le développement exagéré des bractées nuit à l'étalement des stigmates et par suite à la fécondation des épis. La variété de Mä̈s pleureur dont il a été question plus haut présente en particulier des limbes de bractées tellement développés qu'il y a nécessité de dégager les stigmates des jeunes épís pour en faciliter la lécondation (Pl. $\mathrm{Y}$, fig. 52 et 54 ).

Il n'est pas sans intérêt de remarquer que la longueur du limbe des bractées obéit à une loi de répartition sur l'axe de l'épi en tout point analogue à celle que permet d'établir la longueur du limbe des feuilles insérées sur la tige. La longueur du limbe des feuilles du Maïs de Pensylvanie adulte croît à partir de la base, passe par un maximum pour la $6-8^{\text {e }}$ feuille et décroît ensuite; de mème la longueur de l'appendice des bractées, nulle pour les bractées externes et internes de l'épi, a son maximum pour la $7-9^{\mathrm{e}}$ bractée comptée à partir de la base du pédondule.

La relation que l'on a établie dans la première partie de ce mémoire entre l'intensité de l'anomalie des inflorescences et la longueur des axes serait mise en évidence tout aussi commodément par la comparaison de la variation de la longueur des limbes et de la taille des tiges. Il en résulte une équivalence complète des parties.

Réciproquement il n'est pas rare d'observer la métamorphose des feuilles des tiges en bractées. Non seulement la substitution est 
complète sur les rejets provoqués par mutilation qui sont terminés par des inflorescences femelles, ramifiées ou non, mais elle s'observe aussi sur les tiges tordues obtenues soit directement soil dans les lignées dérivées de plantes anormales (Pl. III, fig. 31 et 32).

Enfin l'identité des feuilles caulinaires et des bractées est encore établie par l'apparition d'anomalies identiques sur les deux catégories d'organes d'une même plante. Les bractées à limbe développé montrent la dissociation des nervures principales, les ondulations qui correspondent aux feuilles erispées, la cohẻrence des gaines, et même, la suture des bords qui caractérise les feuilles tulbulées. La variation de port du Maïs plen eur affecte à la fois les feuilles des tiges et les bractées des épis.

En résumé, les mutilations violentes déterminent les dléviations les plus direrses des organes appendiculaires. Les feuilles soudées, à nervures dissociées, cupulées, laciniées, à folioles surnuméraires, etc. peuvent être obtenues par leur emploi. On peut observer, sur les rejets des plantes mutilées, la métamorphose des feuilles en bractées ou des bractées en feuilles. On a pu découvrir dans quelques cas une loi de périodicité des anomalies; on connait des relations entre les variations accidentelles des feuilles primordiales et des feuilles adultes; on sait enfin que les feuilles cohérentes on cupulées accompagnent les fascies et les torsions, que les feuilles laciniées sont fréquentes sur les ramilles. Il n'est pas douteux que la méthode appliquée par HugO dE V'ries à la fixation de races fasciées el tordues puisse fournir de nombreuses formes nourelles à fenilles aberrantes; elle a déjả été appliquée à l'obtention du Trifolium prutense var. quinquefolium. Les traumatismes violents procureront le matériel nécessaire pour la création de variétẹs analogues dans d'autres espèces. 
ANOMALIES DES GRAPPES FLORALES.

\section{4. - Substitution des rosettes feulllées aux inflo-}

\section{RESGENGES.}

Les anomalies des inflorescences dues aux traumatismes violents sont peut-être plus nombreuses que celles des or'ganes rẻgétatifs. Elles le sont lout au moins en apparence, ce qui tient sans doute à ce qu'elles sont plus visibles; clles attirent aussi davantage l'attention des biologistes parce qu'elles montrent des déviations insolites des caractéres les plus stables el considérés comme caractéristiques de l'espèce. Aussi, ai-je fait choix de l'étude des anomalies des inflorescences du Maïs, de préférence á celles que montrent les feuilles et les bractées, pour établir la démonstration expérimentale de la métamorphose des organes à la suite de mutilations.

Dans la première partie de ce mémoire, j'ai montré l'équivalence des bourgeons terminaux et latéranx du Maïs. Les mutilations sont un moyen commode pour mettre ce lait en évidence, soit qu'elles activent, soit qu'elles ralentissent la nutrition et la croissance des bourgeons. Il en résulte qu'à l'origine les bourgeons de Maïs ne sont point différenciés et qu'il est possible de les faire évoluer en grappes mâles ou en épis femelles.

Les lois établies pour le Maïs sont générales et applicables à tous les végétaux, qu'ils soient ligneux ou herbacés, vivaces ou annucls. Les règles de la taille des arbres n'en sont qu'une application dont la valeur a ité élahlie par une longne pratique. Elles consistent en la diminution de l'intensité du traumatisme à mesure que la rapidité de croissance des bourgeons augmente; la taille, dite d'hiver, supprime les grosses branches; elle est pratiquée, selon les essences, soit immédiatement après la fructification, soil dans le conrs de l'hiver, et toujours dans une période de repos végétatif; la taille d'été, ou taille en rert, n'est qu'une extension des opérations d'ébourgeonnement et de pincement; elle ne s'applique qu'aux organes jeunes 
et souvent doit être faite à plusieurs reprises, afin d'éviter l'émission de broussins ou autres anomalies de forme th thoraison.

Le biologiste qui veut obtenir le matériel nécessaire à l’éturle des lois de la inétamorphose des organes se place instinctivement, et sourent sans y prendre garłe, dans des conditions opposées. Il provoque la croissance rapicle des organes par diverses opérations culturales et lait des mutilations violentes à l’époque mème que I'horticulteur considère avec raison comme délavorable. C'est par' sette méthode que KLLEBs (190j) a réussi à provoquer la formation de rosettes feuillées sur des inflorescences de Scmpervivum Funkii; par des traumatismes analogues, j’ai obtenu la métamorphose de rameaux à fleurs de Betu vulyaris, Spinuriu oleruceu, Enothera biennis, I'lantryo lanceolatu, en rosettes véritables qui ont donné l'année suivante des fleurs et les liruits.

L'exemple fourni par l'Enotheru biemmis présente un intérêt tout particulier (PI. VII, fig. 89). Ciette plante bisannuelle est sociale; suuvent beaucoup d'individus croissent còte à côte dans la mème station; ils présentent alors une tige unique qui ne se ramifie que vers son milieu. Parlois des rosettes isolées ct très fortes donnent naissance simultanément à la tige principale couverte de feuilles à la base et de fleurs au sommet, et à des tiges secondaires issues directement de la racine. La section, faite en mai, des tiges principales de ces plantes ma donné la métamorphose des tiges secondaires en rosettes nourelles montrant des fleurs et iles fruits parmi les feuilles de base. A l'automne de la mème année, les feuilles centrales de la rosette subsistent seules et l'on obtient une anomalie de végétation très curieuse qui consiste en la présence sur un axe court de quelques fruils à maturité, puis d'une rosette bien conformée, destinée à fournir, l'année suivante, des grappes florales en tout normales. L’intérêt de cette irrégularité dans le développement normal de la plante est d'autant plus consiclérable que le fait d'avoir des fleurs et des fruits dans la rosette, non signalé à ma connaissance dans le sous-genre QEmothert, est constant dans la plupart des espèces d'un sous-genre très voisin appelé Gnotherium par dE CANDoLLE dans son l'rodiome.

Il semble résulter des expériences de Ḱlebs et de mes propres essais, que cette substitution d'organes à d'autres est à beaucoup de points de vue comparable aux phénoménes si curieux de « Double adaptation » que DE VRIEs décrit dans le chapitre XV de son bel 
ouvrage « Species and Varieties». L'exemple le plus net, fourni par Massart (1902) dans une étude du Polygonum amphibium, montre que les bourgeons de cette plante jouissent de la propriété d'évoluer en plusieurs formes très distinctes, suivant les conditions extérieures et, principalement, suivant l'habitat aérien ou aquatique. De même l'abondance d'eau dans les tissus, provoquée soit par des conditions de culture plus ou moins complexes (expériences de KLEBs), soit par la seule section de la tige principale, qui supprime la transpiration de la plante sans réduire complètement l'absorption, détermine la métamorphose des axes floraux en rosette.

Mais la mutilation est une méthode imparfaite et les plantes qui la subissent ne sont pas toutes au même stade de développement; l'époque de la section joue un rôle considérable et l'on obtient, soit des bourgeons partiellement métamorphosés, soit un mélange complexe des organes différents. Après la mutilation, des rameaux de Betu vulyaris, Spinacia oleracea m'ont fourni, à l'aisselle de chaque feuille, des petites rosettes portant de part et d'autre des fleurs parfaitement conformées qui ont évolué en graines. C'est à la même cause que j'attribue la présence, fréquente dans mes lots d'expériences, de bractées dispersées au milieu des panicules du Maìs. Tout récemment LÆw (1906) a signalé l'apparition d'une anomalie analogue dans l'inflorescence du Typha angustifolic à la suite de la coupe des tiges.

Les bractées des inflorescences, fréquemment avortées (BonNIER, 1882), réapparaissent dans ces conditions; l'anomalie s'obtient avec une grande sûreté dans beaucoup de Composées. Les écailles charnues de la base des capitules d'Helianthus ammus ( $\left.{ }^{1}\right)$, les bractées épineuses du Lappa minor ont évolué, sur les rejets développés après la section des tiges, en rosettes feuillées enveloppant les capitules. Peut-être laut-il y voir l'explication de la métamorphose en feuilles des fleurs d'Anagallis arvensis var. phoenicea et de Trifolium repens foulés aux pieds par les passants et battus par la pluie d'après la description donnée par Viaud Grand-Marais (1861). On pourrait y trouver la cause de certains cas de virescence attribués à des insectes gallicoles que les observateurs n'ont pu découvrir malgré leurs efforts (MolliaRd, 1903).

(1) K. Kraus (1880) a provoqué la même anomalie des bractées de l'inflorescence de l'Helianthus en enlevant les feuilles de la tige. WoLlwy (1885) a fait d'autres expériences très intéressantes sur cette plante entraînant des anomalies de la tige. 
Les fascies et les torsions, étudiées sur les tiges, apparaissent aussi fréquemment sur les axes d'inflorescence. Elles sont d'autant plus intéressantes qu'elles entrainent des sutures de bractées ou de pièces florales qui accentuent davantage les anomalies. Comme ce fait a été très nettement établi pour les rejets, il semble inutile d'y revenir. Je préfère insister sur les caractères particuliers des fasciations qui peurent facilement šétudier sur les inflorescences et, en particulier, sur la condensation des épillets qui accompagne toujours la métamorphose sexuelle des panicules du Maïs.

42. - Compacité des GRAPpes dont LE CAS ExtrêMe EST L'ÉTAT DE FASGiation.

Pour rendre cette étude démonstrative, il est bon de préciser quelques notions. La compacité $D$ d'une grappe florale est définie par le produit $10 \times \frac{a}{1}$ ou a représente le nombre des rameaux de la grappe compris dans la longueur 1 évaluée en centimètres. Pour les Craminées à épis, le mot compacité est remplacé par le terme densité. La lensité des épis est variable; la mesure de ce caractère, sur des centaines d individus appartenant à une population homogène, permet la construction d'un polygone de variation dont le sommet définit la densité inoyenne de la population qui est un caractère héréditaire et permet de distinguer différentes races $\left({ }^{1}\right)$.

En ce qui concerne le Maïs, on peut étudier soit la compacité de la grappe terminale, soit la densité de l'axe ou des rameaux considérés comme des épis. Le matériel des expériences de 1904 et 1905 a donnẻ à l’étude de la compacité des panicules terminales déformées ou nun les chiffres suivants:

Conpacité relative des inflorescences teruinales du Maĩs $\begin{array}{llllllllll}\text { Compacité : } & 5 & 10 & 15 & 21) & 25 & 30 & 35 & 40 & \text { Total }\end{array}$ Panicules normales $38 \quad 51 \quad 11 \quad 100$

$\begin{array}{llcccccccc}\text { - dutype A } & 21 & 15 & \mathbf{3 4} & 19 & 16 & 5 & & 100 \\ \text { - dutype B } & 0 & 5 & 23 & \mathbf{3 8} & 15 & 7 & 12 & 100\end{array}$

(1) La densité des épis est un caractère employé par N. HJ. Nıssos, directeur du Laboratoire de Svalöf (: Suède), pour la distinction des différentes sortes de céréales. sion importance a été contrôlée par des cultures suivies depuis trente années. 
La compacité moyenne rles grappes est l'autant plus élevée que la métamorphose sexuelle des épillets mâles en épillets femelles est plus complète. Les résultats auraient été encore plus nets si on avait limité l'étude à celle de la compacité des cincf rameaux de base des grappes. On sait en effet que, dans les panicules normales du Maïs, les rameaux sonl d'autant plus écartés qu'ils sont situés plus bas sur l'axe. Parce que les panicules du type $B$ montrent rarement plus de 5 ramificalions, les chiffres eussent été plus probants encore si on avait pris cette précaution. Mais les données générales suffisent déjả pour établir la règle.

La loi est tout aussi nette lor'squ'on étudie la densité des rameaux, e'est-à-dire la disposition des épillets sur les ramifications dẹ la grappe. 100 rameaux, montrant l'association des deux sexes étudiés sur des panicules du type $\mathrm{A}$, ont donné:

DENSITÉ DES RAMEAUX

$\begin{array}{lrrrrrrrrrrrrc} & 12 & 13 & 14 & 15 & 16 & 17 & 18 & 19 & 20 & 21 & 22 & 23 & \text { Total } \\ \text { Portion mâle..... } & 2 & 6 & 9 & 17 & 15 & \mathbf{2 3} & 13 & 7 & 5 & 3 & & & 100 \\ \text { Portion femelle... } & & & & 1 & 2 & 5 & 8 & 15 & \mathbf{3 1} & 23 & 12 & 3(1) & 100\end{array}$

Ainsi la fasciation des grappes florales, qui est caractérisée par l'hypertrophie et la succulence des axes, entraine la condensation des rameaux et des épillets.

La meilleure nutrition des épillets développés sur les axes charnus est corrélative de leur évolution en organes femelles, mais la compression qui résulte de leur condensation entraîne leur avortement partiel; on s'explique ainsi la disparition d'une fleur sur deux dans l'épillet, lorsqu'un rameau mâle se métamorphose en rameau femelle. De plus, lorsque la grappe terminale évolue en type $\mathrm{C}$ ou en épi femelle, l'avortement affecte un épillet sur deus.

Enfin l'extrême condensation des parties, due à la fasciation des axes, fournit parfois la suture plus ou moins complète de deux ou plusieurs rameaux voisins, ou la suture longitudinale d'un rameau, d'une bractée avec l'axe de la panicule $\left(^{2}\right)$.

(1) La densité des portions femelles serait encore plus différente de celle des portions mâles si l'on faisait intervenir un facteur de correction traduisant le fait que les épillets de l'extrémité des rameaux sont plus serrés que ceux de la base.

(2) Beaucoup d'auteurs ont regardé la coalescence des parties comme le caractère primordial de l'état de fasciation. A mon avis, la suture des organes n'est qu'un cas extrême de leur condensation. Ou l'observe souvent sur'les fascies, mais elle r'est qu'une conséquence de l'état de fasciation et non la cause. 
43. - Exemples de fasciation, De dissociation et de SUBSTITUTION DES PARTIES DES INFLORESCENCES.

De nombreux rejets développés après section montrent la suture des parties de l'inflorescence. Les capitules multiples qui terminent les rejets fasciés d'Helianthus ammus, Cichorium Intybus, les fascies de Barkhausia taraxacifolia obtenues par GĖEAU DE L AMARLIÉRE (1901), les axes aplatis de Sinapis alba et les crêtes qui couronnent certaines tiges fasciées de Limum usitatissimum doivent rentrer dans cette catégorie. Les Ombellifères en offrent, peut-être, les meilleurs exemples. Les ombelles des rejets d'Her $u$ cleum Sphondylium. Angelica silvestris présentent presque tous la suture longitudinale de deux ou plusieurs rameaux. On peut y ajouter les fascies des grappes florales d'Acer pseudo-Platumus, Soryho communis, la multiplication des capitules de Trifolium pratense à l'extrémité des tiges, etc... Enfin, les observations faites par Molliard (1903), sur des individus anormaux de Matricaria inodora et Senecio Jacobca sont relatives à des phénomènes de fasciation de capitules accompagnée de la prolifération des fleurons. L'étude qu'en a faite l'auteur montre que de simples traumatismes peuvent provoquer des déformations comparables à celles qui sont produites par des insectes gallicoles. Dans l'un et l'autre cas il y a évidemment modification de la nutrition générale, mais la fertilité fréquente des grappes florales modifiées par les mutilations, l'infertilité presque constante des cécidies florales indiquent que l'un et l'autre cas diffèrent par un point capital pour l'érolution des formes.

Lorsque la mutilation n'entraîne pas la fascie des rejets, elle peut provoquer le développement d'un grand nombre de bourgeons qui, dans les conditions normales, restent avortés; on assiste alors à une sorte de dissociation des grappes florales accusée surtout dans les inflorescences condensées. Les épis multiples de Plantago lanceolata apparaissent en abondance a l'automne dans les prairies artificielles soumises à plusieurs coupes; j'ai souvent obserré la présence de pédoncules coupés à la base des pieds déformés. Dans les mêmes conditions, le Lolium italicum et le Dactylis glomeratu montrent des ramifications anormales dans les inflorescences (Pl. VII, fig. 88).

Les expériences très nombreuses que j'ai faites sur l'Orge et sur l'Avoine sont relatives au même sujet. J'ai opéré en culture 
pédigrée, sur des lots de plantes provenant d'une seule graine et choisis, à cause de l'uniformité des caractères de végétation et de grappe florale, pour d'autres recherches $\left({ }^{1}\right)$.

La section des tiges a lieu vers la fin du mois de juin, peu de temps avant la sortie des barbes hors de la gaîne de la feuille supérieure; la sécheresse détermine parfois la mort complète des plantes, mais si le sol est humide, on obtient, avec beaucoup d'anomalies florales, des épis ramifiés comparables par tous leurs caractères aux inflorescences du Blé Miracle. L'épillet uniflore de l'Orge est remplacé par un axe secondaire couvert de fleurs fertiles.

Il est remarquable que, dans ces essais, les caractères spécifiques les plus connus, comme l'épillet réduit à une fleur (caractère du genre Hordeum), l'avortement des épillets latéraux (caractère de l'espèce linnéenne $H$. (listichum) soient les seuls modifiés, tandis que les caractères des grains, moins visibles et moins connus, restent complètement stables. Les poils allongés et simples de l'axe de l'épillet d'Hordeum distichum nutans $\alpha\left({ }^{2}\right)$ ne peuvent être substitués aux poils ramifiés et enroulés en tire-bouchon de l'Hordeum distichum nutans $\%$ alors que l'on peut trouver des transitions entre les épis des Escourgeons et ceux des Orges à deux rangs.

Après mutilation, faite dans des conditions analogues, de pieds vigour'eux d'Avoine, j'ai pu récolter des tiges portant deux panicules, l'une d'elles terminant la tige, l'autre s'étant développée à l'aisselle de la feuille supérieure (Pl. VII, fig. 86-87). J'ai repris, avec ce matériel, tous les essais faits par moi sur le Maïs; je remets à plus tard la description détaillée des résultats.

Les plantes à inflorescences bien définies, capitules, épis ou panicules, sont peut-être les plus faciles à modifier. Il était important de faire des recherches précises sur les Ombellifères dont les grappes florales sont si caractéristiques. J'ai coupé en juillet 1905, les tiges principales d'Heracleum Sphondylium; des rejets nombreux m'ont fourni des ombelles dont les rameaux étaient partiellement soudés et des fleurs composées résultant de la suture de plusieurs fleurs voisines. L'Herucleum Sphondylium vit le plus souvent isolé ; il est

(1) Le matériel soumis à un contróle minutieux et, résultant toujoưrs de l'autufécondation dans le cas de l'Orge, offre des garanties de pureté que ne présente aucune autre flante sauvage ou cultivée.

(2) Pour la définition de ces espèces élémentaires d'Orge, voir: Blaringhem, Revue des Idées, 1905 et Bulletin du Muséum d'Histoire naturelle, 1904 b; J. Costantin (1906). 
difficile d'en rencontrer des stations où les individus nombreux permettent la conservation de plantes témoins. Par contre, dans une prairie basse et marécageuse, inoudée l'hiver, j'ai trouvé une abondante colonie d'Anyelica silvestris composée de près d'une centaine d'indiridus. Le 10 août 1906, la tige principale, atteignant à peine 20 centimètres a été coupée au ras du sol. Les rejets, au nombre de 2 ou 3 , se sont développés, et j'ai pu récolter au début d'octobre bon nombre d'anomalies dont les torsions de tiges et d'axes sont figurées sur la Planche VII (fig. Tí à 85).

La déformation la plus fréquente consiste en la suture longitudinale de deux ou trois rayons de l'ombelle, tantôt complète, tantòt partielle. Souvent aussi l'ombellule se dissocie; des fleurs ou des fruits sont insérés sur la longueur du rayon et non à son extrémité. Il arrive enfin que le rayon avorte complètement et que l'ombelle principale se compose de rayons portant les ombellules et de pédoncules terminés par un seul fruit. On a ainsi tous les stades de transition entre l'ombelle simple et l'ombelle cumposée.

Les anomalies les plus curieuses sont présentées par des inflorescences proliféres dans lesquelles le rayon de l'ombellule se métamorphose en un axe d'ombelle ou mème en une véritable tige terminée par une ombelle composée portant des rudiments de feuilles et des bractées. Commo cas extrème, il faut citer celui de la superposition sur la mème tige de deux ombelles parfaitement conformées et normales, anomalie qui résulte sans doute de la métamorphose du rayon central de l'ombelle inférieure en une tige qui se dissocie immédiatement en une ombelle composée nouvelle (PI. VII, fig. 79).

\section{4. - Régularité Relative Des inflorescences anor-} MALES.

Il est remarquable que les anomalies des inflorescences conservent un certain degré de régularité, souvent particulier à l'espèce ou à la famille. Ainsi, les monstruosités de disposition des fleurs sur les rameaux de la panicule du Maïs peuvent être identifiées avec l'inflorescence latérale. De mème, le rameau de l'ombelle de l'Angélique est remplacé par une tige portant une ombelle, ou une tige feuillée, ou encore par un simple rameau d'ombellule, et non par une inflorescence quelconque. 
De même le groupement compact des capitules d'Helianthus annuus, Trifolium pratense, Cichorium Intybus entraîne non pas la cohésion pure et simple des disques, mais aussi l'arrangement régulier des pièces qui entourent et couvrent le disque terminal. Par exemple, dans le cas de l'Helianthus annuus, il est facile de reconnaitre aux saillies qui parcourent le rejet fascié mais non dissocié, la présence de deux, trois ou quatre axes coalescents. On pourrait s'attendre à ce que chacun de ces axes soit terminé par un capitule complet, de telle sorte que l'inflorescence terminale soit le résultat de la juxtaposition de deux, trois ou quatre capitules. Il en serait ainsi, si le rejet fascié résultait de la suture de plusieurs axes indépendants. Or, dans le cas où la dissociation du rejet n'a pas lieu, le capitule qui le termine présente un contour lobé et irrégulier, mais on ne peut trouver, au centre du disque en apparence composé, les bractées et les fleurons ligulés qui se seraient développés si la dissociation du rejet s'était produite. Il en résulte que les différentes saillies, qui dans le capitule très jeune représentent les bractées ou les fleurons, ne sont pas encore différenciés; elles évoluent en bractées ou en fleurs d'après la situation définitive qu'elles occupent lorsque le rameau fascié est arrivé à son terme de dissociation. 


\section{CHAPITRE XI.}

\section{ANOMALIES DES FLEURS ET DES FRUITS.}

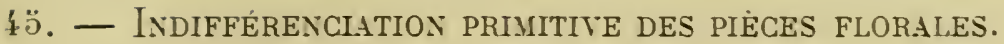

La fleur, considérée au point de rue organographique, est un buurgeon terminant un rameau ou pédicelle, et formé par l'assemblage de plusieurs rerticilles de pièces qui ne sont que des feuilles modifiées. Depuis longtemps la célèbre théorie de la Métamorphose de Gozthe (1790) est adoptée universellement, et il serait facile de montrer que les plantes mutilées fournissent un matériel abondant et démonstratif à l'appui de cette conception. Si l'on a beaucoup insisté jusqu ici sur les exemples de métamorphose d'un sépale en pétale, d'un pétale en étamine, d'une étamine en carpelle, il est bien moins fréquent de trouver l'exposé des causes qui déterminent le déreloppement de pétales et sépales à l'extérieur du bourgeon, d'étamines puis de carpelles au centre. Il est admis que toutes les parties constituantes de la Heur sont des organes équivalents aux feuilles et aux bractées. Pourquoi ces organes, identiques à l'origine, éroluent-ils toujours de la mème manière, les bractées à l'extérieur, les pièces reproductrices à l'intérieur, et, pour ces dernières, les étamines autour de l'oraire?

La loi est générale, et les anomalies florales observées sur les plantes mutilées, loin de la mettre en défaut, en apportent de nourelles confirmations mème dans les cas les plus inattendus.

Lorsque par la compression de l'extrémité d'une lige jeune de Pensée (Viola tricolor var. maxima) on détermine la fasciation de l'axe, les fleurs qui se déreloppent sur lui montrent une auggentation du nombre des pièces (Blarisghey, 190' 1 ( $)$. Il semble, à l'examen des bractées avortées qui se trourent sur le pédoncule, à la présence d’un nombre double de sépales, de pétales, d’étamines et de carpelles, et surtout à la présence de deux pétales à éperons, que la fleur monstrueuse résulte de la coalescence de deux fleurs roisines que la mutilation a rapprochées, a greffées pour ainsi dire 
l'une sur l'autre. Toutefois la greffe aurait provoqué le déplacement des organes ; les sépales des deux fleurs se sont réunis pour former un verticille externe, puis viennent les pétales, et au centre les étamines entourant un ovaire à carpelles soudés entr'eux pour former un dôme unique. Ce ne peut être une greffe véritable au sens que l'on aitribue à ce mot: la greffe rapproche des organes, mais n'en détermine point la variation immédiate.

L'organisation de la fleur monstrueuse de Pensée s'explique en admettant les hypothèses suivantes: la mutilation provoque dans le jeune bourgeon la multiplication des bourrelets esquisses des organes; les organes jeunes sont indifférenciés, leur forme et leurs fonctions dérivent exclusivement de leur situation définitive dans le bourgeon sur le point de s'épanouir.

La multiplication des organes à la suite de la mutilation n'est pas un phénomène nouveau. On l'a reconnue sur les tiges fasciées et tordues, sur les inflorescences qui montrent la condensation des fleurs. Il est naturel de l'admettre pour les bourgeons floraux comme pour les bourgeons végétatifs, puisqu'on connait des méthodes qui permettent de les substituer les uns aux autres. L'indifférenciation primitive des bourrelets est analogue à l'indifrérenciation des feuilles et des bractées. De même que par des mutilations appropriées on permet à une bractée de l'épi latéral femelle du Maïs de prendre le développement, la forme et la taille d'une feuille caulinaire, de même l'afflux local de nutrition, sous l'influence de l'excitation traumatique, modifie les bractées florales, les sépales, les pétales, les étamines et les carpelles qui se substituent les uns aux autres.

\section{6. - Relations Entre Les fascies Des tiges ET LA MULTIPLIGATION DES PIEGGES FLORALES.}

Sur les rejets provoquẻs par une mutilation violente, faite à une époque convenable, on observe souvent des pédoncules floraux fasciés. Si la fascie se dissocie en fourche avec formation de deux pédoncules isolés, les fleurs qui les terminent montrent les deux groupements (calice, corolle, androcée, gynécée) isolés et bien distincts. Si la fascie ne se dissocie point, le bourgeon floral, de forme elliptique, offre une seule série de verticilles (calice, corolle, androcée et gynécée) régulièrement enveloppés les uns dans les 
autres; la fleur complese ne diffère de la fleur simple que par l'augmentation des pièces et non par leur disposition respective.

Or, on sait modifier la croissance ou l'étalement d'une fascie, soit par les aliments fournis à la racine, soit par la suppression d'un nombre plus ou moins considérable de rameaux nu de rejets roisins de la tige fasciée. De mème, on peut modifier à son gré les formes des pédoncules des grappes florales et déterminer la production d'une houppe de petites fleurs normales serrées, ou d'une seule fleur, monstrueuse par l'abondance des pièces qui la constituent.

L'expérience est très facile à réaliser arec certaines plantes potagères qui montrent la fascie héréditaire des grappes florales. La Tomate (Lycopersicum esculentumi) est le matériel le plus répandu et le plus commode pour ces essais. Les horticulteurs connaissent les méthodes de taille qui fournissent les fleurs et les fruits à carpelles surnuméraires mais à formes très régulières. En laissant la plante à elle-mème, ou en opérant à dessein le pincement d'une manière différente, on obtient toutes les anomalies de disjonction irrégulière des bourgeons floraux que l'on peut imaginer. Puisque, mème dans ces fleurs monstrueuses, les bractées florales sont toujours externes, que les étamines et les carpelles sont internes, il est nécessaire que la différenciation des parties se produise très tard dans la croissauce de la plante, au moment mème oú la grappe florale s'étale.

Il résulte de cette étude que tous les facteurs qui ont été signalés comme susceptibles de modifier la croissance des fascies et torsions de la tige peurent ètre emplorés arec succès pour la culture des monstruosités Horales. Lexcès local de nutrition, proroqué soit par des mutilations appropriẻes soit par divers autres procédés, agit exactement de mème sur les bourgeons floraux et sur les bourgeons végétatifs.

\section{7. - Anomalies de fleurs et De fruits. Axomalies} DES APPAREILS REPROdLCTEURS DES CRIPTOGayes.

Mes expériences sur les déformations florales ont porté tout d'abord sur le Hais, mais la plupart des anomalies obserrées rentrent dans une autre catégorie de phénomènes, le changement de sexualité. et seront étudiées plus tard. La Pensée des jardins (Viola tricolor 
var. maxima), puis la Tomate (Lycopersicum esculentum) et aussi le Fraisier (Fragaria vesca var..?) fournissent des exemples très typiques de ces variations. On en récolte aussi un bon nombre sur les arbres et arbustes taillés chaque année (Acer pseudo-Platanus, Hibiscus Rosa Sinensis).

De même, sur les rejets mutilés de Sinapis alba, Polygonum Fagopyrum, Heracleum Sphondylium, Angelica silvestris, on troure des fleurs normales associées par deux ou trois sur des pédicelles soudés sur une grande partie de leur longueur; mais, lorsque les pédicelles sont sovidés sur toute leur longueur, la fleur terminale ne résulte pas de l'accolement de 2 ou 3 fleurs, elle constitue une fleur véritable à verticilles de sépales, de pétales, d'étamines et de carpelles parfaitement continus et superposés les uns aux autres comme dans une fleur normale.

Le degré de la suture est parfois tel qu'il est impossible de reconnaître le nombre véritable de fleurs réunies en une seule. Il arrive bien que le nombre des parties soit exactement le double ou le triple de celui des fleurs normales, mais ce sont des exceptions; presque toujours il y a réduction. Ainsi les fruits récoltés sur les rejets déformés de Polygonum Fugopyrum, normalement à 3 arêtes, en ont rarement 6 , plus fréquemment 5 , et très souvent 4 (Pl. IV, fig. 47-50); il est vrai qu'on observe aussi sur les mêmes rejets des fruits à 2 arêtes. On pourrait prétendre que la réduction du nombre de pièces florales précède la suture; rien ne permet de soutenir cette opinion. Il est bien plus logique de relier ces caractères à ceux que nous ont montré les rameaux et les feuilles anormales des rejets. La mutilation a déterminé des variations importantes dans le nombre des parties; selon que ce nombre est plus ou moins élevé on obtient un nombre plus ou moins considérable de pièces florales. J'ai obtenu des irrégularités de cette nature après des mutilations dans les fleurs et les fruits de Polygonum Fayopyrum, Sinapis alba, Heracleum Sphondylizm, Angelica silvestris, Linum usitatissimum, Hordeum tetrastichum et H. distichum, Zea Mays, Cannabis sativa, Acer pseudo-Platamu, Oenothera biemnis, Beta vulyaris.

Watelet (1856), Kuntze (1898), Molitard (1905), Ducamp (1905), KLLEBS (1905 et 1906) ont lécrit des exemples analogues qu'il m'est possible d'attribuer aux mutilations d'après les circonstances dans lesquelles ces observations ont été faites. Elles montrent les variations florales dues aux traumatismes pour le Raphanus Raphanistrum, 
Papaver Rhoeas, Agave americana, diverses espèces de Sempervivum.

Les mèmes anomalies apparaissent donc bien dans les formes les plus diverses du règne végétal : la démonstration sera plus complète encore si l'on veut faire rentrer dans cette série de faits, les déformations que présentent, aprés la mutilation, les Cryptogames rasculaires et les Champignons à chapeau. ItTAL-Jocte (1864) et Milde (185j) ont décrit et figuré des tigges spicifères d'Equisetum maxim!nin, coupées au-dessus du sixiẻme verticille d'ècailles sporiféres: la plaie béante portait sur ses bords un cercle de $T$ épis secondaires de la grosseur d'un épi terminal d'Equisetum palustre. CHIFrlot (1904) signale la mème anomalie due selon lui à la destruction de l'estrémité de l'épi primitif par le froid et Bocdrer (1897) a décrit un champignon polrcéphale. Gonoderina lucidum, dont les tètes multiples seétaient déreloppées au-dessus diune blessure. De SErase a obtenu le mème résultat arec un Lentinus ( $\left.{ }^{1}\right)$

Limitons-nous aux régétaux supérieurs. On roit que la mutilation létermine non seulement la multiplication des bourgeons adventifs, mais aussi celle des bourgeons floraux. La rapidité de leur formation entraine l'hypertrophie ou l'arortement des organes reproducteurs. Il n'est pas étonnant que l'on obtienne dans les mémes conditions des métamorphoses de pièces florales.

\section{8. - Duplicatlre des fleurs, prolifératiox et} VITIPARITÉ.

La duplicature des fleurs à la suite les traumatismes a èté signalèe par KLeIr (1891) pour les fleurs diun .Esculus Hippocnstanum de Bulapest. Deur Marronniers, denriron 25 ans, furent taillés en pleine feuillaison: l'un des arbres en mourut ; lautre a porté depuis et chaque année beaucoup de petites Heurs tout à fait doubles, mais n’a tardé à dépérir à son tour. Molliard (1905) a décrit la duplicature partielle du Paprcer Rhous aprés la section de la tige principale à dis centimêtres du sol; il a attribué cette anomalie à

1) Ussistr a essayé, pais sans sueces, de réaliser cette monstrunsité sur l'Hypholome fussinblar. 
des conditions défectueuses de nutrition $\left({ }^{1}\right)$. On peut citer encore les observations de Doumet (1879) sur un Rosa Fortunei; il estime qu'une mutilation vi lente aurait provoqué le développement de roses prolifères. La viviparité elle-même est attribuée par certains auteurs (Boullu, 1877) $\left({ }^{2}\right)$ à des causes analogues.

Ces exemples, dont l'étude est imparfaite, parce que le matériel a été rencontré accidentellement, permettent de conceroir comment, après la mutilation des tiges, on peut obtenir des inflorescences latérales de Maïs déformées au point d'être rendues méconnaissables. Le Zea Mays tunicata donne des rejets à panicule du type A renfermant de nombreuses graines. L'anomalie est héréditaire en ce sens que les graines récultées sur la panicule donnent de nouveau des plantes anormales; mais les inflorescences latérales des rejets, aussi bien que celles des individus déformés qui en dérivent, présentent, à beaucoup de points de vue, des caractères voísins des inflorescences charnues des Choux-fleurs (Pl. VI, fig. 68-70). Les bractées épaisses et longues qui enveloppent d'ordinairé la graine avortent complètement; l'ovaire de la fieur femelle est remplacé par un axe blanchâtre, aplati et sinueux, portant sur chacun des bords des échancrures où se déreloppent des axes analogues. Il en résulte une ramification considérable de l'inflorescence et, en dernière limite, la production de toutes petites fleurs femelles, à peine visibles au microscope. Cette monstruosité, extrêmement rare et non signalée à ma connaissance dans les Monocotylédones, entraîne l'avortement complet des graines. La présence de fruits bien conformés dans la panicule permet seule de perpétuer la race.

\section{9. - Polyembryonie et Dégénérescence.}

Il est fréquent d'observer l'avortement partiel ou complet des graines récoltées sur les inflorescences modifiées par la mutilation.

(1) Gøesel (1886), dans son étude des fleurs doubles, indique et discute la pratique horticole qui consiste dans le pincement et la suppression des rameaux des plantes cultivées pour fournir la semence des Giroflées doubles. Il croit à l'influence d'un excès local de nutrition.

(2) Il est intéressant de rapprocher, d'une part les circonstances dans lesquelles BoulLu et Molliard (1895) ont observé, soit la viviparité de plusieurs Graminées, soit la duplicature des fleurs de Ranunculus Flammula et Pelargonium sonale, et, d'autre part l'apparition fréquente des mêmes anomalies sous l'influence d'un parasite. 
L'absence de carpelles dans les fleurs doubles ou prolifères n'est qu'un cas extrême d'une modification toujours très profonde dans le déreloppement des ovules des fleurs anormales. La polyembryonie est en particulier un phénoméne très rare que l'on peut observer de temps à autre sur les rejets des plantes mutilées. Le Maïs m’en a fourni trois exemples dans les cultures de cinq années; l'Orge (Hordeum distichum et Hordeum tetrastichum) en donne des échantillons plus nombreux, et chaque année, on troure toujours des graines munies de deux embryons sur les inflorescences ramifiées; elles ne sont manifestement qu'un cas extrême de la condensation des fleurs. On trouve sur les rejets de pieds d'Orge coupés tous les termes de transitions entre les graines anormales décrites et figurées par Krads (1894).

J'ai suivi arec beaucoup de soin la germination des graines anormales obtenues après la mutilation. Malgr'é mes efforts je n'ai pu amener qu'un tout petit nombre de plantules à un développement suffisant pour observer la constitution des inflorescences. Il semble que les dériations extrêmes dans l'organisation des pièces reproductrices entraînent en mème temps la stérilité. Cette dégénérescence, dont il importe d'établir la preure avec un matériel plus complet et mieux préparé, expliquerait la non persistance dans la nature de nombreuses variations tératologiques que la culture a su propager et répandre. 


\section{CHAPITRE XII.}

\section{CHANGEMENTS DE SEXUALITÉ}

\section{PROVOQUÉS PAR DES MUTILATIONS.}

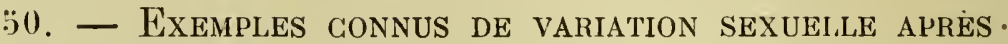

\section{TRAUMATISME.}

Parmi les nombreux cas de métamorphose florale dus aux mutilations, ceux qui entrainent le changement de sexe ont surtout attiré l'attention des savants.

GIARD (1898) a signalé, entre autres exemples de variation sexuelle chez des plantes dioïques et des plantes monoïques, une observation de BI.AVET dans laquelle la transplantation avait provoqué le changement de sexe d'une Cucurbitacée, Thladianta dubia. Gallardo (1901) rapproche de cet exemple les expériences de Spegazzini (1900) faites sur trois plantes de son jardin, à La Plata. Des pieds femelles de Trianosperma (Cayaponia) ficifolia, Dioscorea bonariensis, Clematis Hilarii ont montré, à diverses reprises, des fleurs hermaphrodites et mâles, après la transplantation sans grands égards entraînant la section des rhizomes. La métamorphose inverse est signalée dans un grand nombre de cas. KLEIN (1891) rapporte qu'après la section de la tête des Saules ne portant que des fleurs mâles, il se développe parfois des fleur's femelles.

Mais HAAcke (1896) attribue à la même cause la métamorphose inverse des fleurs femelles de Salix capraca en étamines, dont il a décrit et figuré les différents termes de passage. Plus récemment, Ball (1901) a signalé le changement de sexe du Silene dichotoma après la coupe.des tiges.

La mutilation violente peut donc être utilisée à la fois pour le changement du sexe mâle en sexe femelle et réciproquement. De même que ce procédé provoque la surnutrition du bourgeon ou son affaiblissement selon l'époque et les moyens employés, et par suite, entraîne la fascie ou la disparition de l'étal fascié des rameaux, de même, la mutilation détermine soit la multiplication et la substitution 
des pièces florales femelles, soit la multiplication des piéces florales måles. Тн. \EEHA. (1S72) a déjà insisté sur cette relation et montré que létat de fasciation dù à des circonstances affaiblissantes et la production du sere måle sont sourent simultanés. La pratique s'est mème emparée de cette méthode pour déterminer la surproduction les arbres fruitiers. Leemondage et l'incision annulaire (Tils. 15971901) sont en particulier des procédés courants qui empèchent la coulure du raisin, à la condition qu'on les applique à une époque conrenable.

On peut citer aussi les curieuses coutumes que rapportent HARIOT (1902) et Dıvatu (1903) * Les habitants des oasis du Sud-tlgérien admettent que l'homme peut interrenir pour changer le sese d'un Palmier. Le procédé consiste á déchirer toutes les feuilles des pieds àgés de ? ou 3 ans, de façon que la nerrure médiane soit fendue en deur. depnis le milieu jusqu à la gaine foliaire ». Les jeunes plantes màles auraient donné des plantes femelles. Davatz déclare que ce procédé n’a pas une grande raleur pratique: \& Dans les oasis du Djérid. à peine un tiers des indigènes croient cette métamorphose possible; il paraitrait que dans le souf l'opération est d'application plus courante. Lépoque la plus faromable est la fin de l'hiver. On ne peut guère compter sur une réussite de plus de $50 \%$. et les fruits cles Uattiers, ayant subi cette opération restent de qualité inférieure C"est un résultat remarquable; au point de rue scientifique, comme au point de rue pratique, il y aurait un grand intérèt à ce que des expériences précises fussent faites sur ce sujet.

Elles pourraient ètre appliquées à d'autres espèces de Palmiers. LĖvenLÉ (1591), dans une étude de Palmiers à branches de l'Inde. leur donne pour origine la section du bourgeon terminal ; il cite en particulier un Borassus fabellifarmis hermaphrodite rencontré à Majankarancy, près Acharapakam.

jl. - Expériexces de Bordage sur le Carica Papaja (1598).

Les résultats obtenus par BoRdaGE (1898) apress la section transversale de la tige du Papayer commun (Carica Papuyu) sont de beaucoup plus concluants. Le Papayer est un arbre dioique: l'auteur a pu obserter à la Réunion l'apparition accidentelle de fruits sur des pieds màles mutilés. * Un jeune Papayer màle ayant eu, au 
moment où il allait fleurir, l'extrémité de sa tige cassée net accidentellement, deux bourgeons situés à l'aisselle des 2 feuilles venant directement au-dessous de la surface de section se développèrent, provoquant une dichotomie terminale. Ensuite, au bout de quelques temps, chaque branche de cette dichotomie fleurit, donnant des fleurs femelles qui furent suivies de fruits ». Bordage insiste sur la grande activité de circulation de sève que détermina la mutilation. Le diamètre du tronc était de 4 centimètres 5 avant l'accident, il atteignait, cinq semaines plus tard, près de $\tau$ centimètres. Dans des essais de déformation expérimentale, il reconnut que l'opération devait ètre pratiquée avant l'éclosion des premières fleurs, sur des arbres vigoureux et disposés à fleurir dès la première année de leur existence. La rapidité de croissance des Papayers influe beaucoup sur le résultat des essais.

Cette expérience que le professeur Giard m'a signalée en 1902, au moment où je lui indiquais les résultats de mes recherches sur les anomalies du Maïs, m'a été très utile pour la découverte de la méthode expérimentale que j'ai employée en 1903 et m'a déterminé à faire des essais de métamorphose sexuelle des végétaux vivant sous le climat de Paris. Quelques-uns ont été couronnés de succès, entre autres la mutilation des pieds mâles du Chanvre (Camubis sativa) qui m'ont donné des fleurs hermaphrodites $\left({ }^{1}\right)$. J'ai réussi aussi à récolter bon nombre d'individus à fleurs mâles et femelles après la section des jeunes tiges de Mercurialis amnu et Spinacia olerucea femelles. Mais ce matériel est peu favorable aux essais parce qu'il se présente spontanément, parmi les plantes témoins, des individus hermaphrodites. Enfin le Coix Lacryma, dont les fleurs femelles sont entourées d'une bractée ligneuse qui se durcit à maturité, a fourni, après la section des tiges dès les premiers jours d'août, des épillets mâles renfermant des fleur's femelles à style long.

\section{2. — ExpÉriences SUR I.e Maïs (1903).}

Le Maïs est certainement, sous le climat de Paris, la plante se prêtant le mieux aux essais de métamorphose expérimentale du sexe.

L'étude comparée des fleurs mâles et femelles des panicules ou

(1) Ces expériences peuvent être rapprochées de celles de Moluiard sur les mêmes plantes (1898). 
des épis déformés en a été faite arec soin par KRafrt. Il est inutile d'y revenir. En général, la métamorphose sexuelle est brusque. A des épillels femelles parfaitement conformés, sur leépi et sur la panicale, font suite des épillets mâles pédonculés à deux fleurs ne muntrant aucune trace doraire. Toutefois, mais très rarement, on peut obserrer aussi bien sur les épis que sur les panicules des formes de transition qui se groupent sous deus titres: termes de passage des glumes larges et cornées des fleurs femelles aux glumes allongẻes. étroites et plurinerriées des épillets màles: termes de passage présentés par les fleurs hermaphrodites.

\section{u.-MĖtayorphose des gltMelles et lecr Passage acx feUtlles.}

Dans le Mais ordinaire, les glumes des épillets femelles sont cornées, dépourtues de nerrures, étalées et à èchancrure médiane. L'espèce Zéa Mays turicatu présente seule des glumes foliacées de deux à trois centimètres de longueur sillonnées de nombreuses nerrures. J'ai pu aussi en observer sur quelques épis latéraux de Zeu. Vuys pensylurinicu prorenant de plantes mutilèes. Toujours ces caractères sont apparus sur les épillets de base de l'épi au roisinage du point d'attache des bractées internes. Les deux glumes de lépillet subissent parfois la métamorphose. Le cas le plus fréduent consiste en la transformation de la glume externe seule. A première rue, il semble que celle-ci ait été remplacée par une bractée interne de la gaine dont les dimensions sont très réduites.

On peut ainsi trourer des termes de transition entre les bractées d'enreloppe de l'épi et les glumes des épillets femelles. Il n'est pas douteur que cette métamorphose soit possible lorsqu'on examine ce:taines inflorescences latérales do Zea Mays tunicatu. Sourent les épis de celtı espéce présentent des ramifications latérales, insérées trés près des bractées: ces ramifications charnues, courertes de $\{$ rangées de graines, sont enreloppées dans une gaine spéciale formée de bractées rariables en nombre et en taille, qui passent, par degrrés successifs. aux glumes des épillets femelles normaux; les bractées diminuent de taille lorsquon examine les épillets déreloppés rers le milieu du rachis; elles sont courtes, rers la pointe, érasées comme celles des autres variétés de Mais dont elles ne diffèrent que par la présence d'une pointe médiane et de nerrures assez nettes. Les épillets femelles, à glumes érasées, allongées 
et pointues, ne sont pas très rares sur les panicules déformées ou à l'extrémité des épis latéraux des diverses espèces de Maïs à graines nues. Tous les termes de passage entre les feuilles caulinaires et les bractées de l'épi, les bractées de l'épi et les glumes des épillets femelles de Zea Mays tunicuta, comme aussi entre ces dernières et les épillets femelles de toutes les autres formes de Maïs peuvent être ainsi établies.

Les panicules déformées de Zea Mays tunicata permettent de compléter la série. Elles présentent souvent, au lieu de graines véritables, les petits axes charnus, ramifiés à l'excès, décrits et figurés pour les épis latéraux femelles (page 12:). En ce cas les bractées qui entourent ces axes montrent toutes les transitions entre les glumes des épillets mâles et les bractées de l'épi(Pl.VI, fig. 64). Le développement fréquent de véritables épis munis de leurs bractées sur les panicules mâles rend l'analogie plus complète encore. Ainsi, les inflorescences anormales de Zea Mays tunicatu, la métamorphose partielle ou complète des bractées des épis en feuilles caulinaires permettent d'établir des séries continues de formes allant de la feuille de Maïs normal aux glumes cornées de l'épillet lemelle ou plurinerviées et pointues de l'épillet mâle. Tout ces organes, morphologiquement très diffẻrents, sont de même nature; ils ont la même origine et les mêmes facultés de développement, leur situation seule diffère et détermine leur forme.

MülLER (1858) a déjà signalé des exemples d'épillets dont les glumes et les glumelles sont analogues à celles des fleurs femelles, quoique les organes sexuels soient réduits à trois étamines fertiles. J'en ai trouvé aussi de nombreux exemples (Pl. V, fig. 58-59). Le plus remarquable a été fourni par un pied de Zea Mays.japonica provenant d'une graine récoltée, on 1904, sur une panicule déformée après mutilation. Tous les épillets ont des glumes de fleurs femelles, mais ne renferment que des étamines cachées dans les bractées de l'épí. Ne les ayants vus qu'à l'automne de 1905, je n'ai pu les utiliser pour la fécondation. En 1906, j'en ai récolté aussi un très bel échantillon dans le Maïs de Pensylvanie mutilé (Pl. VIII, fig. 105).

\section{b. - ÉPILletS herMAPHRODITES.}

Cet épi peut servir de transition entre les épis normaux et purement femelles et les épis dont tous les épillets sont bermaphro- 
dites que j'ai observés pour la première fois en 1904, à la récolte des lignées anormales du Mais prorenant de graines développées sur des panicules de plantes mutilées en 1902. J'en ai obtenu depuis des lots reproduisant l'anomalie chaque année (BLARIG GHEM, 1906 '). Rien ne permet, à l'examen des plantes en régétation, de reconnaitre les caractères très spéciaur qu'elles ne montrent qu'à la maturité. Après aroir enleré les bractées qui entourent l'épi, on est étonné d'apercevoir, entre les graines d'une jaune pâle, des appendices verdàtres plus ou moins déformés par la compression. A première vue, ces organes donnent l'illusion de gemmules résultant de la germination hative des graines. Toutefois, si l'on enlère avec soin la graine de l'alvéole oủ elle est enchâssée, on constate que ces org̣anes verdâtres, triangulaires et au nombre de trois sont fixés à la base de la graine par de grêles filets blanchâtres et qu'ils forment autour d'elle un verticille; ce sont des étamines déreloppées longtemps après la fécondation au moment de la maturation de l'épi. En examinant avec plus d'attention toutes les parties de l'épillet femelle qui, d'ordinaire, ne donne qu'une seule graine par' suite de l'arortement d'une fleur, on constate que cette petite fleur arortée est aussi hermaphrodite, renfermant entre ses glumes et glumelles réduites trois petites étamines portées sur de très courts filets et un ovaire central. Au point de rue morphologique, l'épillet femelle normal du Mais composé de deux fleurs, l'une femelle et fertile, l'autre femelle et arortẻe, est remplacé, dans ces inflorescences anormales, par un épillet à deux fleurs hermaphrodites (Pl. VIII, fig. 91-95).

On n'arrive que rarement à distinguer toutes les parties de l'épillet; le déreloppement précoce et exagéré de l'oraire qui donne la graine détermine l'avurtement partiel ou complet de l'autre Heur' et parfois aussi d'une ou plusieurs étamines du rerticille qui entoure la graine. La compression est bien le facteur qui entraîne la disparition partielle des organes. Pour le même épi, elle est plus complète dans la zone mojenne, qui est aussi celle de la densité maxima des épillets. Parmi les étamines qui entourent les graines, celle qui est placée sur la génératrice d'insertion des graines arorte fréquemment, celles qui se déreloppent de part et d'autre de la graine, entre les rangées, sont toujours présentes et bien déreloppées.

Au point de rue physiologique, ces étamines ne sont jamais fertiles. Elles ne renferment pas de pollen bien conformé; d'ailleurs, elles apparaissent toujours peu de temps avint la maturité du Maĩs, 
alors que les ovairès sont depuis longtemps fécondés; elles ne peuvent jouer aucun rôle, inême si, par la destruction précoce d'une partie des ovaires, on facilite leur croissance.

Ces fleurs hermaphrodites diffèrent complètement de celles qu'on olsserve parfois sur les panicules. Les anomalies sexuelles présentées par les grappes terminales consistent souvent en la métamorphose complète de l'épillet mâle en un épillet femelle. On trouve plus rarement des épillets dont l'aspect extérieur diffère de celui des épillets mâles normaux par la présence d'un ou de deux stigmates filiformes et poilus faisant saillie hors des glumes allongėes (PI. VIII, fig. 10I). Trois sortes de fleurs présentent ces caractères:

Aux fleurs mâles peuvent être substituées des fleurs femelles proprement dites composées de 2 glumelles, 2 glumellules et d'un ovaire central. Il est plus fréquent d'observer la métamophose d'une seule des deux fleurs, celle qui est insérée du côté de la glume la plus large ou externe; l'épillet se compose alors de deux fleurs de sexes différents, normales et fertiles.

Il arrive aussi, mais très rarement, de trouver des fleurs hermaphrodites. L'anomalie porte sur une seule fleur, la plus précoce qui présente 2 glumelles, 2 glumellules, 3 étamines entourant un petit ovaire central fertile ou non. Par exception, j’ai observé, sur des panicules, des fleurs hermaphrodites à 4 étamines.

\section{c. - MÉtamorPhose des glumellules en stigmates.}

L'anomalie la plus remarquable, qui n'a jamais été signalée à ma connaissance dans toute la famille des Graminées, est la métamorphose particulière des glumellules des fleurs mâles, en organes épaissis, parallélipipédiques, terminés par de longs stigmates poilus (Pl. VIII, fig. 102-104).

J'ai isolé une race qui la présente régulièrement pạr hérédité depuis trois ans (Bharinghem, 1906 b). Naturellement ces stigmates n'ont aucun rôle physiologique puisqu'ils ne sont pas en relation avec un ovaire; ils sont comparables aux étamines tarlives et plus on moins avortées qui se développent entre les graines des épis femelles, décrits précédemment. 


\section{3. - Expériences de KLlebs sur le Sempervivum (1904).}

KLEBs, directeur du Jardin botanique de Halle, rient de publier plusieurs mémoires sur la métamorphose artificielle des formes régétales (1903-1906). Ses expériences sur les Algues et les Champignons ont muntré que des conditions de vie particulières permetlaient de prolonger ou de réduire le déreloppement régétatif des organismes inférieurs. Par la combinaison des agents physiques (chaleur, lumière, humidité) et des agents chimiques (milieux de culture), il a déterminé le déreloppement mycélien ou l'apparition des spores ou des œufs. Depuis 1903, Kílebs s'efforce de généraliser les lois observées sur les Algues et les Champignons et de les appliquer à la métamorphose expérimentale des régétaux supérieurs. Il a réussi à obtenir des rosettes feuillées sur les inflorescences de numbreuses espèces de Sempervivuin et de Teronica, sur la Betterave à sucre, Cochlearia officinalis. Ajuga repstuns, Lysimachia thyrsifolia, Rumex Acetosa.

Les résultats de ces recherches sont très probants; il n'est plas douteux qu'ils ne soient suiris de succès pour tous les végétaux le jour ou leurs modes particuliers de végétation et de croissance seront bien connus.

liLEBS cherche, comme il le dit dans ses conclusions (1905, p. 345), à déterminer les conditions complexes qui conduisent à la formation de rosettes ou de fleurs et permettent d'obtenir à volonté l'un ou l'autre mode de régétation; ces conditions seraient multiples. Guidé par cette idée théorique, il fait agir simultanément ou successivement les mutilations et les variations de température, d'éclairement, de nutrition et pousse l'analyse au point d'utiliser les lumières monochromatiques et des solutions nutritives où les proportions des sels sont variables. Il réussit ainsi à ébranler les caractéres de l'espéce, à faire apparaître des tendances latentes et à obtenir la métainorphose des organes.

Malheureusement, KLLES a presque toujours fait agir simultanément les mutilations grares et les conditions particulières de nutrition. Il est difficile de se rendre compte de ce qui doit être rapporté à l'un ou à l'autre de ces facteurs, comme il l'aroue luimême: «On est encore trop sous l'action des circonstances accidentelles et on ne peut prévoir, avec certitude, l'apparition des 
anomalies florales ». Autrement dit, les résultats obtenus par ḰLEBS n’ont, jusqu'ici, qu'une valeur docunentaire, ils ne sont point définitifs puisqu'il est encore impossible de préciser les conditions de réussite.

La difficulté gît dans le mélange volontaire de toutes les conditions connues pour agir sur la végétation et des mutilations faites à diffẻrentes époques, sans que soient signalés les caractères des plantes témoins. En outre, l'examen des faits porte sur quelques individus peu nombreux dont les caractères sont déjà ébranlés par des opérations antérieures. Aussi, aurais-je été très embarrassé pour interpréter ces expériences, si l'auteur n'avait signalé, en tête de ses tableaux descriptifs, la section des axes floraux dont l'importance n’est pas reconnue puisqu'elle est à peine indiquée dans le texte même du mémoire publiẻ en 1905.

L'étude détaillée des tableaux descriptifs des expériences m'a permis cependant de constater que, dans lous les cas où ḰLEBs a observé la métamorphose sexuelle des piéces florales du Sempeivivurı Funckii, toujours l'axe principal de la plante avait été enlevé ou atteint d'une mort précoce. Les anomalies se trouvent exclusivement sur les rejets, c'est-à-dire sur les fleurs néogènes, comme les désigne l'auteur dans son mémoire paru en septembre 1906.

Les observations que j'avais cru devoir laire au mois de février de la même année ont amené KLLEBs à reprendre l'étude des métamorphoses florales du Sempervivum. Il insiste sur ce fait que les fleurs archégènes, c'est-à-dire développées sur les axes d'inflorescences non mutilées, ne présentent que des variations légères rentrant dans le domaine des variations habituelles; les fleurs néogénes seules, développées après la suppression de l'axe principal, montrent de nombreuses irrégularités dans le nombre, les proportions et la disposition des pièces florales, comme aussi, des monstruosités véritables consistant en la métamorphose des carpelles en étamines et des étamines en carpelles. L'analogie, si frappante, que l'on peut trouver entre les anomalies du Maïs, celles du Carica Papaya et du Sempervivum montrent bien l'influence de la même cause, les traumatismes. KLeBs discute cette opinion dans la seconde partie de son mémoire (1906, p. 228). L'après lui, les mutilations et en particulier, la suppression de la pousse terminale ne seraient pas nécessaires pour provoquer les anomalies florales; elles réduiraient mème leur nombre lorsqu'elles sont faites avant l'allongement de 
l'axe d'inflorescence. Il tire ces conclusions de taits observés sur trois indiridus dont il a enlevẻ au 15 mai 1905 los points vézétatils: $32,5 \%$ des fleurs étaient anormales. alors que. dans d'autres cas où la section est faite plus tard, il en observe davantage. L'époque de la mutilation a done aussi une grande importance pour le déterminisme des anomalies du sempervicurit. comme elle en a une pour les mélamorphoses sexuelles du Mais et du Paparer. D'aillours. comment expliquer que hilebs ait fait usage de la section des inflorescences principales pour déterminer l'apparition des fleurs néogènes seules déformẻes. puisqu'il prétend que les mutilations réduisent le pourcentage des anomalies? Les nombreuses figures reproduites dans son mémoire sont d'ailleurs des documents en faveur de l'action des mutilations dont on observe les traces.

Il m'est donc permis d'interprẻter les expériences de híLBs comme une confirmation de l'efficacité des mutilations, pour déterminer expérimentalement les monstruosités florales.

\section{:̈. - Variation de lat sextalité aVec la vetritios.}

RELATIONS ENTRE L'ABONDANCE D'EAL ET LE SEXE FENELLE.

Les anomalies sexuelles de la panicule terminale du Yais sont produites à rolonté par la section de la tire principale et diverses autres mutilations; elles naissent aussi dans des circonstances différentes.

Lirnp (1879), dans différents essais de snlutions nutritives, utilisait le Mais. qui se dẻreloppe très bien sur ces solutions et peut être ainsi amené à la floraison. Il a obtenu dans ces conditions une anomalie de l'inflorescence. Les épis étaient mailes à la pointe, mais plus bas et sur le mème axe. se trourait une fleur femelle. hivup attribuait 'ette anomalie à la forme sous laquelle le soufre était fourni dans le mélanz̧ nourricier et annonçait son intention de laire à ce sujet de nourelles expériences dont je nai pas connaissance ( $\left.{ }^{1}\right)$. Plus récemment, Mazé et Perrier (1904) étaient conduits à prendre du Mais jaune à gros grains pour des recherches sur lassimilation de quelques substances ternaires. Ce lais, semé sur des solutions

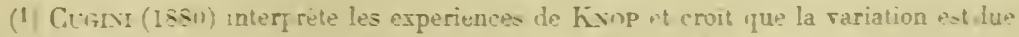
a une insutitisance do nourriture : plusieurs flantes develofpers este à mite et dan= un petit pot lui ont fourni une anomalie analogue. 
minérales additionnées de sucre, fournit des plantes chlorotiques. «Quelques-uns, disent-ils, ont végété ainsi pendant deux mois; la hampe qui s'édifie sur la tige, courte et grêle jusque là, augmente brusquement de diamètre. Au bout de quelques jours, on voit apparaître un épi simple, émergeant d'un bouquet de trois à quatre feuilles de grandeur moyenne, qui présente cette particularité l'être constitué par des fleurs mâles à l'extrémité el des fleur's femelles à la base ». Ces deux expériences montrent l'influence très nette des solutions nutritives pour la métamorphose sexuelle du Maïs. N'est-il pas possible de les rapprocher de celles que j'ai faites en employant la mutilation?

Dans un cours professé à la Sorbonne en 1898, Giard a exposé les multiples hypothèses proposées pour expliquer l'évolution sexuelle. La théorie qui répond le mieux aux faits consiste à admettre des modes différents de nutrition pour les organes mâles et pour les organes femelles. Les tissus des ovaires sont bourrés d'aliments de réserves qui ne seront utilisés qu'après la fécondation; les organes mâles sont grêles et en ètat d'épuisement. Ainsi un excès momentané de nutrition à l'époque de la différenciation sexuelle favorise la production du sexe femelle, la pénurie d'aliments entraîne comme conséquence l'apparition du sexe mâle. Plus tard (1902), à propos dè la fécondation artificielle réalisée par Loeb et Dei $a$ age, Giard ( ${ }^{1}$ ) est conduit à constater que nombre de faits relatifs à la Parthénogénèse expérimentale prouvent que l'ovule se développe, lorsque, par un procédé physique ou chimique, on a pu lui enlever une certaine quantité d'eau. Il en résulterait que l'élément femelle bourré de l'éserves est aussi gorgẹ d'eau, que l'élément mâle a pour premier effet, laus la fécondation, le le déshydrater par son contact puis par sa fusion et qu'ainsi, des phénomènes d'ordre purement physiques détermineraiunt le début de l'évolution de l'oul $\left.{ }^{2}{ }^{2}\right)$.

En admettant ces hypothèses, il est facile d'expliquer les métamorphoses sexuelles que j’ai pu provoquer expérimentalement dans les inflorescences terminales et latérales du Maïs. Les rameaux

(1) L'opinion exposée par le professeur Grakn, cn 1902 dans son cours à l'Université de l'aris, a été précisée depuis ((IIAR1), 1904).

(2) Pour se rendre comple des effets de laugmentation de l'eau dans les tissus on peut lire le travail de GaIN (1895) relatif au rôle de l'eau dans les conditions normales de végétation. 
chargés de fleurs femelles sont succulents et de consistance herbacée. Les pertes d'eau par dessication à l'éture des portions de panicules femelles sont dans la proportion de 6.5 à $\$ 2 \%$ du poids total, celles des portions mâles des mêmes panicules dans la proportion de 35 à $40 \%$. La section de la tige principale du Mais, qui supprime subitement tous les organes aériens sans endommager les racines, limite forcement l'évaporation par transpiration. tandis que l'absorption de la sève brute continue à se faire puisque un liquide abondant s"écoule pendant quelques jours par la blessure. Les grappes florales des rejets qui se déreloppent rapidement subissent l'influence de l'excès d'eau et montrent la métamorphose partielle ou totale des fleurs màles en fleurs femelles. Dans les expériences de Itazé et de Perrier. la mème anomalie est le résultat de la culture en solutions nutritives. Ces derniers ont lonruement insisté sur le développement anormal de lappareil radiculaire des plantes qui ont présenté les grappes florales à sexes mélangés.

Ainsi. l'affux de sève brute ou de solutions salines détermine la sexualité des bourgeons : plus tard seulement, lorsque les feuilles sont épanouies, lexcitation produite par les bourceons femelles détermine l'accumulation de réserres hỹdrocarbonées que la plante peut alors former en quantité suffisante. Toutefois, les réserves ne sont pas assez abondantes pour entrainer forcément le déreloppement des épis latéraux femelles. Les épis des rejets avortent souvent en totalité ou, silss se déreloppent, ils présentent des particularités morphologiques curieuses, comme la réluction en nombre des rangées, l'apparition de fleurs hermaphrodites ou màles, ou encore les ramifications exagérées à l’infini que montre le Zea .Mays tunicata. 


\section{MÉCANISME DE L'HÉRÉDITÉ DES ANOMALIES.}

\section{3̈. - LES ANOMALIES VÉGÉTALES DUES AUX TRAUMATISMES SONT DES GAS PARTICULIERS D'ADAPTATION BRUSQUE.}

Les anomalies de tiges, de feuilles et de fleurs, que j’ai examinées rapidement dans les chapitres précédents, sont de la mème nature. Elles apparaissent sur les mêmes individus et après la même modification apportée au développement les organes. Le rejet fascié présente à la fois les caractères de tige aplatie, succulente, dissociée et non ramifice, qui cléfinissent l'état de fasciation, les feuilles cohérentes, cupulées et lacinées, les grappes florales compactes et les épis multiples, les fleurs soudées et prolifères. Toutes ces anomalies sont étroitement liées entre elles, et il est plus difficile de les trouver isolćes que de les rencontrer groupées sur le même individu ( $\left.{ }^{1}\right)$.

Elles montrent les mèmes caractères. La multiplication des bourgeons, sur les fascies, correspond à la ramification excessive des nervures des feuilles, des bractées et des pièces florales; la réduction des bourgeons, sur les ramilles, entraîne l'avortement partiel des fenilles, des bractées, de tout ou d'une partie des organes de la fleur. A la condensation extrême des bourgeons qui caractérise les rejets el les grappes fasciées, correspond la multiplication des nervures des feuilles simples, l'augmention du nombre des folioles des feuilles 'omposées, la duplicature des fleurs, la prolifération des axes. Il est possible de comparer les feuilles tubulées aux fascies annulaires, d'identifier les irrégularités de nombre des pièces florales aux folioles surnuméraires des feuilles des Légumineuses, la ramification des folioles à celle des pétales des fleurs doubles. Tous ces phénomènes sont l'expression d'une seule et même réaction à la variation de nutrition que provoque le traumatisme.

(1) Lissbauer, I. et K. (1900) ont insisté sur la réunion de nombreuses anomalies régelatives et florales sur une même souche de Chèvrefeuille (Lonicera tartarica). 
La mutilation ag̣it arec une grande intensité parce quelle est riolente. A un ensemble compleze d'organes aériens, la section transtersale de la tige substitue quelques bourgeons adrentifs à peine esquissés qui éroluent très rapidement et fournissent des dériations multiples aux caractères de l'espèce on meurent et entrainent la mort de la souche qui les porte. On peut dire que les rejets sont des organes adaptés á la rariation brusque de nutrition que provoque le traumatisme ( $\left.{ }^{(}\right)$.

Les lois de l'Adaptation au milieu ont été établies pour les formes végétales d'abord par l'accumulation d'exemples de particularités morphologiques que montrent tous les indiridus soumis aux mèmes facteurs de rariation. De mème que les plantes, appartenant aux familles les plus diverses, réagissent à l'influence des conditions physiques et chimiques réalisées sur le bord de la mer par la réduction de la transpiration, par l'enroulement ou l'épaissisement des organes, ou encore, par la rapidité de déreloppement des fleurs qui entraine la précocité, de mème, les plantes les plus variées donnent après la mutilation les anomalies de croissance. de bourgeonnement, de ramification qui accompagnent les fascies ou les ramilles.

Les lois de l'adaptation au milieu ont été vérifiées par l'étude anatomique des tissus. Aux variations de formes correspondent des variations de structure dont les caractères sont dordinaire assez précis pour que lon puise prévoir la forme des cellules d"un organe placé dans des conditions bien définies. si l'on suit le développement des parties, on est mème conduit ả regarder les modifications extẻrieures des tiges et des feuilles dues aux conditions de milieu comme la conséquence des rariations internes qui les précedent et les accompagnent.

Il en est de mème pour les monstruosités végétales proroquées par des traumatismes. Les derviations iusolites des tiges, feuilles et Heurs sont la conséquence directe des anomalies de structure, de ramification et de disposition relative des faisceaux rasculaires qui constituent la charpente sur laquelle sont édifiés les organes.

1 Reine (1904) dit que les formes normales des plantes sont des adaptations aur cunditions normales de rie des plantes. Mais, si les conditions d'un dévelofpement normal sont compensées dans leurs etets pardes actions estérieures, alors, il se produit une déformation qui est comme la caricature de la plante normale ,p. 9S). 
ら6. - Variation DE Structure, DE NOMBre E'T DE DISPOSITION DES FAISGEAUX VASGULAIRES DES REJETS.

Le fait que les mutilations modifient la texture des vaisseaux du bois est établi par de nombreux travaux. Hugo dE VRies a signalé (1876 et 1891 "1) la fragmentation des cellules ligneuses développées après la section locale des tissus. Les vaisseaux sont constitués par des cellules courtes résultant du fractionnement en 2, 3 ou 4 parties des cellules primitives. Il en résulte une forme cubique au lieu d'une forme allongée. Les ouvrages de Franci (1895), Sorauer (1886), Hartig (1900) donnent de nombreux exemples des modifications ligneuses dues aux blessures, et décrites sous les noms de Maser-

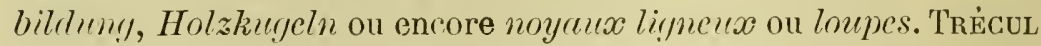
(1853), dans une étule du développement ies loupes et des broussins, insiste sur les anomalies de disposition des vaisseaux qui entrainent les vallonnements et les rugosités des arbres et il en figure de très curieuses. Il suffit de feuilleter la troisième édition du livre de HARTIG pour voir les multiples variations de formes des couches ligneuses et se rendre compte de l'efficacité des mutilations pour la déviation voulue et régularisée des faisceaux du bois. L’ouvrage de Sorauer permet de suivre sur les planches VII-XII les multiples associations de cellules longues et courles, étirées, tordues qui correspondent à toutes les anomalies provoquées par des tailles trop violentes faites en pleine période de végétation. Enfin Grifros (1897) a donné quelques exemples de l'indiffèrenciation des tissus développés sur des souches ayant subi une gelée printanière.

Si les mutilations sont la cause indiscutée des variations anatomiques descrites ci-dessus, il est logique de reconnaître à ce facteur la propriété de fournir des fascies, des torsions, des feuilles soudées ou cupulées etc., car, ces dernières anomalies sont la conséquence immédiate de variations anatomiques des tissus jeunes analogues à celles que l'on observe sur les loupes et les broussins ( ${ }^{1}$ ).

(1) Kövessı (1901) a insisté, à plusieurs reprises, sur l'influence de l'époque de la taille pour l'aon̂tement des rameaux de la vigne et a montré la relation de la différenciation ligneuse des tissus avec l'afflux de l'eau. Laurent (1905) a émis des considérations qui mo somblent très justes sur ces phénomènes, mais qu'il importe de vérifier avec rigueur. 
Nestler (1894) a étudié avec soin la structure anatomique des fascies. Il a reconnu la substitution de crêtes, soit linẻaires pour les fascies proprement dites, soit circulaires pour les fascies annulaires. de jeunes cellules qui se substituent aux cellules initiales des tiges et des rameaux. En suivant la méthode adoptée par cet auteur, on est forcé d'admettre les conclusions, déjà énoncées, que les fascies résultent, non pas de la suture de jeunes organes qui restent cohèrents pendant une période plus on moins longue. mais bien, d'une absence d'indiridualisation des cellules ou massifs de cellules en bourgeons indépendants. La fascie résulte d'un retard dans la dissociation des parties, et elle se traduit par des irrégularités nombreuses dans la course des faisceaux libero-ligneux.

Les mèmes conclusions doirent ètre adoptées pour l'explication des anomalies de feuilles. Tout récemment FigDoR (1906) déterminait la division en fourche du limbe de feuilles de Sculopendivium Scolopend,ium par la section d'une très petite portion de la pointe en roie de croissance (1). Evidemment la nerration irrégulière traduit la disjonction en deux massifs principaux des faisceaus qui constituent normalement la nerrure principale. L'étude anatomique détaillée que LíerN a fait des monstruosités de fenilles trourées sur les rejets des régétaux les plus rariés montre aussi la multiplicité des variations de structure que provoque la mutilation violente (189:). Elles sont identiques à celles que l'on peut observer dans la structure des pétioles des feuilles cupulées, comme il résulte des coupes faites, soit dans les folioles surnuméraires, soit dans les petiolules d'Ascidies que Hochreutiver (1897) a observées sur une plante de Trifolinin repens. anormale, et Gir.Lot et Maнev (1005) sur des: Saxifrages.

Pour compléter ce travail sur les déviations insolites aux 'aractères les plus stables proroquées par des mutilations, il serait done utile de suirre pas à pas les modifications anatomiques des rejets, des feuilles et des fleurs déreloppées après la mutilation. Jaai réuni un bon nombre le stades de ramification anormale, de bifurcation inattendues, de transitions entre les portions fasciées et les portions simples des mêmes rameaux de diffẻrentes inflorescences anormales du Maïs. Je remets leur description à un mémoire ultérieur. Pour le moment, il me suffit d'établir la continuité rigoureuse qui existe entre les

(1) GúkBhard, A. (1895) arait déjà signalé ce fait discuté par GAbelul (1896). 
rameaux fasciés ou tordus, les feuilles cohérentes ou cupulées, les fleurs à pièces multiples, continuité qui se manifeste aussi nettement par l'examen extérieur des anomalies, les saillies visibles sur les fascies et les torsions, les nervures visibles sur les feuilles, les bractées et les différents organes de la fleur.

\section{7. - Continuité des anomalies De tiges, de Feuilles,} DE FLEURS ET DES GRAINES DES REJETS.

Un exemple, ehoisi parmi beaucoup d'autres tout aussi nets, montrera l'importance des relations qui unissent les anomalies végétatives et florales d'un même bourgeon. L'Érable faux-Platane (Acer pseudo Platunus) est un arbre fréquemment planté dans les bois des environs de Paris, ou dans les jardins. A Meudon, on pent faire chaque année une abondante récolte de tiges fasciées, de feuilles 'ohérentes, d'ascidies et autres anomalies végétatives sur les rejets de première année qui se déreloppent immédiatement après la coupe des trones; elles sont beaucoup moins fréquentes sur les tiges de seeonde année et très rares lorsqu'on examine des plantes non mutilées depuis longtemps.

l'étude comparée d'Érables non taillés et d'Érables soumis chaque année à un élagage très important conduit aux mêmes observations. Les pousses à feuilles verticillées par trois, les fascies et les torsions sont fréquentes sur ces derniers, alors qu'elles sont nulles sur les arbres laissés à leur libre développement. Nais la variation peut être suivie sur ces plantes jusque sur les grappes florales et les fleurs (Pl. II, fig. 30).

J'ai fait cueillir sur l'une et l'autre catégorie d'arbres vivant dans les mèmes conditions (jardins de l'Ecole normale supérieure, à Paris) plus de mille grappes florales qui ont été l'objet d'un examen minutieux. Les sutures de pédoncules floraux, de fleurs, sont trouvées exclusivement sur les arbres taillés chaque année. L'étude des carpelles, faite sur un nombre considérable de lots, est la plus coneluante. Voici

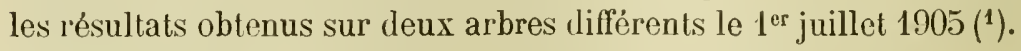

(1) L'étude de différents arbres a donné lieu a des observations sur des variations individuelles très curieuses qui seront l'objet d'une mémoire spécial. 
Acer pseudo-Plátenus taillé chaque année en forme de candélabre. Age approximatif: 60 ans.

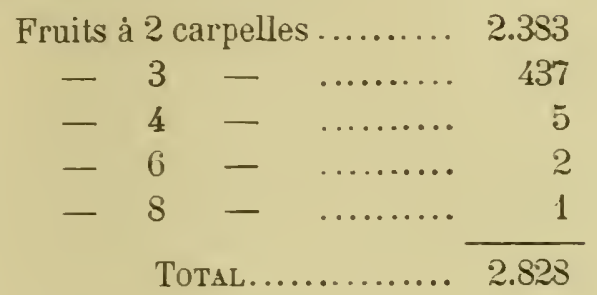

Acer psezerlo-Platanus non taillé. Age approximatif: 40 ans.

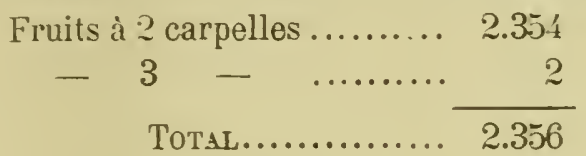

Sur ces arbres, j'ai fait récolter deux cents fruits à maturité et j'ai fait l'épreure de la proportion des plantules tricotylées, par des semis en serre, durant l'hirer de l'année suivante. Les résultats obtenus ont été :

\begin{tabular}{cccccc} 
& Plantules & \multicolumn{3}{c}{ Nombre de plantes à : } \\
& levées & 1 & 2 & 3 & 4 cotylédons. \\
Arbre taillé........... & 151 & 1 & 143 & 8 & 2 \\
Arbre non taillé...... & 161 & 0 & 160 & 1 & 0
\end{tabular}

Enfin, j'ai pu observer par la dissection des carpelles, soit de fruits a deux ailes, soit de fruits a trois carpelles et davantage, que les embryons tricotylés correspondent aux grappes florales les plus modifiées en ce qui concerne la suture des rameaux de la grappe, la compacité des grappes de fleurs et la variation des pièces florales.

ว̈8. - MÉcanisMe yoRphologique et anatomique DE L'HÉRÉDITÉ DES ANOMALIES.

De l'ensemble de ces faits, il résulte que l'on peut suivre la continuité des anomalies de tiges, de feuilles, de bractées et de piéces florales soit par le seul examen de la disposition des bourgeons et des nervures, soit par la distribution plus ou moins régulière des faisceaus rasculaires, soit enfin par la dissection fine des parties 
constituant l'ovaire. On met ainsi en évidence les relations qui unissent les plantules tricotylées aux fascies qui leur ont donné naissance et la transmission héréditaire du caractère déterminé par la mutilation.

De même que l'évolution d'un jeune rejet à feuilles éparses en une tige fasciée ou tordue résulte de l'excès de nutrition momentané que l'on peut provoquer, soit par des cultures sur des milieux nutritifs appropriés, soit par des tailles ou des ébourgeonnements, soit par l'emploi simultané des deux méthodes, de même on obtient un pourcentage de plantules tricotylées plus élevé, dans la descendance d'un individu fascié, si l'on dispose des moyens qui permettent de provoquer un afflux de nutrition à l'époque de la différenciation des pièces florales, surtout des, carpelles. 11 n'est pas plus difficile de réaliser la tricotylie des graines, qui ne sont qu'une portion de la feuille carpellaire, que de léterminer la ramification en trois parties d'une nervure de feuille se bifurquant d'ordinaire en deux nervures secondaires. Les embryons monocotylés présentent la suture de leurs feuilles cotylédonaires et les embryons qui donnent des plantules en cornet (Choux, Radis) montrent la déviation en ascidies des feuilles primitives.

Les anomalies de plantules sont plus rares que les anomalies de bourgeon, non pas parce qu'elles diffèrent au point de vue morphologique, mais parce qu'il est difficile d'obtenir la maturation des fruits surnourris, et surtout parce que la périodle de repos végétatif est souvent fatale aux organes anormaux. De même que la plupart des rejets fasciés périssent pendant l'hiver qui suit leur production, de même, les graines tricotylées résistent mal à la dessiccation qui précède leur germination.

Naturellement les conclusions présentées ici ont encore un caractère hypothétique. Les liaisons qui unissent les diffẻrents organes d'un même végétal sont mal connues, mais les observations faites sur les plantes les plus variées et dans la culture d'un grand nombre d'anomalies permettent de concevoir par quelles méthodes il est possible de suivre la naissance el l'hérédité de formes végétales nouvelles. 


\section{CONCLUSIONS DE LA DEUXIEME PARTIE.}

Les mutilations violentes modifient les formes des végétaux les plus divers. Elles agissent sur les Graminées, les Ombellifères, les Composées, les Papilionacées, les Crucifères, les Crassulacées, etc... et les anomalies sont d'autant plus nettes que les caractères des familles qui les subissent sont mieux définis. Les Cryptogames n'échappent pas plus que les Phanérogames à leur action. Le phẻnoméne est général. On le retroure lans les cas d'Héléromorplrose [Loes (1891)] provoquée sur les animaux sans vertẻbres; la polydactylie des Batraciens, observée par Giand (1895) sur le Plempoleles: IT ultlii après la mutilation d'une patte antérieure, n'est qu'un exemple particulier de la mème loi.

Les effets des mutilations sont aussi nombreux que variés. Tous les types d'anomalies régétales, fascies et torsions des axes, suture et dédoublement des feuilles, ascidies, hypertrophie ou avortement des bractées, multiplication ou réduction en nombre des pièces florales, duplicature des fleurs, métamorphose des étamines et des carpelles, polrembryonie des graines, plantules à cotylédons multiples, sont une conséquence directe des traumatismes violents.

Pour établir ces résultats d'une manière définitive, il est nécessaire de reprendre sur de nombreuses formes végétales les diverses opérations qui ont été faites sur le Maïs. Ces dernières seules ont la valeur d'expériences, puisqu'il est possible, par des procédés définis, de provoquer des effrets déterminés et prévus. Le travail qui reste à aceomplir est considérable. Il importe, tout d'abord, de bien connaitre les modes particuliers de végétation des plantes en expérience, de pouroir en cultiver un grand nombre, puis, de découvrir la mutilation la plus violente qu'elles puissent supporter sans mourir, enfin, de fixer l'époque favorable à la mutilation. 1)ans ces conditions, le succès est certain. Les essais que je poursuis depuis 191)' sur un grand nombre de formes cultivées, principalement sur l'Orge et l'Avoine, me donnent la preuve de la généralité des lois établies avec rigueur, pour les anomalies de la panicule d'une variété de Maïs, dans la première partie de ce Mémoire. 


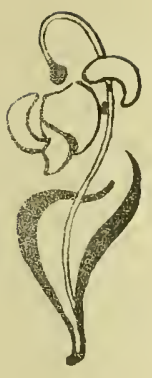




\section{HÉRÉDITÉ DES ANOMALIES PROVOQUÉES PAR DES MUTILATIONS.}

CHAPITRE XIV.

CULTURE ET HĖRĖDITÉ DES ANOMALIES DE LA PANICULE DU MAÏS.

59. - Avantages eT INCONVÉNients dFS PLANTES CUlTIVÉES. VICINISME.

L'étude des caractères héréditaires nécessite la culture des espéces, qu'elles soient saurages ou cultivées. La culture des espèces sauvages est sourent délicate, parfois impossible à réaliser; si l'on prend comme point de départ une plante saurage, il est évident qu'il faudra l'isoler, la semer et la suivre dans des terrains appropriés, la soumettre à toutes les pratiques désignées sous le nom de culture. Il est probable que, dans ces conditions, les plantes dites sauvages parce qu'elles ont eu des ancètı'es récents dérelopués dans la libre nature, seront beaucoup plus variables que celles qui sont soumises au mème traiteuent depuis des milliers d'années. Je plus, le choix de plantes cultivées présente un avantage considérable pour la démonstration des lois de l'Évolution des formes. La culture de lignées variables pendant de nombreuses générations, et sur un nombre d'individus aussi important que possible, est pour cela indisjensable. Les plantes cultivées, en particulier les céréales, permettent de rẻaliser les "xpériences sans grands frais el mème avec profit. Si les nourelles variétés obtenues présentent des arantages sur les formes d'origine, la grande culture s'empare bientôt de la nouveauté 
et en fait le contrôle sur une échelle qu'on ne pourrait réaliser avec un matériel n'ayant qu'un intérèt purement scientifique. Il s'aỹit évidemment ici de formes dont l'usage nécessite le contròle constant de la pureté $\left({ }^{1}\right)$. La stabilité de ces formes est alors bien mieux lémontrẻe que eelle des plantes sauvages elles-mêmes. Hugo ve VRies déclare (Species and Varieties) que le succès des observations sur l'origine des nouvelles espèces sera atteint plus facilement si l'on choisit les plantes développées spontanément de préférence à celles qui sont l'objet d'une culture attentive. Les chances de réussite sont moindres avec le matériel qui a été étudié et suivi par l'horticulteur et le sẻlectionneur pendant de nombreuses années.

Mais l'emploi des plantes cultivées nécessite quelques précautions. Il faut éviter de confondre les variations brusques ou anomalies, héréditaires en tolalité ou en partie, avec les variations dues au Vicinisme, si fréquentes parmi les plantes cultivées. Pendant longtemps, cette cause d'erreur a été méconnue ainsi que le prouve l'un des exemples les plus caractéristiques invoqué il y a un demisiècle par Darwin (1868), en faveur de l'évolution gracluelle des formes. Metzane (1811) rapporte qu'ayant introduit en Allemagne une variété américaine de Maïs, il en obtint, au bout de quelques années, une forme identique par tous ses caractères à la variété indigène la plus répandue. On a expliqué cette métamorphose par l'influence du climat, du sol, des conditions de culture. Il est bien certain aujourd'hui, d'après les indications laissées par METzGER, qu'il n'y a pas eu dans ce cas transformation d'une variété en une autre mais simplement substitution. La variété américaine ne mûrissait pas ses graines dans la région; seules quelques fleurs femelles, fécondées par le pollen de la variété indigène cultivée dans le voisinage, donnaient des graines pouvant être utilisées pour les semis ultérieurs. Les métis ainsi obtenus ne tardèrent pas à montrer la dissociation des caraclères et bientôt, par l'élimination des plantes ne mûrissant pas leurs graines, METzGer obtint la variété indigène complètement pure.

Des faits de cette nature ont donné naissance à des opinions qui ne sont nullement fondées sur l'instabilité des caractères des variétés de Maïs.

Des savants de haute valeur ont contribué à les répandre. Il est

(1) Toir Blaringhem. La Notion d'espèce (Revue des Idées, 15 mai 1905). 
pénible de voir dans le livre très estimé de KícrNicke et WERNER, Hamlbuch des Getreidebures (1885), d'une part, l'exposition très détaillée de la fréquence de la fécondation croisée entre les direrses variétés de Mais et de la disjonction ultérieure des caractères, d’autre part, la classification des variétés de Maïs connues d'après les caractères mèmes qui rendent cette disjonction apparente $\left({ }^{1}\right)$. Le mal est d'autant plus considérable que la classification de K̋́ksicke est encore adoptée par la plupart des établissements scientifiques et par les jardins bolaniques chargés de distribuer les échantillons de graines nécessaires aux recherches de Biologie régétale.

Avant de décrire les diverses formes apparues dans mes cultures à la suite de mutilations, il importe de faire connaitre en détail les caractères de la variétẻ de Maïs qui ma servi de matériel d'expérience et les moyens de contrôle que j'ai employés pour m'assurer de sa stabilité.

\section{0. - Classification Somarare des espéces ÉlÉMentaires}

\section{Du Maïs.}

Tournefort (1700) avait adopté le nom Mays pour le genre particulier de Graminées où les fleurs, à sexes séparés, étaient disposées sur des inflorescences spéciales. Livxé (1753) adopta le noin d'espèce Zea Mays; Gartrer, en 17S8, l'appelait encore Mays Zea. Depuis, la désignation de Liswé a prévalu. Pour la plupart des auteurs, le genre Zea ne renferme qu'une espèce, mais on sait (voir H. DE Vries Die. Mutationstheorie, vol. I) que les divisions en espèces linnéennes sont purement systématiques et ne répondent nullement aux faits.

Alefeld, Serivge (1818) puis Bonafous (1836), Metzger (1841), KerNiche (1885) et beaucoup d'autres () ont donné la description 'd'un grand nombre de variètés nées dans la culture ou introduites de l'Amérique ou de l'Extrème-Orient. Leurs descriptions sont en général imparfaites; il est difficile d'en tirer parti pour un essai vraiment scientifique de classification.

(1) La variété Zea . Jays rulgaris leucodiasacchara KiønNicke (loc. cit., Bd. 1, p. 363) est définie par la présence sur le mème épi de grains sucrés et de grains amylacés, caractère montrant la Jénie du Maïs et manifestementinstable.

(2) HARshbERGER (1893) donne une bibliographie très importante des espèces du Mais. 
La culture pédigrée permet d'isoler un certain nombre d'espèces élémentaires dans l'espèce linnéenne Zea Mays. Les caractères des graines paraissent les meilleurs caractères spécifiques. Quoique mes recherches dans ce domaine soient encore incomplètes, je propose la classification suivante :

\section{Espèces de Maïs définies par lues Caractéres des Grains.}

$1^{0}$ Zeà Mays tunicuta Larranhaga ou Maïs à grain tuniqué, que les glumes foliacées et allongées enveloppent étroitement.

$2^{0}$ Zea Mays macrosperma KL. renfermant les Maïs à très gros grains connus dans le commerce sous le nom de Cuzco. Originaire du Pérou, il ne vient pas à maturité en Europe.

$3^{0}$ Zeu Mays dentiformis KCKE, dont le grain est allongé et étroit, à fossette terminale sur le bord de laquelle on peut voir la base desséchée du style. Par sa forme, il rappelle la « dent de cheval », nom sous lequel on le désigne habituellement. Körnicise y fait rentrer le Maìs géant Caragua.

$4^{0}$ Zeu Muys vulyuris Kcke ou Maïs orlinaire, à grain plus ou moins aplati par la compression et à pointe arrondie. Il faut placer, dans cette catégorie, les nombreuses variétés cultivées à grains jaunes, blanes, rouges, bleus ou bruns, ou striés de rouge, et aussi, les formes de Nlais dites à graines sucrées (variétés succhuratu de Kö̈riclie) dont les nombreuses rugosités ne sonl dues qu'à la dessiccation d'un albumen corné (elles ne présentent aucune particularité saillante en dehor's de ce caractère de variété proprement dite).

$5^{0}$ Zeu Muys acuminutu KCliE ou Maïs a grains de taille moyenne et pointus. Le style, desséché, est porté sur un bec très saillant. Les variélé rostralu Bonafous, ucuminutu KGKe, Perle, etc.. rentrent dans, cette catégorie. On les désigne sous le nom de Maïs à bec.

$6^{0}$ Zen Muys microsperma Kícke ou Naïs à petits grains pointus et très serrès comme le $Z$. M. oryzoüdes. D'après líörnicise, il faudrait y joindre le Z. M. xumthornis licke, le Z. M. yracillima Kcike et beaucoup d'autres formes intermédiaires entre cette catégorie et les séries 4 el 5 . Il n'est pas possible de discuter ici cette upinion.

Cette esquisse de classification est naturellement incompléte. Il fiut la considérer comme un simple essai. Durant les trois années 
de culture des nombreuses variétés citées pages i6-is. portant sur près de cent individus de chaque forme, je n'ai point nbservis de rariation de ces caractères ni récolté d’ẻpis portant des mélanges de grains de l'une ou l'autre forme. Beancoup de ces groupes ne so croisent pas entre eux. Toutefois, le Zen. Mreys turimicrte donne des métis arec un assez grand nombre de variétés à graines nues.

\section{1. - Caracteres du Maïs de Pensyluane.}

Le Maîs ordinaire, à çrains jannes, cultivé dans le Nord de la France jnur le fourrage vert, appartient à l'espéce élémentaire $Z$. Ways: cullyuis. Il y murit trés difficilement ses graines bien que certains auriculteur réussissent à conserver chaque année de la semence en quantité suffisante pour les plantations ultérieures. Le plus souvent, les semences sont achetées dans la régrion des Charentes (France).

liaprés les descriptions et les planches si belles de linsafucs (1-36), ce Mais se rapproche du Zen. Mayss perisylumiru de ce

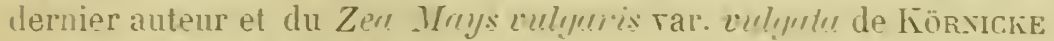
et Werser (15-5, p. 37:). Ciest la forme la plus cultivée en Enrope; elle a naturellement donné naissance à un grand nombre de variétés quiil est inutile de dẻcrire iei. Je préfềre donner les résultats les nombreuses mesures et observations qui m'ont permis de préciser les caractéres de la Variété qui m'a sẹrvi de matériel d'expérimentation.

Au premier rang, riennent la compaciti des yrappes floivles et la remsite des ipillets sur les inmemur et les épis lntéroux.

Les panicules sont plus ou moins denses. Les chiffres donnés par l'examen de 100 panicules récoltées sur les plantes témoins de 1903, 1904, 1905 et 1906, sont concordants.

\section{NOMBRE}

CoMPacité dEs PANicules

$\begin{array}{lllrrrrrrrrrrr}\begin{array}{c}\text { de panicules } \\ \text { en }\end{array} & 5 & 6 & 7 & 8 & 9 & 10 & 11 & 12 & 13 & 14 & 15 & 16 & 17 \\ 1903 \ldots \ldots & & & 1 & \& & 17 & 16 & 25 & 18 & 12 & 1 & 2 & & \\ 1904 \ldots \ldots & 2 & 0 & 3 & 11 & 19 & 20 & 18 & 7 & 10 & 7 & 3 & & \\ 1915 \ldots \ldots & 1 & 2 & 1 & 7 & 11 & 23 & 14 & 17 & 8 & 5 & 6 & 5 & \\ 1906 \ldots \ldots & & 3 & 10 & 15 & 14 & 21 & 17 & 7 & 5 & 5 & 3 & & \end{array}$


La densité des épillets des rameaux donne des résultats analogues:

Densité dU RAMEAU INFÉRIeUr des 100 PANIGULES:

Nombre

de rameaux

en

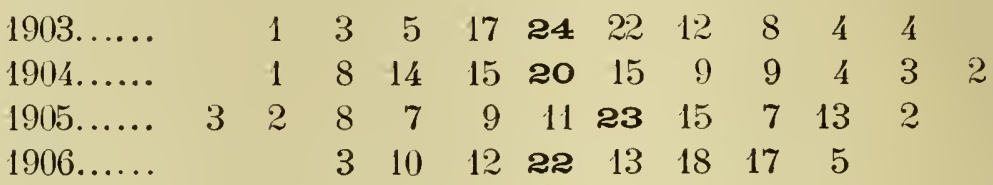

La densité des épis est particulièrement intéressante parce qu'elle traduit la compression plus ou moins forte des graines dont la forme ronde ou aplatie est caractéristique.

\begin{tabular}{|c|c|c|c|c|c|c|c|c|c|c|c|c|}
\hline \multirow[b]{2}{*}{$\begin{array}{l}\text { Nombre } \\
\text { d'épis } \\
\text { en }\end{array}$} & \multicolumn{12}{|c|}{ DENSITÉ DES ÉPIS } \\
\hline & 14 & 15 & 16 & 17 & 18 & 19 & 20 & 21 & 22 & 23 & 24 & 25 \\
\hline 1903. & 1 & 3 & 7 & 16 & 11 & 22 & 19 & 13 & 6 & 1 & 1 & 1 \\
\hline 1904. & 2 & 2 & 5 & 10 & 17 & 16 & 18 & 15 & 9 & 4 & 2 & \\
\hline 1905. & 0 & 2 & 6 & 12 & 13 & 19 & 32 & 11 & 4 & 1 & 0 & \\
\hline $1906 \ldots$ & 0 & 3 & 2 & 8 & 9 & 12 & 23 & 15 & 14 & 8 & 4 & 2 \\
\hline
\end{tabular}

L'importance de cette méthode d'analyse des caractères des variétés apparaîtra plus nettement encore si l'on observe que les caractères de grappes florales sont en relation avec le nombre des bractées d'enveloppe des épis et des feuilles des tiges.

Les nombres des bractées des épis d'ordre 1 ont été étudiés pour 100 plantes témoins en 1903, 1904, 1905 et 1906 :

$\begin{array}{lrrrrrrrrrrr}\begin{array}{l}\text { Nombre } \\ \text { d’épis }\end{array} & 6 & 7 & 8 & \mathbf{9} & \mathbf{1 0} & 11 & 12 & 13 & 14 & 15 & 16 \\ \text { en } & & & & & & 14 & & \\ 1903 \ldots \ldots & & 3 & 14 & 21 & \mathbf{3 2} & 13 & 8 & 6 & 3 & & \\ 1904 \ldots \ldots & 1 & 7 & 18 & \mathbf{2 9} & 20 & 14 & 5 & 3 & 1 & 2 & \\ 1905 \ldots \ldots & & 2 & 13 & 19 & \mathbf{2 8} & 19 & 9 & \mathbf{4} & 2 & 3 & 1 \\ 1906 \ldots \ldots & 2 & 8 & 21 & \mathbf{2 4} & 17 & 11 & 7 & 8 & 2 & & \end{array}$


De mème les feuilles caulinaires:

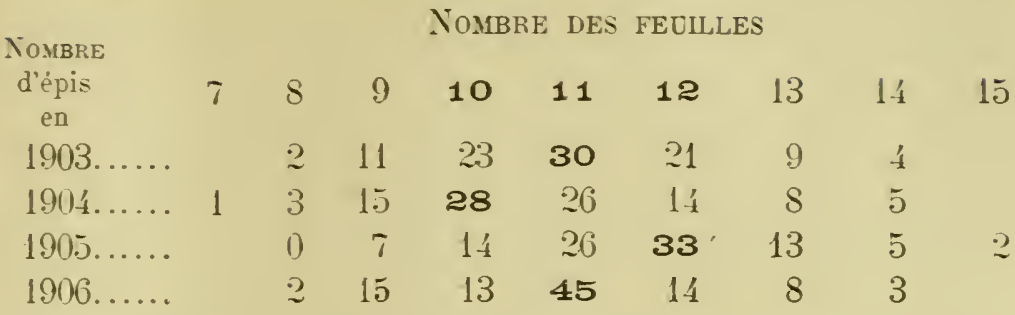

Les nombres de rangées de graines des épis out aussi leur importance.

NoMbre

de plantes

en

$1903 \ldots \ldots \ldots \ldots$
$1904 \ldots \ldots \ldots \ldots$
$1905 \ldots \ldots \ldots \ldots$
$1906 \ldots \ldots \ldots \ldots$
Noybre DE RANGEES DE GRAINES

46

8

10

12 TUTAL

\section{7}

84

7

2

100

$9 \quad 86$

2

681

8

100

371

2.2

15

\section{2}

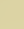

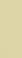

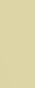

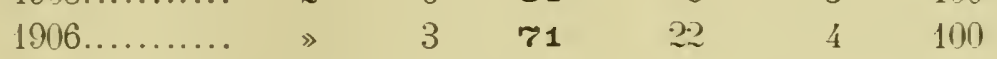

Les variations extrèmes de tous ces caractères apparaissent sourent sur les mèmes plantes. C'est ainsi que les tiges rigoureuses el épaisses (ce ne sont pas toujours les plus hautes) ont un nombre élevé de feuilles et de bractées, 12 rangées de graines aux épis et des panicules à rameaux nombreux et serrés.

L'analyse de ces séries de nombres, et mieux encore des séries de rapports de nombres dont on a établi auparavant le parallélisme, permet de déterminer descaractéristiques pour la plupart des formes du groupe Zea .Mays vulyaris L. telles que, Zea. Mays crythrolepis Boxafous, Zea Mays japonica liche, Zea. Mays vulgate Kiche. On se rend compte ainsi que ces formes sont parfaitement définies et stables et correspondent aux véritables espèces élémentaires ou espèces jordaniennes découvertes parmi les plantes sauvages.

Les caracte̊res de coloration sont d'ordre secondaire quoique plus saillants. Il existe dans le Zea Mays vulgaris des variétés à grains jaunes, blancs, ronges ou bleus, amỵlacés ou sucrés dont le mode de végétation ef la disposition relative des organes correspondent complétement à ceux de la variété de Mais à grains jaunes décrits précédemment. Au point de vue phylogénétique, les caractéres de coloration se forment après la métamorphose complète de l'espèce 
élémentaire. Je le montrerai plus loin à propos des espèces et variétés donl j'ai provoquẻ et suivi la naissance (Zeu .Mays praceox var. alba).

\section{6\%. - Gulture des Anomalies de la paniGule.}

La grande analogie existant entre les déformations sexuelles dı Maïs, accompagnées de la fasciation des portions de grappes couvertes d'ipillets femclles, et les monstruosités hóréditaires décrites par Hute de VRIEs (1892-1894) me conduisirent à faire des essais de culture de graines provenant de plantes anormales.

1.e succès rapide des expériences du professeur hollandais résulte to la découverte de caractères particuliers des jeunes plantules. Ia présence de trois cotylédlons ou de cotylẻdons soudés et fourchus est l'indice d'une anomalie grave dans l'organisation le la plante; la culture appropriẻe de ces individus conduit à l'obtention presque assurée de plantes fasciées ou torlues. Il m'était difficile d'opérer suivant la même méthode, le Maïs ne montrant qu'un seul cotylédon l'ailleurs peu développé. La culture des graines récoltées sur les panicules anormales devait être modifiée pour cette raison.

I es caractères particuliers des plantules de Maïs qui donneront les pieds déformés ne se reconnaissent qu'assez tard, lorsque les trois ou quatre premières feuilles sont visibles; leur détermination est encore bien incertaine, même à ce moment. Les jeunes plantes anormales paraissent tout d'abord moins vigoureuses, leur développement est plus lent et leurs fenilles s'étalent au lieu de rester emboîtées comme celles des plantules normales. Le limbe des jeunes leuilles est, en général, plus large mais moins allongé; ces caractères sont surtout accusés sur la première feuille développée après la rupture de la gaîne tubulée qui renferme la gemmule à la germination. Ce sont toutefois des caracteres mal définis, trop imprécis pour qu'on puisse établir un pourcentage hérérlituire d'après la seule culture des graines dans des cuvettes de germination. Cette mise à l'épreuve, qui a donné de si beaux résultats à DE VRIEs, n'a pu être utilisér pour l'étude du Maïs, car cette plante supporte mal la transplantation et le repiquage. Sans doute, on peut obtenir des reprises nombreuses, mais les individus souffrent beancoup de ces opérations qui mołlifient sensiblement leur croissance. I e repiquage, malgré tous les soins qu'on y apporte, détermine toujours des muti- 
lations de racines et dp fouilles, peut-être mème de tị̂es ; ces raisons multiples m interlirent de pratiquer ce mode de culture. Jai donc planté les graines à demeure afin que les essais fussent complets et considérés comme définitifs. Il en est résulté plusieurs inconvénients. Depuis quelques années, aussi bien dans le Nord de la France que dans les environs de Paris. les hivers ne sout pas assez rigoureux pour détruire les Vers. les Mrriapodes et les lartes des Insectes qui nuisent aus semis. ILes cultures, au printemps de 1903, ont eu beaucoup à souffrir de leurs ravages et. toutes les fois qu'il má été possible d'obtenir dans la suite des graines en nombre suffisant. jai pris la précaution de les planter sur des lignes écartées de 3 n centimètres et à des intervalles de 10 centimètres. Plus tard, aprés la lerée, jai supprimé une plantule sur deux, de laçon à ramener los intervalles des plantes à 31$) \times$ ?h centimètres, intervalles adoptés dans tous mes essais. Cette précaution n’a pas toujours sulfi pour me donner des cultures régulières. Les graines récoltées sur les panicules sont souvent plus petites que celles qui se déreloppent sur les êpis: les pluies qui surviennent après les semailles peurent, ou les entrainar à une profondeur dẻpassant $S$ et 10 centimètres, ou les mettre à nu: ce sont des semences perdues. Enfin, certaines ne germent pas: d'autres donnent des plantules complétement dépourmes de hlorophylle qui ne tardent pas à périr.

L'exposé des cultures doit par conséquent comprendre le nombre de graines plantées et colui des plantes déreloppées, afin le faire connaitre les circonstances particulières pourant avoir elı une influence sur le poureentage des anomalies.

La culture pédigrée, par l'isolement des ilescendants d'un seul indiridu ou d'un couple unique, est absolument indispensable pour l'étude des caraclères héréditaires. Par toute autre méthode. on risque d'enlever toute raleur scientifique aux résultats des expériences qui sont d'ailleurs d'autant plus probants qu'lls portent sur un nombre plus consillérable de plantes. Il faut done désigner par un nom ou un numéro d'ordre les porte-graines, origine des différentes lignées, et le: choisir de telle sorte que les fruits obtenus soient nombreux et bien conformés. Il importe aussi de réserrer toujours une bonne part des graines, souvent la moitié, pour les cultures ultérienre: de contròle qui permettent d'alfirmer le mode d'apparition d'une particularité obserrée accidentellement et surtont de reconnaitre les caractères qui sont en corrélation avec elle. 
Les premières cultures penvent être désignées sous le nom de Cultures d'Observation; elles permettent de reconnaître et de comparer toutes les particularités de végétation et de formes, qui distinguent les plantes mises à l'épreuve des plantes normales témoins. Tous les résultats doivent être indiqués sur un cahier ou Stammbook des cultures. - La véritable expérience consiste à refaire une fois, deux fois s'il est possible, l'épreuve de la même plante dans des Cultures dites de Cortrôle. Les qualitẻs héréditaires des individus mis à l'essai apparaissent ainsi avec netteté ; les cireonstances particulières qui accompagnent le développement de l'anomalie, lont l'étude est souvent plus importante que celle des monstruosités mêmes, sont ainsi reconnues dans le détail. Il me paraît impossible d'attribuer une valeur quelconque à certains essais dans lesquels cas précautions sont négligées. C'est une des raisons importantes pour lesquellesje n'ai publié les résultats de mes expérienees qu'après des cultures de eontròle répétées deux et trois fois.

Grâce à ces précautions, j'ai pu obtenir un matériel abondant et sùr de formes nouvelles et stables, que j'ai remis au Muséum d'Histoire naturelle de Paris afin de le répandre et d'en permettre le contrôle. Mes expériences ne sont pas encore complètement terminées et je me propose de faire pénétrer dans le domaine public toutes les Variètés et Espèces élémentaires qui naîtront dans les cultures ultérieures.

\section{3. - Hérédité des Anomalies de la panicule.}

Dès 1903, j'ai pu reconnaître la transmission partielle par voie de semis, des anomalies sexuelles de la panicule terminale du Mlais. Les grappes florales choisies, au nombre de trois, étaient des panicules du type $\mathrm{B}$, récoltées dans la parcelle de Maïs dont le propriétaire avait coupé les tiges vers la fin de juillet 190? (Blaringhem, 1902). Elles ont été désignées par les numéros $\mathrm{H}_{1}, \mathrm{H}_{2}, \mathrm{H}_{3}$.

$\mathrm{H}_{1}$. - Grappe terininale du type $B$ portée sur une tige de 13 décimètres. L'axe présente 6 rangées de graines fécondées; trois ramifications latérales, dont les points d'insertion sont très rapprochés et presque disposées en un verticille, portent 2 et 4 rangées de graines bien développées. A u total, la grappe offre 60 graines saines; quelques-unes étaient mangées par des insectes. 
$\mathrm{H}_{2}$. - Grappe terminale du type $B$ sur une tige 10 décimètres. L'ase central grêle porte un petit nombre de graines à son extrémité: les quatre ramifications latérales, bien déreloppées et assez écartées (compacité 36), ont 4 rangées de graines, avortées vers la pointe. Le nombre des graines saines est de 114 .

$\mathrm{H}_{3}$. - Grappe terminale du type $B$ sur une tige de 7 décimètres. L'ase central à $\&$ rangées porte de nombreuses graines: l'unique ramean latéral a 4 angles. Au total, 191 graines saines récoltées.

Les cultures de ces graines ont été faites dans le jardin potager de l'école communale de Locon (Pas-de-Calais) qui offrait par son entourage, bâtiments et haies. et par son écartement de toute autre parcelle cultivée en Mais (plus de 500 mètres), des garanties sérieuses contre la fécondation étrangère. Les semailles ont eu lieu le 15 mai 1903. dans un sol arģileux, mal préparé et fortement détrempé par des pluies abondantes d'avril suivies d'un temps sec continu. La levée en a beaucoup sonffert. 60 graines de chaque inflorescence ont été plantées en lignes, distantes de 30 centimètres et renfermant chacune $: 0$ graines écartées de 20 centimètres. Le tableau ci-contre (page 156) donne le relevé des anomalies.

Les proportions des anomalies de panicule sont considérables et rendent évidente l'hérédité de l'anomalie proroquée par la section transwersale des tiges de Mais. Sur 28 pieds, 20 présentent des panicules déformées, soit plus de 70 pour 100. Les grapnes florales à métamorphose partielle ou complète des épillets màles en épillets femelles sont au nombre de 41 , soit plus de la moitié de toutes les panicules observées sur le lot.

Des trois panicules déformées, utiliséps comme porte-graines en 1903, $\mathrm{H}_{1}$ présente au plus haut degré la transmission de l'anomalie. Les deux autres, cultivées dans les mèmes conditions, ont donné les résultats moins accentués, mais néanmoins probants, qu"il est inutile de décrire en détail.

La transmission des caractères anormaux. l'hérédité, est seule en cause dans ces résultats et non les conditions particulières de régétation qui n'ont joué qu'un ròle secondaire. On peut en donner la preure. en comparant les résultats obtenus dans les cultures des graines des mèmes panicules anormales, en 1903. à Locon et en 1904, à Chaville (Seine), dans un terrain approprié à la culture de l'Orge et n'ayant pas reçu de fumure. 


\section{TALLEAU XXI.}

HÉREDITÉ DES ANOMALIES DE LA PANIGULE H (1903).

60 graines plantées;

37 plantules levées dont 5 dépourvues de chlorophylle.

Etude de Contrôle le 30 août:

28 plantes vivantes lont 20 anormales.

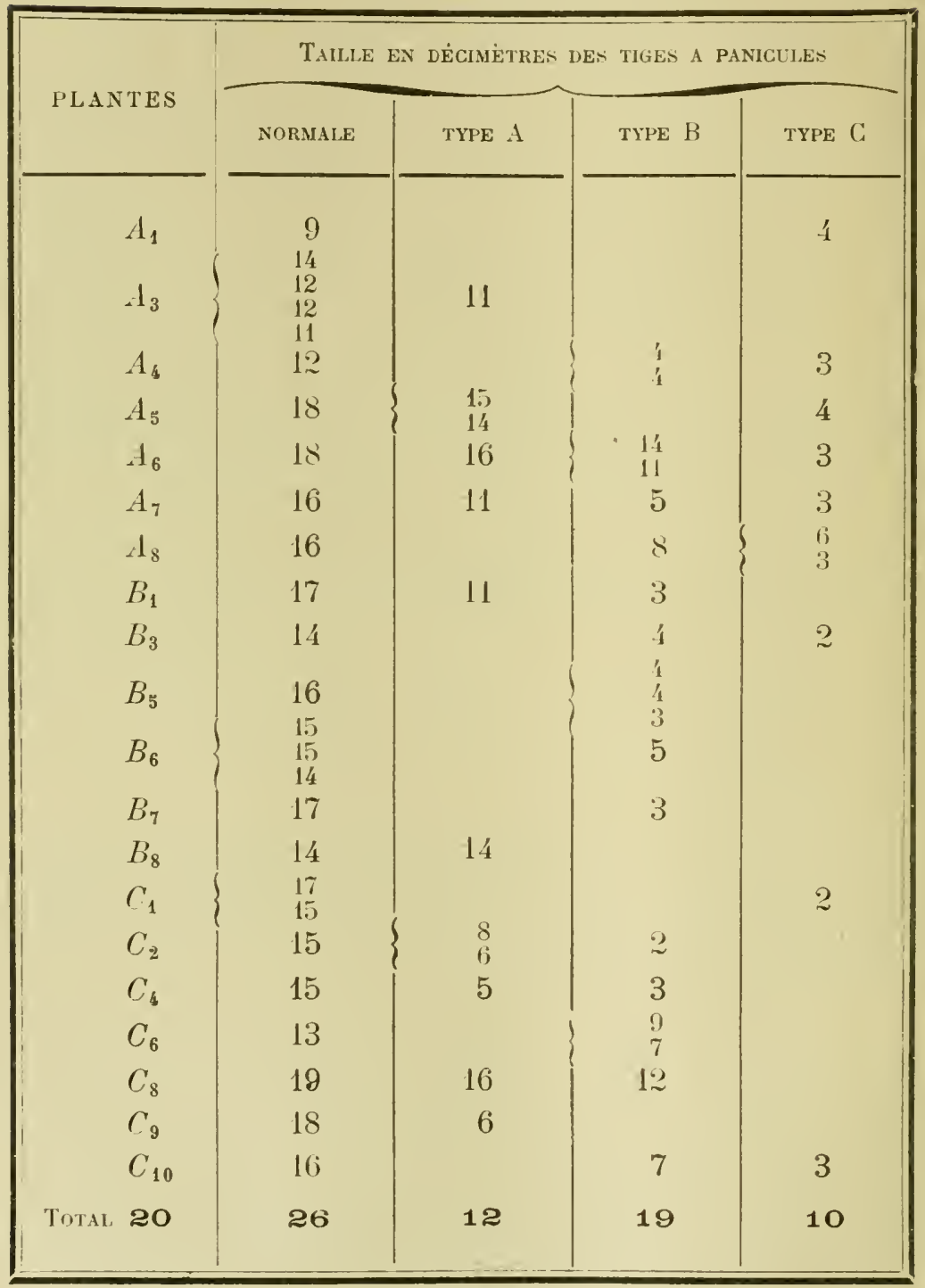


HÉRÉdTÉ DE L'ANOMALIE DE LA PANTCCLE Hב
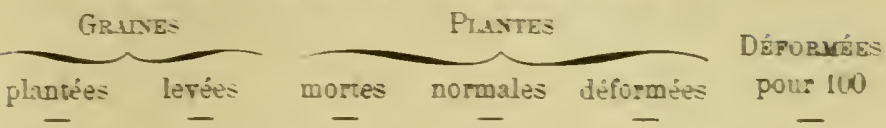

$\begin{array}{lllllll}1903 \ldots & 60 & 42 & 8 & 18 & 16 & 47 \\ 1904 \ldots & 40 & 33 & 7 & 14 & 12 & 43,5\end{array}$

HÉRÉdTÉ DE L'AYOMALE DE LA PATCCLLE $\mathrm{H}_{3}$.
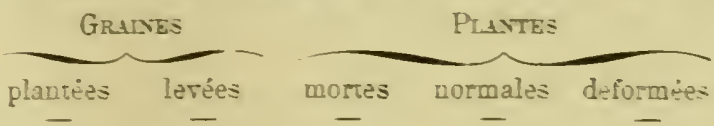

DÉFURMEES pour 100

$\begin{array}{rrrrrrr}1903 . . . & \text { (5) } & 4 i & 9 & 25 & 13 & 31 \\ 1974 . . . & 6 ! & 5 ? & 13 & 22 & 17 & 13.5\end{array}$

Ces tableaux montrent que, dans chaque liznée. la mortalite des jeunes plantules. suit par suite le leur albinisme complet, soit pour d'autres cauves, evt en relation arec le pourcentage plu- élevé des anomalies récoltées sur les panicules. Ces remarques sont dordre général. Plus lis jeunes plantules présentent de variation dans leur croissance. leur forme un leur couleur, plus grand sera le nombre des anomalies de toutes natures, aprés leur déreloppement complet.

L'héridité des anmalies de la panicule de Maīs a été déją l'ubjet

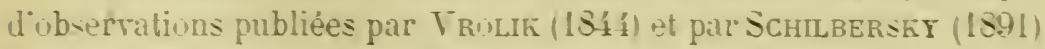
dont je nai au connaissance que tout ricemment.

\section{6\%. - Citltures des PORTE-GRaines ET CUltures DE} CONTRÒLE.

La culture des limées tératologiques en vue de lobtention de race- nourelles très délicatr. Les anomalies sont découvertes au milieu des plantes normalns et les rraines quiplles fournissent sont le plu - wurent de nature hrbrilor $\left({ }^{1}\right)$. Pour ivoler arec sủreté toutes les forme- nouvelles. il impurte de suirre les lignéps purm nn cultur pédigrẻe. Les hrbrides ne sp dissocient le plus surent qu à la secunde renération mais dés rette époque wa obtient des races complètement tisées.

1) L'1)rgo est un matériel trés commode pour letude de lhénedité a cause de l'autofácondation constante de la plupart des furnes. Mes recherches fartes sar ces plantrs conñrment les faits ubservés sur le Maïs. 
La méthode s'applique difficilement au Maïs. Quelques auteurs (Mac Cluers, Früwirth, 1903) déclarent que le Maïs est stérile par la stricte autolécondation. Corress, dans son remarquable Mémoire sur la Xénie (1903), ne semble pas admettre cette opinion et mes expériences montrent que cette loi n'est pas vérifiée pour toutes les variétés de Maïs. Toutefois, dans la crainte de perdre les lignées rendues tératologiques par des mutilations, je n’ai pas tenté de faire l'autofẻcondation sur les plus intéressantes de mes cultures; j'ai toujours eu recours à la fécondation croisée entre des individus issus d'une même famille.

L'origine d'une famille est une plante mutilée, qui donne plusieurs inflorescences normales ou déformées fournissant des lots plus ou moins considérables de graines. J'ai toujours cultivé séparément les l'ruits récoltés sur des rejets distincts d'une même plante et aussi ceux des épis latéraux et des panicules anormales d'une même tige. Il en résulte qu'un même individu a pu fournir plusicurs lots de semences désignées par les lettres grecques $\alpha, \beta, \gamma, \delta \ldots$

Les cultures poursuivies depuis 1904 ont été livisées en deux séries parallèles, l'une destinée à l'obtention des porte-grraines, l'autre à la détermination du pourcentage héréditaire.

La culture des porte-graines a été faite à Locon (Pas-de-Calais) sur un sol bien préparé et suffisamment fumé. Je dispoșais de plusieurs enclos et jardins potagers écartés de toute plantation de Maïs et isolés par des habitations et des lıaies. Dans le même enclos, je ne semais que les graines issues d'une même lamille ; les diflẻrents lots de semences, récoltés à l'origine sur le même individu anormal et plus tard sur les descendants de cet invilu, étaient séparés par des plates-bandes de Chanvre ou par de larges parcelles de plantes potagères. De cette façon j'ai limité dans la mesure du possible les mélanges de lignées à évolution distincte.

La détermination du pourcentage hèréditaire fut faite dans les champs d'essais de la Société d'Encouragement à la culture des Orges de Brasserie, en 1904 à Chaville (Seine-et-Oise), en 1905 et 1906 à Bourg-la-Reine (Seine). Le sol, choisi pour la culture de l'Orge, n'a pas reçu de fumure spéciale. Les plantes de Maïs y furent donc peu nourries. Les nombreux lots de 50 à 100 plantes que j'y ai cultivés étaient séparés par des parcelles d'Orge, d'Avoine, de Chanvre ou de Sorgho à balai. Malgré cette précaution, il y eut toujours des mélanges dus à la fécondation croisée par le vent, car, en certaines 
années, jai eu plus de 200 parcelles de Maĩs disséminées sur moins de 5!) ares de termain. Aussi je n’ai utilisé qu’exceptionnellement les graines récoltées dans ces champs et aprés avoir rẻalisẻ l'autufécondation.

Il m'était impossible de faire l'autolécondation pour toutes les lignées. Le choix des plantes anormales ne peut aroir lieu quau moment de la récolte, d'après le nombre de graines saines portẻes par les inflorescences et le pourcentage héréditaire observé sur le lot. J'ai done dù me limiter, sauf indications contraires, à l'isolement des lamilles pour la production des graines des semences. V'ailleurs, jai tou jours cultivé, à Locon comme à Chaville et à Bourgla-Reine. un grand nombre de plantes témoins sur lesquelles je na ai observé qu'un très petit nombre de variations. Les plantes qui ont servi de point de départ à mes expériences n'ont présenté dans leur descendance aucun caraclére de xénie ni d'hybridation. Les variations héréditaires dont il va ètre question doirent donc ètre attribuées aux metilution: qui ont fourni les indivilus anormaux.

J'ai isolé des Varietés instubles dont les caractéres noureaux sont des monstruosités, comme la fascie des rameaux de la panicule et des épis latéraux, la torsion des tiges, la suture des bords des feuilles, la métamorphose des fleur's màles en fleurs femelles ou celle des fleurs femelles en Hleurs màles etc. Les anomalies obtenues dans la descendance sont trés variables en intensité et les pourcentages héréditaires sont à un haut degré fonction des conditions particulières de nutrition. La sélection des porte-graines est d'ailleurs limitée aux cas morens car la torsion des tiges ou la suture des bords des feuilles déreloppées à leur maximum entrainent la stẻrilité complète des individus. Les rariétés instables correspondent donc exactement aux eversporting Varieties définies récemment par Hugo de VRIEs (Species and Vurieties, p. 309).

Il est sourent difficile de reconnaitre la part de l'hrbridation initiale et celle de l'instabilité de la race. La nature hybride d'une des rariétés nourelles obtenues en 1903 m'est apparue arec netteté dans une forme de liais à ģraines de couleur acajou. Les phénomènes de disjonction obserrés depuis sa naissance sont caractéristiques.

Enfin, j'ai obtenu des Variẻtés nourelles et stables, soit par élimination graduelle du sang étranger, soit par fixation immédiate de caractères noureaux pour la famille origine. Elles seront l'objet d'une étude détaillẻe. 


\section{VARIÉTÉS INSTABLES OU « EVERSPORTING ».}

\section{3. - Définition des variétés instablees.}

Hugo de VRIEs a récemment introduit (Species and Varieties), dans le domaine des sciences biologiques, une notion nouvelle et pleine d'intérêt. Cette notion consiste en la découverte, dans la nature de variétés toujours instables dont le principal caractère est l'apparition et la disparition inattendues, sur des proportions variables de descendants, des particularités qui définissent la race. Grâce à cette conception, il est possible d'appliquer à l'étude des lignées tératologiques connues parmi les végétaux, les diverses méthorles d'analyse en usage pour l'étude des variétés et des races proprement dites. Le pourcentage des indivilus aberrants est regardé comme un caractère variable, dont on peul, comme pour le degrẻ de l'anomalie, étudier les conditions favorables ou défavorables de développement, la transmission dans les croisements, etc.....

Les monstruosités appartiennent le plus souvent à ces variétés «eversporting ». La découverte de la transmissibilité partielle des caractères anormaux par voie de semis a conduit DE VRIEs à élargir la conception admise à l'heure actuelle sous le nom de Caractère spécifique. Les caractères d'espèces, de races, de variétés renferment tout ce qui se transmet par hérédité et en particulier la faculté de donner des anomalies. Hugo de Vries tire ainsi parti d'une notion restée dans le seul domaine de la théorie quoique acquise depuis longtemps. Moquin-T'andon l'annonçait en 1841, en ces termes. «Les anomalies sont des modifications particulières qui peuvent étre ramenées à des principes communs, simples et précis, lesquels ne sont eux-mêmes que des corollaires des lois les plus générales de l'organisation ». (Éléments de tératologie vérjétule, p. 19).

Si la qualité de donner certaines monstruosités peut être regardée comme un caractère spécifique d'une lignée, on peut imaginer des races définies par l'association de plusieurs de ces qualités évoluant 
indépendamment les unes des autres. Autrement dit, s'il faut considérer comme l'expression d'une même qualité la présence simultanée de la fascie des rameaux et de fleurs femelles dans la panicule du Mais parce que ces caractères sont en corrélation étroite, on doit se garder de réunir sous le même titre la métamorphose des épillets mâles des panicules et l'apparition des fleurs hermaphrodiles dans les épis. Parfois, la même plante offre la réunion de ces caractères anormaux; ils sont le plus souvent dispersés sur des individus diffẻrents; ce sont done des caractères distincts, quoique parfois associés sur la même lignée.

Parmi les plantes récoltées en 1903 pour servir de point de départ de races nourelles, il m'est arrivé sourent de faire choix des indiridus offirant à la fois la métamorphose partielle de la panicule et d'autres anomalies comme celles de feuilles tubulées ou à nerrures dissociées. Dans les cultures ultérieures, l'un des caractères a pu s'accentuer, l'autre tendre à disparaître. Les diverses lignées doirent donc être étudiées à plusieurs points de rue, ce qui rend très difficile l'exposé des rẻsultats. Malgr'é mes efforts, je n'ai pu isoler aucune forme qui ne diffẻre des plantes témoins que par un seul caractère instable ou stable. Toujours, diverses anomalies réapparaissent dans la descendance, plus ou moins accentuées, plus ou moins nombreuses. Aussi, dans l'exposé qui va suivre, ne faut-il pas s'étonner de trourer la description de particularités qui, plus ou moins réduites pendant une ou deux générations, sont réapparues plus tard. On donne sourent le nom d'atavistes aux indiridus qui présentent ainsi des caractéres déjà observés sur leurs ascendants. Mieux raut, sans doute, ne pas employer ce terme qui n'explique rien, et considérer le caractère comme instable et peu accentué.

\section{6. - Famille I.}

La section de la tige principale d'un pied de Maïs, faite à la fin du mois de juillet 1902, a proroqué le déreloppement d'un rejet terminé par une inflorescence du type $B$ à trois ramifications et portant 60 graines saines.

Les cultures de 1903, dans un terrain isolé de toute plantation de Mais, ont montré l'hérédité du caractére anormal de la panicule, fascie des rameaux et métamorphose des fleurs mâles en fleur's femelles, qui a été transmis à $71,5 \%$ des descendants (tableau XXI, p. 156). 
Ces derniers sont l'origine de lignées à tendances diverses qui peuvent être désignées sous les titres:

a. - Variétés instables fasciées.

b. - Variétés instables tordues.

c. - Variétés instables à feuilles tubulées.

1. - Variétés instables albines.

e. - Variétés instables à feuillage rouge.

Dans la même famille jaai isolé des variẻtés stables et complètement fixées que je décrirai plus loin sous les noms :

f. - Zea Mays var. pseudo-androgyna.

\%. - Zea Mays var. semi-praecox.

et une espéce élémentaire véritable, le Zea Mays praecox ('), qui a donné depuis 1903, date de son apparition, une Variẻté is grains blancs fixée elle aussi.

\section{a. - VARIÉTÉs instables fasciées.}

La plus intéressante dérive de l'individu $A_{6}$ des cultures de 1903. Il présentait, sans qu'aucune trace de mutilation accidentelle ait pu être remarquée sur lui :

Une tige normale de $1^{\mathrm{m}}, 78$ portant deux épis latéraux femelles renfermant ensemble plus de 250 graines (lot $\alpha$ ).

Une tige de $\mathrm{I}^{\mathrm{m}}, 60$ a panicule terminale du type A portant 23 graines saines (lot $\beta$ ).

Une tige de $\mathrm{I}^{\mathrm{m}}, 38$ à panicule terminale du type $\mathrm{B}$ dont l'axe central transformé en épi à 8 rangées de graines et les 5 rameaux latéraux portaient ensemble 110 graines saines (lot $\gamma$ ).

Une tige de $1^{\mathrm{m}}, 07$ à panicule terminale du type $\mathrm{B}$ composée d'un axe et de 2 rameaux portant environ 180 graines (lot $\delta$ ).

Un bourgeon de $0^{\mathrm{m}}, 28$ à graines à peine mùres et non conservées.

La culture des descendants de cet individu a donné:

(1) La désignation Zea Mays prapcox a été adoptée pour mettre en évidence la nature des différences qui la distinguent des autres formes conıues de Maïs; on a désigné sous les noms Zea May.s var. semi-praecox, Zea .IIays var. pseudo-androgyna les formes nouvelles peu différentes, par l'ensemble de leurs caractères, du Mü̈s de Pensylranie auxquel elles se rattachent. 


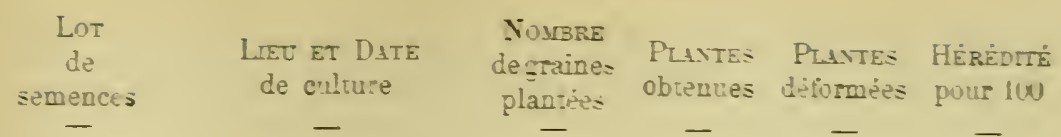

Q Génération.

\begin{tabular}{|c|c|c|c|c|c|}
\hline \multirow{3}{*}{ 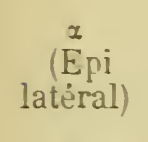 } & Locon. 0i......... & 25 & 21 & 3 & 14 \\
\hline & Chaville. 04....... & 100 & 87 & 7 & s \\
\hline & Bourg-la-Reine. 15 & 100 & 75 & 12 & 16 \\
\hline \multirow{4}{*}{$\begin{array}{c}\beta \\
\text { (type }-1) \\
\gamma \\
\text { (type } B)\end{array}$} & Locon. $04 .$. & 21) & 15 & 4 & 22 \\
\hline & Locon. $04 . . . . . . .$. & -21) & 17 & 7 & $\$ 1$ \\
\hline & Chaville. 1)i....... & 40 & 36 & 11 & 31 \\
\hline & Bourg-la-Reine. 10.j & 4i) & $2: 3$ & II) & 11 \\
\hline \multirow{4}{*}{ (type B) } & Locon. 04 ......... & $21)$ & $16^{2}$ & $\Xi$ & ओ) \\
\hline & Chaville. $04 . . . . .$. & S1) & il & 25 & 35 \\
\hline & Bourg-la-Reine. 05 & 50 & 41 & 19 & $40^{3}$ \\
\hline & $3^{e} G$ & & & & \\
\hline \multirow[t]{2}{*}{ (type B) } & Locon. $05 \ldots . . . .$. & 25 & 23 & 7 & 30,5 \\
\hline & Buurg-la-Reine. 05 & $10 i)$ & $\$ 9$ & 24 & 27 \\
\hline \multirow[t]{2}{*}{ (tıpe C) } & Locon. $05 . . . . . .$. & 25 & 21 & $s$ & 33 \\
\hline & Bourg-la-Reine. 0.5 & 100 & 74 & 17 & 23 \\
\hline
\end{tabular}

\section{$4^{e}$ Générution.}

\begin{tabular}{|c|c|c|c|c|}
\hline (type B) & Locon. $06 . . . . . .$. & 25 & 22 & 5 \\
\hline & Bourg-la-Reine. 06 & 100 & 91 & 10 \\
\hline (trpe C) & Locon. $1 \times 0 . . . . .$. & $\partial=$ & 23 & 6 \\
\hline & Bour-la-Reine. 166 & 10 ? & 9.5 & 18 \\
\hline
\end{tabular}

2. Générntion (1904 et 1005).

Les graines du pied $A_{6}$ furent plantées en partie à Locon et à Charille en 1914, en partie à Bourg-la-Reine, en 1915. La transmision du caractère de fasciation des rameaus et de métamorphose des fleurs màles en fieurs femelles a été variable pour les differents lots et comprise entre $\&$ et 5$)$ pour lixi. Le poumentage le moins élevé est fourni par les plantes issues de graines récoltées sur les épis latéraus (lot $x$ ), le pourentage le plus éleré par les graines du trpe B portẻes par laxe le plus court (lot $\delta$ ) et par conséquent développées le plus tard. Les cunditions particulières de régétation influent sensiblement sur le nombre de plantes anormales. Les 
cultures faites à Locon en 1904 dans un terrain potager bien fumé donnent les meilleurs résultats; l'humidité, plus forte en 1904 qu'en 1905 , permet aussi de croire à une action favorable au développement de la fascie.

\section{$3^{e}$ Génération (1905).}

Les cultures de 1905 ont porté sur des descendants à panicuie anomale du type $\mathrm{B}$ et du type $\mathrm{C}$ dérivés du lot $\delta$ et récoltées à Locon dans l'automne 1904. La tendance à la fascie des rameaux diminue; elle est traduite par des pourcentages de plantes déformées compris entre 23 et 38 .

\section{$4^{\circ}$ Génération (1906).}

Malgré le choix comme porte-graines des plus belles inflorescences du type B récoltées en 1905 á Locon, les proportions de plantes déformées diminuent chaque année. Elles sont comprises entre 11 et 26 pour 100. L'impossibilité de réaliser l'autofécondation peut avoir joué un rôle considérable dans l'atténuation des caractères nouveaux apparus après la mutilation. D'autre part le développement de l'anomalie exige des conditions de forte fumure du sol, cle chaleur et d'humidité qu'il est impossible de réaliser dans les champs de grande culture. Hugo DE VRIEs a insisté longuement sur l'influence de la bonne nutrition pour l'obtention des belles fascies (1899 $a$ ) ou des capsules multiples de la variété Pupaver somiferum polycephalum $(1899 b)$ qui montrent la métamorphose des étamines en carpelles. Le maintien partiel de l'anomalie de la panicule du Maïs dans des conditions défavorables n'en est que plus probant.

\section{b. - VARIÉté a Panicules tordues.}

En 1904, j'ai isolé dans la descendance du même pied $A_{6}$, unc plante provenant du lot de graines $\delta$ (type B) dont la tige principale, terminée par une panicule normale, portait trois feuilles bractées insérées côte ä côte à 7 centimètres au-dessus du rameau inférieur de la panicule. Cette plante est l'origine d'une lignée qui a présentẻ en 190 j et en 1906, en plus de panicules couvertes de fleurs femelles, des tiges coudées ou tordues. La torsion est localisée aux deux ou trois nœuds supérieurs de la tige et les feuilles qui s'y développent ont leurs gaînes enroulées les unes dans les autres ou sont réduites à des bractées linéaires dressées (PI. IIl, fig. 31-36). 
Lépi latéral femelle récolté en 1904, appartenant à la deuxième génération, a donné:

\section{LIEC ET DATE de culture}

$3^{e}$ Génération. Locon. 05.......... Bourg-la-Reine. 15

$4^{e}$ Génération. Locon. 06......... Bourg-la-Reine. 60

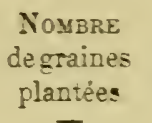

Plavies
obtenues

Plavtes HÉRÉnTĹ tordues pour 100

$\begin{array}{rrrr}- & - & - & - \\ 25 & 23 & 10 & 43 \\ 100 & 91 & 54 & 67 \\ 25 & 24 & 7 & 29 \\ 60 & 52 & 17 & 31\end{array}$

Lanomalie s'est donc atténuée en 1906 pour lensemble des descendants, mais elles'est déreloppée sur plusieurs d'entre eux. En particulier j'eu ai récolté deus pour lesquels la torsion était très accusée sur toute la longuear de la tige (fig. 36); malheureusement je n'ai pu en obtenir des graines. Leur dérelo ipement très lent a entrainé l'arortement complet des épis femelles dont les stigmate: étaient à peine saillants au début du mois d'octobre.

\section{c. - TARIÉTE 1 FECILLES TLBCLĖES.}

Les graines du lot $\varphi$, récoltées sur le rejet du trpe B de la plante $A_{6}$ (1903), sont l'origine d'une rariété instable ả feuilles tubulées. Les bords des gaines de feuilles, libres jusqu'à la base dans le Mais normal, sont soudés sur toute leur longueur et, dans les cas extrèmes, la suture se prolonge jusque sur la moitié et même les deux tiers du limbe (Pl. IT', fig. 41-45).

La feuille supérieure du rejet B présentait, en 1903, une gaine tubulée très nette. Arant la récolte j'ai dù à plusieurs reprises percer arec une aiguille la base de la feuille pour permettre l'écoulement de l'eau retenue dans le tube. Les descendants du lot de graines y ont donné :

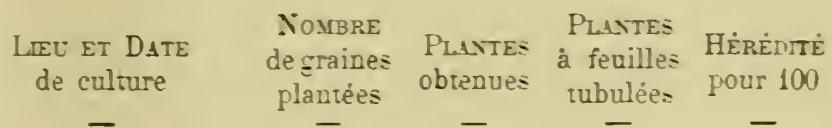

2e Gèneration. Locon. 04..........

Charille. 04.......

40

Bourg-la-Reine. 05

40

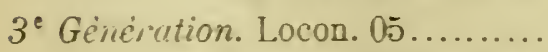

25

Bourg-la-Reine. 05

40

$4^{e}$ Géverition. Locon. 06..........

25

Bourg-la-Reine. 06

50

17

36

23

23

$3-4$

21

39 
J'ai pu observer aussi, en 1905 et en 1906, l'apparition du même caractère dans d'autres lignėes tératologiques de Maïs. En particulier, l'espèce Zeu Muys pruecox, isolée dans la même famille, me l'a présenté sur plusieur's exemplaires. Il est possible aussi que la suture des borls des feuilles soit en relation plus ou moins directe avec la qualité nourelle présentée par la Vurićté à port pleureur; les lots de plantes à gânes tubulées présentent la courbure fréquente de la panicule et conservent leurs feuilles enroulées jusqu'à la floraison. Toutefois les plus beaux exemples de Maïs à port pleureur ont été obtenus dans une autre famille.

Le déreloppement de l'anomalie a été très accusé en 1905, peut-être à cause de l'abondance des pluies d'été. Il m'a été possible d'étudier la périodicité de ce phénomène anormal et de montrer que la plus grande fréquence est offerte par la cinquième feuille comptée à partir de la base (Blaringhem, 1906 $九$ ); mais elle varie avec les années.

\section{1. - Plantes albines et panachées.}

La panachure des feuilles dans les lignées anormales de Maĩs que j'ai obtenues après des mutilations est extrêmement rare. Je ne l'ai observée qu'en 1914), sur deux individus dérivés de la plante $A_{6}$ (lot de graines $\delta$ ) cultivés à Locon, et, en 1906, sur une plante d'une autre famille qui sera décrite plus loin. Des deux individus panachés en 190', l'un avait une seule tige normale et portait sur toutes ses feuilles une ou deux larges bandes jaunâtres parcourant la longueur du limbe. L'autre pied présentait deux tiges panachées l'une terminée par une panicule normale, l'autre par une panicule du type B. Les stries blanches qui ornaient les feuilles de cet échantillon étaient plus fines et plus serrées et donnaient à la plante l'aspect des individus de la variété horticole Zea Mays japonica foliis variegatis. Les leux plantes panachées étaient de faible taille $\left(1^{\mathrm{m}}, 60\right.$ et $\left.1^{\mathrm{m}}, 70\right)$ et très précoces ; par ce caractère, elles ne pouvaient être confondues avec les diverses váriétés de Maïs panaché connues qui sont toutes tardives et mûrissent difficilement leurs graines dans les environs de Paris.

Leurs descendants ont fait retour à la variété de Maïs de Pensylvanie en conservant leur caractère de précocité relative et, à ce point de vue, ils diffèrent peu de la variété stable semi-prctecox née dans la même famille. Bon nombre d'entre eux ont aussi montré les caractères nouveaux de tiges tordues ou d'inflorescences latérales 
hermaphrodites, mais je n’ai pu en observer qui aient présenté le port pleureur.

Si la panachure ne s'est pas maintenue dans les cultures, il est toutefois possible de la considérer comme latente en raison de la fréquence des plantules complètement dépouriues de chlorophrile qu'on observe chaque année à la levée. Malg̣é mes soins, je nai pu en amener aucune au stade de la floraison: leur culture sur des solutions nutritives de hiop additionnées de glucose (Méthode de IAzE et Pergier, 19)í) a seulement permis de prolonger leur existence d'enriron trois semaines.

Lalbinisme est une anomalie de rézétation très répandue dans toutes les lignces tẻratologiques de Mais obtenues aprés des mutilations. Elle apparait dans les lots les plus difeereuts aussi bien parmi les formes tardires que parmi les variétes los plus précoces. La mutilation n'est pas la cause directe de l'apparition de ce caractère : on l'observe en effet sur les plantes témoins, dans les champs de grande culture et aussi sur les lots de plantes de rariétés direrses obtenues soit dans le commerce snit dans les jardins botaniqnes. mais toujours sur un petit nombre d'exemplaires. J'ai obserré aussi cette anomalie sur des plantules d'Orye ef je me propose d'en continuer l'étude.

\section{e. - VARLÉTE் $\triangle$ FETLLLAGE ROCGE.}

Lapparition d'un pigment rouge sur les orqanes arant subi une mutilation quelconque est bien connue. La nombre de mémoires et de notes parues sur cette question est trop considérable pour qüil soit possible d'en parler ici. L'étude quen ont fait Lutgr Bescalingi et Giro Pollaca ( 190$)$ est trés complète et donne des indications précieuses sur la généralité du phénomène. La rubéfaction à la suite de lésions mécaniques a puètre obtenue pour les plantes les plus différentes, Vibumum Opulus et Lanternu. Cru-

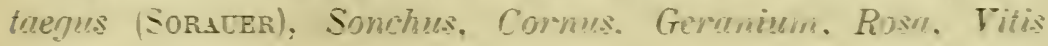
(Rathar, WhHelu, WIEssien) pendant que dautres plantes et en particulier des Graminées (KRsts) n'ont pas rougi. Doautre part. ces auteurs ont insisté sur l'augmentation constante de l'acidité contenue dans les tissus des organes rouges; enfin ils ont montré que sourent les plantes rouges transpirent moins. Les obserrations de Btscalto et PoLtacci sont importantes pour grouper les phẻnomènes que jai 
observés sur les plantes de Maïs mutilées et leur descendance, phénomènes dont je poursuis l'étude.

Les tiges de Maïs ayant subi la section longitudinale (Lignes B des Parcelles d'expérience de 1903) ont toutes montré le développement d'un abondant pigment rouge sur les fragments des tiges et sur les feuilles. Les épis latéraux multiples et succulents n'ont pas mûri leurs graines quoique les stigmates, sortis relativement tard, aient pu recueillir du pollen.

Dans la descendance des plantes mutilées, même de celles qui ont subi la section transversale des tiges, il est très fréquent d'obtenir des individus complètement rouges. Les phénomènes de la floraison sont normaux, mais, à la récolte, les tiges sont succulentes, non desséchées, et les rachis des épis ne présentent qu'un très petit nombre de graines ou même pas du tout (Pl. VIII, fig. 98). Bon nombre des plantes issues du pied $A_{6}$ (1903), cultivées à Chaville en 1904 pour le contrôle, avaient ce caractère et naturellement toutes avaient des panicules normales ne montrant aucune graine. La pigmentation rouge des tiges et des feuilles est une des causes de l'incomplète transmission de la fascie des rameaux de la panicule.

Les cultures de contrôle faites en 1905 à Bourg-la-Reine avec les graines récoltées sur les épis ébréchés ( $\left.{ }^{1}\right)$ des plantes rouges ont montré l'hérédité partielle de l'anomalie:

\begin{tabular}{|c|c|c|c|c|}
\hline Bourg-la-Reine. 05 : & $\begin{array}{c}\text { GrainES } \\
\text { plantées } \\
-\end{array}$ & $\begin{array}{c}\text { Plantes } \\
\text { obtenues } \\
-\end{array}$ & $\begin{array}{l}\text { Plantes } \\
\text { rouges }\end{array}$ & $\begin{array}{l}\text { HÉRÉDTT } \\
\text { pour } 100 \\
-\end{array}$ \\
\hline Épi très ébréché.. & 20 & 17 & 11 & 65 \\
\hline Épi demi $\quad$ - . & 40 & 32 & 19 & 59 \\
\hline Épi peu - & 60 & 44 & 23 & 52 \\
\hline
\end{tabular}

Dans les cultures du Maïs de Pensylvanie témoin et non mutilé la proportion des pieds rouges n’a jamais dépassé 10 pour 100.

D'autre part l'avortement partiel des graines était de beancoup plus accusé sur les épis latéraux des plantes rouges où il affecte des rangées entières que sur les épis latéraux des plantes vertes où il n'apparaît que sur quelques fleurs: (On n'a pas tenu compte des épillets terminant l'épi dont l'avortement est fréquent aussi bien sur

(1) Johnnnsen (1903) désigne sous le nom de Schartigkeit l'avorlement partiel des épillets de l'Orge qui donne les épis ébréchés. Cette propriété est héréditaire. 
les plantes vertes que sur les plantes rouges par suite de la sortie tardire des stigmates et la pénurie du pollen à cette époque) :

\begin{tabular}{clc} 
& \multicolumn{2}{l}{ Pluites rertes } \\
Grains & \multicolumn{2}{c}{-} \\
arortés & 0 & 21 épis \\
1 & $12-$ \\
2 & $11-$ \\
3 & $7-$ \\
4 & $6-$ \\
$5-9$ & $8-$ \\
$10-19$ & $6-$ \\
$20-29$ & $2-$ \\
5.5 & $1-$ \\
Total..... & 74 épis.
\end{tabular}

\begin{tabular}{ccc} 
Rangées & \multicolumn{2}{l}{ Plavtes rotges } \\
arortées & 8 & 1 épi \\
& 7 & 2 épis \\
6 & $2-$ \\
5 & $3-$ \\
4 & $4-$ \\
3 & $7-$ \\
2 & $9-$ \\
1 & $9-$ \\
$\frac{1}{2}(+)$ & $11-$ \\
$\frac{1}{2}(-)$ & $14-$ \\
Total..... & 62 épis.
\end{tabular}

L'arortement complet ou partiel des graines des plantes rouges est sans doute la conséquence de conditions mauraises de nutrition des oraires. Les tiges rouges renferment à l'époque de la floraison environ trois fois plus d'eau que les tiges vertes, et les analyses de sève brute que j'ai pu en extraire par le ràpage suivi de la compression des tissus montrent des variations considérables dans les proportions des corps rédacteurs qui y sont dissous. L'étude des jus ne ma pas permis de mettre en éridence ni saccharose ni glucose à l'aide du polarimètre; les essais à la liqueur de FeHLING indiquent des proportions variables de corps mal définis dont l'examen doit être repris pour aroir quelque valeur.

De la mème plante mère $A_{6}$ (1903), déricée d'une tige dẻformée après mutilation du pied, j'ai obtenu aussi une forme nouvelle et complètement stable pourvue d'épis latėraux hermaphrodites. Elle est décrite dans le chapitre suivant sous le nom de Zea Mays rar. pseudo-androgyna.

Les rariations héréditaires fournies par le seul individu $A_{6}$ des cultures de 1903 peuvent donc ètre représentées par le tableau suivant qui les résume: 


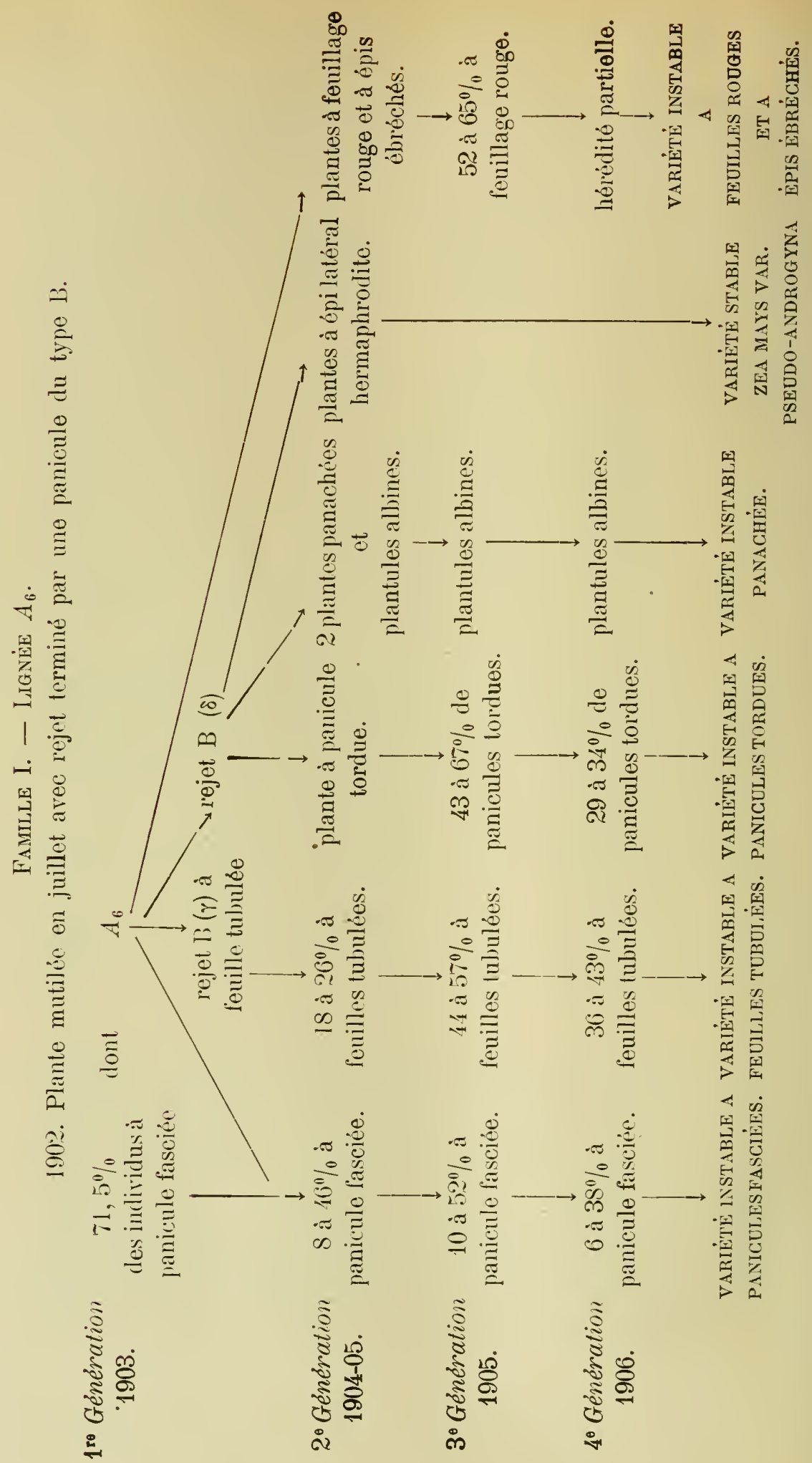


Dans la mếme Famille I, jai suiri la descendance des indiridus $A_{8}, C_{6}$ et $C_{10}$ décrits au tableau XII. Ces diffẻentes lignées m'ont permis de reconnaitre l'existence de rariations analogues à celles qu'a fournies le pied $A_{0}$ : limpossibilite de suirre attentirement toutes les formes $m$ a fait porter mon attention sur les descendants de $A_{6}$ qui montraient les pourcentages les plus élerés en 1904. Toutefois jai cultivé la lignée $C_{10}$, qui est lorig̨ine d'une variété stable et nourelle déerite sous le nom de Zea Wuys rar. semi-pjaecox (page 1\$3).

Enfin lespèce nourelle et stable Zea Mays praecox est dérivée de lindiridu $A_{1}$ isolé dans la mème Famille. Outre la conservation des caractères noureaux qui permettent de l'assimiler à une véritable espèce au sens de JoRDAx, elle a fourni des rariations stables à grains blanc: ou instables à grains ridés et à gulumellules métamorphosées en stigmates. I) plus quelques indiridus, obtenus en 1905 et en 1906 : ont montré des feuilles tubulées, des tires tordues, et aussi des épillets màles dispersés au milieu des graines des épis femelles (Pl. IT, fig. 46). Leur culture permettra peut-être la séparation de nouvelles formes stables ou instables. Quoi qu il en soit, il en résulte que tous les descendants de la Famille I montrent les caractères d'affolement qui ont été mis en reliel dans la liggnée $A_{6}$.

\section{6i. - Famille II.}

J'ai démontré dans la première partie de ce mémoire que la stelion transrersale de la tige principale du Vais. faite à une époque conrenable. proroquait la fascie des rameaux de la panicule et la métamorphose sexuplle des épillets mâles en épillets femelles. Il n’r a point de doute que lia mutilation riolente soit lorigine de l'apparition de ces caractêres nonveaux et partiellement héréditaires.

Les autres modifications, torsion des tiges, suture des bords des fenilles, épillets à fleurs hermaphrodites, etc... nont été reconnues, dans la Famille I. que sur la descendance des plantes mutilées. Pour aroir le lroit d’affïmer qu’elles résultent de l’ébranlement déterminé par la section de la tige, il importe de montrer que la mème mutilation a prornqué les mèmes effets dans dautres familles. Les Familles II et III ont été obtenues par des traumatismes faits en 1913 et présentent des rariations analogues. Il me serait facile d'en indiquer d'autres, dérirées de rariétés de Mais tout à fait différentes par leur 
origine et leurs caractères, et mutilées en 1904. Le petit nombre de générations qu'il m'a été possible d'observer jusqu'ici me force à remettre à plus tard leur étude.

Le pied origine de la Famille II a été mutilé en 1903 et il est décrit dans le tableau $V I$ sous le nom $B_{26}$ (page 49).

La plante ne présentait qu'une seule tige de 45 centimètres de hauteur lorsque j'en ai fait la section longitudinale. La panicule, complètement formée mais non étalée, fut enlevéc avec soin, puis les deux portions de tiges furent placées côte à côte et maintenues par un fil de coton. Il en est résulté la suture des parties de la tige sur une longueur de 20 centimétres environ. A la récolte, en fin de septembre, la plante entière était couverte d'un abondant pigment rouge. La tige principale, dressée sur une grande partie de sa longueur, portait latéralement un épi triple composé de deux épis de second ordre à 6 et 4 rangs dont aucune fleur n'était féconde, et un épi terminal à 4 rangs portant 43 graines assez bien conformées, qui constituent le lot de semences $\alpha_{2}$.

Un rejet á panicule normale atteignant 14 décimètres s'était développé vigoureusement après la mutilation de la tige; il portait, groupées en verticille, trois feuilles bractées réunies au même nœud sous la panicule et un épi latéral femelle à 8 rangés de graines que j'ai pu récolter à la fin d'octobre; elles forment le lot de semences $\beta_{2}$.

Dans la descendance de cet individu j'ai pu observer la plupart des anomalies de tiges, de feuilles et de fleurs rencontrées dans la Famille II, telles que les panicules à rameaux fasciés et chargés de fleurs femelles, les tiges tordues, les feuilles à nervures doubles ou tubulées, les bractées disséminées parmi les rameaux de la panicule, les feuilles rouges et les plantules dépourvues de chlorophylle.

De plus j'ai isolé deux variétés eversportinq qui sont presque complètement fixées à l'heure actuelle. Je les désigne, d'après leurs caractères les plus saillants, sous les noms de Varièté à port pleureur, $\left(a_{2}\right)$ et Variété à épis dissociẻs, $\left(b_{2}\right)$.

\section{$a_{2}$. - Variété De Maïs PleUReUr.}

Les graines du lot de semences $\beta_{2}$ furent plantées en 1904, á Locon et à Chaville. Elles donnèrent des plantes anormales à divers degrés et en particulier une forte proportion d'individus où la disposition 
alterne-distique des feuilles était profondément altérée. Les variations étaient très accusées à l'époque de la floraison de la panicule. Les feuilles longues et larges s'étaient enroulées en cornet et retombaient comme si les nervures n'étaient point assez fortes pour les tenir dressées (Pl. V, fig. 52). En particulier, j’ai récolté dans ce lot uue plante dont la feuille la plus élevée était totalement dépourvue de nervure principale. Je n'ai porté dans l'examen de ces cultures qu'une faible attention à ce caractère de port, mes efforts étant dirigés vers l'obtention d'une forme à feuilles insérées sur une ligne spirale, Pour les cultures de 1905, jai mis à part l'épi latéral d'un individu ayant les feuilles groupées par 3 sur les trois nœuds supérieurs de la tige $\left({ }^{1}\right)$.

Les graines de cet épi furent semées à Locon et à Bourg-la-Reine et, cette fois, la fréquence des tiges courbées et des feuilles retombantes me donna l'espoir d'isoler une forme de Maïs à poirt pleureur. Dans l'étude de contrôle, faite à la fin de septembre, j'ai tenu compte, comme appartenant à la variété nouvelle, de tous les individus portant une panicule fortement arquée. Il en fut de même en 1906. La variété est très vigoureuse; elle mûrit tard ses épis qui sont enveloppés par des bractées à limbe très développé (PI. V, fig. 54), et les graines ont à cette époque une couleur rose mat qui s'atténue avec la dessiccation.

Les pourcentages héréditaires ont été établis en 1904 en ne tenant compte que des individus à insertion foliaire différente de la disposition alterne-distique des feuilles; les chiffres sont certainement inférieurs à ceux qu'aurait fournie l'étude seule du port qui a été prise pour critérium en 1905 et en 1906.

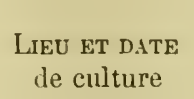

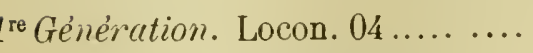

Chaville.04........

$2^{\mathrm{e}}$ Génération. Locon. 05..........

Bourg-la-Reine. 05

$3^{\mathrm{e}}$ Génération. Locon. 06.........

Bourg-la-Reine. 06

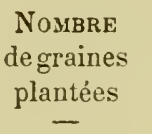

20

50

25

75

25

100

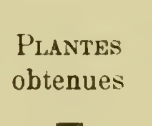

Plantes

à port pleureur

HÉRÉDITÉ pour 100
17

43

18

61

19

88
5

28

\section{1}

61

42

69

$14 \quad 74$

86
74

97,5

(1) LoEsEner a décrit récemment (1903) une plante de Maïs offrant ce caractère. 
Les résultats fournis par la troisième génération indiquent que la variétẻ de Maïs à port pleureur est presque complètement fixée. Cette obtention a une grande importance au point de vue horticole, non seulement par ce qu'elle fournit une plante d'ornementation curieuse, mais surtout, parce qu'elle permet de concevoir comment sont nées les variétés d'arbres et d'arbustes pleureurs, et parce qu'elle montre la transmissibilité du caractère par voie de semis.

\section{b. - VARIÉTĖ a ÉPIS DISSOCIÉS.}

La tige du pied de Maïs $B_{26}$ après avoir subi la section longitudinale a présenté une forte coloration rouge et, par corrélation sans doute (voir page 168), a donné un épi latéral multiple portant un faible nombre de graines. La culture de ces dernières a fourni peu de plantes à feuillage rouge, mais a permis de constater la persistance des caractères de la ramification de l'épi, et surtout de celui de n'avoir que quatre rangées de graines. Les pourcentages héréditaires sont:

\begin{tabular}{|c|c|c|c|c|c|}
\hline & Culture faite à & $\begin{array}{c}\text { Nombre } \\
\text { degraines } \\
\text { plantées } \\
-\end{array}$ & $\begin{array}{c}\text { Plantes } \\
\text { obtenues } \\
-\end{array}$ & $\begin{array}{l}\text { Plantes } \\
\text { à épis } \\
\text { à } 4 \text { rangs }\end{array}$ & $\begin{array}{c}\text { HÉRÉDITÉÉ } \\
\text { pour } 100 \\
-\end{array}$ \\
\hline $1^{\mathrm{re}}$ Génération. & Locon. $04 . . . . . . .$. & 25 & 22 & 9 & 41 \\
\hline $2^{e}$ Génération. & $\begin{array}{l}\text { Locon. } 05 . . . \ldots \ldots \\
\text { Bourg-la-Reine. } 05\end{array}$ & $\begin{array}{c}25 \\
100\end{array}$ & $\begin{array}{l}17 \\
83\end{array}$ & $\begin{array}{c}8 \\
37\end{array}$ & $\begin{array}{l}47 \\
45\end{array}$ \\
\hline $3^{\mathrm{e}}$ Génération. & $\begin{array}{l}\text { Locon. } 06 \ldots \ldots \ldots \\
\text { Bourg-la-Reine. } 06\end{array}$ & $\begin{array}{l}25 \\
100\end{array}$ & $\begin{array}{l}19 \\
91\end{array}$ & $\begin{array}{l}11 \\
54\end{array}$ & $\begin{array}{l}58 \\
60\end{array}$ \\
\hline
\end{tabular}

L'anomalie est partiellement héréditaire. Elle n'a aucun intérêt agricole puisqu'elle réduit dans des proportions sensibles le rendement en poids des graines, mais elle présente des particularités très importantes au point de vue scientifique, surtout lorsqu'on tient compte des curieuses observations de HARHSBERGER (1893-1896) sur une plante que l'auteur a considérée pendant quelques années comme l'ancêtre sauvage du Maïs el qu'il a reconnu depuis être un hybride entre le Zea Mayss et l'Euchlaena mexicana.

Le Zea canina WATSON, qui a étél'objet de l'ètude de HARSHBERGER, présente en effel des inflorescences latérales femelles à plusieurs ramifications décrites et figurées aux Planches I et II de son mémoire (1893). Les dessins pourraient être conservés sans modifications 
sensibles pour la description de l'inflorescence latérale femelle multiple du Mä̈s à épis dissociẻs (Pl. VIII, fig. 95-97).

Le fait le plus remarquable est la métamorphose partielle des épillets femelles en épillets mâles. J'en ai récolté un bon nombre en 1905, et les indivilus des cultures de 1906 en ont inontré des échantillons plus jolis encore. Naturellement, il est nécessaire d'en continuer l'épreuve pour pouvoir affirmer si la tendance à un retour atavique présumé pourra être définitivement fixée.

Dans le même lot de plantes à épis latéraux dissociès, courerts d'épillets mâles et femelles, j'ai mis à part aussi, en 1905, deux plantes à épis hermaphrodites. A la base des graines, on peut apercevoir les restes desséchés d'étamines avortées, développées tard après la fécondation. Elles sont identiques par leurs caractères à celles qui définissent une variété nourelle et stable isolée dans la Famille II et décrite plus loin sous le nom Zea Mays pseudo-androryna.

Ainsi la variété instable à épis latéraux à 4 rangs se dissocie actuellement en des formes différentes dont l'étude doit être poursuivie. Les caractères présentés par cette lignée sont particulièrement intéressants pour l'essai de reconstitution de la phylogénie du Maïs.

En résumé la FAMILIE II, issue d'une

Plante mutilée en 1903 (Section longitudinale), a donné:

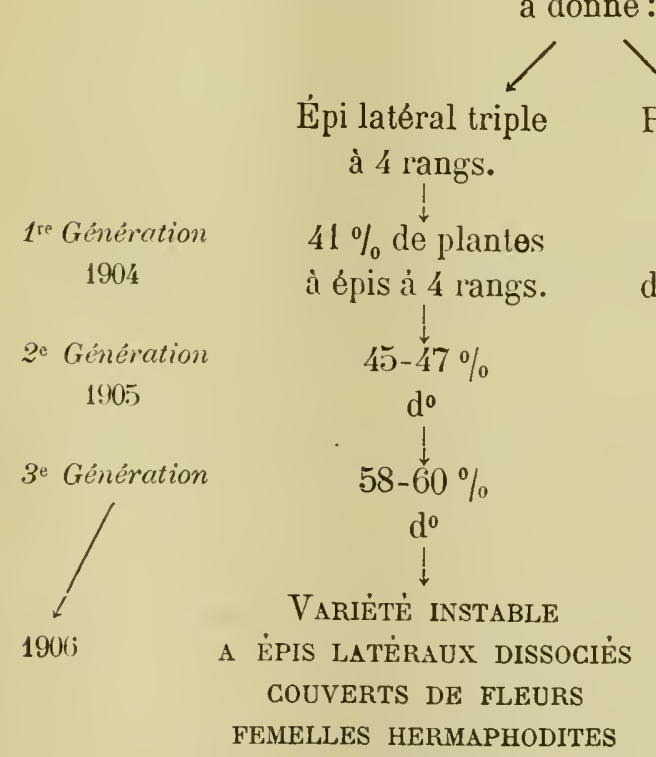

Rejet à 3 feuilles groupées

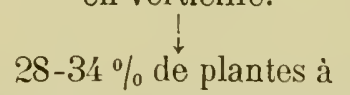
divergence foliaire variable $61-69 \%$ de plantes à port pleureur.

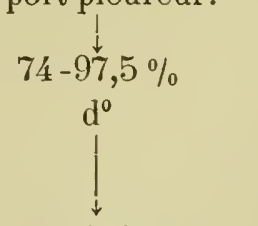

VARIÉTÉ DE

MAïs a PORT PLELREUR. ET MALES. 


\section{8. - Famille III.}

VARIÉTÉ HYBRIDE A GRAINS ACAJOU.

Une variété à grains rouges est nẻe dans mes cultures expérimentales de 1903. Elle dérive de l'individu $A_{5}$ (tableau $I I$, p. 40) ayant eu la tige principale coupée au ras du sol le 10 juillet et qui a fourni deux rejets, courts et grêles, terminés par des panicules du type B, peu ramifiées, portant ensemble 17 graines complètement rouges.

La couleur des graines de teinte acajou et la disjonction des caractères apparue dans les cultures ultérieures montrent bien la nature hybride de cette variété nouvelle.

En 1904, sur 10 graines plantées à Locon, trois plantes seulement ont étẻ obtenues dont toutes les graines, aussi bien celles des épis latéraux que celles de la panicule anormale récoltẻe sur l'un d'eux, étaient d'une teinte acajou clair. Jusqu'à la fin de septembre, les graines sont d'un blanc jaunâtre, puis l'albumen jaune donne sa teinte au fruit dont l'enveloppe est transparente, tandis que la couleur rouge s'étale sur l'ovaire seul, à partir de la base du stigmate d'une teinte foncée jusqu'à la ligne d'insertion de l'ovaire sur le rachis qui est jaune.

A la dissection, le grain montre tous les caractères qu'a décrits et figurés Correns (1901) dans son travail sur la Xénie (Pl. I, fig. 41). Le pigment rouge est localisé dans la paroi de l'ovaire, et dans aucun cas il ne se communique aux cellules de l'assise protéique qui recouvrent l'albumen. L'albumen est d'une couleur jaune franc, de teinte plus accusée peut-être que celle qui colore l'albumen du Maïs de Pensylvanie. La superposition des couleur's, rendue possible par la transparence relative de l'ovaire, donne la teinte acajou caractéristique de cette variété hybride.

La disjonction des caractères est apparue en 1905 et s'est continuée en 1906. Elle a fourni des proportions variables de plantes à graius acajou et de plantes à grains jaunes. Mais aucun épi ne portait des fruits d'un rouge franc:

LieU ET DATE de culture

$1^{\mathrm{re}}$ Génération. Locon. 04..........

$2^{\circ}$ Génération. Locon. 05.......... Bourg-la-Reine. 05

$3^{\theta}$ Génération. Locon. 06 .......... Bourg-la-Reine. 06

NoMBre
degraines
plantées

10

25

100

25

100
Planites obtenues

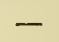

3

4

21

17

82
Plantes à graines HÉRÉDITÉ acajou pour 100 
La couleur rouge de l'ovaire a été dominante pendant la première génération, si toutefois il est possible d'interpréter les résultats d'une observation faite sur un nombre si peu élevé d'individus. Dans les générations suivantes, le nombre des plantes à grains jaunes a dépassé de beaucoup celui des plantes à grains acajou. La nature hybride des individus de 1905 et de 1906 n'est pas douteuse, et sans doute elle tient à la fécondation des grains rouges des panicules déformés de 1903 par le pollen des plantes à grains jaunes qui l'entouraient.

Il est plus singulier de n'avoir pu récolter jusqu'ici aucune plante à graines d'un rouge franc; d'ailleurs cette forme présente d'autres particularités de végétation qui nécessitent une étude plus approfondie. Ainsi, il est remarquable qu'en 1904 je n'ai pu obtenir la levée que de 3 plantes sur dix graines plantées; de mème l'obtention de 4 plantes sur 25 graines et de 21 plantes sur 100 graines, en 1905 , indique des difficultés de germination et de développement très anormales si on compare ces résultats à ceux fournis par les plantes tẻmoins. J'ai remarqué qu'aux graines non levées correspondaient des enveloppes de fruits dont le contenu était complètement détruit par des pontes de Geophilus terrestris; des semis faits en serre dans de la terre stérilisée ont indiqué un retard de plus de dix jours, dans la germination des graines de couleur acajou, sur la germination de graines de Maïs de Pensylranie plantées dans les mêmes conditions. Sans doute la lenteur dans la germination a favorisé l'attaque des Myriapodes qui sont très friands de Maïs.

Peut-être faut-il attribuer à la nature hybride des graines, la mauvaise conformation de l'embryon qui se traduirait par la lente germination et aussi par l'abondance des plantules dépourvues de chlorophylle dans cette lignée? Si le caractère a été moins accentué en 1906 qu'en 1905, on peut en trouver l'explication dans la proportion plus élevée de plantes à grains jaunes et á l'élimination des types anormaux à graines acajou. Toutefois, une plante qui appartient à ce dernier groupe a montré en 1906 une anomalie de végétation qui semble confirmer les différentes hypothèses soulevẻes par ce cas difficile à interpréter. Elle consiste en la survivance d'une plantule albine à la levée, qui a pu croître grâce à la réapparition du pigment chlorophyllien dans les feuilles supérieures. La première feuille, à limbe court et large, était complètement blanche; la seconde, étalée neuf jours plus tard, montrait deux fines stries vertes 
parcourant le limbe; les bandes vertes s'élargirent sur les feuilles suivantes et la panachure s'évanouit graduellement pour disparaître complètement sur la sixième feuille. La plante fleurit relativement tard, mais ses graines mûrirent au début d'octobre; elle était de taille peu élevée et paraissait beaucoup moins vigoureuse que les autres plantes du même lot.

La décroissance de la panachure avec l'âge est tout à fait anormale pour le Maïs. En ce qui concerne les formes Zea Mays juponic a foliis variegatis, Z. M. tricolor, Z. M. quadricolor, la panachure est toujours plus accusée dans les stades de développement rapide des plantes que dans les débuts de la végétation. Les rejets, qui apparaissent tard, soit spontanément, soit après la section, sont décolorés presque entièrement. Il est probable que la panachure, transmise héréditairement par ces formes diffère totalement de celle qu'a montrée la plante à graines acajou qui est peut-être d'une nature infectieuse, comparable à celle que Lindemuth (1878) a découverte sur les Abutilons et qui a été tout récemment l'objet d'une étude très intéressante de E. BAUR (1906).

L'apparition du pigment rouge sur les fruits du Maïs après nutilation n'est pas limitée à ce cas. Dans mes nombreuses lignées tératologiques, j’ai séparé des formes dont les graines présentent soit des taches rouges correspondant à la base du stigmate, soit des stries plus ou moins nombreuses et plus ou moins accusées. Enfin il est des formes ou la coloration rouge semble limitée aux stigmates, ou aux étamines, ou enfin aux enveloppes florales. L'étude de tous ces caractères doit être continuée pendant plusieurs années pour qu'il soit possible de se faire une opinion sur leur valeur au point de vue de l'hérédité.

De même, je décrirai dans un mémoire ultérieur la naissance et la fixation partielle ou complète de formes nombreuses, plus ou moins stables, qui montrent les feuilles plissées, ou lobées, ou couvertes de crêtes, ou encore des dispositions héréditaires des épillets sur le rachis de l'épi qui entrainent des variations stables et très importantes dans la forme des graines. Toutes ces formes devraient être classées actuellement parmi les variétés instables, mais leur étude n'est pas assez complète pour qu'il soit possible de dire si les variations sont dues à une hybridation initiale ou à la nature même de l'anomalie. 
Ion intention est de me limiter dans ce travail à la description des formes nourelles nées après la mutilation du Maïs de Pensylvanie. Toutefois je ne puis passer sous silence les variétés instables que j'ai pu isoler dans des lignnées d'autres variétés de Maïs ayant subi la section de la tige principale.

Le Mä̈s d'Alyejerie a donné une variété instable à épis ramifiés, dont les épillets femelles sont métamorphosés partiellement en épillets mâles.

Le Mays sucré ridé taidif de VILMonix est l'origine d'une forme nouvelle à panicules tordues, et d'une variété instable à épis latéraux fasciés (Blarnchen, 1905 $~$ ).

Les variétés à grains rouges et blancs du Zeu Mays oryzoüdes ont fourni des lignées instables dont les épis latéraux fasciés se dissocient en rameaux couverts de fleurs mâles et de fleurs femelles.

Le Zeu Mays tunicuta à graines blanches et à graines rouges fournit chaque année de fortes proportions de plantes dont les panicules sont chargées de fleurs femelles tandis que les épis latéraux, ramifiés à l'excès, constituent des inflorescences analogues par leurs caractères à celles des Choux-fleurs (BLARnghem, 1904 c).

Jusqu'ici, je n'ai cultivé que les lots nécessaires à la conserration des anomalies apparues après la mutilation ; mais je n’ai pu faire ni la séparation des lignées, ni l'autofécondation, puisque j'ai fait·mes cultures dans les champs d'essai de Chaville et de Bourg-la-Reine où le mélange des formes est inéritable. Mais le seul fait daroir pu récolter chaque année des individus ayant conservé les caractères anormaux des parents montre que la transmission est certaine. Aussi, je puis affirmer que la mutilation permet de créer et de fixer des formes nourelles, non seulement dans la rariété de Maïs de Pensylvanie, mais dans la plupart des variêtés de Iaïs que j'ai eues en culture. La méthode peut d'ailleurs se généraliser et elle est applicable à l'Orge (Hordeum tetrastichum et $H$. distichumi) et aussi au Sinapis alba. KLEBs a décrit des phénomènes analogues dans la descendance de plantes mutilées de Veronica Chamaedrys (1906). 
VARIÉTÉS ET ESPÈCE ÉLÉMENTAIRE NOUVELLES OBTENUES APRÈS MUTILATION.

\section{9. - Famille I.}

Malgré les difficultés d'isolement des lignées et l'impossibilité complète de protéger, à la première génération, les graines des individus anormaux contre la fécondation croisée, j’ai réussi à fixer complètement plusieurs variétés et espèces élémentaires nouvelles. Leur étude comprend l'examen des circonstances qui ont déterminé leur naissance, la détermination des pourcentages héréditaires, et enfin, l'analyse détaillée d'un certain nombre de caractères qui permettent de les distinguer de la variété de Maïs de Pensylvanie dont elles dérivent.

l.es formes nouvelles et stables ont été isolées dans la Famille I (page 161), issue des graines d'une panicule du type $\mathrm{B}$ développée, en 190:2, sur une plante dont la tige principale avait été coupée. Ce sont ou bien des variétés proprement dites que je désigne sous les noms :

a. - Zea Mays var. pseudo-androgyna $\left(^{1}\right)$,

b. - Zea Mays var. semi-praecox,

ou bien de véritables espèces élémentaires nouvelles, comme la forme

c. - Zea Mays praecoso $\left.{ }^{(}\right)$,

qui a donné depuis naissance à la variété à grains blancs :

l. - Zea Mays praecox var. alba.

a. - Zea MaYs Var. PSEUdo-androgyna.

La variété stable de Maïs à épis latéraux chargés de fleurs hermaphrodiles dérive du pied $A_{6}$ (tableau XXI, p. 156). La culture des graines du rejet à panicule du type B (lot $\delta$ ), faite à Locon en 1904, a donné 16 plantes dont 8 présentaient la transmission héréditaire de la fascie des rameaux; deux plantes du même lot ont en outre

(1) La description de ces formes a été faite rapidement dans des notes présentées à l'Académie des sciences de Paris, Blaringhem (1906 b, $1906 c$ ). 
montré la panachure des feuilles. Des autres individus, en apparence normaux, j'ai conservé pour les cultures ultérieures deux épis latéraux pourvus de 8 rangẻes de graines bien mûres à la fin du mois de septembre. Ces épis sont l'origine de deux lignées distinctes: l'une est la varièté instable à tige tordue déjà étudiée; l'autre est la variété pseudo-androgyna complètement fixée.

Les caractères particuliers des épillets femelles qui définissent cette variété ne me sont point apparus à la récolte. Ce n'est que plus tard, en février 1905, et en détachant les graines du rachis de l'épi qui les portait, que j'ai remarqué à la base de la plupart d'entre elles des appendices de couleur brune, portés par des filets grêles. Tous les épillets n'étaient pas hermaphrodites au même degré; ceux de la pointe et de la base de l'épi portaient des étamines bien visibles, au nombre de trois, régulièrement placées autour de l'ovaire (Pl. VIII, fig. 92 et 93); les épillets du milieu de l'épi montraient parfois un ou deux ou même trois appendices, mais très réduits, et j'ai pu trouver parmi eux 79 fleurs fertiles ne montrant pas de traces d'étamines même à la loupe. Les cultures faites à Locon, en 1905, ont porté exclusivement sur des graines provenant d'épillets où les étamines étaient bien visibles; dans les cultures de contrôle, faites la mème année à Bourg-la-Reine, j'ai utilisé 50 graines de fleurs hermaphrodites et 50 graines de fleurs femelles.

Dès les premières cultures, je pus reconnaître la transmission du caractère nouveau à un grand nombre de descendants. A Locon, sur 21 plantes obtenues, 2 seulement ne montraient pas d'étamines; toutes les autres en portaient, plus ou moins développées, mais visibles sur tous les épillets examinés. Un épi latéral, récolté sur l'une de ces dernières plantes, fut choisi pour les cultures de 1906 qui ont montré, aussi bien à Locon qu'à Bourg-la-Reine, la transmission complète du caractère à tous les descendants. Ainsi, en deux générations, le caractère nouveau était complètement fixé:

$$
\begin{aligned}
& \text { LieU et Date } \\
& \text { de culture }
\end{aligned}
$$

$1^{\mathrm{re}}$ Génération. Locon. 05..........

$$
\text { Bourg-la-Reine. } 05
$$$$
\mathrm{d}^{0}
$$

$2^{\mathrm{e}}$ Génèration.

\section{Granses plantées}

Puantes obtenue

PLATTEs à fleurs $\hat{\Phi}$

25

$50 \hat{\text { ọ }}$

50 우

$$
21
$$

19

91

47


Si l'on compare les résultats obtenus, en 1905 à Bourg-la-Reine, avec les graines de fleurs hermaphrodites (50 §) et les graines de fleurs femelies (50 ठै), on voit que les proportions de la transmission du caractère nouveau sont sensiblement égales dans les deux cas. Il faut en conclure que les fleurs femelles de l'épi latéral récolté en 1904 possédaient le caractère nouveau à l'état latent. L'obtention si rapide d'une variété nouvelle et stable tient donc à l'apparition brusque en 1904 du caractère anormal, celui de fleurs hermaprodites, qui a été fixé de suite. On s'explique mal, dans cette hypothèse, l'absence d'étamines sur les épillets de 16 individus des cultures de 1905. L'étude microscopique des alvéoles où étaient enchâssées les graines, faite pour bon nombre d'entre eux, n'a pas permis d'en découvrir des traces. La latence, puis la réapparition, du caractère peut être attribuée à des conditions défavorables de développement; de même que le Papaver somniferum polycephalum ne fournit pas de capsules surnuméraires lorsqu'il est cultivé par H. DE VRIEs (1899) dans un sol épuisé, de même l'humidité considérable de l'été 1905 a pu nuire en partie au développement des étamines tandis que l'été sec de 1906 l'a favorisé. De nombreuses observations permettent d'affirmer que les étés humides favorisent la fascie des rameaux de la panicule du Maïs et la métamorphose des épillets mâles en épillets femelles; les étés secs fournissent un plus grand nombre de cas d'épis latéraux femelles couverts d'épillets mâles (variẻté instable de Maïs à épis dissociès), et il est permis de supposer qu'une action analogue puisse avoir une influence sur le développement des épillets hermaphrodites.

L'hermaphroditisme de la variété pseudo-ındrogyna est purement morphologique. L'examen des épillets de la pointe ou de la partie moyenne des épis, à l'époque où les stigmates sont prêts à la fécondation, ne permet pas de reconnaître la trace des étamines, mème sur des coupes fines examinées au microscope. Leur développement est tardif et correspond à l'époque où l'ovaire fécondé atteint sa taille maxima et où l'albumen, de couleur jaune pâle, commence à durcir. D’ailleurs je n'ai pu réussir à trouver aucune étamine ayant les anthères allongées et linéaires caractéristiques des Graminées. Les anthères verdâtres, étalées à la base el retrécies à la pointe, ont la forme d'un fer de lance; elles ne renferment point de pollen. Ces particularités m'ont conduit à regarder la variété nouvelle Zea Muys var. pseudo-androgyna non pas comme une forme régressive, ayant 
fait retour à quelque tỵpe ancestral du Maïs, mais comme une variété progressive mettant en évidence un caractère nouveau pour la tribu des Maydées (Blaringhem, 1906c).

\section{b. - Zea Mays var. semi-Praegox.}

Cette variété, complètement fixée depuis 1905, est issue du pied $C_{10}$ (Tableau XXI) de la Famille I.

Dans les cultures, faites en 1903, des graines récoltés sur la panicule terminale d'un rejet apparu en 1902 après la mutilation, le pied $C_{10}$ se distinguait, de ses voisins de même origine, par sa vigueur et sa taille relativement faible. La tige principale, très épaisse à la base, avait un diamètre de 32 millimètres mesurée sur un entrenœud à dix centimètres au-dessus du sol, et n'atteignait que 16 décimètres de hauteur. Les feuilles développées sur elle, au nombre de 12, étaient larges, mais relativement plus courtes que celles des pieds voisins. Deux épis latéraux, à 10 et $S$ rangées de graines, furent récoltés sur cette tige à la fin du mois de septembre. Ils correspondent au lot de graines $\alpha_{3}$.

La même plante portait deux rejets anormaux; le plus élevẻ des rejets n'avait que 7 décimètres de hauteur, et il portait une panicule du type B à cinq rameaux latéraux couverts de graines très bien conservées parce qu'elles furent protégées, jusqu'à leur maturité, par les feuilles supérieures groupées de manière à former une gaîne d'enveloppe. Ces graines, au nombre de 140, furent aussi récoltées à la fin du mois de septembre et constituent le $\operatorname{lot} \beta_{3}$.

L'autre rejet, de faible taille (32 centimètres), portait une inflorescence uniaxe courerte de fleurs femelles et appartenant au type C. Les graines, à peine mûres au moment de la récolte, se conservèrent mal ; 20 seulement purent être utilisées pour les semis et forment le lot de semences $\%_{3}$.

Dès la fin du mois d'août, j'arais été frappé par la précocité relative de cette plante dont les épis latéraux et la panicule du type B étaient déjà très épais et relativement durs au toucher. Cette observation, dont j'avais pris note à l'époque de l'étude de contrôle, me permet de faire remonter à cette génération l'acquisition du caractère de précocité relative qu'a montré depuis la lignée issue de cette plante. Car, les cultures de 1904 ont été faites dans le seul but de suivre la transmission héréditaire de l'anomalie de la 
panicule des rejets. En 1905, puis en 1906, j’ai reconnu que le caractère de précocité observé sur toute la descendance en 1904 était complétement fixé.

Au prẹmier examen, les plantes de la variété semi-praecox diffèrent peu des autres individus issus de lignées tératologiques de Maïs. La variété stable pseudo-androgyna et la variété instable à tiges tordues sont aussi plus précoces d'environ trois semaines que la variété de Maïs de Pensylvanie qui a servi de point de départ; mais une étude attentive permet de reconnaître des particularités de végétation complètement fixées dans la variétẻ semi-praccox et qu'on ne trouve qu'accidentellement dans les autres lignées. Les plantes sont plus épaisses, plus trapues et semblent aussi plus vigoureuses, quoique leur taille soit relativement basse; elles restent d'un beau vert longtemps après la dessiccation des stigmates. Les épis latéraux, gros et couris, sont en moyenne plus nombreux que ceux des variétés de même taille; ils se développent très rapidement et croissent davantage en épaisseur qu'en longueur, si bien que la gaîne de la feuille qui les embrasse, n'ẻtant pas assez souple pour s'écarter de la tige, se ronpt suivant une ligne médiane correspondant à la nervure principale de la feuille; la tige épaisse résiste bien à la pression de l'épi et ne montre qu'à un faible degré le port en zig-zag si accusé sur les formes à épis longuement pédonculés.

Vers la mi-septembre, rien ne révélo à l'extérieur la maturité presque complète des graines. Les panicules sont, il est vrai, totalement desséchées, mais beaucoup de formes à maturité lardive présentent aussi ce caractère; les bractées des épis, les tiges et les feuilles sont encore succulentes lorsqu'il est possible de faire la récolte des fruits.

J'aurais pu méconnaître la précocité de cette lignée si mon attention n'avait été attirée par l'épaississement rapide des inflorescences latérales; j'évite en effet de dégarnir ces dernières, des bractées qui la protégent, avant la maturité complète de la plante. En cherchant la cause de la rupture des gaînes des feuilles qui aurait pu être soit la présence d'épis doubles, soit celle d'épis fasciés ou à rangées de fruits plus nombreuses, j'ai pu constater la maturité précoce des graines.

Il m'est arrivé, en 1905, de laisser intactes jusqu'au début du mois d'octobre les plantes de cette variété de Maïs cultivées pour le contrôle à Bourg-la-Reine; elles diffẻraient alors sensiblement des 
autres lignées par la dessiccation complète des épis dont les bractées, d'un jaune pâle, faisaient contraste avec la couleur vert rougeâtre des feuilles et des tiges. En 1906, j’ai constaté que la dessiccation des bractées était brusque; en moins de huit jours, les bractées vertes prennent la teinte jaune caractéristique de la maturité complète. Cette rariation est d'autant plus frappante qu'on n'a que rarement l'occasion de la constater dans les environs de Paris où les diverses variétés de Maïs à gros grains arrivent rarement à maturité et ne se dessèchent qu'avec les premières gelées.

La variété Zea Mays semi-praccox est née en 1903 dans la descendance directe d'une plante mutilée. Elle a offert, dès le début, des symptômes très nets de maturation rapide, symptômes qui n’ont été reconnus d'une façon précise que plus tard par l'examen attentif des lignées en culture de contròle. Si je n'ai attaché à ce caractère physiologique qu'une faible importance en 1903, la découverte, faite en 1904, d'une espèce élémentaire très précoce et née dans la même lignée, le Zea Mays praecox, m'a conduit à apporter à son étude une attention toute spéciale. Les résultats obtenus par la culture de lignées mutilées, soit du Maïs de Pensylvanie, soit d'autres variétés de Maïs, soit encore de plantes très différentes (Hordeum tetrastichum et $H$. distichum, Enothera biennis...) me permettent d'affirmer que la section de la tige principale est une méthode commode pour obtenir avec sùreté des variétés nourelles plus précoces que celles qui servent de matériel d'essai.

Le caractère noureau apparait dès l'année même de la mutilation. Il est très remarquable que la maturation des fruits du Mlaïs exige tout l'été lorsque les fleurs femelles sont portées par les inflorescences latérales tand is que les fruits des rejets développés après la section de la tige principale, faite à l'époque de la floraison de la mème plante, peuvent être récoltés à la fin du mois de septembre. L'intervalle de temps nécessaire pour aller de la jeune plantule de Maïs, renfẹrmée dans la graine, à la graine mûre est le double de celui qu'exige le passage du bourgeon ad̉entif, déreloppé après la section d'une tige vigoureuse, au rejet à panicule déformée couverte de graines à point pour la récolte.

Il est facile de se représenter la généralité de cette loi par des exemples pris dans la pratique agricole. On sait que le trèfle (Trifolium pratense), semé en mars dans les céréales de printemps, fleurit l'année suivante au mois de mai et donne des graines mûres 
au début de juillet. Il faut près de 18 mois pour passer de la graine à la graine. La première coupe du trèfle a lieu vers la fin du mois de mai; les rejets, qui se développent rapidement, fleurissent en aoûtet, à la mi-septembre, on peut récolter des graines mûres sur le tréfle de seconde coupe ; l'intervalle de temps nécessaire pour passer du jeune bourgeon adventif, développé après la coupe, à la maturation du fruit, n'est plus en ce cas que 4 mois, soit le quart du temps nécessaire lorsque la mutilation n'intervient pas.

De même, l'Escourgeon (Hordeum tetrustichum pallidum $\beta$ ) est une forme d'Orge qui se sème avant l'hiver et se récolte en juillet. Dans certaines régions, on l'utilise à l'état vert pour la nourriture des chevaux et la coupe se fait à l'époque de la floraison des épis, en juin. Les rejets qui se développent dans la suite donnent des épis, très anormaux d'ailleurs et ramifiés pour la plupart, dont les graines sont mûres en septembre.

L'Enothera biemis, plante bisannuelle comme son nom l'indique, fleurit au début de juillet. J'ai coupé la tige principale de plantes de cette espèce vivant à l'état sauvage au début du mois de juin; en fin de septembre j'ai pu récolter des fruits mûrs sur les rejets dont les graines m'ont donné des plantes annuelles.

Enfin, c'est une pratique courante en horticulture, pour faire l'essai de variétés nouvelles d'arbres fruitiers, de recourir à la greffe d'une branche d'un jeune arbuste sur un porte-greffe plus âgé. On réduit les générations à deux où trois années, de la graine à la graine, alors que la culture des arbres adultes exige cinq ou dix ans.

Toutes ces opérations ont la même conséquence; elles mettent à la disposition d'un jeune bourgeon un appareil radiculaire vigoureux, elles déterminent la floraison rapide et la maturité précoce des fruits.

Pour les plantes herbacées dont j'ai fait l'essai, la précocité obtenue par ce procédé est héréditaire. La variation est brusque; elle rentre dans la catégorie des variations créatrices d'espèces que Hugo DE VRIEs a fait connaitre sous le nom de Mutation. On pourrait m'objecter, dans le cas de la variété semi-p’aecox que jai obtenue, que le souci de récolter pour les semis ultérieurs des inflorescences femelles saines et bien mûres m'a conduit, à mon insu, à faire une sélection dans cette direction. Il est en effet difficile en certaines années de récolter en abondance des épis femelles de Mä̈s de Pensylvanie suffisamment mûrs pour la culture des plantes 
témoins. Or la sélection, très stricte dans ce dernier cas, ne parait pas modifier, mème légèrement, l"époque de la maturation des graines. Il en est de mème pour la variété nouvelle de. Yaizs à port pleureur. Dans l'un et l'autre cas, la maturité des graines n'est suffisante quà la fin du mois d'octobre.

Il en résulte que le $Z$. M. var. semi-praecox, complètement stable depuis 1905, est né par mutation, en 1903, dans la descendance dune plante mutilée ayant déjà offert les caractères de la rapide maturation des graines. La mutilation est la cause directe de l'apparition du caractère noureau.

\section{0. - Origine de L’espéce Élévestaire Zea Muys} praecox ET DE SES VARIÉTÉS.

De toutes les formes nourelles, obtenues dans les lignées anormales de Yais. la plus remarquable est l'espèce élémentaire Zéa Mays praecox (BlarisgheM, 1906 b). Elle diffère par l'ensemble de tous ses caractêres du Maīs de Pensylvanie dont elle dérive : elle montre, depuis 1904, la constance absolue de toutes les propriétés nourelles qui la définissent comme espèce: enfin. elle a donné naissance à quelques formes stables ou instables qui sont des rariétés proprement dites nées dans l'espéce élémentaire sous mon contròle.

La lignée qui a donné sans aucun retour le Zea. Mays praecox dérive de la plante $A_{1}$ (tableau XXI) des cultures faites en 1903; on 5 a reconnu la transmission, par roie dẹ semis, des caractéres anormaux de fascies des rameaux et de métamorphose des épillets màles en épillets femelles proroqués, en 1902, par la section de la tige principale d'un pied de Maîs. Le rejet à panicule du tỹpe B, récolté vers la mi-septembre, est l'origine de la Famille I, etl'espèce nouvelle Zect Muys piatecox doit donc ètre classée parmi les nombreuses variations stables en totalité ou en partie que j'ai décrites dans la descendance de cette famille (page 161).

Première génération. - La plante $A_{1}$ se distinguait, dans les cultures de 1903, par sa petite taille et sa précocité. Elle présentait deux tiges ; l'une, de 9 décimètres de hauteur, ètait terminée par une panicule normale et dépourrue d'épi latéral femelle fertile; l'autre, développée à la base de la première, n'a vait que ú lécimètres de haut, un petit nombre de feuilles et une inflorescence terminale uniase 
couverte de 10 rangées de grainés. Je n'ai pu assister à la floraison des inflorescences mâles et femelles de cette plante; elle était terminée lorsque, le 10 août 1903, je fis l'eramen du lot. A cette époque, la plante $A_{1}$, restée naine et d'une teinte jaunâtre, paraissait a voir souffert dans son développement, caractères que j'ai attribués alors à sa situation spéciale sur le bord de la parcelle de culture où le sol était peut-être plus compact qu'ailleurs. La récolte des graines fut faite le 30 août dans l'étude de contrôle qui a porté sur le lot tout entier ; j'ai cueilli à la même date, quelques inflorescences du type $A$ portant des graines saines et mûres sur d'autres plantes de la même famille.

2 Générution. - Les graines de la panicule du type C du pied $A_{1}$ furent plantées en 1904, à Locon et à Chaville. Dans les deux localités, l'apparition des caractères nouveaux fut complète et frappante; la floraison des panicules mâles se fait dans la première quinzaine de juillet et se prolonge pendant la plus grande partie du mois. Les stigmates sont desséchés lorsque les plantes de Maïs de Pensylvanie, ou même de la variété semi-praecox, commencent à donner leur pollen; il en résulte l'impossibilité d'une fécondation croisẻe et par suite l'isolement de la lignée.

Les caractères de végétation, suivis à Chaville sur les 50 graines plantées pour le contròle, ne permettaient pas de reconnaitre à la levée les qualités nouvelles de la forme précoce. J'ai noté, parmi les plantules, trois plantes albines qui ne tardérent pas à mourir, mais ce fait est fréquent dans les lignées tératologiques de Maīs; quatre graines n'ont pas germé ou ont été détruites par les Vers ou autres animaux nuisibles aux cultures, ce qui a réduit à 43 le nombre des plantes bien développées. Au début de juillet, leurs tiges grêles étaient sensiblement plus élevées que celles des plantes voisines; les entrenœuds de base, à peine visibles sur les plantes témoins, étaient dans ce lot bien marqués, et toutes les panicules encore enveloppées par les feuilles supérieures de la tige étaient visibles lorsqu'on examinait la plante de haut en bas. Dés cette époque, les différences de la forme Zeu Mays pruecox avec les autres lignées de même origine se sont accusées rapidement. La floraison est dans son plein vers le 16 juillet et, les jeunes plantes, quoique de taille restreinte, se distinguent à longue distance des autres parcelles de Maïs.

Toutes les plantes issues du pied $A_{1}$, cultivées soit en 1904 , soit en 1905 et 1906 à Locon, Chaville et Bourg-la-Reine, ont montré les 
mêmes caractères de régétation et de précocité. Les conditions de culture, la nature et la préparation du sol, la fumure ne semblent aroir d'autre efiet que daugmenter ou de réduire dans des proportions faibles la taille et le nombre des organes sans modifer la prícocité; les caractères d'espèce élémentaire nouvelle sont complètement fixés.

La variation des caractères affecte tout dabord le port. La plante est grêle, basse, offre un petit nombre de feuilles qui sont courtes et étroites; les nœuds ne sont guêre espacés et la panicule qui termine la tige a un petit nombre de rameaur relativement serrés, oủ les épillets sont très denses. Il en est de mème pour ce qui concerne la disposition des graines sur le rachis de l'épi. On peut résumer en une phrase les caractéres de cette forme en disant qu'elle montre la réduction des organes régétatifs et la condensation des oryanes floraux. Toutes ces qualités seront l'objet d'une étude détaillée fondée sur le tracé de polggones de rariation indiriduelle. La loi de réduction des organes régétatilis est surtout manifeste pour les bractées d'enveloppe de l'épi, organes d'importance secondaire ue jouant pas un ròle capital dans l'assimilation en raison de leur courte lurée et de l'absence complète de limbe.

Quoique les épis latéraur soient courts, le nornbre des graines qu'ils portent est presque aussi éleré que celui des épis du Mais de Pensylranie. Le nombre des rancées de graines est le plus sourent dis, partois douze; les rangées sont serrées, sourent imbriquées les unes dans les autres, par suite irrégulières, et les graines se rapprochent de la forme arrondie alors qu'elle est aplatie pour le Mais origine. La rariation consiste dans la réduction de la taille de lovaire, réduction qui améne la diminution en rolume de l'albumen alors que les dimensions de l'embryon sunt à peine modifiées. Il en résulte que l'ezamen comparé des graines de la variété de M!nys de Pensylunnie et de l'espèce élémentaire Zea Mays praecox donne les caractéres les plus nets et les plus précis de la distinction des formes. On ne peut trourer aucun terme de passage par l'examen des iruits déreloppés sur les inflorescences latérales femelles. Seules les graines déreloppées sur les panicules déformées de Mais de Pensrrlvanie présentent des caractères intermédiaires et pourraient ètre difticilement séparées par le triage dans an mélange accidentel ou rolontaire des lots de semences.

La difficulté est renciue plas grande encore par des variations dans la coloration de l'alburnen que présentent les graines récoltẻes sur 
les panicules déformées. Il est facile de remarquer, à la récolte, la teinte jaune franc cles fruits développés à l'air libre qui fait contraste avec la couleur jaune pâle des graines développées sur les épis latéraux de la même plante. Le Zea Mays praecox présente aussi cette coloration jaune foncé qui est caractéristique des fruits développés à l'air libre pour la variété de Maïs de Pensylvanie. Peut-être faut-il attribuer ce caractère à la maturité précoce, à une époque où l'atmosphère est chande et sèche, ou bien encore à une action directe de la lumière qui. peut pénétrer facilement entre les bractées peu nombreuses et entrouvertes des épis? Il est probable toutefois que la variation de teinte de l'albumen est un caractère nouveau, apparu sur la panicule $B_{2}$ de la plante déformée expérimentalement en 1902 et conservé seulement sur une partie de la descendance. Car la forme Zea Mays praccox, née en 1903, a donné naissance, en 1904, à une variété nouvelle à grains blancs complètement stable lorsqu'on la cultive séparẻment.

Toutes les plantes récoltées à Locon en 1904 portaient des grains jaunes. Parmi les épis cueillis à Chaville, à la fin du mois d'Août de la même année, j’en ai observé deux portant quelques graines blanches disséminées parmi les fruits jaunes du typo. Il y en avait 5 sur l'un des épis, 4 sur l'autre, et ces graines furent plantées en 1905, à Locon. Les 7 plantes qui en sont nées portaient des grains blancs. La même variation s'est reproduite à plusieurs reprises depuis dans des lignées à graines jaunes; il est possible que ce caractère nouveau soit apparu dès 1903, qu'il ait été caché par un phénomène de xénie à la récolte de cette année, et qu'il se produise depuis une disjonction des caractères. J'ai, d'autre part, des lignées de $Z$. M. praecox qui n’ont jamais montré la variation à grains blancs.

C'est à une variation analogue des caractères de l'albumen que j'attribue l'apparition, en 1905, de fruits ridés et jaunes. Je n'ai pu fixer cette variation en 1906, mais elle s'est reproduite sur un nombre suffisamment élevé de pieds pour que je conserve l'espoir d'isoler cette tendance. Elle présente un grand intérêt parce que on ne possède pas, à ma connaissance, de variétés de Maïs qui aient un albumen ridé de couleur jaune mat et foncé.

La même lignée m’a fourni une variété « eversporting 》très curieuse dont les caractères nouveaux n’ont pas été signalés jusqu'ici dans les Graminées. Ils consistent en la métamorphose des glumelles 
en bàtonnets charnus, prolongús par des stigmates comparables à ceux de loraire du Maĩs ordinaire. Ce caractére a fait son apparition en 1904 sur quelques indiridus observés à Chaville; je n'ai pu le retrouver sur les plantes de mème origine cultivées à Locon la mẻme année parce que. á l'époque oủ jen ai fait l'esamen, les panicules étaient desséchées depuis longtemps. Peut-être existait-il sur la panicule de la plante $A_{1}$ des cultures de 1913 ? C'est une bypothẻse qu'il est matériellement impossible de rérifier. Quoi qu'il en soit, la métamorphose des glumellules en stigmates est réapparue, dans de fortes proportions, sur quelques lignées cultivées à Locon et à Bourg-la-Reine en 1916. Il est probable que ce caractére anormal ne pourra ètre fixé complètement et caractérise une variété ecerspinting au sens de H. DE TrREs.

Le tableau suirant résume les rariations observées dans la lignẻe du Zeu Mays praecox:

1902. Panicule du type B sur une plante mutilée.

1903. Plante $A_{\S}$ déformée, précoce, naine.

1901.

Zeu Muys proterox.

type à grains jaunes rar. à grains blancs
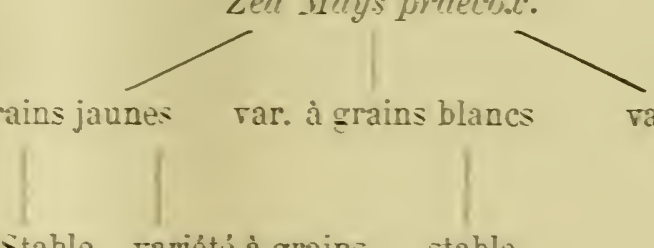

1905. Stable variété à grains ridés

1906.

var. à glumellules

stigmatifêres

Z. I. PRAECOS VAR. NATABLE

ESPÉCE ÉLÉYIEX- A GRANS JACNES

TAIRE STABLE.

RIDÉ:.

stable

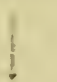

instable

Z. II. PRAECOX

TAR. INSTABLE

TAR. $I L B A$

STABLE.

$\triangle$ GLCMELLCLES

STIGMATIFËRES.

La facilité arec laquelle l'espèce Zea. Mays prraecox a été obtenue pure de tout mélange, dès sa décourerte, tient certainement à la précocité de sa floraison. L'absence d'hŗhridation arec la forme de Mais tle Perisyluarie, au milieu de laquelle elle est née, permet de croire que son isolement, dú á des circonstances purement phrsiologiques, était réalisé dés 1903, et que lon doit rapporter à cette date la manifestation de la rariation brusque ou Jutation qui Iui a donné naissance. 
Malgré la fixité des caractères qui distinguent l'espèce élémentaire Zea Mays praecox des autres variétés connues de Mais cultivées par comparaison, l'état d'affolement qui caractérise la lignée n'a pas disparu. On s'explique ainsi l'obtention d'une variété stable à grains blancs, de variêtés instables à grains ridés ou à glumellules métamorphosées en stigmates. J'ai récolté, en 1906, bon nombre de plantes à feuilles tubulées, à tiges tordues, à épis couverts d'épillets mâles et femelles, à rejets dont les panicules ont des rameaux fasciẻs, et leur culture permettra peut-être la fixation de variétés nouvelles.

\section{1. - Étude biométrique des Caractėres qui définissent} LES FORMES NOUVELLES ET STABLES.

Les cultures de contrôle, faites en 1906 sur un grand nombre d'individus appartenant à chaque lignée nouvelle, m'ont permis de préciser les différences plus ou moins accusées que présentent les espèces et variétés nouvelles nées dans la variété de Maïs de Pensylvanie à la suite de mutilation; les chiffres ont été obtenus soit à la récolte, soit plus tard au laboratoire où j'ai fait transporter les panicules et les épis. Les tableaux suivants les renferment et permettent d'en faire la comparaison.

\section{TAILle DES tiges (en décimètres).}

Formes :

$456 \quad 7 \quad 8 \quad 91011 \quad 1213141516171819202122232425$

Z. M. pensylvanica........

$Z$. $M$. v. pseudo-androgyna..

$Z$. M. v. semi-praecox.....

Z. $M$. praecox............

$\begin{array}{llllllllllllll}1 & 1 & 4 & 1 & 5 & 14 & 21 & 15 & 11 & 10 & 6 & 7 & 3 & 1\end{array}$

Z. M. praecox v. alba..... 325112315161411

II. Nombre DE FEUILLes.

\begin{tabular}{|c|c|c|c|c|c|c|c|c|c|}
\hline Formes : & 6 & 7 & 8 & 9 & 10 & 11 & 12 & 13 & 14 \\
\hline Z. M. pensylvanica. & & & 2 & 15 & 13 & 45 & 14 & 8 & 3 \\
\hline Z. M. v. pseudo-androgyna... & & & 3 & 27 & 48 & 20 & 2 & & \\
\hline$Z$. M. v. semi-praecox....... & & & 3 & 10 & 40 & 31 & 12 & 3 & 1 \\
\hline Z. M. praecox.............. & & 2 & 19 & 44 & 31 & 3 & 1 & & \\
\hline Z. M. praecox v. alba......... & 5 & 40 & 41 & 11 & 3 & & & & \\
\hline
\end{tabular}


Formes :

\section{CoMPacité des Panicules.}

Z. M. pensylvanica....... $31015142117 \quad 7 \quad 5 \quad 5 \quad 3$

Z. ... v. pseudo-androgyna. $126 \quad 8 \quad 13232213884$

Z. M. v. semi-jraecox.....

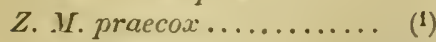

Z. .Y. praecox v. alba...... (1)

$\begin{array}{llllllllllll}6 & 7 & 8 & 9 & 15 & 17 & 16 & 6 & 7 & 5 & 2 & 1\end{array}$

$\begin{array}{lllllllllllllll}3 & 2 & \text { fi } & 7 & 10 & 11 & 12 & 15 & 8 & 7 & 7 & 5 & 4 & 1\end{array}$

$\begin{array}{llllllllllllll}3 & 11 & 9 & 17 & 12 & 11 & 9 & 6 & 2 & 3 & 5 & 6 & 4 & 2\end{array}$

IV. Nombre de RAMEaUX dES PANicUles.

$\begin{array}{llllllllllll}\text { Formes: } & 0 & 2 & 4 & 6 & 8 & 10 & 12 & 14 & 16 & 18 & 20\end{array}$

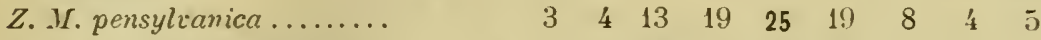

Z. I. v. pseudo-androgyna.. $\quad \begin{array}{llllllllll} & 2 & 5 & 18 & 36 & 14 & 11 & 10 & 3 & 1\end{array}$

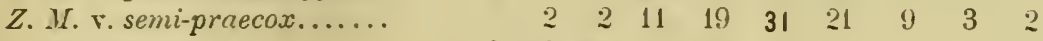

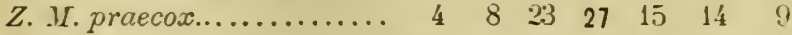

Z. M. praecox v. alba...... $15 \begin{array}{lllllll}5 & 13 & 28 & 24 & 11 & 4 & 5\end{array}$

T. Dexsité DES RaMeAUX DES PANicules.

(établie pour le rameau inférieur de toutes les panicules)

Formes :

Z. .Y. pensylranica........

Z. .I. r. pseudo-androgyna. .

Z. .M. r. semi-praecox......

Z. I. praecox.............

Z. I. praecox v. alba....... $\begin{array}{llllllllllll}11 & 12 & 13 & 14 & 15 & 16 & 17 & 18 & 19 & 20 & 21 & 22\end{array}$

$\begin{array}{llllllll}3 & 10 & 12 & 22 & 13 & 18 & 17 & 5\end{array}$

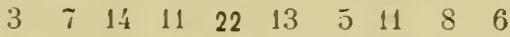

$\begin{array}{lllllllllll}2 & 4 & 7 & 19 & 20 & 17 & 9 & 11 & 7 & 3 & 1\end{array}$

$\begin{array}{lllllllllll}2 & 4 & 5 & 7 & 9 & 12 & 23 & 15 & 12 & 10 & 1\end{array}$

$\begin{array}{llllllllll}3 & 6 & 8 & 11 & 13 & 19 & 16 & 14 & 8 & 2\end{array}$

VI. Nombre de BRACTÉEs d ENveloppe de L'ípI 1. (L'èpi 1 est l'épi inséré le plus haut sur la tige)

$\begin{array}{llllllllllllll}\text { Formes: } & 3 & 4 & 5 & 6 & 7 & 8 & 9 & 10 & 11 & 12 & 13 & 1.4 & 1.5\end{array}$

Z. M. pensylvanica .......

Z. M. v. pseudo-androgyna..

Z. M. v. semi-praecox.......

Z. M. praecox........... $3247 \quad 16 \quad 5$

Z. M. praecox v. alba...... 13 27 $40 \quad 16 \quad 4$

VII. Nombre de RANgées de graines suR LES ÉpIS 1.

Formes:

Z. U. pensylvanica .........

Z. .Y. v. pseudo-androgyna. .

$\begin{array}{llllll}4 & 6 & 8 & 10 & 12 & 14\end{array}$

Z. .I. v. semi-praecox.......

$\begin{array}{llll}3 & 71 & 22 & 4\end{array}$

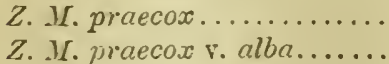

$\begin{array}{lll}3 & 87 & 10\end{array}$

$44 \quad 45 \quad 8$

VIII. COMPACITE் DES ËPIS 1 .

$\begin{array}{llllllllllll}\text { Formes: } & 15 & 16 & 17 & 18 & 19 & 20 & 21 & 22 & 23 & 24 & 25\end{array}$

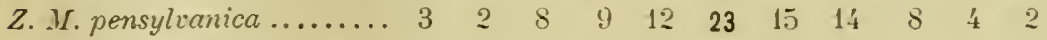

Z. M. v. pseudo-androgyna.. $\quad \begin{array}{lllllllll}2 & 3 & \tau & 18 & 35 & 23 & 9 & 3\end{array}$

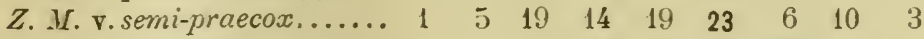

Z. Ir.praecox............ $\quad 3 \quad 13 \quad 24 \quad 35 \quad 10 \quad 3$

Z. M. praecox v. alba...... $\quad 3 \quad 3 \quad 9 \quad 19 \quad 42 \quad 23 \quad 4$

(1) La compacité des panicules ne peut s'établir que si le nombre des rameaur dépasse 3. Les formes $Z$ M. praecox ont toujours un nombre faible de rameaux, ce qui explique l'irrégularité relative des séries de chiffres. 


\section{FAMILLE I.}

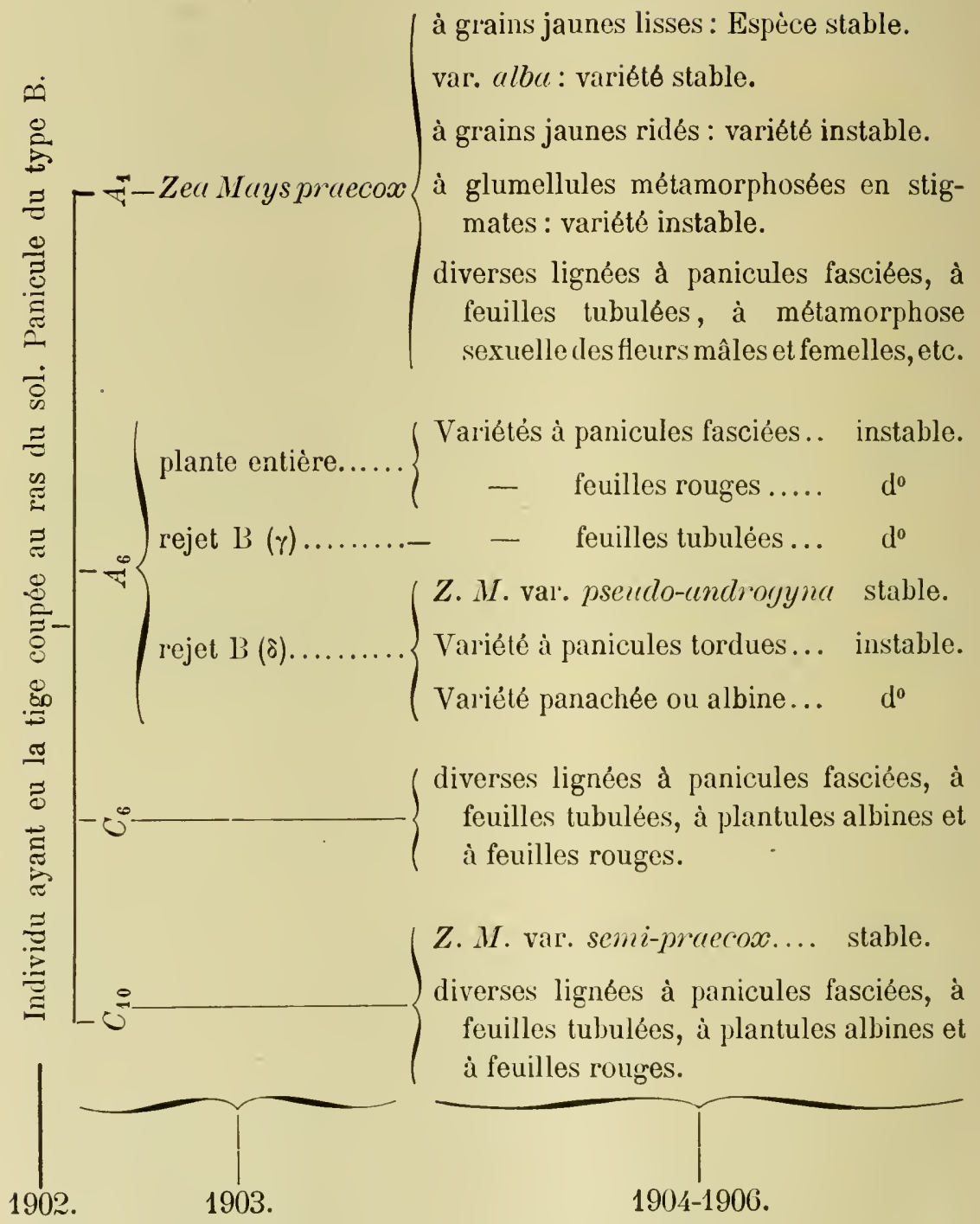




\section{MUTATIONS ET TRAUMLTISMES.}

\section{2. - RÉSumé DES VARIATIONS HÉRÉditaires DE LA Famille I.}

Si l'on résume dans un tableau d'ensemble les rariations béréditaires observées dans la descendance de la Famille I, on constate que la panicule anormale du type B obtenue, en 1902, après section de la tige principale d'un pied de Maïs, a donné naissance à un grand nombre de lignées distinctes de la rariété de Maïs de Pensylranie.

Ce sont d'abord les formes instables ou variétés eversporting qui reproduisent dans des proportions variables la fasciation des rameaux de la panicule, la métamorphose des épillets mâles en épillets femelles, la torsion des tiges, la suture des bords des feuilles ou le port pleureur.

Il en est d'autres qui ne peuvent se perpétuer en raison de leur nature mème. Les lignées tératologiques donnent sourent des plantules dépourrues de pigment chlorophyllien incapables de déreloppement, et aussi des indiridus dont les tiges et les feuilles rouges modifient la transpiration et déterminent la stérilité. Il est impossible de songer à la fixation de ces caractères incompatibles arec les lois les plus générales de l'organisation régétale.

Viennent enfin les rariétés et les espèces noureiles complètement stables. Elles montrent l'acquisition de caractères morphologiques noureaux et inconnus jusqu'ici dans le genre Mais, comme l'hermaphroditisme des épis latéraus de la variété pseudo-andiogyjun, ou encore la production de races semi-précoces dont le principal caractère distinctif est d'une nature physiologique, comme on peut le reconnaître sur la variété semi-pirclecox; ou enfin, des modifications complétes dans le mode de régétation, la taille et la dimension des organes, les époques de floraison et de maturité qui distinguent l'espèce élémentaire nouvelle Zea Mays jraccox et les variétés dérivées. 
Toutes ces variations, héréditaires en totalité ou en partie, doivent être rapprochées des variations créatrices d'espèces, définies récemment par Hugo de Vries sous le nom de Mutations. Elles en suivent les lois les mieux établies: (H. DE VRIEs, Mututionstheorie, vol. I, p. 174).

\section{3. - Lois DE la Mutation.}

I. - Les Nouvelles espéges ĖLĖMentaires NAISSENT tout a COUP, SANS TERMES de PASSAGE (loc. cit., p. 174).

L'apparition de la forme Zea Mays praecox, découverte en 1904, a été subite et l'acquisition des caractères nouveaux totale et sans retour. Il faut attribuer ce succès inattendu à la nature même des qualités nouvelles. Par sa floraison rapide, le Zea Mays praeco:x ne peut être fécondé par le pollen de la variété de Maïs de Pensylvanie qui lui a donné naissance; son isolement fut immédiat et complet.

Il est établi que les variétés semi-praccox, pseudo-androyyna sont nées par le même processus. Si leur isolement a demandé quelques générations, cela tient à l'hybridation forcée des individus origines des lignées nouvelles avec la variété de Mä̈s de Pensylvanie au milieu de laquelle ils sont apparus. La facilité avec laquelle j'ai réussi à obtenir les variétés pures et stables montre que leur création a été subite. Il n'existe pas, à vrai •dire, de termes de passage entre la forme ancestrale et les variétés nouvelles. Lorsque sur un épi des cultures de 1904 j'ai observé les caractères de la variété pseudo-androgyna visibles seulement sur les deux tiers des épillets, l'épreuve des graines non entourées d'étamines visibles a montré l'existence latente du caractère, puisque plus de 80 pour 100 de leurs descendants le mettaient en évidence. Il faut donc admettre que la variation s'est faite par saut, sans termes de transition.

L'obtention dans la même famille d'une variété semi-praecox et d'une espèce élémentaire $Z$. M. praecox aurait pu, dans d'autres circonstances, être considérée comme un exemple de variation héréditaire due à la sélection graduée d'une qualité nouvelle. Imaginons que, dans la culture des descendants de la Famille I, on n'aie pas pris le soin de cultiver séparément les graines récoltées sur des individus diffẻrents ; on aurait pu faire, après quelques générations, choix des individus mûrs à la fin de septembre et séparer un mélange 
de Z. M. var. semi-praecox et de Z. M. praecox de la variété de Mä̈s de Pensylvanic; ce premier progrès aurait pu ètre complété plus tard par l'isolement d'un nombre plus ou moins élevé d'indiridus de l'espèce Zea Mays praecox renfermant encore en mélange quelques individus de la variété semi-praecox. On conçoit qu'une sélection riğoureuse aurait éliminé peu à peu ces plantes qu’on aurait regardé comme atariques, pour donner la forme Zea Mays praecox complètement pure.

Si mème les différences de floraison entre les deur formes avaient été moins accusées, et, avaient permis leur mélange par hybridation, il aurait été nécessaire de faire le choix des indiridus les plus précoces pendant dix ou même vingt générations pour arriver à ce résultat, et toujours il serait resté quelque formes intermédiaires ou ataviques causes de la Régression, inéritable lorsque la sélection n'est plus rigoureuse.

Ainsi, la culture en bloc des individus d'une population sans isolement des lignées, conduit à attribuer à la sélection lente et graduée des qualités qu'elle ne posséde point et qui sont le résultat d'une variation brusque initiale. Johasssex (1903) a insisté longuement sur cette cause d'erreur qui accompagne la majeure partie des exemples de création des variétés par la seule sélection des variations individuelles, considérées à tort comme lentes et graduées.

Dans la Famille I, l'individu $A_{6}$ est l'origine de la lignée, née par variation brusque, $Z$. $M$. var. semi-praecox, l'individu $A_{1}$ est l'origine de l'espèce $Z$. M. praccox, indépendante de la première, quoique apparue en mème temps. La séparation des lignées, faite à l'époque mème de la variation, fournit immédiatement les formes nouvelles et stables qu'une sélection lente n'aurait pu donner que par l'élimination difficile et loujours incomplète de l'une ou l'autre lignée.

II. - LES NOUTELLES ESPËCES ĖlÉveNTAIRES SONT, POUR LA PLUPART, COMPLÉTEMENT STABLES DÉs LES PREMIERS MOMENTS DE LEUR NaIssaxce (Mututionstheorie, I, p. 175).

Depuis 1904, époque à laquelle j'ai découvert l'espèce Zea Lays praecox dans mes cultures, $\mathrm{j}$ 'ai cultivé environ un millier d'individus appartenant à cette forme nouvelle. Je n'ai pu observer aucun cas de retour à la varièté de Maïs de Pensylvanie. Bien plus, il est 
apparu dans cette lignée des variations nouvelles, comme celle de la variété $Z$. M praecox alba complètement fixée, ou les variations à grains ridés et glumellules métamorphosées en stigmates, ou des individus à feuilles tubulées, à épis latéraux mâles et femelles, etc..., sans qu'on puisse y reconnaître aucune tendance atavique.

Toutes les plantes issues du pied $A_{1}$, des cultures de 1903, offrent tous les caractères généraux qui définissent l'espèce nouvelle Zea Mays praccox, dont les caractères sont équivalents à ceux de toutes les espèces de Maïs connues, puisqu'ils montrent une constance absolue malgré la fréquence des anomalies de végétation.

La fixation des variétés $Z$. M. pseudo-androgyna, Z. M. semipreccox, quoique plus récente, ou plutôt, contròlée sur un nombre moins élevè de générations, est aussi très nette. Je les soumettrai à une étude de contrôle pendant plusieurs années encore ( ${ }^{1}$ ).

V $\left({ }^{2}\right)$. - LES PROPRIÉtÉS NOUVELLES NE MONTRENT AUCUNE RELATION Particuliére aVEc la Variation individuelle (Mutationstheorie, I, p. 179).

Tous les caractères qui rẻsultent de l'hérédité particlle ou complète d'une anomalie font évidemment partie de la variation accidentelle. Tels sont les fleurs hermaphrodites de la variété pseudo-androryna, les graines incolores du Zea Mays praccox var. alba, la suture des bords des feuilles de la variété à feuilles tubulées, le port de la vuricté de Mar̈s pleureur, etc. La discussion pourrait avoir quelques

(1) Il est une épreuve qu'il m'est impossible de tenter seul et pour laquelle je demande l'aide des biologistes, des harticulteurs et des agriculteurs. J'ai fait la récelte d'une grande quantité d'épis des variétés et espèces nouvelles que je considère comme fixées. M. le professeur Costantin, directeur du service des échanges de graines du Muséum d'Histoire naturelle de Paris, a bien voulu se charger de les mettre en circulation: elles seront remises à quiconque en fera la demande. Les lets d'envoi permettront de faire la culture cemparée des formes nouvelles nées dans mes essais. Il serait très intéressant de pouvoir comparer les résultats des cultures faites en des localités très différentes comme sol et comme climat, et je serais très reconnaissant aux personnes qui, ayant fait l'épreuve du matériel mis à leur disposition, consentiront à me faire part de leurs observations. D'autre part l'envoi d'un épi de chaque forme me permettrait de contròler la stabilité de quelques caractères morpholegiques visibles sur les graines méthode qui donne d'excellents résultats dans la multiplication des lignées pures d'Orge de Brasserie (Blininghem, 1905).

(2) Les chiffres romains placés devant les propositions énoncées par Hugro dE VRIEs indiquent l'ordre que l'auteur a suivi dans l'exposé des lois de la Mutation. J'ai trouvé avantage à le modifier. 
raisons d'être en ce qui concerne l'apparition du caractère de précocité. La maturité précoce est souvent considérée comme un caractère soumis à la variation individuelle, mais on ne peut ranger dans cette catégorie une variation subite tellement accusée que la fécondation entre le type nouveau et la variété ancestrale est impossible. Les conclusions qui ont été établies à propos du rôle de la sélection dans la fixation des formes précoces peuvent être invoquées ici pour montrer la véritable nature de la variation qui a formé le Zea Mays praccox et la rariété semi-praecox. Je reviendrai plus loin sur la généralité de la production de formes naines et précoces à la suite de mutilations.

VI. - LES MUTATIONS QUI DÉTERMINENT LA FORMATION DE YOUVELLES ESPECES ĖLEMENTAIRES NE SUIVENT PAS DE DIRECTION DËFINIE. LA VARIATION AFFECTE TOUS LES ORGANES ET LES FAIT VARIER DANS TOUS LES SENS (Mutationstheorie, I, p. 179).

L'examen, même superficiel, des variations héréditaires présentées par les différentes lignées de la Famille I, montre la fixation de nombreuses particularités de forme ou de régétation complètement indépendantes. L'existence de variétés à panicule fasciées, à tiges tordues, à feuilles tubulées ou courertes d'un abondant pigment rouge, les différences frappantes que l'on peut établir entre les épis du Maïs de Pensylvanie et ceux de la variété semi-praecox, de la forme instable à épis ébréchés et de l'espèce Zea Mays praecox, les caractères très singuliers des fleurs hermaphrodites de la variété pseudo-androryma, enfin toutes les variations de taille, de nombre de feuilles, de nombre de bractées d'enveloppe et de rangées des épis, de compacité de grappes florales montrent que la variabilité affecte tous les organes et les modifie dans tous les sens.

Le nombre des lignées cultivées depuis 1903 a été limité. Parmi les 28 plantes appartenant à la Famille I, quatre individus seulement ont été choisis pour l'étude de la transmission du caractère des rameaux fasciés. J’ai repris, après la décourerte des nombreuses variations, la culture d'un certain nombre de lignées issues de la même famille qui me donnent tantôt des formes analogues à celles qui sont décrites plus haut, tantôt des caractères plus aberrants encore et, en particulier, le développement de crêtes poilues sur les feuilles, ou les feuilles lobées. 
Toutefois il est un caractère qui se présente dans la plupart des lignées ; c'est la précocité relative que seuls les pieds à port pleureur ou à feuillage rouge ne présentent point.

III. - La plupart des nouveauX types correspondent par LEURS PROPRIĖTÉS A DES ESPE்CES ÉLE்MENTAIRES ET NON A DES VARIÉTÉS PROPREMENT DITES (Mutationstheorie, l, p. 176).

La proposition s'applique évidemment au Zea Mays praecox qui a donné naissance ultérieurement à des variétés au sens où les a définies Hugo de VRIEs; la forme Zea Mays praecon alba, les variétés instables à grains ridés et à glumellules métamorphosées en stigmates sont nées dans l'espèce élémentaire Zea Mays praecox, soit par la mise en latence d'un seul caractère (albumen blanc, ou ridé), soit par l'apparition d'un caractère nouveau pour les Graminées (métamorphose des glumellules en stigmates). Cependant, il est hors de doute que la forme Zeu Mays prcecox se rapproche par la plupart de ses caractères de l'EEnothera nanella née par mutation dans la Famille $2 E$. Lamarchiana et que Hugo DE VRIES considère comme une variété. (Species and Varieties, p. 531).

En adoptant cette opinion, le Z. M. pseudo-androgyna serait une espèce nouvelle au même titre que l'E. lata puisque l'une et l'autre forme sont définies par des variations florales analogues; la rariété instable de Maïs à feuilles rouges pourrait être comparée à l'Enothera mbrinervis, etc.

La discussion provient de la difficulté qu'il y a à définir avec précision l'espèce élémentaire et la variété proprement dite. Par l'étude des travaux très remarquables de Hugo de VrIes sur la Variation et l'Hérédité, on arrive à une conception nette de la distinction que l'on peut établir entre ces deux modes de groupement des individus. Deux espèces élémentaires voisines diffèrent par tous leurs caractères qu'on ne peut associer deux à deux. Une variété dillëre de l'espèce élémentaire de laquelle elle est née par la mise en latence ou par la variation d'un seul ou de quelques caractères; mais il est toujours facile de décomposer les unités spécifiques de l'une et l'autre forme at de les associer par groupes binaires. Il en résulte que la variété peut être facilement définie par un mot, par l'addition d'un qualificatif, comme c'est le cas pour la forme de Maïs d̀ port pleureur ou Mä̈s précoce d̀ grains blancs; au 
contraire, le nom qui permet de distinguer les espèces élémentaires ne peut opposer des qualités, c'est un indice, un signe qui correspond à toute une série de qualités nouvelles et anciennes groupées d'une façon différente. En adoptant cette convention on peut regarder les formes Zea Mays praccox, Z. M. pseudo-androgyna, Z. M. semipraccox comme des espèces élémentaires nouvelles, et les Maïs à port pleureur, à feuilles tubulées, à tiges tordues, comme des variétés ( $\left.{ }^{1}\right)$.

\section{4. - Discussion de la périodicité de la mutation.}

Il reste à examiner, pour complèter l'analogie entre les variations de l'Enothera Lamarckiana et celles de la Famille I du Maïs de Pensylvanie mutilé, les propositions IV et VII qui suivent:

IV. - LES ESPÉGES ÉLĖMENTAIRES APPARAISSENT LE PLUS SOUVENT EN UN NOMBRE DÉTERMINÉ D'INDIVIDUS, SOIT SIMULTANĖMENT, SOIT DANS LA MÈME PĖRIOdE (Mutationsthemie, I, p. 177).

VII. — La Mutabilité apparait PĖRiodiquement (loc. cit., p. 181).

H. DE VRIES a énoncé cette dernière loi en insistant sur son caractère hypothétique. La constance des espèces est un fait démontré par l'expérience; les essais de Jordan, repris et vérifiés par NaEgELI, DE BARY et d'autres, formaient un obstacle en apparence insurmontable à la vérification expérimentale du principe de la Descendance de Dirwin. La découverte de la Nutation, créatrice d'espèces, apparaissant brusquement et disparaissant sans laisser de traces autres que celle de formes nouvelles et complètement stables, à détruit toutes les critiques que l'on a pu faire à la théorie de l'Évolution des formes. Les espèces sont stables pendant une grande partie de leur vie; de temps à autre il se produit une modification d'équilibre qui permet la variation par saut des formes, et ces périodes de Mutabilité, très courtes par rapport à la vie de l'espéce, passent inaperçues. Le hasard, aidé par un souci constant de la culture de lignées pures, permet seul de les découvrir. On assiste alors à la variation désordonnée; la Mutation dans tous les sens

(1) La possibilité d'obtenir des hybrides féconds et iustables ne paraìt pas devoir être invoquée ici, puisque l'Enothera latn considérée comme une espèce nouvelle par Hugo DE VRIES ne differe point par ce caractère de l'CEnothera nanella. 
fournit les espèces nouvelles les plus variées et les mieux adaptées par élimination des faibles au crible de la sélection.

A l'hypothèse d'une Mutabilité périodique dont les causes sont inconnues, je suis conduit, par mes recherches sur le Maïs, à substituer celle d'une Mutabilité provoquée par des causes acciclentelles, mutilations violentes, galles, Insectes ou Champignons parasites, greffe, variation brusque du milieu, etc...

En me limitant aux faits exposés dans ce mémoire, je crois avoir établi que les mutilations violentes, qui souvent causent la mort de l'individu, déterminent l'apparition de caractères nouveaux ou ataviques, plus ou moins stables, qui subsistent en partie dans la descendance et peuvent pour la plupart être fixés. Les traumatismes permettent de provoquer la période d'affolement, de Mutabilité créatrice d'espèces et de variétés nouvelles.

On peut faire de nombreuses objections à cette interprétation. Tout d'abord le choix du Maïs comme matériel d'expérience est mauvais. Quoique la plupart des cas de variations signalées dans cette espèce résultent de la méconnaissance des faits de Vicinisme, il n'en est pas moins vrai que les variétés de Maïs sont trop mal définies et peut-être trop nombreuses pour qu'il ne reste pas un doute sur la véritable nature des modifications que l'on peut suivre dans leurs transformations. Mes expériences sur le Maïs n'ont point été entreprises pour l'étude de la Mutabilité. Au début de mes recherches, j'avais seulement en vue la détermination expérimentale du sexe des fleurs. Ayant récolté en abondance des graines saines sur des inflorescences d'ordinaire stériles, j'ai été conduit à en faire les semis et à reconnaître l'hérédité partielle du caractère anormal des parents. La culture des lignées séparées montre l'apparition de caractères nouveaux qui de suite ont été fixés. 11 m'était impossible de ne pas rapprocher ces phénomènes de ceux qu'a étudiés Hugo DE VRIES dans l'Enothera Lamarckiuma.

En 1903, j’avais cn culture un grand nombre de plantes témoins. Aucune d'elles n'a donné spontanément les variations héréditaires que j’ai provoquées expérimentalement par des mutilations apropriées. La variété de Maïs de Pensylvanie cultivée dans le Nord de la France n'était donc pas en période de Mutabilité avant que je lui aie fait subir des déformations expérimentales. D'ailleurs la même méthode a donné des résultats analogues pour la plupart des variétés de Maïs que j’ai pu me procurer. 
Le Naïs est en effet un mauvais matériel pour les études sur la variation. Il est défectueux parce qu'il est difficile, lorsqu'on ne dispose que de surfaces restreintes de culture, d'isoler suffisamment les lignées pour faire l'épreuve de la transmission des caractères. Les recherches analogues que j'ai entreprises sur l'Orge seront plus concluantes et plus nettes, plus faciles aussi parce que la plupart des formes d'Orges connues sont strictement autofécondées. Il est d'autant plus remarquable que le Maïs, en quelques années, ait donné un si grand nombre d'espèces et de variétés nouvelles et stables.

Le Maïs est un matériel défectueux parce qu'il donne un faible nombre de grains. Les panicules anormales portent rarement plus de cent fruits bien formés et sains ; les épis latéraux fomelles donnent en moyenne deux cents grains. Il en résulte que l'étude de contrôle des qualités héréditaires d'un individu ne peut se faire sur plus de cent descendants alors que certaines plantes, comme l'Enothère ou le Tabac, donnent des milliers de plantules. De plus, les caractères anormaux transmis sont facilement reconnus sur les jeunes plantes pourvues de cotylèdons étalés et de feuilles primordiales libres. Grâce à ces circonstances farorables, H. DE Vries a pu faire l'étude des pourcentages héréditaires dans des cuvettes, en serre, en disposant de tous les facteurs de bonne nutrition et d'humidité conrenable pour la culture des porte-graines. Le sarant hollandais a insisté longuement sur les avantages de cette méthode pour la sélection, ou mieux, l'épuration des lignées anormales (1892-94) et c'est gràce à elle qu'il a pu établir la loi IV :

LES ESPĖCES ÉLĖMENTAIRES APPARAISSENT LE PLUS \$OUVENT EN UN NONBRE DÉTERMINÉ D'INDIVIDUS SOIT SIMULTANÉMENT SOIT DANS LA MÈME PÉRIODE (Mutationstheorie, I, p. 177).

Il semble qu'il y ait discordance entre cette règle établie sur les variations de l'Enother Lumarckianu et les faits observés dans mes cultures de Maïs. L'explication peut en être donnée par les circoustances différentes dans lesquelles la mise à l'èpreuve des lignées a été faite dans les deux cas.

H. DE Vries a observé la Mutation dans une Famille de plantes qui devait ètre depuis longtemps déjà dans l'état de mutabilité. Les recherches minutieuses, faites récemment sur les dates d'introduction de l'Enothera Lamarckiana en Europe, montrent que cette espèce possédait probablement, vers 1860 , la qualité de mutante découverte 
beaucoup plus tard. D'ailleurs cette qualité ne s'est guère atténuée depuis le début des observations c'est-à-dire depuis vingt années. Il est probable que les lignẻes anormales de Maïs laissées à elles-mêmes ne tarderaient pas à montrer les mêmes caractères. Si dans mos cultures j'ai mis en évidence un nombre considérable de formes nouvelles relativement au nombre d'individus observés, cela tient sans aucun doute à l'isolement immédiat des plantes anormales dont l'affolement n'avait pu être atténué par le croisement avec les formes ancestrales. D'ailleurs, il suffit de suivre la progression décroissante du pourcentage des anomalies qui ne peuvent être isolées avec sûreté, pour reconnaître qu'en peu d'années les lignées à rameaux fasciés, par exemple, ne fourniront plus qu'un faible nombre d'individus aberrants.

Alors que les plantes mutantes sont dans la proportion de 1 à 3 pour 100 parmi les descendants de la Famille Enothera Lamarchirana, entrée depuis longtemps dans la période de Mutabilité, la proportion décroît pour les lignées de Maïs anormales progressivement de $71,5 \%$ dans la première génération à $50 \%$ dans la deuxième, $38 \%$ dans la troisième, $26 \%$ dans la quatrième. Il est probable que cette famille tend vers une position d'équilibre où le nombre des anomalies ne sera guère plus élevé que celui qu'on observe dans la Famille Lamarckiana.

De l'ensemble de cette discussion il résulte que: la Famille II de Maïs tératologique, obtenue après la mutilation, est en période de Mutation.

Il s'agit maintenant de savoir si la méthode qui consiste à faire subir à des plantes des traumatismes violents, accidentels ou volontaires, a joué un rôle considérable dans l'évolution des formes sauvages ou cultivées. Il serait trop long de signaler ici les multiples exemples de variation par bourgeons décrits par DARwiv (1868), Carrière (1865), Verlot (1865), Korschinsicy (1901) dont un grand nombre semble dû à des mutilations initiales. Je me contenterai de mettre en relief le rôle des traumatismes pour la production expérimentale des espèces élémentaires nouvelles, naines et précoces. 
CHAPITRE XVIII.

CRÉATION DE FORMES PRÉCOCES CULTIVÉES OU SAUVAGES.

\section{5. - DÉveloppement RAPIDE DES REJETS.}

La précocité relative des lignées anormales obtenues par mutilation a déjà été l'objet d'une étudo spéciale. J'ai montré que la méthode qui m’a donné le Zea Mays praecox, les variétés semi-praecox, pseudo-androgyna, et la variété instable à tiges tordues, toutes plus précoces que le Maïs de Pensylvanie, a fourni des résultats analogues arec diverses espèces d'Orges et a rendu des lignées d'Enothera biemnis annuelles. La loi semble générale, et il est peu de plantes qui ne puissent en montrer les effets. Parmi mes nombreux essais faits dans les environs de Paris, seul le Ricin (Ricinus communis) ne m'a pas permis de récolter de graines mûres sur des rejets développés après la section des tiges au début de la floraison.

Les rejets dérivent de bourgeons latents qui ne se développeraient point si les tiges existantes restaient intactes ; l'excitation inhibitoire que leur communique le bourgeon principal cessant avec sa disparition, ils évoluent très rapidement en rameaux feuillés et fleuris parce qu'ils sont abondamment nourris par une souche souterraine vigoureuse. En général les débuts de végétation d'une plantule sont lents; la croissance de la tige est limitée par le pouvoir absorbant des racines qui sont peu fournies, et pendant une grande partie de la vie végétative, il s'établit un équilibre entre les échanges de matériaux fournis par les organes aériens aux racines, et par les racines aux organes aériens. Vient ensuite la période de préparation des organes reproducteurs; elle se caractérise chez les plantes annuelles par la croissance rapide des axes, des bractées, des grappes florales. L'appareil radiculaire s'épuise sans profiter des réserves abondantes que forment les feuilles au maximum de leur développement et les matériaux accumulés sont transportés aux fleurs et aux fruits pendant que se fait la dessiccation.

La suppression totale des organes aériens détermine l'apparition de 
bourgeons adventifs qui, pour le succès de l'expérience, doivent être en nombre limité; les jeunes bourgeons évoluent plus rapidement que les tiges principales des mêmes plantes, parce que les inatériaux de construction sont exclusivement utilisés pour la croissance des tiges, l'appareil radiculaire étant complètement formé. Il en résulte un développement rapide favorisé par la chaleur plus forte de l'été. Les jeunes bourgeons de Maïs, d'Orge, d'Enothère qui, bouturés, auraient exigé six mois et même davantage pour la production des graines, les donnent en moins de trois mois.

\section{6. - LA PRÉGocité RÉSUlte DE L’AdAPTATION.}

On ne peut guère parler de qualité acquise en ce cas. Il n'est pas douteux que si l'on pouvait réaliser la greffe des jeunes tigelles de Maïs sur une souche de la même plante on n'obtienne avec le bourgeon terminal des résultats analogues. La preuve en est fournie par la pratique horticole qui consiste à réduire le nombre de générations nécessaires pour faire l'épreuve d'une variẻté d'arbre ou d'arbuste en greffant les extrémités des jeunes rameaux sur des souches ou des tiges très vigoureuses. Il faut en conclure que la plupart des bourgeons des plantes sauvages et cultivées possèdent la qualité d'une double adaptation, ou mieux d'une adaptation multiple aux conditions générales de nutrition. Ces phénomènes sont étroitement liés à ceux que Massart a mis en évidence pour les bourgeons du Polygonum amphibium (1902) et que DE VRIEs a assimilés à de nombreux cas de polymorphisme (Species and Varieties, p. 430).

S'il est facile de concevoir la possibilité de déterminer expérimentalement la floraison et la maturation précoce, il est moins commode d'expliquer comment se fait la transmission héréditaire de cette qualité. En réalité elle n'est pas nouvelle pour la plante; elle existait déjà à l'état latent et elle s'est maintenue sur un certain nombre de descendants. Or il existe un grand nombre d'exemples de variation brusque de bourgeons qui correspondent à la mise en latence d'une qualité ou à l'apparition d'un nouveau caractère. Le mémoire de Konschinsiry (1901) est le rẻsumé de nombreuses observations, décrites soit dans les publications scientifiques, soit dans les traités spéciaux à l'agriculture et à l'horticulture, qui montrent que l'évolution des formes, dans la plupart des cas, est le résultat de l'Hétérogénèse ou de la variation de bourgeon. La stabilité des 
caractères nouveaux est un fait expérimental qu'il est pour le moment impossible d'expliquer sans hypothèses inutiles. Il en est de même pour l'acquisition du caractère stable précocité.

\section{7. - DIMORPHISE SAISONNIER.}

Il est intéressant de constater que ces conclusions, déduites de recherches d'ordre expérimental, s'accordent complètement avec celles que R. vox WETtSTEIx est conduit à adopter, après une longue étude de la répartition géographique et des affinités systématiques d'espèces sauvages. Sous le nom de Dimorphisme saisonnier, WEttsten (1900) décrit l'existence dans la nature de formes de plantes très différentes d'aspect, de port et surtout de précocité, qui montrent entre elles des analogies de caractères telles qu'il est facile de les associer par groupes binaires et d'en déduire l'étroite parenté. Les unes sont élancées, grèles, ne portent qu un petit nombre de feuilles et de rameaux, mais des fleurs nombreuses et très fécondes ; elles fleurissent tôt et leur's graines sont mùres de très bonne heure. Les autres, tarlives, sont basses, étalés, très ramifiées et ont le port des plantes ombrophiles; quoique déreloppées en pleine lumière, elles possèdent une longue période de vie purement végétative et ne dressent leurs rameaux couverts de fleurs que tard dans la saison. Les différences d'aspect sont frappantes au point d'aroir nécessité la création de noms d'espéces différents, quoique des particularités morphologiques peu saillantes, poils, dents des calices, disposition particulière des organes, montrent leur aftinité réelle et rendent leur distinction difficile au seul examen des fragments de plantes.

WetTstein a rapproché les formes qui montrent le dimorphisme saisonnier par groupes de deux espèces. En roici quelques exemples:

\section{Groupe des Gentiana.}

G. praeflorens WETTsr. prẻcoce correspond à G. austriaca A. et J. Kens. tardive

G. praecox A. et J. Ker.

G. praematura BonB.

G. antecedens WETTST.

De mème :

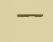

$-$

carpatica WETTST.

G. stiriaca WeTtst.

G. calicina Косн.

$E$. Rostkoviana HArve

E. stricta Host.

o. serotina LAMARCK

calium verum L.
Odontites verina BELL.

Galium praecox L.

etc... 
Or WetTstein, dans l'étude de la répartition géographique des espèces, montre que le dimorphisme saisonnier, absent dans les régions élevées des montagnes, paraît être la règle dans les régions basses et surtout pour les espèces précoces des prairies et des champs: "On ne peut admettre, dit-il, que l'action de conditions favorables de nutrition détermine la production des formes par la seule variation individuelle, car les caractères particuliers sont constants et héréditaires ». L'auteur en a d'ailleurs fait l'épreuve par des cultures précises, et par conséquent ces formes appartiennent bien à la catẻgorie des Espèces Jordaniemnes ou espèces élémentaires.

\section{8. - Discussion des conclusions de Wettstein.}

Wettstern trouve l'explication du dimorphisme saisonnier dans l'adaptation directe. Il serait la conséquence de l'action de facteurs définis pour une station déterminée qui se traduirait par l'acquisition de propriétés nouvelles des plantes. Les espèces précoces possèdent le minimum de feuilles et de rameaux et n'ont pas d'organes inutiles; les espèces tardives restent longtemps à l'état de rosette; elles étalent leurs branches et ne les allongent que très tard dans la saison avant de donner leurs fleurs. La différentiation maxima s'observe au mois de juin, à l'époque de la fenaison. Il en conclut que « la coupe régulière des prairies et des champs a agi dans le cours des temps sur la variation individuelle et, par le moyen de la sélection, a créé les espèces dimorphes » (1900, p. 344).

Cette conclusion trouble WETTSTEIN et ne satisfait pas complètement aux faits. Selon lui, la forme primitive serait l'espèce tardive, la seule qui existe dans les bois et dans les montagnes; les espèces précoces en seraient dérivées par la sélection inconsciente de l'homme qui, par le fauchage répété, a supprimé les intermédiaires. D'ailleurs la variation n'a pas dû être régulière et uniforme. « Je suis porté à croire, dit-il, que tout d'abord les plantes tardives ont donné des formes déviées (ou anormales) en rapport avec l'adaptation directe. Les types qui se rapprochaient morphologiquement des espèces précoces se sont définitivement maintentas en raison du milieu et de la sélection $\gg(1900$, p. 346).

Le mémoire de WetTstein était rédigé au mois d'octobre de 1899. Les conclusions n'auraient-elles pas été plus affirmatives si l'auteur 
avait eu connaissance de la Théorie de la Mutation énoncée par Hugo de Vrres un an plus tard? Des détails de son travail, laissés à dessein dans l'ombre, montrent que WETTSTEIx a songé à l'existence possible de variations accidentelles. Il a constaté par exemple que la Campanula glomerata donne dans les prairies soumises à la coupe régulière une forme naine Campanula serotina et tout d'abord il avait cru que cette espèce n'était autre qu'un individu de Campanula glomerata dont la tige avait été coupée à la base et dont les rejets fleurissaient en automne pour la seconde fois. La culture des graines faite au jardin expérimental lui a montré que les Campanula serotina WETTST. conservaient leurs tiges courtes et basses pendant deux générations (1895-1897).

L'obtention du Zea . Kays piraecox dans mes cultures de lignées tératologiques de Maïs de Pensylvanie me paraît fournir l'explication des faits observés par Wettster. Les caractéres qui distinguent la forme nouvelle de la variété origine sont exactement ceux qui définissent le Dimorphisme saisonnier. La localisation des espéces naines et précoces dans les prairies et les champs soumis à des coupes régulières permet de déterminer la cause-de la variation. Les traumatismes violents sont, d'après WWETSTErs, influencé par les notions admises sur le processus de l'Évolution, la cause indirecte du dimorphisme saisonnier; après la découverte de la variation créatrice d'espèces par HUgo DE Yries, après l'obtention de formes nouvelles et précoces complètement stables dans des lignées mutilées de Maïs, je suis autorisé à proposer l'hypothèse que les traumatismes violents, les coupes répétées, sonit la cause directe du diriorphisme saisonnier, hypothèse qui a l'arantage de pouroir ètre soumise à une vérification expérimentale. 


\section{ÉVOLUTION DU GENRE ZEA.}

\section{9. - Création méthodique de formes nouvelles.}

S’il est possible d'obtenir avec certitude une forme précoce de toutes les espèces tardives connues par l'emploi rationnel des mutilitions violentes, ne peut-on dire que l'on possède un moyen commode le création expérimentale d'espèces nouvelles?

Puisque la plupart des végétaux réagissent au traumatisme par la production d'anthocyanine $\left({ }^{1}\right)$, et que les plantes à feuillage rouge obtenues par ce procédé conservent cette propriété par hérédité, n'est-on pas en droit d'admettre que le problème de la production des variétés nouvelles est en partie résọlu? Une telle interprétation des faits serait erronée. Il y aurait tout au moins une disproportion considérable entre les conséquences d'une affirmation aussi naturelle et les expériences trop peu nombreuses et bien imparfaites encore qui permettent de l'énoncer.

Il ne faut pas oublier que les variations qui sont les conséquences directes d'une mutilation brutale sont désordonnées, qu'elles affectent à la fois les tiges et les feuilles, les fleurs et les fruits, et qu’à priori, il est difficile de dire quelle sera la conséquence immédiate de la sertion des tiges d'une plante. La fascie des rejels, la torsion des axes, la suture des bords des feuilles, la cohérence des tiges, rameaux ou feuilles, la métamorphose des pieces florales sont toutes anomalies distinctes, très différentes les unes des autres, dont le seul lien est précisément les multiples variations lans le nombre et l'assemblage des faisceaux libéro-ligneux. La mutilation détermine l'affolement des plantes qui la subissent; elle n'a qu' rarement des effets précis et déterminés à l'arance. Aussi, on ne peut dire que la section des tiges d'une espèce permettra d'en oblenir des formes nouvelles à qualités prévues; mais il est plus conforme à la rẻalité

(1) FlerofF (1906) a montré que les mutilalions agissent mème sur la pigmentation des champignons inférieurs tels que le Penicillium purpurogenum. 
d'affirmer que les traumatismes déterminent l'irrécularité dans les lignées les plus régulières, et qu'il est pariois possible l'isoler. dans ce chaos, des espèces et des variétés montrant des groupements nonveaus de caractères, ou mème des qualités tout à fait nourelles et inattendues.

Lorsque, dans la première partie de ce travail, j’ai montré que pour une variété déterminée de Mais, il existait une mutilation suffisamment violente qui, à une époque bien définie de la régétation, léterminait la métamorphose certaine des épillets mâles des rejets en épillets femelles, jai rouln insister sur la possibilité de faire de la Tératolog̣ie expérimentale uue science précise arec ses règles et ses lois. Il est probable qu'une étude sulfisamment prolongée des causes de lapparition des feuilles tubulées sur la tige de Mais conduirait aus mèmes résultats. Toutelois. sül était nécessaire de mettre en lumière les lois de la production des feuilles en cornets, il serait préférable d'abandonner le Maĩs et le faire choix, comme matériel d'expériences de plantes offrant très sourent des ascidie's, comme l'Orme, le Noisetier, le Tilleul, etc. En d’autres termes, les différentes espèces végétales ont des tendances diverses, mises en éridence soit par la plus ou moins grande fréquence des anomalies trouvées dans la nature, soit par la plus ou moins grande lavilité arec laquelle elles apparaissent sous laction des conditions de vie. des mutilations, des parasites animaux et régétaus. et mème de l'hy̧bridation.

Les mutilations ne créent pas de iaractères, d'unités spécifiques nourelles. Elles ditruisent les équilibres réalisés entre les tendances risibles, modifient leurs rapports et permettent l'épanuuissement des tendances latentes. Il est possible que dans l'èbranlement froroqué quelques groupements noureaux soient compatibles arec les conditions générales de rie: les indirilus qui les portent, isolés. sont l'origine d'espèces nourelles.

Il en résulte que la création expérimentale llune forme nécessite la combinaison simnltanée de trois catégories de recherches:

$1^{0}$ La décourerte des conditions particulières de milieu (substratum, lumière, chaleur, humidité, etu.) qui firorisent l'ẻpanouissement d'un caractère dẻterminé. Les horticulteurs et les aģriculteurs possèdent les éléments de cette science de l'élereur; ils déterminent, par l'emploi judicieur de semis espacés ou serrés, de la chaleur vu du froid, de l'humidité ou de la sécheresse, de la lumière ou de 
l'obscurité, ou encore, par le seul choix de la date des semis, le développement de rosettes de feuilles abondantes (Salades et Choux tournés), de racines charnues (Carottes, Raves, etc.) ou l'allongement des axes et la floraison abondante et précoce. L'étude scientifique de ces facteurs est à peine commencée. KLEBS (1905) y porte tous ses efforts, et les résultats, obtenus récemment par Molliard (1905) sur le Radis, sont assez surprenants pour montrer combien il reste à faire dans cette voie.

$2^{0}$ Il est possible que des conditions extrêmes de végétation déterminent l'ébranlement des équilibres qui définissent l'espèce. La démonstration de cette hypothèse reste à établir. Mais il n'est pas douteux que l'hybridation et les traumatismes violents provoquent l'affolement des individus et permettent la découverte des caractères latents. Le seconde partie de ce mémoire est consacrée à l'étude des variations de toute nature affectant les organes les plus variés et qui résultent de l'action des mutilations. La troisième partie a montré que bon nombre de ces états peuvent être fixés.

$3^{0}$ Il y a lieu de se demander si les formes nouvelles isolées par ce procédé sont quelconques, s'il n'est pas possible de préroir les groupements de caractères les plus stables, et d'orienter le choix des individus, origines de lignées nouvelles, pour obtenir des races fixées. Il me semble que la connaissance de toute la série des formes déjà décrites dans l'espèce linnéenne Zea Mays, dans les genres qui composent la tribu des Maydées (Zea, Euchlaena, Tripsucum, Coix, etc.), et même dans les autres genres de Graminées, farorise. le choix des anomalies qui doivent être cultivées et soumises à l'épreuve du pourcentage héréditaire.

Une première raison de simple prudence milite en faveur de cette hypothèse. Les caractères ne sont pas créés par la mutilation, ils existent avant le traumatisme qui en détermine seulement des groupements diffẻrents. Or, on connaît très mal les liaisons qui unissent les caractères les uns aux autres; l'étude des corrélations est délicate et on en connaît un trop petit nombre d'exemples pour établir sur eux un raisonnement solide. Parmi les multiples combinaisons possibles des caractères, il en est qui ne peuvent être réalisées, soit parce qu'il y a incompatibilité (plante précoce à rendements élevés), soit pour des causes inconnues. Le ineilleur moyen de déterminer à l'heure actuelle les combinaisons possibles de caractères consiste à examiner celles qui existent déjà dans la 
nature et qui sont offertes par les varıétés. les espèces ou les genres roisins de la forme étudiée.

C'est d'autre part un fait admis que les mutilations, on les insectes parasites, ou le froid, déterminent le retour accidentel ou constant à des formes ancestrales. L'atarisme est sourent inroqué pour expliquer les variations de bourgeons, et la méthode la plus commode pour arriver à la connaissance des ancètres est de tracer la généalogie des espéces en saidant de tous les documents connus. La Srstématique, fondée sur les Enchainements naturels, est l'expression mème de l'Érolution. Lontogénie, reproduisant la phỵlogénie, d'après Fritz Mت̈Ller, permet d'établir les chainons indispensables pour suirre la diffèrenciation progressive des formes.

On a sans doute attribué un trop grand rôle à la Sélection en affirmant quelle seule proroque le parallélisme des caractères de diffèrenciation progressire des formes. Il est difficile d'expliquer, par sa seule action, la persistance de caractères peu visibles mais très stables, comme celni de la présence de poils fins sur les pédoncules des épillets de l'Orge et de l'Aroine, alors que ces poils ne jouent aucun ròle connu dans la phrsiologie des espèces qui les présentent. Les documents paléontologiques, d'ailleurs, ne permettent point de méconnaître la loi de complication progressive des êtres. Si donc on reut préroir les tendances possibles d'une espèce en roie d'ẻrolution. il y a intérèt à examiner les stades parcourus par une espèce ou un genre roisin et plus érolué. La morphologie, lanatomie et la physiologie comparée peurent rendre de nombreux services dans la recherche des formes nourelles.

Ces notions resteraient confuses si on ne les dẻreloppait par l'étude, aussi succincte que possible, l'un esemple. Il importe donc d'essayer de reconstituer l'histoire érolutire du genre Zea et de montrer par quelle méthode on peut fournir la justification des hrpothèses énoncées.

\section{0. - Etude de L'origine d'Une espéce, le Zea .Hays L.}

L'ancètre sauvage lu Mais est inconnu. Beaucoup d'auteurs, arec A. DE CAxdolle (Iミ§3), admettent son origine américaine: malgré les recherches, on n'a pu trouver jusqu'ici aucune forme de Maïs virant à l'état spontané. La succulence des tiges, l'incomplète protection des graines, dont les oiseaux sont très friands, permet 
d'ailleurs de supposer que le Maïs, tel que nous le connaissons, ne pent se multiplier sans le concours constant de l'homme.

En 1893, Harshberger décrivit, dans une étude botanique et économique du Maïs, une plante vivant au Mexique qu’il considérait ('omme le type sauvage. Le professeur l)ugés l'avait trouvée au More Leon (ou Congregacion), où elle rtait connue des indigènes sous le nom «le « Maiz de Coyote». Watson l'avait désignée sous le nom de Zea cunimu (1891).

Il est reconnu aujourd'hui que le Zeu c‘nima W. n'est pas une espèce réritable, mais un liybricle entre le Zeu. Wuys et l'Euchlucun mexicunu (H.arshberaer, 1901). Abandonné à lui-même, il donne par disjonction des caractères l'Éuchluenu mexicume pur, mais, placé dans de bonnes conditions de vie, il se clange en moins de trois années en une véritable plante de Zer. Hays. Cette circonstance avait fait prévaloir l'opinion fausse que le Zeu cuninu posscialait deux états, la forme sauvige, étroitement reliẻe au genre Euchluenu (1), et la lorme cultivée, proche parente de toutes les variétés comues de Maïs. Le professeur Sigura, ell 1896, décrivait à HARShberger les conditions dans lesquelles prenait naissance la forme Zeu cumimu rt démontrait la nature hybride de cette plante. Ces faits, publiés par Harshberger (1896 et 1901), sont l'occasion d'une description détaillée de l'Euchluena mexicuna, plante dont je n'ai pu obtenir d'échantillon fleuri.

L'Enchlıenu mexicum a le port. „lu Maïs, mais il est plus grèle ot plus buissonnant. Les épis femelles, grroupés en grappe, sont étroits et munis de deux rangées de graines; lem ensemble, enveloppé de bractées, est situé à l'aisselle les fruilles latérales de la tige tandis que la panicule terminale, dégagée, offre tous les caractères de la panicule de Maïs. Les èpillets femelles, composés d'une fleur fertile et d'une fleur rudimentaire, sont placés dans une dépression en forme de coupe creusée dans le rachis et fermée en partie par la glume infẻrieure coriace. La plante hybrile $(E$ Echlucm mexicana $\times$ Zeu Mruys) décrite par Harsiberger (1893, Pl. I) ne diffère guère de l'Euchluena à la première génération; les grraines sont disposées d'une manière distique sur chaque branche de l'inflorescence et sont légèrement plus grosses que celles du Téosinté (Euchlaenu). Si on

(1) Ascherson, P. (1876-79) a insisté longuement sur les affinités systématiques des genres Zea et Euchleana (Reana). 
fait usage de pollen de Maïs pour la fécondation de l'hỵbride en hruxième génération puis en troisième génération, on obtient des graines très roisines de celles du Mais et des épis dont le nombre des rangées augmente et passe à 4 ou à 6 . Laxe moelleux de l'épi grossit, il so dissocie parfois en deux branches paraissant brisées. La plante correspond alors au Zee cunime Watsox.

\section{1. - Comparaison du Zen caning areg la variété NOUTELLE DE MAÏS A ÉPIS DISSOCIÉS.}

Or la description de ceite plante conconle assez exactement arec celle de la rariété instable de Maïs à épis à í rangées de graines et multiples, que jai obtenue en cultirant les semen ps portérs par un plante mutilée en 1910:3 (page 17 í et Pl. VIII, fig. (5-97). L'épi initial portait quatre rangées de graines, et la transinision du caractére

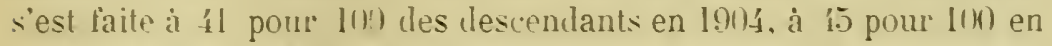

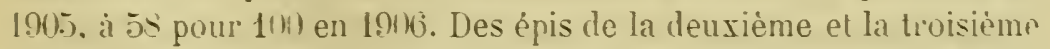
génération ont mème montré un caractere noureau pour le Maîs el 1+ Téosinté qui consiste en la métamorphose partielle des épillets femelles en fpillets máles ou hermaphrodites. Je discuterai plus loin la valeur des fleurs hermaphrodites.

La ramification des inflorescences latérales femelles a la suite de la mutilation, la fixation plus ou moins parfaite l'une forme á épis ra mifiẻs et ne portant que á rangées de graines. peuvent être regardées comme un retour à une espèce ancestrale intermédiaire entre le $Z e^{\prime \prime \prime}$

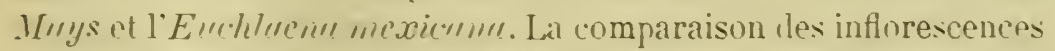
latérales femelles uniaxes du Maïs ordinaire, les inflorescences femelles ramifiées of du terme extrème où les rameaux à qualre rangées dlépillets montrent la métamorphose partielle les ipillets lémelles en ípillets màles, permet l'établir une sériation continue les formes corresponlant it un état lo fasciation décroissant des axes. C'est la disparition locale de la lastie qui détermine la métamorphose des fleur's femelles en Heurs màles, c'est une atténuation de la fascie qui fournit l'inflorescence ramifiẻe au lieu de l'inflorescence uniare.

De cette discussion il résulte que l’ẹpi latéral femelle du Maïs ne diffère de l'inflorescence latéralc femelle de l'Eu-hluenu mexicmun que par l'état de fasciation très accentuée des parties de cette inflorescence. Il existe deux stades d'équilibre, celui de l'Euchlacinn. 
mexicana et celui du Zea Mays, complètement stables, définissant deux espèces distinctes mais très voisines. Entre ces formes, on connaît de nombreux intermédiaires, montrant une hérédité partielle. Ce sont les différents degrés d'hybridation trouvés entre le Zea Mays et l'Euchlaena mexicana dont un terme moyen est le Zea canina Watson, ou, dans mes cultures, les différents termes de passage trouvés entre l'épi femelle uniaxe du Maïs et les inflorescences latérales ramifiées, chargées de fleurs mâles et femelles, dont un terme moyen est la variété « eversporting » nouvelle à épis dissociés et couverts de 4 rangées de graines.

\section{2. - Origine DES ESpÉcE. du Genre Maïs.}

Les plantes cultivées offrent de fréquents exemples de formes opposées complètement stables, entre lesquelles oscillent des degrés intermédiaires moins bien fixés. Le groupe des Choux se rapproche par bien des caractères du cas présenté par le groupe EuchlaenaZea et permet d'en comprendre parfaitement la valeur. Il est arlmis que le Brassica oleracea ( $\left.{ }^{1}\right)$, plante bisannuelle vivant à l'état sauvage sur les bords de la mer du Nord, est l'origine des nombreuses races potagères ou ornementales répandues dans la culture. On en connait des formes ramifiées, élancées et grêles à l'époque de la floraison, et d'autres qui, comme le Chou-fleur, ont une tige épaisse et courte couverte par une agglomération de lames enchevêtrées et serrées, qu'un examen même superficiel fait reconnaître pour des fascies typiques. Les Choux sauvages et les Chouxfleurs sont stables dans les semis. Les premiers peuvent être rapprochés de l'espèce Euchlaena mexicana, les seconds du Zea Mays. Toutefois le Maïs donne des graines fécondes, sauf dans le cas de l'inflorescence prolifère du Zea Mays tunicata décrite antérieurement. Le Clıou-fleur ne mûrit ses graines que, si par des procédés appropriés, on réduit l'état de fasciation et on détermine l'allongement de quelques ramifications, méthode adoptée par les horticulteurs pour propager la race Chou-fleur.

(1) Il est possible que les espèces vivaces et ligneuses Brassica balearica et Br.cretica, des bords de la Méditerranée, aient contribué à la production de plusieurs de nos races de Choux cultivés. Ce fait n'infirme nullement le rapprochement établi entre le Maïs et le Chou-fleur. 
Il est facile de reconnaître le parallélisme suivant :

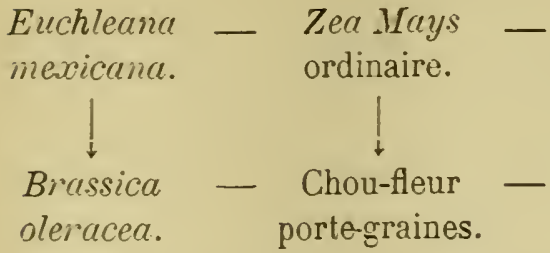

Zea Mays tunicata

(à inflorescences Chou-fleur).

Il en résulte que l'ancètre saurage du Maïs est l'Euchlaena mexicana au mème titre que le Brassica oleracea L. est l'ancètre saurage du Chou-fleur.

Le Maïs peut être considéré comme une forme particulière du genre Euchlaend montrant la persistance complète par voie de semis de la fasciation des inflorescences latérales femelles. Cette opinion n'est pas nouvelle; elle a été adoptée par HARshberger (1893-1896), par Schomaxx (1904), MIoxtgomery (1906), et les arguments nombreux que je pourrais invoquer en sa fareur entraîneraient l'exposé diffẻrent de la plupart des particularités végétatives et florales qui ont été décrites dans ce mémoire. La conriction serait plus complète encore, s'il m'était possible de faire l'étude comparée des différentes formes de Maîs que j'ai eues en culture, avec les espèces peu étudiées jusqu'ici du genre Euchlaena.

Il y a lieu de se demander, en effet, si plusieurs espèces élémentaires du genre Euchleana ont contribué à l'édification des nombreuses formes qui constituent l'espèce linnéenne Zea Mays, ou si toutes les variétés connues du . Vaïs dérirent d'une même lignée initiale d'Euchlnena mexicana fasciée. Naturellement la réponse dépend exclusirement des résultats que pourraient donner des cultures expérimentales d'Euchlaena mexicana, faites dans le but d'isoler les petites espèces réunies dans cette espèce linnéenne, cultures qui ne peurent ètre faites qua Mexique.

En l'état actuel de nos connaissances, il est logique d'admettre que beaucoup de formes nouvelles sont nées dans le genre Zea.Muys, et, en particulier, les variétés et espèces précoces, puisqu'on ne connaît aucune forme d'Euchlaenu qui mûrisse régulièrement ses fruits hors du Mexique. C'est sans doute aussi après la fixation de caractères de fascie des inflorescences latérales que sont apparues les multiples variations de coloration des graines (couleur de l'oraire, de l'assise protéique, de l'albumen), des bractées florales, des 
fenilles et des tiges. Les fruits de l'Euchlenu mexicun que j’ai pu observer sont bruns et cornés ; les variétés de Maïs à grains jaunes, blanes, à albumen amylacé et sucré, correspondent à la mise en latence de caracteres de la plante sauvage. Ja coloration rouge de l'ovaire du Mais serait un retour partiel it la coloration brune de l'ovaire du Téosin!é. Ces retours sont variés et le plus souvent incomplets, d'oì résultent les multiples formes à grains noirs, rouges, striés de rouges, ou maculés de rouge, de gris ou de bleu connus dans les variétés de Maïs. Il est facile de se rendre compte de leur origine, et il n'est pas rare d'en voir naitre dans les cultures de plantes affolées.

Il est moins commode de déterminer l'époque relative de la disjonction des formes décrites dans ce mémoire sous le nom d'espèces élémentaires. Elles diffèrent surtout par la forme des fruits, mais aussi par la plupart de leurs caracteres vigétatifs et floraux. Sans doute, la plupart sont apparues dans, l'espèce Zcu Muyss déjà fixée, et la lorme Zeu Muys pirncox, née dlans mes cultures expérimentales, permet de soutenir cette hypothèse; mais il est possible aussi que cerlaines d'entre elles soient apparues au moment même oủ l'Euchlacna mexicum a donnè naissance à l'espèce tératologique Zea Muys. l.es nombreuses divergences de caractères que prennent les descendants d'une même plante en piriode de mulation, rendent cette explication plausible; elle parait d'autant plus rraisemblable que la taille et la forme des graines varie sensiblement suivant le legré de fisciation de la portion de rameau qui les porte; les fruits récollés sur les panicules anormales et ramifiées sont petits et arrondis, alors que les graines des épis latéraux sont grosses el symétriques par lapport à un plan; les fruits des diffrirentes génerations de l'hybride Zee comim W. varient dans leurs formes avec l'état plus ou moins accusé de fascie des inforescences latérales. Il rst probable que les individus origines du genre Zen n'ont pas tous présenté le mème degré de succulence et d’épaissement des axes, el, par suite, ont fourni des espèces élímentaires distinctes. Enfin, l'hypothèse la moins vraisemblable est eelle de l'origine distincte des différentes espèces élímentaires de Maïs, chacune d'elles étant issue d'une espèce élémentaire antérieurement diflẻrenciée d'Éuchlaena.

L'espèce élémentaire $Z c u$ Moys tunicutu appartient à la catégorie de formes qu'on a coutume de désigner sous le nom d'ataviques. Elle est caractérisée par le grand développement des glumes des 
épillets femelles qui sont analogues à celles des épillets mâles de toutes les Maydées. Entrainés par cette ressemblance, beaucoup d'auteurs ont regardé le Vais tuniqué ou Bulyumix comme le type ancestral clu Mais cultive: Acguste ST-Hilare (1820), Darwin (186is) et peutètre Aschersox (1sii) ont soutenu cette hrpothèse que Wrimuck (ISoli) réfute en attribuant le caractère particulier à un état de rirescence des bractées florales, qu'on peut assimiler complètement aux bractées foliaires.

Liopinion de Wrrtusck ast évilemment adoptée par tous les auteurs qui considèrent l'Euchluém uiexicum comme un ancètre du Mais. En effet les bractées les épillets lemelles sont léjà très modifiées pour toutes les plantes de la tribu des Maydées. Leur nature cornée et cartilagineuse est commune aux genres Zeu, Euchlueur, Tripsumm. et le Coix Lucrymu, très différent de ces plantes, possècle une bractée florale temelle ligneuse qui a fait comparer le fruit à une larme durcie. Le retour atarique doit ètre therchẻ bien loin. dans la tribu des Andropogonées. et il est manifestement plus diffir-ile d'établir une filiation entre les Andropogonées et le Ze"l Mays tumicutu que de suirre la série trés naturelle: Andropogonées. Tripsucum, Euchlercuu et $Z$ e'».

Le déreloppement foliacé des bractées d'enreloppe des fruits du Zeu. Muys tunicutu est une anomalie de régétation qui a pu ètre fixée, suit par les efforts de l'homme. soit par l'avantage qu'elle offre pour la protection des graines contre les rarages des animaux et en particulier des oiseaux. Mais ce n'en est pas moins une anomalie. au mème titre que la suture des borls de feuilles. ou lo déreloppement d'étamines auteur de l'oraire fécondé de là variẻté pxéurdo-rundiryIy yu. Dans mes cultures expérimentales. j’ai pu les obserter dans les mèmes lignées tératologiques et elles sont des caractères noureau: pour le genre $Z e^{\prime \prime}$.

Ce serait une grave erreur de supposer qu'un caractère ne pent ètre noureau pour une lignée que si on n'en troure point de traces dans tous les ascendants proches ou reculés de la lig̣née (1). Malgré la multiplicité des formes possibles. il est reconnu que toutes celles que nous présentent les organes des plantes rentrent dans quelques

1) Cette opinion est adoptée par la plupart des auteurs qui attribuent à l'atarisme une action capitale et ront mème (P.x, 1s90) jusqu'd regarder toutes les anomalies régetales comme des exemples de retour à des formes ancestrales. 
catégories bien limitées. Les traités d'Organographie ou de Phytomorphie dérivent de cette loi. En raison du nombre limité des formes, il est fatal que la variation en reproduise qui soient déjà connues, et les variations stables, créatrices d'espèces, doivent précisément reproduire fréquemment des formes existant dans les familles voisines, dans les genres ou les espèces alliés, car, la lutte pour l'existence élimine les combinaisons très variées mais peu favorables à l'accomplissement des fonctions vitales. Aussi, faut-il éviter l'emploi du mot ataviste pour désigner les individus qui présentent des variations qu'on n'observe point sur les lignées dont la parenté directe et proche est bien établie.

Les caractères: glumes herbacées des épillets femelles, épillets hermaphodites des inflorescences latérales, feuilles à bords soudés, sont des caractères nouveaux pour la tribu des Maydées; ils sont nouveaux pour l'espèce Zea Mays, et surtout, pour la variété de Maïs de Pensylvanie sur lesquels ils ont été observés. La forme stable Zea Mays var. pseudo-androgyna est donc bien une varièté progressive au même titre que le Zea Mays praecox et la variété $Z$. $M$. semi-praecox. Par contre, la variété Zea Mays praecox alba, caractérisée par la mise en latence du pigment qui colore l'albumen, est une variété régressive.

En résumé, le genre Zea dérive d'un ou de quelques individus, appartenant à une ou plusieurs espèces élémentaires du genre Euchlaena, dont les inflorescences latérales ont montré, à la suite de causes inconnues, l'état de fasciation plus ou moins complète. 11 est peu probable que les fruits des plantes fasciées, aient été épargnés des oiseaux, et autres animaux qui en sont friands, sans l'intervention de l'homme. Le genre Zea est né dans la culture ou a contribué à provoquer chez l'homme le souci de la récolte et de la plantation, c'est-à-dire les premiers rudiments de la culture. Dans tous les cas, le genre Zea doit son origine à une anomalie, à une variation brusque. C'est un exemple de mutation ayant donné naissance à un genre nouveau.

Des anomalies accidentelles ou provoquées, soit involontairement soit à dessein, très probablement locales, sont les origines des multiples formes, espèces élémentaires ou variétés connues à l'heure actuelle. Les mutilations violentes constituent, en particulier, un moyen commode de création de nouvelles espèces dans le genre Maïs. 


\section{CONCLUSIONS GÉNÉRALES ET RÉSUMÉ.}

L'objet de ce travail est de mettre en évidence un facteur très important, et méconnu jusqu'ici, de l'érolution des formes régétales:

"Les traumatismes violents, qui parfois détruisent l'individu, provoquent souvent le développement surabondant de rejets dont tous les organes, tiges, feuilles, fleurs et fruits montrent des déviations considerables du type spécifique et constituent de véritables monstrusitẻs. Gráce anx mutilations, on peut inetre la plupart des végétaux dans l'état d' «affolement»qui est, pour les horticulteurs, la période de la vie de l'espèce qui fournit les nouvelles variètès».

"Parmi les plantes que des mutilations ont mises dans l'étut $d$ ' affolement», ètat qui correspond à un déséquilibre du type moyen, un certain nombre présentent des anomalies partiellement héréditaires. Dans leur descendance, celles-ci fournissent, en outre des anomalies graves, des plantes nomales ayant. repris l'équilibre ancestral et de très rares individus présentant des anomalies légères. Ces dernières sont totalement héréditaires et constituent des variétés complètement nouvelles et stables $\gg$.

Ces conclusions ont été énoncées dans une note présentée à la Société de Biologie de Paris le 18 novembre 1905. A cette date, j'avais réuni toutes les preures qui sont exposées dans ce mémoire et, si j'ai tardé à en fournir la démonstration détaillée, c'est que, annonçant la production expérimentale de variations héréditaires, il importait de préciser la nature des caractères nouveaux par 
l'étude d'un grand nombre de lignées et aussi de faire une abondante récolte de graines pour permettre le contrôle des faits observés ( ${ }^{1}$ ).

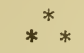

Mes efforts ont porté, dans ce travail, sur la description de la méthode expérimentale qui m'a conduit à la découverte des lois énoncées. J'ai étudié, en détail, la nature et les causes d'une anomalie bien caractérisée de la panicule du Maïs ; j'ai montré, par l'interprélation des tableaux de culture, comment il est possible d'obtenir quelque précision dans l'analyse de phénomènes où tout varie, en apparence, d'une manière désordonnée; j'ai établi, par des cultures comparées, la nature véritable des caractères apparus dans les lignées tíratologiques. Enfin la description des monstruosités les plus différentes, développées sur le Maïs et sur les plantes les plus variées, m’a permis de généraliser les lois reconnues dans un cas particulier.

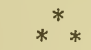

I a Première Partie de ce mémoire est consacrée à l'analyse dẻtaillẹe des causes qui provoquent la métamorphose des organes sexuels du Maïs.

Les diffẻrences morphologiques et physiologiques que présentent les bourgeons terminaux et latéraux du Maïs sont dues à des variations très accusées dans leur mode de nutrition et de croissance. A l'origine les bourgeons sont indifférenciés et équivalents. lia démonstration directe et la réciproque de cette alfirmation sont établies par l'existence d'inflorescences anormales qui sont des termes de transition entre les panicules terminales et les épis latéraux, et inversement.

L'étude de la répartition des anomalies des inflorescences du Maïs dans les champs de grande culture conduit à la découverte de la (ause déterminante de la métamorphose sexuelle des fleurs. Les mutilations violentes permettent d'obtenir soit la métamorphose dess

(1) Les formes nouvelles et stables obtenues dans mes cultures sont distribúcés gratuitement par les soins du Service d'échange de graines du Musćum d'Histoire naturelle de Paris. 
fleurs mâles en fleurs femelles, soit la métamorphose des fleurs femelles en fleurs måles.

Des expériences faites sur un grand nombre de plantes de Maîs cultivées dans des conditions comparables montrent que:

à un degré de mutilation croissant correspond un pourcentage (roissant de plantes anormales :

à une époque déterminée de la mutilation correspond une intensité lèterminée de la métamorphose des inflorescences $\left({ }^{1}\right)$.

I. degré de la mutilation est défini soif par le pourcentage des morts parmi les inclividus opérés, soit par le pourcentage des rejets dereloppés sur les plantes survirantes. Lev deus méthodes de mesure sonl toncordantes. D'autre part. liutensitè de l'anomalie est éraluée par les différentes étapes de la métamorphose seruelle des fleurs qui est un phénomène continu. La décourerte d'une méthode qui fournit un nombre aussi grand que l'on désire d'inflorescences anormales de Maís permet lapplication des régles en nsage dans l'étude de la rariation indiriduelle à leétude de la variation accidentelle. Il en résulte la possibilité d’ẻliminer les erreurs inhérentes à la nature mème des expériences et d’établir aussi rigoureusement que possible les relations de cause a eflet qui unissent les traumatismes aux anumalies des inflorescences terminales du Jaï.

Les mẻmes lois pourraient ètre étudiées sur les inflorescences latérales. Il faudrait faire choix d'une rariété de Maïs qui, jar son mule le vérritation. rende facile la torsion des épis latéraux très jeunes.

Les expériences faites sur 58 rariétés de Mais montrent la généralité de la méthode. Elles établissent que la réussite des essais dépend ex llusirement de la vigueur et de la rapidité de croissance des individus mutilés.

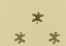

La secrumle I'tric renferme l'exposé des faits qui permettent d'appliquer aux espèces régétales les plus variées les lois démoutrées arec rigueur dans le cas des anomalies de la panicule du Mais.

(1) La précision arec laquelle ces résultats ont élé obtenus semble fournir la solution d'un probleme fondamental de la Murghologie des plantes pose frar GoEBEL 19014) au Congrès des Arts et des sciences de St-Louis. 
L'épreuve de la méthode faite sur des végétaux sauvages et cultivés, appartenant aux genres, aux familles, aux embranchements les plus distincts, me permet d'affirmer la généralité de l'action des traumatismes comme cause déterminante de l'«affolement 》. Les caractères spécifiques les mieux définis sont modifiés par des mutilations appropriées, et cette qualité distingue les traumatismes de la plupart des autres facteurs connus de variation. J'ai recueilli sur cette question les documents les plus probants, et il suffirait de reconstituer avec méthode l'histoire de l'origine des variétés si nombreuses de nos arbres à fruits ou d'ornement, pour être frappé par l'abondance des cas où la variation résulte d'une mutilation initiale. Je me propose de revenir sur cette question dans des mémoires spéciaux.

Dans ce travail, j'ai préféré insister sur la multiplicité des anomalies que permet d'obtenir la section des tiges ou des rameaux vigoureux. Les fascies, les torsions, la coalescence des rameaux et des feuilles, les déformations cupulées, la métamorphose des pièces florales... sont fournies par des mutilations, faites à une époque convenable soit sur le Maïs, soit sur d'autres espèces végétales.

Les tiges fasciées et tordues sont le résultat d'une même cause déviatrice, la section du bourgeon terminal d'une tige en voie de développement. Elles sont fréquemment associées sur les mêmes souches et sont des termes extrêmes d'une même modification de croissance qui se traduit par la variation désordonnée de la divergence foliaire des rejets.

Les feuilles doubles, laciniées, à folioles surnuméraires et les ascidies, sont fréquentes sur les tiges anormales obtenues après la mutilation; elles sont dues aux mêmes causes.

J'ai montré que la section des tiges est une méthode qui fournit la métamorphose des inflorescences en rosettes végétatives, des pièces florales en bractées, des étamines en carpelles et des carpelles en étamines.

Toutes ces déviations sont l'expression d'un seul phénomène, l'adaptation forcée d'un jeune bourgeon à des conditions tout à fait insolites. On peut suivre par les déformations des axes, des feuilles, des bractées et des pièces florales, les relaiions qui unissent les fascies et les torsions aux embryons tricotylés et se rendre compte du processus qui rend inévitable la transmission héréditaire de ces anomalies végétales. 
La mutilation entraine la multiplication des bourgeons. les variations de nombre. dimportance et de situation des bractées qui composent les bourgeons. les rariations des nerrures, on plutùt des faiceaus vasiulaires qui forment la charpente les bracties. On pent suirre. sur un rejet fascié ou tordu. la discowiation aberrante des faisceaur vasulaires qui entraine les fascies en balai. les feuilles en houppe ou enpulées, les pièces fiorales dícoupées. soulées ou métamorphosées. et par suite. il est trés facile de serpliquer la production de plantules tricotyles ou himieutylies qui. llapres las travaux de HCGo DE Vrres, donnent à leur toar les plantes fasciées ou tordues.

Les déviations morphologiques sont la conséquence de conditious phrsiologiques anormales déterminées par la rupture déquilibre des functions. Lépoque la plus farorable à la proluction d'anumalies végétales par des mutilations est celle lu maximum de croissance de lindividu soumis an traumatisme. Il existe alurs une opposition violente entre l'absorption de l'ean par les racines, et la diminution brusque de la transpiration: lexcés d'eau modifie les jeunes tisus des bourgeons alrentifs et détermine las trubble graves dans la formation des organes lont le retentissement se proluit jusqu'aus élẻments seruels et. par là. à la postérité.

L'étude de la transmission héréditaire des anomalies torales da Mais fait lobjet de la Troisiéuse Purtie.

Il importait de définir ave précision les caractèras de la variété de Mais utilise dans les escais. Les classifieations en uiage répondent mal au degré de précision exigé actuellement dans les rechenhes sur la Tariation des formes. J'ai adopté la subdivision du genm Zen en espéces élémentaires définies par les cara téres du iruit. puis en variétés de diffërentes natures. La justification de la méthode employée dans ce trarail exige l"étude d'un grand nombre de formes connues de Mais que je me propuse de décrire ultérieurement.

Les conditions de culture ont étés exposées dans le détail. Le Yais se féconde par le vent: pour ériter les erreur dues à l'hybridation, jai été conduit à faire la culture sịf farée des porte-graines et des plantes de contròle. 
Mes essais m'ont conduit a l'isolement rapide d'un grand nombre de formes nouvelles.

Il en est dont les caractères distinctifs, constituant une anomalie grave, entraînent la déformation très accentuée des organes végétatil's et l'accomplissement difficile des fonctions. On ne peut songer à les fixer complètement, et elles correspondent aux variétés instables ou eversportiny de Hugo dE VRIEs. Telles sont les vuriétés:

1. à punicules fusciées et à métumorphose sexuelle des fleurs,

2. à punicules tordues,

3. ¿̀ feuilles tubulées,

4. âferilles punachées et à plantules ulbines,

5. it tiges et ì feuilles rouges,

6. à port pleureur,

7. à épis dissociés.

Il est possible que ces deux dernières formes puissent être complètement fixées par l'isolement complet et la stricte autofécondation des plantes sur lesquelles les caractères sont accentués au maximum. Ces variétés doivent alors rentrer dans la eatégorie des formes hybrides dont la vuriété àyiaius arrijou, est le type.

Grâce aux précautions prises, j’ai réussi à fixer complètement deux variétés nouvelles. L'une d'elles est caractérisée par le développement d'étamines dans les épillets qui couvrent l'épi latéral. L'hermaphroditisme des fleurs est purement morphologique et non physiologique. C'est la variété que j'ai nommée Zea Mays pseudoandrogyna.

L'autre forme, désignée sous le nom Zea Mays var. semi-praecox, se distingue du type par des différences accusées dans la taille des tiges, le nombre des feuilles, des bractées et des rangées de graines, par la compacité des panicules, la densité des épillets mâles et femelles. Elle est plus précoce que le Zea Mays pensylvanica Bonafous qui a servi de point de départ.

Enfin l'acquisition la plus remarquable est cortainement celle de l'espèce élémentaire nouvelle Zea Huys pruccox. L'étude comparée des caractères montre que la variation a été complète.

Le Zea Mays praccox est né subitement, sans termes de transition, et n'a pas offert de cas de relour au type ancestral. L'isolement n'a présentẻ aucune difficulté, parce que la floraison très hâtive de cette 
forme ne permet pas son eroisement areo la rariété de Mais de Pensrlvanie au milieu de laquelle elle est apparue. Létude des circonstan pas qui ont accompagné cette rariation permet d'expliquer le Dimorphismie suisonnier que WetTsters a reconnu dans beaucuup de familles de plantes saurages rivant dans les prés suumis chaque année à des coupes répétées.

La stabilité des caractéres qui définissent l'espèce élémentaire nourelle Zell . Kays proecox n'erclut pas la tendance trés accuée que possède la lignée à donner des formes nourelles. Jai déjà pu isoler une variété Zea Mays próconx alba, complètement stable après autofécondation et qui est définie par l'absence de pigrment Jans l'albumen des graines. J'Y ai obserté des plantes dont les graines ont à la fois un albumen jaune et ridé. dont les panicules sont fasciẻes. Lont les feuilles sont tubulées, dont les épillets màles se métamorphusent en épillets femelles et inversement. La plupart des variations accidentelles présentées par les plantes mutilées parentes se retrourent sur les individus da cette e-pèce élémentaire nourelle. Le Zen. Wuys pruecorx est mème la sule forme cunnue de Graminées qui présente l'anomalie partiellement héréditaire de la métamurphose des glumellules en stigmates.

La grande majorité des formes nouvelles obtenues dans mes culture dérive d'un seule plante de Mais, mutilée en 19ie? et arant porté une panicule terminale offrant la métamorphost des teurs màles en fleurs femelles fertiles. Dans la descendance de cette plante. jai mis en éridence la variation brusque et héréditaire. créatrice d'especes nourelles. que H. DE VRIEs a désignée et étudiée sous le nom de Mutrition.

La culture de plantes de Mais témoins. l'obtention de résultats

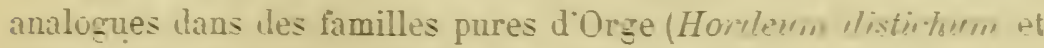
tetrastichum). de Simats albu, prourent que: les mutilations violentes constituent "in moyca
général et conmorle de procoquer la Mutubilité de lignées de plantes parfaitement stables jusque là. 
Les variations héréditaires provoquées par des traumatismes affectent tous les caractères de l'espèce. Il en résulte une pulvérisation du type en des formes multiples et distinctes, qui sont tantôt de nature régressive et rappellent les ancêtres du Maïs, tantôt de nature progressive et montrent l'acquisition par l'espèce Maïs de caractères nouveaux pour le genre, la tribu et même la famille des Graminées.

L'étude des variations observées à la suite de mutilations permet de reconstituer l'érolution du genre Zea, et d'établir que l'ancêtre sauvage du Maïs cultivé est l'espèce Euchluena mexicana. Le genre Zea est une forme monstrueuse du genre Euchlaena née et propagée par les soins de l'homme.

L'ensemble de ces faits prouve que la Mutilation est un facteur très important de l'Évolution des formes végétales. 


\title{
INDEX BIBI.IOGRAPHIQUE.
}

\author{
ALEFELD. - Landwirthschaftliche Flora.
}

1S' Archesegr, A. N. rox. - Leber ataristiche Blattormen des Tulpenbaumes (Anseiger der Faiserlichen Akademie der Wissenschaften, Mathematik-Naturclasse, Wien, 1204, p. 70).

1Fri. A-chersox, P. - (Sitsungsberichte der Gesellschaft naturforschender Freunde a Berlin, 17 Uctober 18\%,. et Botanische Zeitung. 18\%. p. 191).

1579. Aschers=ox. P. - Leber aestige Maiskolben. (Sitzungsberichte des botch. Tereins der Pror. Brandenburg. 230 September 1s\%?).

19u1. Bar. Тн. - Leber androgyne Blūthenstănde und ūber Pelorien, (Wien. illustrierte Garten-Zeitung. XIVI, p. 400 résumé dans Botanisches (entralbatt. t. \&?. p. for).

1x'1. B.rtet, E. - De l"influence exercée par l'époque de l'abatage sur la production et le développement des rejets des souches. (Annales de la science agronomique frangaise et étrangère, VIII, p. 4i-10\%).

150i. Butr. E. - Weitere Mitteilungen ueber die infectiōse Chlorose der Malraceen und ueber einige analoge Erscheinungen bei Ligustrum und Laburnum. (Berichte der deutschen botan. Gesellschaft, t. XIIT, p. $\left.411^{2}-12 \pi\right)$.

1825. BEсK. G. ros. - Eine interessante neue Missbildung im Blüthenstande des Maises. ( Wiener landuirthschaftliche Zeitung, 1s5, p. 619).

1872. Belmoxмe. - Leture sur une variété de Mais, dite du Sénégal, à épis femellesandrogynes. (Bulletio de la Société botan. de Fiance, IX, p. .i33).

1.42. ButrivgheM, L. - Remarques sur du Mais tératologique dit " Mais dègenenéré D. (Comptes-Rendus des Séances de la Société de Biologie, Paris. t. LI).

1.04a. Blarisghej, L. - Production par traumatisme d'anomalies florales dont certaines sont héréditaires. (Bulletin du Muséum d'Histoire naturelle, $1: 04, n^{\circ} 6$, p. 329$)$.

160łb. Bltrirghem, L. - Le Laboratoire dessais de semences de Sralöf (Suède). (Bulletin dut Yuséum d' Histoire naturelle, 1!01, $\mathrm{n}^{\circ}$ 7, p. 514).

1mic. Burrighes. L. - Sur une monstruosité du Zea Ways tunicata I). provoquie par un traumatisme. (Comptes-Remulus des séances de la société de Biologie, Paris, t. LVII. p. 5J).

190id. Blaringhes, L. - Hérédité danomalies florales présentẻes par le Zea Mays turicata DC. (Comptes-Reirdus des Séances de lu Société de Biologie, Paris, t. LVII, p. 5io). 
1905a. Blaringhem, L. - Anomalies héréditaires provoquees par des traumatismes. (Comptes-Rendus de l'Académic des Seiences, Paris, t. CXL, p. 378).

19056. Blaringhem, L. - Action des traumatismes sur les plantes ligneuses. (C'omptes-Rendus des Séances de lı Société de Biologie, Paris, t. LVIII, p. 945).

1905c. Blaringhem, L. - A propos d'un Mémoire de G. Klebs sur la Variation des fleur's. (Comptes-Rendus des Séances de la Société de Biologie, Paris, t. LIX, p. 454).

1905. Blatinghem, L. - Action des traumatismes sur la Variation et l'Hérédité. (Comptes-Rendus des Séunces de la Société de Biologie, Paris, t. LIX. p. 45(i).

1506a. Blaringhem, L. - Production de feuilles ell cornet par traumatisme. (Comptes-Rendus de l'Académie des Sciences, Paris, t. CXLII, p. 1515).

1906 b. Blangahem, L. - Production par traumatisme d'une espèce élémentaire nouvelle de Maïs. (Comptes-liendus de l'Académie des Ściences, Paris, t. CXLLIII, p. 2'15.)

1906 c. Blaringhen, L. - Production par traumatisme et fixation d'une variété nouvelle de Maïs, le Zea Mays var. pseudo-androgyna. (ComptesRenulus de l'Académie des sciences, Paris, t. CXLIII, p. 125:).

18:17. Bomivant, A. - Recherches sur les organes de remplacement chez les plantes. (Amales des Sciences naturelles. Botanique, s'me Série, t. Vl, p. $309-400$ ).

18:33. Bonafous. - Traité du Maïs. (Mémoires de la Société royale et centrale d'Agriculture, année 33, Paris).

1836. Bonafuus. - Histoire naturelle agricole et économique dı Naïs, Paris.

1882. Bonnier, G. - Sur la présence normale des bractées dans l'inflorescence des Crucifères. (Bulletin de la Société botanique de France, t. XXIX, p. 250$)$.

1900a. Bunnier, G. - Sur l'ordre de formation des ẻléments du cylindre central dans la racine et lans la tige. (Comptes-Renulus de l'Académie des Sciences, t. CXXXI, p. 781).

19006. Bonnier, G. - Sur la diffẻrenciation des tissus vasculaires de la feuille et de la tige. (Comptes-Rendus de l'Académie des sciences, t. CXXl, p. 1276).

18!3. Borbas Vincenz. - Zwillingsblätter. (Botunisches Centralblatt, Bd. LV, p. 363).

1898. Bordage, E. - Variation sexuelle consécutive à une mutilation chez le Papayer commun. (Comptes-Rendus des Séances de la Société de Biologie, t. LII, p. 708).

18:7. Boudier, 1. - Note sur un cas de formation de chapeaux secondaires sur un pédicule de Gonodernu lucidum. (Bulletin de la Société Mycologique, Paris, t. XV, p. 188).

1876. Buullu. - Note sur les Graminées vivipares. (Amales de la Société botanique de Lyon, 1876, p. 28). 
1891. Buchexat, F. - L'eber einen Fall der Entstehung der eichenblätterigen Form der Hainbuche (Carpinus Betulus L.) (Botanische Zeitung, 49 Jahrg, p. 97).

1904. Burss, G.-P. - Heterophylly in Proserpinaca pahustris L. (Annals of Botany, vol. XVIII, p. 579).

190'. Btscalion, L. et Pollacar. - Le Antocianine e il loro significato biologico nelle Plante. (Atti del Istituto botanico di Pavia, $2^{\text {me }}$ série, rol. VIII).

1824. C.Avdolle, A.-P. DE. - Prodromus systematis naturalis regni regetabilis, Parisiis.

182\%. C.Arnolle, A.-P. DE. - Organographie régétale, 2 vol., Paris.

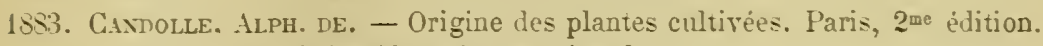
Bibliothèque Scientifique internationale:

1!n5. Cannolle. C. DE. - Observations tératologiques. (Bulletin de la Société botanique de Genère, t. XI, p. 3).

1Vī. Carriere. - Production et fixation des Variétés dansles régétaux, Paris.

1:01. Cuateat, E. - Notes tératologiques. (Bulletin de la Société d'Histoire naturelle d'Autun, t. XIT, p. 192).

1:01. Chiffot, J. - Sur un cas rare d'hétérotaxie de l'épi diodangifère de l'Equisetum anaximum L. et sur les can-es de sa production. (Saciéte Linnéenne de Lyon, d'après Botanisches ('entralblatt, t. (6). p. 32'i).

1:01. Culsaz, E. - Lne inflorescence moustrueuse du MaIs. (Archices des

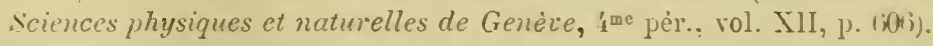

1:01. Correxs, C. - Bastarde zwischen Maisrassen mit besonderen Berūcksichtigung der Xenien. (Billiotheca botanica, Stuttgart, Bd. X).

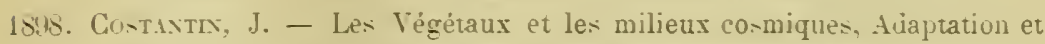
Erolution. Paris, Bibliotheque Scientifique internationale.

1:0 j. Costaxtix, J. - Le transformisme appliqué à lagriculture, Paris, Bibliothèque scientifique internationale.

1850. Cugrvi, G. - Intorno ad un'anomalia della Zea . Mays L. (Nuoro Giomale botanico Italiano, rol. XII, p. 217).

18is. Darwax, Ch. - De la Variation des Animaux et des plantes. 2 vol. Traduction française, 1879 (B.RBIER).

IFM3. Daratz. II. - Sur la prétendue modification de Ilattiers par déchirure des feuilles. (Journal d'Agriculture tropicale. Paris. IlI année, n³0).

1852. Dietz. ‥ - Beiträge zur Kenntniss der teratologischen Fülle des Maì. (Botanisches ('entralblatt, X, p. 413).

1879. Docmet, A. - Sur un cas de tératologie observé sur un des rameaux de Rosa Fortunei. (Bulletin de la Suciété Botanique de France, t. X.IVI, p. VIII).

1605. Ducaup, L. - Fleurs anormales d'Agave americana. (Revue générale de Botenique, t. XIII, p. 116).

183't. Duval-Joure. - Histoire naturelle des Equisetum de France, Paris, pp. 66 et 42 .

1:(x). Errers, L. - Conflits de préséance et excitations inhibitoires chez les végétaux. (Bulletin de la Société royale de Botanique, Bruxelles, t. XLII, p. :7). 
1889. von Ettingshausen et Krasan. - Latavisme chez les plantes. (Archives des Sciences physiques et naturelles de Genève, 1889; et Revue scientifique, XLV, p. 188).

1!106. Flerofr, M.-A. - Die Bedingungen der Pigmentbildung bei den Pilzen. (Bulletin du Jardin impérial de Botanique de St-Pétersbourg, t. VI, p. T1).

190i. Fifidor. - Regeneration der Blattspreite bei Scolopendrium scolopendrium. (Berichte der deutschen botanischen Gesellschaft, Bd. XXIV, p. 13).

185.). Franck, B. - Die Krankeiten der Pflanzen, 2 édition, vol. I, p. 124.

1903. Früwırth, C. - Die Züchtung der landwirthschaftlichen Kulturpflanzen. Bd II : Züchtung von Maïs,.... Berlin.

18!16. Gabeli. L, L. - Sulla causa degli sdoppiamenti fogliari. (Malpighia, vol. X, p. 67).

1893. Gagnepain. - Lettre sur divers cas tératologiques. (Bulletin de la Société botanique de France, t. XL, p. 311).

1815. Gars, E. - Rôle physiologique de l'eau dans la végétation (Amales des Sciences naturelles, Botanique, Te série, t. XX).

1901. Gallardo, A. - Sobre los cambios de sexualitad en las plantas. (Communicationes tel .Museo nacional de Buenos tires, t. I, no 8, p. 273).

1903. Galduardo, A. - Notas de teratologia vegetal. - Consideraciones sobre la fasciation. (Anales del Museo nacional de Buenos Aires, t. IX, p. 525).

190'. Gallardo, A. - Maiz clorántico. (Anales del Iuseo nacional de Buenos Aires, t. XI, p. 315).

1906. Gautier, A. - Sur la coloration rouge éventuelle de certaines feuilles et sur la couleur des fenilles d'automne. (Comptes rendus de l'Acculémie des Sciences, t. CXLIII, p. 490).

1843. Gavdichaud, сн. - Recherches générales sur l'organographie, la phy'siologie et l'or'ganogénie des végétaux. (Mémoires des Savants étrangers, Académie des Sciences de Paris, t. Vlil).

1886. Grard, A. - Sur la transformation de Biota orientalis en Retinospora, (Bulletin scientifique du département du Nord, t. XVII, p. 131).

1895. Giard, A. - Polydactylie provoquée chez Pleurodeles Waltlii (Comptes renulus des Séances de la Soc. de Biologie, Paris, 1895, p. 789).

1897. Grard, A. Sur les Régénérations hypotypiques. (Comptes rendus des Séances de la Société de Biologie, Paris, 1897).

18:18. GaArd, A.- Les variations de sexualité dans les végétaux. (Comptes rendus cles Séances de la Société de Biologie, Paris, 10e sér. vol. II).

1904a. Grard, A. - Tonogamie. La Chose et le mot. (Comptes rendus des Sćances de la Sociélé de Biologie, Paris, t. LVI, p. 479).

190' $b$. Giard, A. - Sur la parthénogẻnése artificielle par dessèchement physique. (Comptes rendus des Séances de la Société de Biologie, Paris, t. LVI, p. 5 ! $\left.)^{\prime}\right)$.

1879 a. Gunron. - Ftudes morphologiques sur la famille des Graminées. (Revue des Sciencrs nuturelles, t. VII, p. 396 et t. VIII, p. 14).

1879l. Godron. - Les bourgeons axillaires et les rameaux des Graminées. (Revue des Sciences naturelles, t. VIII, p. 428). 
18\&6. Goerel, h. - Beitrāge zur Kenntniss gefüllter Blüthen. (Pringsheim's Jahrbiucher für wissenschaftliche Botanik, Bd. XVII. p. 287).

18:8. Goebel, K. - Organographie der Pflanzen, Jena, Theil I. p. 35 et 152.

190'. Gozbel, K. - Die Grundprobleme der heutigen Pflanzenmorphologie. (International Congress of Arts and Science in Saint-Louis, 21 septembre 180', reproduit dans Biologisches Centralblatt, Bd. XXV. p. 603$)$.

18n3. Gowerts, W.-J. - Leber die Verbānderung bei Alnus incana. (Garten Flora, '́2. Jahrg., Berlin, résumé dans Just's Botanischer Jahresbericht, XXI-2).

10r. Griffos. - Sur l'influence des gelées printanières sur la végétation. (Revue Générale de Botanique, t. 1., p. 417).

185. Guḱbhard, A. - Sur les partitions anomales des fougères. (Feuille des Jeunes naturalistes, $\mathrm{n}^{\circ} 2(13)$.

18\%. HAACKe, WrLhely. - Entwickelungsmechanische Untersuchungen, III: Beiträge zur Teratologie der Gattung Salix, (Biologisches Centralblatt, Bd. XVI, p. S18).

1901. Halsted BrRox, D. - Diembryony in corn (Torreya, I).

1902. Hariot. - Chronique du «Jardin », 2 juin 1902: résumé dans: Peut-on modifier le sexe d'un Dattier? (Journal d'agriculture tropicale. $\left.\mathrm{n}^{\circ} 18\right)$.

1!05. Harms. H. - Leber Heterophyllie bei einer afrikanischen Passifloracae. (Berichte der deutschen botanischen Gesellschaft, Bd. XXIl, p. 1ii).

18.3. Harshberger. Johr-W. - Maize, a botanical and economic study. (Contributions from the Botanical Laboratory of Pennsyltania, rol. 1, p. $75-202$ ).

10\%6. Harshberger, Johy-WW. - Fertile Crosses of Teosinté and Maize (Garden and Forest, p. 522; résumé dans Just s Jahresbericht, 18ru, 11, p. 314).

1:01. HArshberger. Johs-W. - A study of the fertile hrbrids produced by crossing Teosinte and Maize. (Contributions from the botanical Laboratory of Pennsyliania, rol. II, p. 231-2:35).

1:00. Hartig. R. - Lehrbuch der Pflanzenkrankheiten, $3^{\text {me }}$ édition, Berlin, 1:00, I. p. 203.

1853. Htxcks. W. - Note on the nature of fasciated stems. (Proceedings of Linnean Society of London, 5 avril 1853).

18r. Hochrectiner. - Remarques sur quelques fenilles composees monstrueuses. (Bulletin de Therbier Boissier, t. V, p. 485).

1855. Hofmax, H. - Ueber Sexualität. (Botanische Zeitung. Bd. ILIII, p. 144).

1814. Jassicke. - Bildungsabweichungen an Weigelien. (Berichte der deutschen botanischen Gesellschaft, Bd. IX, p. 26hi).

1003. JAxse, J.-.I. - Polarität und Organbildung bei Caulerpa prolifere. (Pringsheim s Jahrbucher für usissenschaftliche Botanik, XLII, p. 394).

1903. Јонымssex, W. - Leber Erblichkeit in Populationen und in reinen Linien, Jena, Fischer. 
1898-99. Klebs, G. - Zur' Physiologie der Fortpflanzung einiger Pilze, (Pringsheim's Jahrbücher für Wissenschaftliche Botanik, Bd. XXXIl et XXXIII).

1903. Klebs, G. - Willkürliche Entwickelungsänderungen bei Pflanzen, Jena, $1 ! 103$.

1904. KLeBs, G. - Ueber Probleme der Entwickelung. (Biologisches Centralblatt, Bd. XXIV).

1905. Klebs, G. - Ueber Variationen der Blïten. (Pringsheim's Iahbü̈cher für wissenschafftliche Botanik, XLII, pp. 155-320).

1906. KLens, G. - Ueber künstliche Metamorphosen. (Abhandlungen der Naturforschenden Gesellschaft zu Halle, Bd. XXV, pp. 137-294).

1891 a. Ku,EIN, J. - Ueber Bildungsabweichungen an Blättern. (Botanisches Centralblatt, Bd. 47, p. 262).

18916. KLEIN, J. - Ueber einige Bildungsabweichungen an Blättern. (Mathematische und naturwissenschaftliche Berichte aus Ungarn, Bd. IX, . p. 354-362).

1812. KuErn, J. - Untersuchungen neber Bildungsabweichungen an Blättern. (Pringsheim's Jahrbücher für Wissenschaftliche Botanik, t. XXIV, p. 415-498).

1878. KNop, W. - Ueber eine merkwürdige Umgestaltung der Inflorescenz der Maïspflanzen bei künstlicher Ernährung. (Sitzungsberichte der liöniglichen Sächsischen dkudemie der Wissenschuften, Bd. XXX, d'aprés Botanische Zeutung, 37, Jahırg. p. 292).

18!8. Kxy. - Ein Versuch zur Blattstellungslehre. (Mittheilung der deutschen botanischen Gesellschaft, t. XVI, p. (60).

1872. Koenvicise, Fr. - Vorläıfige Mittheilungen über den Mä̈s. (Verhandlungen des naturh. Vereins für Rheinland und Westfalen, t. XXIX, p. 61).

1885. Karrnicke, Fr. und Werner H. - Handbuch des Getreidebanes, 2 vol. Bonn.

1901. Konschinsky, S. - Heterogenesis und Evolution. (Flora, Marburg, t. 89, p. 240).

1901 a. Kavessi, F. - Sur la taille rationnelle des végétaux ligneıx. (Comptesrendus de l'Académie des Sciences, Paris, t. CXXXII, p. (123).

1901 b. Kavessi, G. - Sur la proportion d'eau comparée à l'aoûtement des végétanx lignenx. (Comptes-rendus de l'Académie des Sciences, Paris, t. CXXXIl, p. 135!t).

1869. Krzaff, G. - Ueber der Bau der Maisblüthe. (Ablucndlungen eler K. K. Zool. Bot. Gesellsch. in Wien, t. XIX, p. 65).

1870. Krafft, G. - Die normale und anormale Netamorphose der Nä̈spflanze, Wien, $71 \mathrm{p}$.

188'. Krasan, F. - Unstersuchungen neber die Ursachen der Abänderugen der Pflanzen. (Engler's Botunische Jahrbüchern, t. V).

1889). Kr.LsAn, F.-(H). Ueber contimuirliche und sprungweise Variation (Engler's Botanische Jahrbücher, t. IX).

1890. Krasan, F. - Voir von Ettingshausen. 
1814. Kratss, C. - Zweifrüchtige Aerchen bei der zweizeiligen Gerste. (Botanisches (entralblatt, Bd. LIX, p. 129).

1850. Linıts, K. - Untersuchungen ueber künstliche Herbeiführung der Verlaubung der Bracteen der lïröbchen von Heliunthus ammus. (Wollny's Forschungen auf dem Gebiete der Agriculturphysik, t. III).

1596. licstze, O. - Blüthen der Agaven an Seitentrieben mit Bemerkungen von P. Mifrcs. (Gartentora, t. XLV'lI, p. 215, résumé dans Just's botanischer Jahresbericht 18!18, t. 1I, p. 503).

1!03. Küster, E. - Ueber abnormale Gewebewucherungen an P'tanzen. (Naturro. Wochenschrift, nene Folge, Bd. Il).

18ty. Lamarliére, GÉNeat DE. - Sur la production expérimentale de tiges et d'inflorescences fasciées. (Comptes rendus de l'Académie des Sciences, Paris, t. CXIVIll, p. 1601).

19N5. LiUrext, J. - Les facteurs de la structure chez les végétaux. (Bulletin de lu Société d'étude des Sciences naturelles de Reinis, 1:05),

1603. Lemucx, P. - Essais sur la régẻnération expérimentale des feuilles chez les légumineuses. (Annales des sciences naturclles, Botanique, série 8 , t. IVIII).

189. Lenecek, O. - Ueber Folia cucullata bei Ulmus. (Mitth. des noturc. Vereins. Wien, t. II, p. 18 - résumé dans Just's Gotanischer Jahresbericht, XXIl - 2. p. 21!).

1813. LENECEK, O. - Ueber schildförmig und dütenartig verwachsene Lindenblätter (loc. cit.).

18n1. Leverlué, H. Les: Palmiers à branches, dans l'Inde. (Bulletin de la Société botunique de Frunce, t. XXXIIII, p. 214).

1878. Liмneмctн, H. - Leber vegetative Bastarderzeugung durch lmpfung. (Landucirtschaftliche Jahibücher, 1878, p. S87).

1900. Lisnsbauer L. ET K. - Einige teratologische Befunde an Lonicera tartarica. (Esterreichische botanische Zeitschrift, t. L, p. 115).

1891. LoeB, J. - Untersuchungen zur physiologischen Morphologie der Thiere: I, Leber Heteromorphose, II, Organbildung und Wachstum, Wurzbürş.

1903. Lasener, TH. - Leber eine Bildungsabweichungen bein Mais. (Terhandlungen des bot. Ver. d. Prov. Brandenburg, t. XLT. p. 146).

1906. Law, E. - Der Saisondimorphismus ron Typha minima Fuxk. (Berichte der deutschen bot. Gesellschaft, Bd. XXIY, p. 201).

1903. Lopriore y Conglio. - La fasciazione delle radici in rapporto ad azioni tranmatiche. (Atti dell Accall. Giania de Sc. Natur. Catania, rol. X ITI, p. 1, résumé dans Botanisches Centralblatt, t. (5, p. 27.3).

1904a. Lopriore, G. - Verbänderung in Folgen des liöpfens. (Berichte de (leutsch. bot. Gesellschaft, Bd. XXII, n. 301).

190'b. Lopriore, G. - (H). Künstlich-erzengte Verbänderung bei Phascolus multiflorus (loc. cit., p. 39't).

1905. Manet J. et Gillot X. - Ëude morphologique et histologique des ascidies de Saxifrages. (Joumal cle botunique, Paris, t. XlX, p. 2i).

1899-1900. Martr, P. - Fenilles dormeanx bilobés. (Fenille des Jeunes naturalistes, $3^{\ominus}$ Sér. XXIX et XXX). 
1895. Massart, J. - Sur la morphologie du bourgeon. (Annales du Jardin bot. de Buitenzorg, t. XIII, p. 121).

1902. Massart, J. - L'accommodation individuelle chez Polygonum amphibium. (Bulletin du Jarlin botanique de l'État, Bruxelles, vol. 1, fasc. 2).

1869. Masters, M.-T. - Vegetable teratology, London.

1902. Masters, M.-T. - Fasciation in Valeriana urivonica. (Gardener's ('hronicle, 3me série, XXXI, p. 101).

1904. Mazé, P. et Perrier, A. - Recherches sur l'assimilation de quelques substances ternaires par les végétaux à chlorophylle. (Annales de l'hnstitut Pasteur, t. XVIII, p. 721).

1872. MeEhax, T. - The law of Fasciation and its relations to sex in Plants. (Procecdings Am. Association for Advancement of Science, New-York, 1872, p. 276, résumé dans Botanische Zeitıng, Bd. XXXIl, p. 332).

1841. MetzGer. - Landwirthschaftliche Pflanzenkunde, Heidelberg.

189.). Molliard, M. - Recherches sur les Cécidies florales. (Annales des Sciences naturelles, Botanique, $S^{\mathrm{e}}$ série, t. l, pp. 67-246).

1898. Muldino, M. - De l'hermaphroditisme chez la Mercuriale et le Chanvre. (Revue générale de Botanique, t. $\mathrm{X}, \mathrm{p} .321$ ).

1903b. Moluiard, II. - Tératologie et traumatisme. (Revue générale de Botanique, t. $\mathrm{XV}, \mathrm{p} .337$ ).

1904. Moluaro, M. - Sur la production expérimentale de Radis à réserves amylacées. (C'omptes-rendus de l'Acalémie des Sciences, Paris, t. CXXXIX, p. 885).

190.5. Moluard, N1. - Deux cas de duplicature florale provoqués par une nutrition défectueuse et hérédité de cette anomalie. (Bulletin de la Soc. Botanique de France, t. LII, p. 13).

190t. Montgonery, E.-G. - What is an ear of eorn? (Yopular Science Monthly, t. LXVIII, p. 55).

1841. Moqun-Tandox. - Éléments de tératologie végétale, Paris.

1905. Mоrot, L. - Notes de Biologie végétale: I. Quelques remarques sur les fenilles du Broussonetia papyrifera. (Juurnal de Botanique, t. XIX, p. 182).

1858. Müller, KarL. - Zur Kenntniss der Lmwandlung männlicher Blüthen in weibliche beim Mais. (Botanische Zeitung. t. XVI, p. 2(7)).

1906. Мuth, Frixz. - Ueber die Verwachsung der Seitentriebe mit dem Abstammungsachse bei Salvia pratensis L., sowie einige andere teratologische Erscheinungen an derselben. (Berichte der deutschen botanischen Gesellschaft, Bd. XXIV, p. 353).

186'a. Nestler, A. - Untersuchungen ueber Fasciationen. (Esterreichische botmische Zeitschrift, XLIV).

1894b. Nestler, A. - Leber Ringfusciation. (Sitzungsberichte der Kais. Akademie der Wissenschaften, Wien, Bd. CllI, p. 153).

1894. Pater, BelA. - Einige Unregelmäsigigkeiten des Blüthenstandes der Gramineen. (Botanisches C'entralblatt, t. LVII, p. 36). 
1800. PAx. F. - Allgemeine Morphologie der Ptanzen mit besonderer Berūcksichtigung der Blüthenmorphologie. Stuttgart.

153. PexzIG. 0. - Studj morphologici sui cereali. - I. Anomalie ossertate nella Zea Mays. (résumé dans Botanisches ('entralblatt. t. XXIII. p. 353).

15taly. Perzig. O. - Pllanzenteratologie. 2 rol. Geneva.

1994. Rernke. J. - Leber Deformation ron Ptlanzen durch āussere Einflūsse. (Botanische Zeitung, Bd. L.III. p. 81).

1su4. Russel. W. - Observations sur quelques cas de fasciation. (Bulletin de la societs botanique de France, t. XLI, p. S3̉).

150. SAchs.. J. rox. - Physiologische Versuche weber die Keimung der Schminlbohne (Phaseolus multifurus) (Sitsungsberichte der $\mathrm{h}$. Akad. d. Wissenschajten in Wien. Bd. XXXITI, p. 5i).

1SA. SANT-HILtre, A. DE. - Leitre sur du Mais à grains enveloppés Zea Mays var. tunicata et sur l'origine du Mais cultivé. (Annales ales Sciences naturelles. serie I. rol. ATI. p. 143).

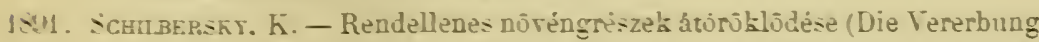
anomaler PAanzentheile) (Terméssettudomanyi Fiōslōny, Budapest. Bd. XXIII. p. 3i: résumé dans Just's botanischer Jahresbericht, XIX-I. p. .55).

1605. Scuotte, J.-C. - Ueber die Terâstelung bei monocotylen Bâumen. (Avinales du Jardin botanique de Buitensorg. vol. II. p. 53).

15\%4. Schress, H. - Teratological notes. (Bulletin. Torrey botanical Club, Lancaster, rol. XII. p. 2203i).

190'. Schumsx, K. - Mais und Teosinté. (Festschrift fur Ascaersor, Leipzig, 190 , p. 137).

1905. Sotwr. - Cas de fasciation observé chez un Cerisier (Bulletin du Vuséum d Histoire naturelle. Paris, 1:05).

1035. Sortier, P. - Ptanzenkrankheiten, 2xe édition.

1000. SPEgazznt, C. - Las plantas dioicas en ciertos casos pueden volvere monoicas a hermaphroditas? (Anales de la Societad cientifica Argentina, t. XLIX, p. 12:3).

1!0'. TAMes Tnes. - Uebe: eigenthümlich gestaltete Maserbildungen an Zweigen ron Fngus silcatica L. (Recueil des travenux botaniques néerlandais, Nimègue, rol. I. p. S1).

15i3. Tréctz. - Mémoire sur le développement des loupes et des broussius. (Annales des Sciences Botaniques, =érie III. t.:00, p. (5)).

1yis. Verlot, B. - Sur la production et la fixation des variétés dans les plantes d'ornement. Paris.

1097. Vial et G. Rabactt. - Recherches sur lécimage de la vigne. (Revue de Fiticulture, 1evi).

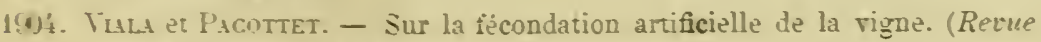
de Viticulture, $1: 0 i)$.

1vio. Viatud Grasd-Maras, A. - Note sur la gemmation surnuméraire de (ar) inus Betulus. (Bulletin de la ذocièté botanique de France. t. VII. p. $S s^{2}(1)$.

15.0. VRIES, Htgo DE. - Leber Wundholz. (Flora, 15.6, fasc. 1-6). 
1889. VRIEs, Hugo DE. - Ueber Erblichkeit der Zwangsdrehungen. (Berichte $d$. deutschen bot. Gesellschaft, Bid. VII, p. 291).

$1891 a$. Vries, Huro DE. - Ueber abnormale Fintstehung sccundärer Gewebe. (Pringsheim's Jahrbücher für wissenschuftiche Botanik, t. 22, p. 3.)).

1891 b. Vrifs, Hugo de. - Sur un spadice tubulcux de Peperomia maculosa. (Archives néerlandaises des Sciences exactes et naturelles, 18!)I, p. 258).

1892. Vries, Hugo DE. - Monographie der Zwangsdrehungen. (Pringsheim's Jahrbücher für Botanik, Bd. 23, p. 166).

1894. Vrifs, Hugo De. - Eine Methode Zwangsdrehungen aufzusuchen. (Berichte d. deutschen bot. Gesellschaft Bd. XII, p. 25).

1899a. Vries, Hugo DE. - Ueber die Periodizität der partiellen Variation. (Berichte d. deut. bot. Gesells., Bd. XVII, p. 45).

1899b. VRies, Hugo de. - Sur la culture des Monstruosités. (Comptes-rendus de l'Académie des Sciences, Paris, t. CXXVIII, p. 125).

1899c. VRies, Hugo DE. - Sur la culture des fasciations des espèces annielles et bisannuelles. (Revue générale cle Botanique, t. XI, p. 136).

1900. Vries, Hugo DE. - Alimentation et Sćlection. (Volume jubilaire du Cinquentenaire de la Société de Biologie de Paris, p. 17).

1900-1903. Vries, Hugo DE. - Die Mutationstheorie, 2 vol., Leipzig.

1906. (1) Vrres, Hugo DE. - Species and Varieties. Their origin by Mutation, Chicago, $2^{e}$ édition.

1905. Vries, Hugo De. - Ueber die Daiter der Mutationsperiode bei Enothera Lamarckiance. (Berichte der d.bot. Gesellsch. Bd. XXIII, Heft 8).

1844. VвоL.л. - Ueber eine sonderbare Wucherung der Blumen bei Digitalis purpurea. (Flora, 1844, p. 1-13).

1902. Vurclemin, P. - Une série de feuilles d'Orme à ramification latérale. (Revue générale de Botanique, t. XIV, p. 51).

1906. Vunlemin, P. - Sur les causes de l'apparition des formes dites cinomales. (Compltes-rendus de l'Académie des Sciences, Paris, t. CXLIII. p. 320).

1856. Watelet, A. - Note sur un cas de tératologie observé dans une Crucifère. (Bulletin de la Soc. bot. de France, t. IlI, p. 644).

1891. Watson, S. - Upon a wild species of Zea from Mexico. (Procecdings American Academy of Arts and Science, t. XXVI, p. 158).

1899. Wersse, A. - Ueber Veranderung der Blattstellung an aufstrebenden Axiliarzweigen. (Berichte d. deut. bot. Gesellsch, t. XVII, p. 343).

1904. WeIsse, A. - Blattstellungstudien an Popnelus tremula. (Festschrift für Ascherson, Leipzig, p. 518).

1900. Wettstein. R. von. - Descendenztheorische Untersuchingen: I. Untersuchungen über den Saison-1)imorphismus im Pflanzenreich. (Denkschrift der Mathemat. naturw. Klasse der Akad. Wien, t. LXX, p. 303).

(1) Une traduction française de l'ourrage Species and Varieties, de Hugu dE VRIEs, paraîtra en 1907, dans la Bibliotheque Scientifique internationale. 
1904. WEtTsters. R. rox. - Die Biologie unserer Wiesenpflanzen. (Schriften des Vereins zur Verbreilung naturciss. Kenntnisse in Wien, t. XLIV, p. 35i).

1893. Wrdexims, A. rox - Leber geschlitzte (laciniate) Rlattformen. (Juhresber. des Vereins für vaterl. Naturk. Würtemberg. t. 49, p. Li).

1880. WrtтмAck, L. - Ueber antiken Mais aus Nord-und Sud-Amerika. Zeitschrift für Ethnologie, p. 85, résumé dans Just's botanischer Jahres bericht, VIII-2, p. 3(i8).

1855. Wolly, E. - Einfluss des Entgipfelns auf das Wachstum der Sonnenrose (Forschungen auf dem Gebiete der Agriculturphysik. Bd. VIII, p. $1(1 /)^{2}$. 


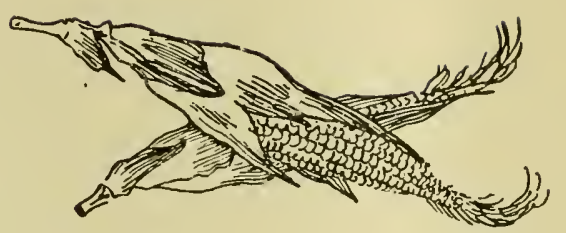




\section{INDEX ALPHABÉTIQUE.}

\section{A}

\section{tbutilon, 178.}

Acajon (Tariété de Maìs à grains), 1îti. Acer psevdo-Platanus, (x), 102. 104.

113. 120,140 et Pl. II, fig. 3).

Arer platanoides, 100.

Adaptation brusque. 13n, $2(0)$.

Adaptation double, 10\%, $2000^{\circ}$.

Esculus Hippocastanum, ה. 121.

Affolement diune espèce, 14, \$n, 2:1.

Agare americana, 121.

Ajuga reptans. 131.

Albine (Tariété de Maīs), 1002 ).

Albine (Plante hybride), $1 T$.

Allongement des pédoncules des épis de Mais, il

Anayallis arcensis var. phenicea, 110.

Angelica silcestris, 02. 113, 115, 1:10 et Pl. VII, fig. $74-55$.

Anomalies (Cause des). 30.

Anomalies (Continuté des), 103. 140.

Anomalies (Culture des), $95,15 \%, 15 \%$.

Anomalies (Définition des), 2 ?

Atwmalies des ap pareils reproductenrs: de: Cryptogames, 121.

Anumalies des feuilles et des bractées, (w), 127 et Pl. II.

tnomalies des fleurs et des fruits, 119 . Anomalie: de = infiorescences, 103.

Anomalies des plantules, 142.

Anomalies des tiges, SS et PI. II.

Aromalies florales du Maīs, 22, is, 81 et Pl. I.

Anomalies (Hérèdité des), 130̉. 141 , 145,154 .

Anomalies (Intensité des), 59, i0.

Anomalies (Régularitẻ des), 115.
Anomalies sexuelles. 124.

Anthocyanine (Production d), 43. 16i, 210.

Ascidies, 101.

A-cidies (Périodicité des). I(P2.

dscidies (structure des pétioles des.

13 ?.

Atari-me, $\sqrt{1}, 103,219$.

Arena satica. 113, 213 ет Pl. VII, fig. ST.

Arortement des bractées. 110.

Arortement des rraines. 25, 1,

Arortement du limbe. $1(\bar{k})$.

Aroriement de- panicules, 3n. 103.

\section{B}

Barkhausia taraxacifolia. \&8. 11:3.

BELHOMNE. 82. 22:!

Beta vulgaris, (1). 1(n), 110, 1:20, 131 .

Betula alba. (x).

Biota orientalis. ( 7 .

Blè miracle, 114 .

Borafots, :37?, 37. 117, :30.

Busirer. G.. 1.07, 1(N). 110. 23\%).

Borassus flabelliformis, 125 .

BORDAGE, E.. 1:5. 230.

Bourgeon adventif, 2hk.

Bourgeon (Tariation de), 201. 2006.

Bourgeonnement accessoire, 28, 62, 68 . Bractées (Anomalies des), $(\Omega$ et Pl. V, fig. 54 .

Bractées (Arortement des), 110.

Bractées (Relations arec les feuilles des), 105.

Bractees (Tariation du nombre des), 150.183.

Brassica balearica, 216.

Brassica cretica, 210. 
Brassica oleracea, 216.

Broussins, 89, 138.

Broussonetia payyrifera, 103.

Buscalioni, L., 16 .

\section{C}

Calycenthus floridus, 100.

Campanula glomerata, 209.

Campanula serotina, 209.

Cannabis sativa, 120, 126.

Caractère dominant, 177.

Caractère latent, 25, 102, 106.

Caractère spécifique, sa valeur, 114.

Caractères (Groupement des), 212.

Carica papaya, 125, 132.

Carpinus Betulus, 89, 90, 104.

Castanea vulgaris, $90,103$.

Cayaponia ficifolia, 124.

Cécidies, 90, 113.

Celosia cristata, 96.

Champiguons à chapeau, 121 .

Chanvre, 120,126 .

Charme, 89, 90,104 .

Châtaignier, 90), 103.

Chêne, 89, 103.

Chicolée, 92, 113, 116.

Chon, 216.

Clion-fleur (Origine du), 216.

Chorl-fleur (Inflorescences de Maïs), 122,216 et Pl. VI.

Cichorium Intybus, 92, 113, 116.

Clematis Hilarii, 124.

Coalescence des fleurs, 117.

Cochlearia officinalis, 131.

('oüx Lacrymu, 126, 212.

Coloration des feuilles, 43, 167.

Coloration des graines, $176,190$.

Compacité (Définition de la), 111.

Compacité des épis, 150, 193.

Compacité des panicules, 111, 149, 193.

Compacité, Relation avec les fascies, 112.

Comparaison des inflorescences du Maïs, 20.

Comparaison des anomalies du Maïs, 26.

Compression de la tige du Maïs, 73. Condensation des organes, 112 et Pl.VII. Conifères, 90.
Continuité des anomalies, 103, 140.

Comus, 167.

Cormis alba, 100).

C'omus sanguinea, 90.

Corrélation des Organes (Loi de), 87.

Corress, C., 153, 176.

Corylus Avcllan", 89, 90, 101. 10\% H. II, fig. :20.

Costantin, J., 1, 3, $76,1: 18$.

Crassulacées, 143.

Crataegus, 167.

Création de formes nouvelles, 210.

Crepis biemis fusciata, 96.

Crêtes de Coq, 96.

Groisement, 146, 176, 214.

Croissance du Maïs (Rapidité de), 17 .

Crucifères, 143

Gryptogames, 121, 143.

Cucurbitacées, 124.

Cultivées (Plantes), 145.

Culture des anomalies, (15), 152, 210 .

Culture de Contrôle, 15'́

Culture des porte-graines, $15 \pi$.

Culture pédigrée, 114, 15:3.

Cydonia vulgaris, 100.

\section{D}

Dectylis glomerata, 113

DARWIN, 146, 2(1).

Dattier (Changement de sexe du), 125.

Dégénérescence, 12:3.

Densité (Définition de la), 111.

Densité des épis, 150, 193

Densité des rameaux, 112, 150, 193.

Dimor'plisme foliaire, 103.

Dimorphisme saisonnier, 22).

Dioscorea bonariensis, 12'.

Dipsacus silvestris, 89, 95.

Dipsacus silvestris, var. torsus, 89, 92, 99.

Disjonction des caractères, 176 .

Dissociation des fascies, 95,104 et Pl. II.

Uissociation des épis de Maïs, 97, 174,

215 et Pl. VIII, fig. 9.5-97.

Dissociation des inflorescences, 113 et Pl. VII.

Dominant (Caractère), 177.

Duplicature des fleur's, 121. 


\section{E}

Eau (Rôle de l'), 13'́.

Eleagnus, 89, 9'.

Épinards. 101, 102. 109. 110. 1215 et PI. II. fig. 2\$-2?.

Époque de la Mutilation (Rôle de l'). 65. 83. 121). 135.

Épis de Mais (Anomalies des), 24 . 11. 81 et Pl. I, fig. 13-19.

Épis de Mais "Chou-fleur 》. 122, 216 et Pl. TI.

Épis de Maìs dirsociés, $97,17,215$ et PI. VIII, fig. (5-nt.

Épis de Mais ébréchés, 165 et Pl. VIII, fig. as.

Épis de Mais fanciés. 179.

Épis de Mais: (Densité des), 111, 150. 193.

Équilibre des organes, s。.

Equisetum maximum, 121.

Equisetum palustre. 121.

ERrerA, L.. 50.

E-courgeon, 11'́, 18i.

Espèce élémentaire (Notion d'). 200.

Espèce élémentaire de Maì ( Touvelle). $18 \%$.

E-pèce:- démentaires: (Stabilité des). 114.

Espèces élémentaires (Tariation créairice d"). 200.

Espèces élémentaires de Maĺ (Clarification des). $14 \%$.

E-pèces élémentaire: de Maì (Orig̣ine des), 216.

Espices élémentaires à dimorphisme saisonnier. 218.

Ėvolution progressive, 209. 213. 210. 228.

Exolution régressive, 220 .

Érolution (Róle des traumatismes dans l'). 228.

Exonymus europeres, 90.

Evonymus japonicus. 10.

Euchlaena mexicana, 9i, 17' 212, 214.

Euphrasia, $20 \pi$.

Excitation inhibitoire, $50,56,72$.

\section{F}

Fagopyrum esculentuin, 91, 102, 1:0 et Pl. IT". fig. 'AT-50.

Fugus silvatica. s). 103.

Faisceaux vasculaires (Variation des), 138.

Famille I de Mais tératologique. $\mid$ hil, $1 \% 0$.

Famille I (Tableau récapitulatif de la), $19 \dot{ }$

Famille II, $1 \pi 1$ et $1 \%$.

Famille III, 176.

Fasciation due aux traumatismes, 83 et P1. II.

Fasciation (Cause de l'état de), 88.

Fasciation (Perte de l'état de). 96.

Fascies annulaires, 10\%.

Fascies de racines. 83.

Fascies de tiges. S8 et Pl. II.

Fascies deépis de Mais, 179.

Fascies dissociées. (5. 139.

Fascies (Culture des), 96.

Fascies (Structure anatomique des). 13 ?.

Feuilles (Anomalie: de), 90.

Feuiller avortes. 103.

Feuilles cohérentes. 99.

Fetille- crispées. 104.

Feuilles cupulées, 101 et PI. II.

Fenille- découpées, I(13.

Fenilles à folioles surnuméraires. 103.

Fenilles éparses. s? 9 '

Fenilles ondulées. 104.

Fenilles (Relations arec les bractées), 105.

Feuilles (Nombre des feuilles du Mais). 1.51. 192.

Feuilles rouges (Variẻté de Mais à). 1138 et Pl. VIII. fig. 98.

Fenillles tubulées (Variété de Mais à), 101,165 et $\mathrm{Pl}$. 1V.

Ficus australis, 100.

Fleurs (Anomalies de), 117.

Fleurs doubles. 121.

Fleurs hermaphrodites de Mais, 23, $128,181$.

Fragaria vescr. 120.

Fraxinus excelsior, $89,90,102,101$ et Pl. II, fig. :26-2i.

Fruits (Anomalies de), 120, 123, 111. 


\section{G}

Galium (Dimorphisme saisonnier du), 207.

Gallardo, A., 31, 124.

Galles, 113.

Gaudichaud, Сн., 87, 100.

Gentiance (Dimorphisme saisomier des), 207.

Geranium, 167.

GiARD, A., 2, 97, 104, 12', 126, 134, 143.

Giroflées doubles, 122 .

Goebel, K., 88, 122, 22:3.

Gozthe, 87, 117.

Gonoderma lucidum, 121.

Graminées, 143, 167.

Greffe, 90, 118, 186.

Groupement des Caractères, 212.

\section{H}

Haricot, 93.

HARSHBERGER, JoHN IV., 147, 174, 214, 217.

Helianthus anmuns, 91, 104, 110, 113.

Heracleum Sphondylium, 9:, 113, 114, 120.

Hérédité des Anomalies, 154.

Hérédité (Mécanisme morphologique et anatomique de l'), 141.

Hermaphrodites (Variété de Maïs à épis), 180 et Pl. VIII, fig. 91-94.

Hermaphroditisme du Chanvre, 126.

Hermaphroditisme du Cö̌x Lacryma, 126.

Hermaphroditisme du Maïs, 23, 1:8, 181.

Hétérogénèse, 206.

Hétéromorphose, 143.

Hêtre, 89, 103.

Hibiscus Rosa sinensis, $90,102,120$.

HrNcks, 88, 95.

Hordeum (Espèces élémentaires d'), 114.

Hordeum distichum, 114, 120, 123, 179, 185 et Pl. VII, fig. 86.

Hordeum tetrastichum, 120, 123, 179, $185,186$.

Hybride, 146, 157, 176.
Hybride (Euchlaena et $Z e a), 214$.

Hybride (Race de Maïs), 176. Hypholoma fasciculare, 121.

\section{I}

Indiffèrenciation des organes, 118.

Inflorescences (Anomalies des), 108 et Pl. VII.

Inflorescences du Maïs (Anomalies des), 22, 78 et Pl. I.

Incision annulaire, 125.

\section{J}

Johannsen, W., 168.

Joubarbe, 131.

\section{K}

KleBs, G., 88, 109, 1:0, 131, :1:2.

KLLIN, J., 88, 89, 94, 100, 121, 124.

KNop, W., 133, 167.

KNy, 89.

KöRNiGKE, FR, 37, 147.

Korschinsky, S., 2(1)4, 206.

Krafft, G., 36, 106, 126.

Krasan, F., 97, 103, 104.

LAMARLİ́re (GÉNEAU DE), 88, 113.

Lappa minor, 110.

LEDOUX, P., 104.

Légumineuses, 103, 104 .

Lentinus, 121.

Ligustrum vulyare, 90.

Linum usitatissimum, 91, 113, 120.

Lolium italicum, 113 et Pl. VIl, fig. 88.

Lonicera fragrantissima, 100.

Lonicera tartarica, 136.

LOPRIORE, G., 88.

Loupes, 89, 138.

Lycopersicum esculentum, 119, 120.

Lysimachia thyisifolia, 131. 


\section{M}

Mais, Voir Table des matières.

Maì (Anomalies des bractéesdu), 20,1 6 et Pl. Y., fig. 54 .

Mais (Anomalies des feuilles du), 101, 104 et Pl. III, IV et $\mathrm{Y}$.

Mais (Anomalies des fleurs du), 2.2, 110 , $122,120,130,191$ et Pl. I. T et VIIl.

Mais (Anomalies des fruits du), 123.

Mais (Anomalies des inflorescences terminales du), $, 2,-75,78,110$ et PI. I erV.

Mais (Anomalies des inflorescences latérales), 24, $71,81,97,122,168$ et Pl. I, VI et VIII.

Mais (Croissance du), 17, 79.

Maīs dégénéré, 3 (1.

Maî: (E-pèces élémentaires de), $14 \pi$.

Mais, Espèces et Variétés expérimentées, 76 et $i \tau$.

Mais. E-pèce et Variétés nouvelles, 180, 226 et Pl. VIII.

Mais de Pensrlranie (Description du), 149.

Maì. Variẻté d’Algérie, 27, 82. 179.

Maīe, Tariété nourelle à épis dissociés, $97,174.215$ et PI. VIlI, fig. $45-97$.

Mais, Variété nouvelle à épis ébréchés, 167 et PI. TIII, fig. 98.

Mais. Variété nourelle à épis fasciés. 179.

Mais, Variété nourelle à épis hermaphrodites, voir Zea Mays pseudoandrogyna.

Mais, Varieté nourelle à feuille- panachées, 116.

Mais, Variété nourelle à feuille- rouges. voir à épis ébréchés.

Mais, Variété nourelle à feuilles tubulées, 101,165 et Pl. IV.

Mais, Variété nouvelle à inflorescences "Chou-fleur ». 122, 216 et Pl. VI.

Mais, Variété nourelle à plantules albines, 160.

Mais, Variété nouvelle à paniculer fasciées, 162 et Pl. I.

Mais, Variété nouvelle à port pleureur, (12, $1(n), 16 \%, 186$ et PI. 1.

Maìs, Variété nourelle à tiges tordues. $92,16 \dot{\text { et }}$ et PI. III.
Mais, Variété nourelle précoce à grains jaunes, 16:, 171, 187, 192 et Pl. VIII. fig. 100 .

Maìs, Tariété nouvelle prẻcoce à graius blancs, 152, 190, 192.

Mais, Variété nourelle précoce à grains ridés jaunes, 190.

Mais, Variété nouvelle précoce à glumellules stigmatiféres, 190 et PI. ITII, fig. 101-104.

Mais. Variété nourelle semi-précoce, 162. 171, 175, 183, 192, 195, et Pl. TIII, fig. 99.

Mais, Variété nourelle hybride à grain acajou, 176.

Marronnier, 121.

MAssart, J., 11(), 1:21, :2(x).

Masters. M-T, \&8, (5).

Matricaria inodora, 113.

MAZĖ, 133, $16 \overline{\text {. }}$

Medicago, 104.

Mercurinlis annua, 41, 1:16.

Métamorphose des épis du Mais, i1, 81 .

Métamorphose des glumelles. 1:6.

Métamorphose des glumellules en stigmater, 130. 190 et Pl. VIII.

Métamorphoze des panicules. 5 , is.

Métamorphose (Théorie de la), 8i. 11\%.

Metzger, $146,147$.

Molliard, M., 2, 110, 113, 120, 121. $1 \div 2,126,21 \%$.

Moqun-Tandon, 8i, (5), 160 .

Morus alba, $1(x)$.

Morus nigra, 100.

Moutardelle, $11,43,113,120,179$.

Multiplication de- organes. 118, 136.

Mutilation (Degré de la), 5 .

Murilation (Epoque de la), (i), 93, 126 , 133.

Mutation (Théorie de la). 13.

Mutation (Lois de la), 1!6.

Mutation dans le Mais. 191. 195.

Mutation (Périodicité de la), Z(11.

Müller, K., 3.), 122.

\section{N}

Nanisme, T!!, :2(1)!.

Verium oleander, 110.

Nilssos, N. HJ., 3, 111. 
Noisetier, 89, 90, 101, 102 et Pl. II, fig. 20.

Nombre de feuilles des Variétés de Mais, 192.

Nombre de rameaux des Variétés de Mais, 193.

Nutrition et Anomalies, 95 .

Nutrition et Caractères spécifiques, 212. Nutrition et Sexualité, :20, 84, 133.

\section{0}

Odontites, Dimorphisme saisonnier, 207.

Enothera biennis, 92, 95, 109, 120, 185 et Pl. VII, fig. 89.

Enothera Lamarckiana, 200.

Enothera lata, 201.

Enothera nanella, 200, 201.

Enotherium, 109.

Ombelliferes, 113, 114, 143.

Onobrychis sativa, 10!'.

Origine d'une espéce, le Zea Mays L., 213.

Orge, 123, 157, 167, 198, 205.

Orge, Espéces élémentaires, 114, 213.

Orge, Ramification des épis, 114 et

PI. Vli, fig. 86.

Orme, 90, I0I et Pl. II, fig. 25 .

\section{P}

Palmiers (Sexe des), 125.

Panachées (Variétés à feuilles), 8I, [66, 178.

Panachure infectieuse, 178.

Panicules (Anomalies des), 22., 39, 78, 152 et $\mathrm{Pl} . \mathrm{I}$.

Panicules (Compacité des), 111, 149, 193.

Panicules fasciées (Variétés de Maïs à), 162 et Pl. I.

Panicules tordues (Variétés de Maïs a), 9:, 164 et I'l. III.

Pupaver Rhoees, 121.

Pripuver somniferum polycephalum, 164.

Papayer (Sexe du), 1:5, 133.

Papilionacées, 143.
Parthénogénèse artificielle, 134.

Pédoncules des épis (Allongement des), 71.

Pelargonium zonale, 122.

Penicillium purpurogenum, 210.

Pensée, 117, 119.

Pexzig, 0., 35, 91.

Peperomia maculosa, 102.

Périodicité des Anomalies (Loi de), 102.

Perrier, 13:3, 167.

Phaseolus multiflorus, 88, 93.

Philalelphus coronarius, 100.

Phytons (Théorie des), 87, 100.

Picris hieracioüdes, 95.

Pinus maritimu, 90.

Pinus silvestirs, 90.

Plantayo lanceolata, 109, 113.

Plantules (Anomalies des), 142, 152.

Pleureur (Variété de Maïs), 9:2, 10k), 166,186 et Pl. Y.

Pleurodeles Waltlii, 143.

Pollacci, voir Buscalioni, L.

Polydactylie des Batraciens, 143.

Polyembryonie, I

Polygones de Variation de taille des rejets, 133 .

Polygonum amphilium, 110, 206 .

Population de plantes, 197.

Populus albee, 90, 104.

Populus tremule, 89.

Pourcentage des Anomalies, 58.

Pourcentage des Mutantes, 203.

Pourcentage héréditaire, 15:2, 158, 159.

Précocité, 79, 18.5, 205, 20(j.

Prolifération, 113, 115, 122.

\section{$\mathbf{R}$}

Racines (Fasciation de), 88 .

Radis, 120,212 .

Ramification des épis de Maïs, 43, 72.

Rangẻes de graines les épis de Mais

(Nombre de), 151, 193.

Renuncules Flammula, 122.

Raphronus Ruphanistrum, 1?().

Rapidité de croissance du Maïs, 18.

Régénération expérimentale, 88, 104 .

Régénération hypotypique, 97 .

Régularité des Anomalies, 115. 


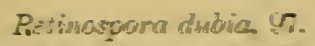

Pucturs compramis, 16.

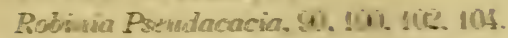

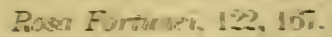

Rouge Prunduction de piguenat. 13. 10.210 .

Roure Tarte a fanilles. !5\%

Rouces (Vartés à graines, 1705 .

Rouge Toritus à grainer surets de. 173

Paryez action, 131.

\section{S}

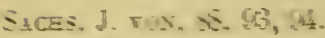

Saluz: (1)

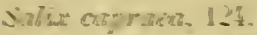

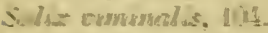

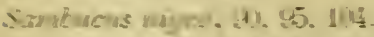

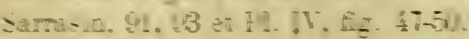

satule. Bis, 104.124.

serifr:-2. 124.

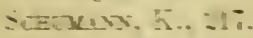

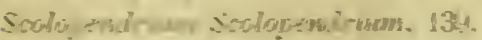

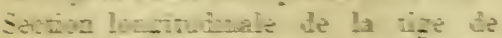
Meis. 34

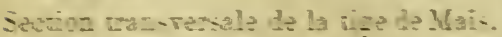
43.

Silectioc. 1.ti.

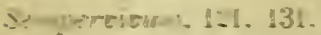

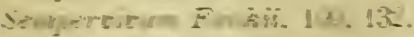

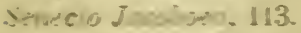

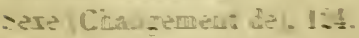

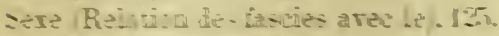

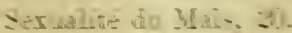

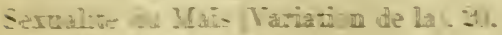

51. 1.4. 1: ex DI I.

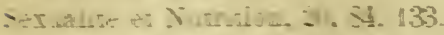

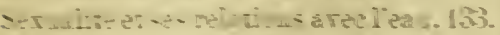

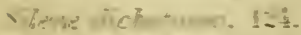

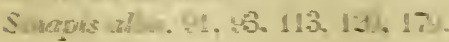

Sinchas. ปñ.

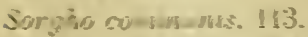

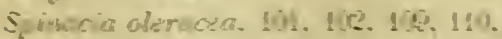

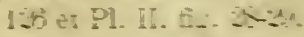

Subrutida ter foulles ate brackes. 1 (r).

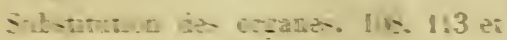
P1. II!

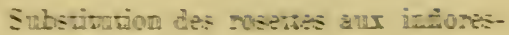
ceacs. 118.

Sucen du Mais. 31.

Suture der ponds des bracties. 200.

Suture det burls des ferilles, 101.

Sutures Relations des tarcies er des. 112.

Symphoriong us mocrmacms. I(LB.

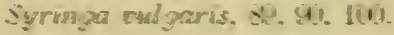

\section{T}

Table des Mati-nes, 5.

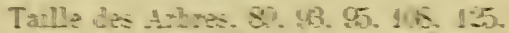

Taille ist rejer al arpant de Mais. 5.

ii).

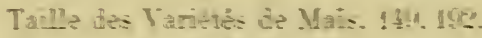

Terormenn efficunale. Alt:

Tendazne ratialle des diverto mat

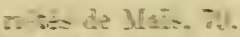

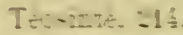

Thand anha it bia. $12 \div$.

Thes Ar malies de-,$\infty$

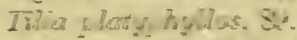

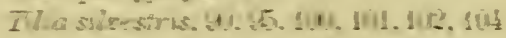
e: P1. II. $\pm z .: 1-24$.

Toma:e 11\% 1:11.

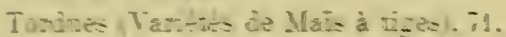

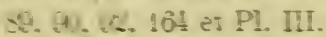

Terson des eqis de Mais - -4.

Torion de thes de Mais. M.

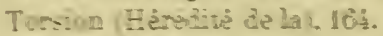

Tournsal. cii.

Trusmati-mes. Voir la Table des Mationes.

Trianos, renera ficipilia. 124.

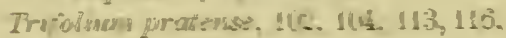
155.

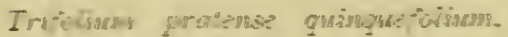
1.5. 10\%.

Ir viotisen regens 100. 13.

$T$ - 6 , sacsans, 21:

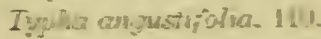

\section{U}

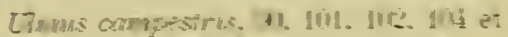
P1. il, fg. 5 . 
Valernana diö̈ca, 92.

Variation accidentelle, 32 .

Variation brusque, 196.

Variation de divergence foliaire, 89.

Variation héréditaire, 197.

Variation uniforme, 31, 198.

Variation sexuelle, 124 .

Variétés (Garactères des), 200.

Variétés instables, 159, 160.

Variétés de Maïs (Caractères des), 151.

Variétés de Maïs (Nouvelles), 180, 226 et PI. VIII, voir à Maìs.

Variétés de Maïs soumises aux traumatismes, 76,77 .

Veronica, 131.

Veronica Chamaedrys, 179.

Veronica longifolia, 102.

Viaud Grand-Mlarais, 89, 110.

Viburnum Lantana, 167.

Viburnem Opulus, 90, 95, 167.

Vicinisme, 140.

Viola tricolor var. maxima, 117, 119.

Vitis, 167.

Viviparité, 122.

V'ries, Hugo de, 2, 13, 25, 88, 89, 96, $99,102,105,107,109,138,146,152$, 159, 160, 164, 196, 198, 206, 209, 225.

VullLeMIN, P., 102, 104.

\section{W}

Weigela, 99.

Weigela rosea, 100.

Weisse, A., 89, 94.

Werner, 37, 147 et voir Körnicke.

Wettstein, R. von, 207.
Xẻnie, 14خ, 158, 176.

\section{Z}

Zea (Évolution du genre), 210 .

Zea canina, W., 174, 214.

Zea Mays (Espèces élément. de), 147.

Zea Mays (Origine de l'espèce), 216

Zea Mays, Liste des 58 variétés expérimentées, $76,7 \tau$.

Zea Mays acuminata, 148.

Zea Mays androgyna, 82.

Zea Mays dentiformis, 148.

Zea Mays japonica, 76, 128.

Zea Mays japonica foliis variegatis,

81, 178.

Zea Mays macrosperma, 148.

Zea Mays microsperma, 148.

Zea Mays oryzoüdes, 2:6, 179.

Zea Mays pensylvanica, 37, 127, 149, 192 et Pl. V'1II, fig. 90.

Zea Mays praecox, 162, 171, 175, 183, 192,195 et Pl. VIll, fig. 100-104.

Zea Mays praecox var. alba, 152, 190, 192.

Zea Mays pseudo-androgyna, 162, 169, 180, 142, 195 et Pl. VIII, fig. 91-94.

Zea Mays semi-praecox, 16:, 171, 175, 183, 192, 195 et PI. VIII, fig. 99. Zea Mays tunicata, forme à épis "Chou-fleur », 26, 121, 127, 135, 148, 179 et PI. VI.

Zea Mays vulyaris, 37, 148. 


\section{PLANCHE I.}

WÉTAMORPHOSE DES INFLORESCEYCES DC MAÏS.

Les figures 1-12 montrent les différentes étapes de la métamorphose des panicules ramifiées et màles du Mais en inflorescences uniaxes fenrelles :

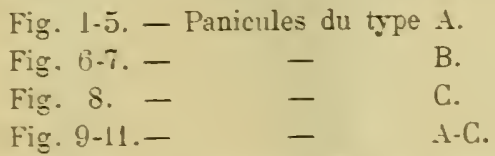

Fig. 12. - Panicule màle réduite à un axe.

La métamorphose la moins accusée consiste en la substitution d'un ou de quelques épillets femelles aux épillets mâles insérés à la base de la grappe tiorale (fig. 1 et 11 ): la métamorphose pent ensuite ètre plus déreloppée à la base des rameaux de la panicule quà la pointe de laxe (fig. 2) ou inversement (fig. 3). Les figures 4. 5. 6 et $i$ montrent les transitions graduées qui relient les panicules du type A (fig. $\dot{4}$ et j) et les panicules du type B (fig. 6 et i). On pent suirre, sur ces exemples. l'angmentarion de la compacité des grappes arec le degré de la métanorphose et la réduction corrélative du nombre des rameaux. La ramification est nulle pour les intore-cences représentées par les figures 8.9, 10 et 11 qui, rangées dans cet ordre, montrent leur lien arec la panicule màle réduite à lase (fig. 12).

Les figures 13-19 sont relatives i la métamorphose des inflorescences latérales femelles du Mais en inflorescences courertes dépillets màles. La figure l'́ représente un épi latéral dont l'axe est prolongé par une pointe grèle couvere de $\dot{f}$ épillets réduits à des bractées et comparables aux glumes des épillets màles de la panicule. Le rapprochement des figures $S$ et lf́ établit l'identité morphologique et physiologique des deux inflorescences dont l'une est terminale, lautre latérale.

On reconnait, sur les figures $15,16.17$ et 18 , différentes étapes de la métamorphose des épillets femelles en épillets nàles et, en mème temps, la ramification corrélative des inflorescences latérales, analogue à celle de la rariété

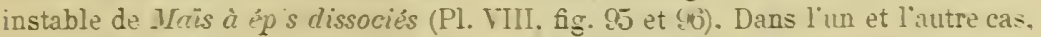
la ramification des inflorescences est la conséquence de l'allongement des pédoncules et de la diminution de la compacité des grappes qui entraine la diminution de densité des épillets: le nombre des rangées de graines est réduit et la torsion des rangees, visible sur les figures 16, 18, 19. augmente lintervalle qui sépare les épillets.

La métamorphose des épiilets femelles en épillets mâles est accompagnée de l'amincissement du rachis (fig. 16, 17.18, 19), de mème que la nétamorphose des épillets mâles en épillets femelles correspond à l'épaississement de l'axe ou des rameaux de la panicule (fig. 3, f, 6, 10). Le plus sourent la métamorphose est bruique comme le montre la figture 19 yui est la photographie en grandeur 
naturelle de l'extrémité de l'épi représenté par la figure 18. Toutefois, la règle n'est pas absolue. On trouve parfois des épillets mâles sur des portions épaisses et charnues des axes et des rachis (fig. 9 et 15) mais, en ce cas, leurs enveloppes ont la forme caractéristique des glumes des épillets femelles sans en avoir la consistance cornée.

La figure 13 est la photographie d'une partie de la tige de Maïs trouvée dans un champ de grande culture (page 34) et offrant la métamorphose partielle des épillets mâles en épillets femelles. L'extrémité du rachis, couverte d'épillcts mâles, fait saillie hors des bractées d'enveloppe. L'épi est écartẻ de la tige; on peut apercevoir, à son point d'insertion sur la tige, la torsion qui a entrainé l'anomalie. Il ne faut pas tenir compte du port particulier de la panicule et des feuilles qui résulte de ce que la photographie a été faite après la dessiccation de l'échantillon.

Tous les exemples ont été observés sur le Maïs de Pensylvanie. 


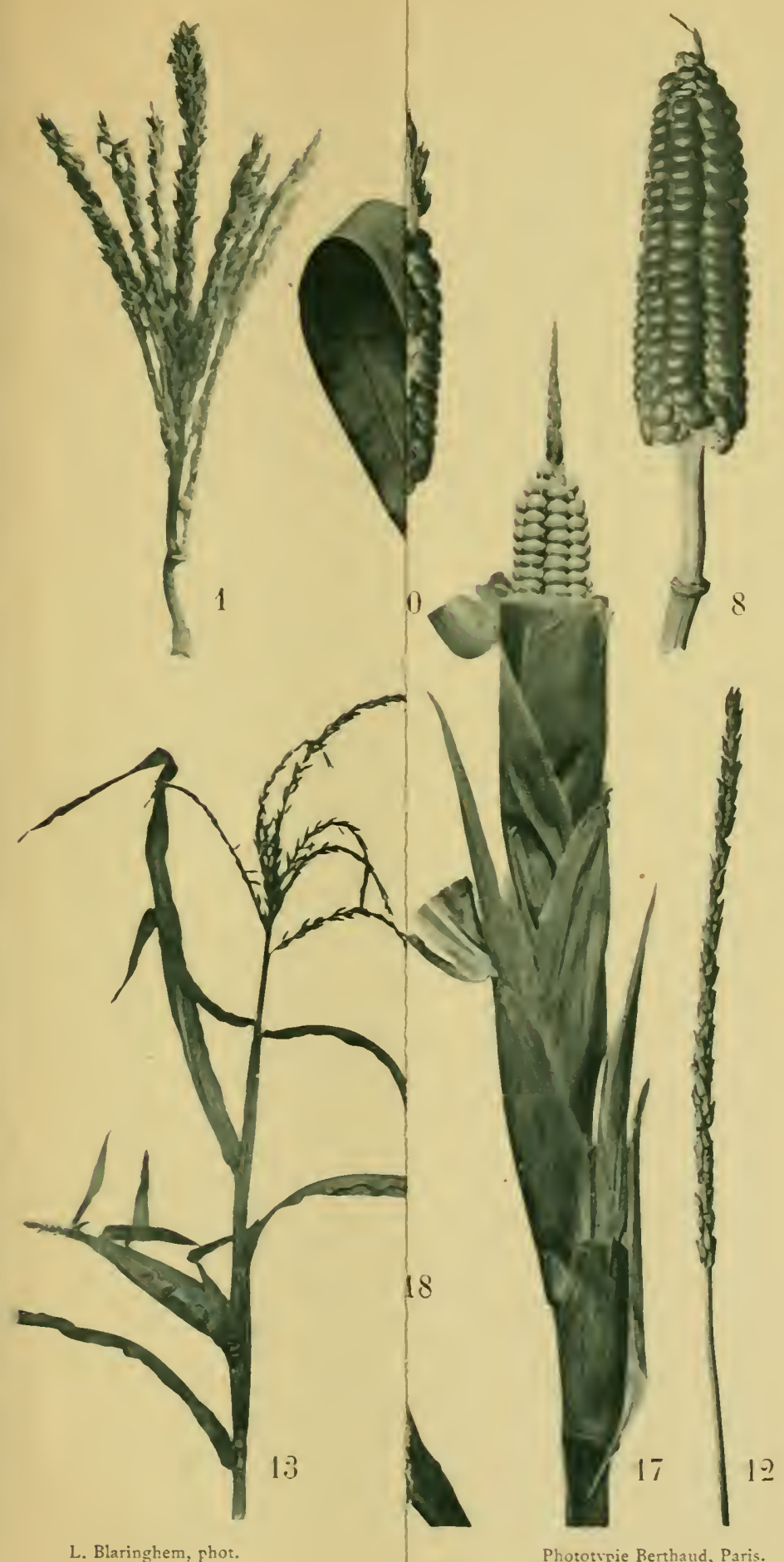

L. Blaringhem, phot.

Phototypie Berthaud, Paris. 


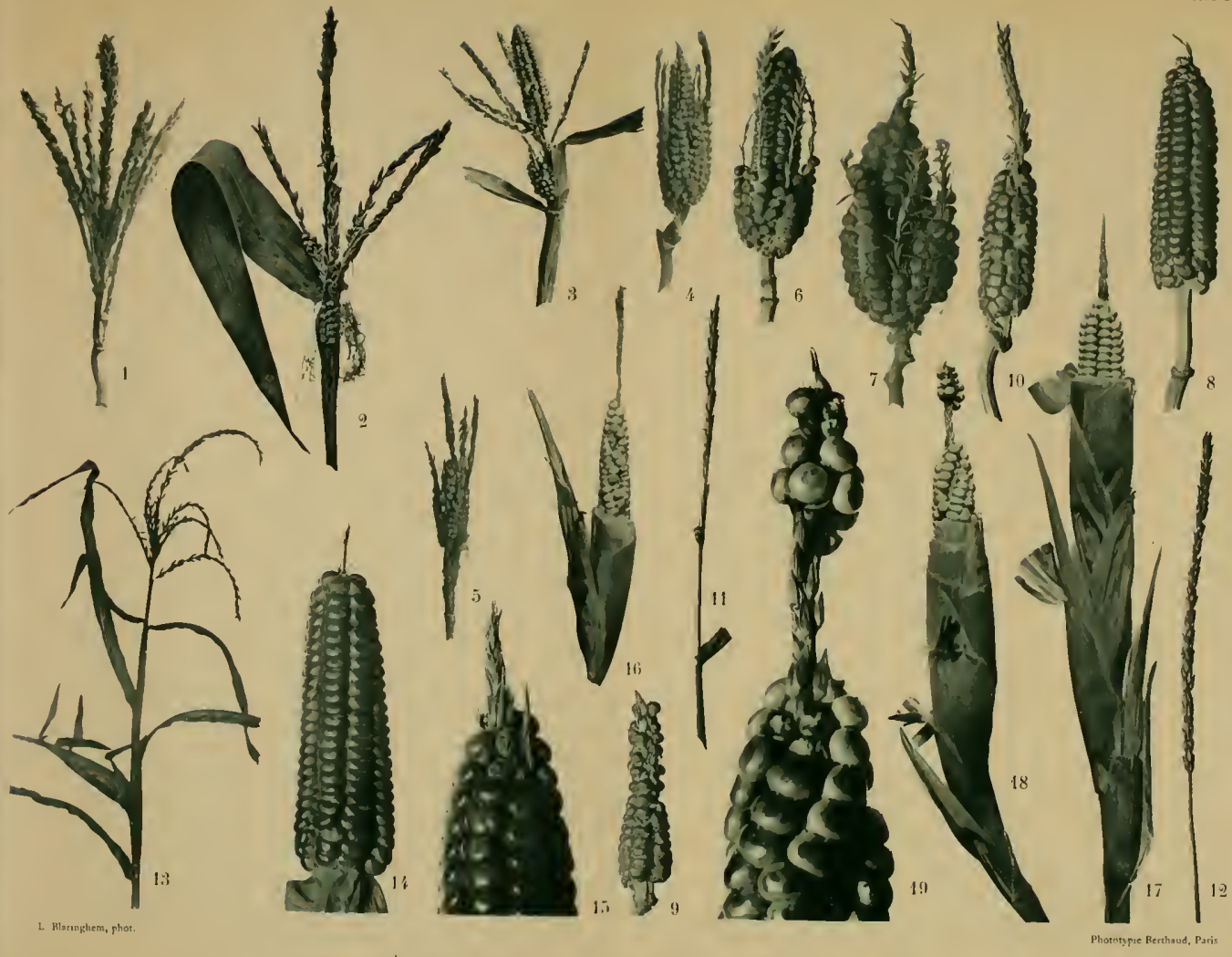

MEIAMORPHOSE DES INHIORESCENCES DU MAISS. 
PLANCHE II.

A.OMALIE: LE TIGES ET DE FEIILLES. 
Les photographies 20 - 30 représentent diverses anomalies de tiges et de feuilles observées sur des rejets de

Corylus Avellana, fig. 20,

Tilia silvestris, fig. 21-24,

Ulmus campestris, fig. 25 ,

Fraxinus excelsior, fig. $26-27$,

Spinacia oleracea, fig. 28-29,

Acer pseudo-Platanus, fig. 30.

Les figures $20,23,28,29$ et 30 montrent différentes fascies qui toutes résultent de la dissociation tardive d'un bourgeon terminal; la base des pousses est arrondie et présente les feuilles éparses caractéristiques de l'anomalie, la portion centrale est aplatie et la dissociation est complète ou partielle à l'extrémité du rejet.

On peut observer sur les mêmes figures l'association fréquente des fascies et des ascidies. Les feuilles de l'extrémité de la pousse de Corylus Avellana (fig. 20) sont peltées, celles de la fascie de Tilia silvestris (fig. 23) offrent dillërents cas de métamorphose en cornet; enfin, à la bifurcation de la fascie de Spinacia oleracea (fig. 28, et grossie, fig. 29), on trouve une ascidie longuement pédonculée.

L'association des feuilles doubles et des ascidies est très apparente sur les rejets de Tilia sylvestris (fig. 22 et 2 '), sur le rejet d'Vlmus campestris (fig. 25) et de Spinacia oleracea (fig. 28 et 29). Leur distribution au milieu des feuilles en cornet (fig. 22,24 , et 25 ) montre qu'elles sont la manifestation extérieure du même phénomène.

La déformation simultanée de nombreux organes du même rejet est rendue évidente par les figures 20-25; elle apparaît même sur les parties ou folioles d'une feuille de Fraxinus excelsior (fig. 26 et 27) offrant une anomalie qui tient, à la fois, de l'avortement du limbe et de sa métamorphose en ascidie. Enfin l'examen attentif de la figure 30 permet de constater que la pousse fasciée d'Acer pseudo-Platanus porte à droite une grappe florale fasciée reconnaissable à la densité très élevée des fleur's qui couvrent l'axe de la grappe. 


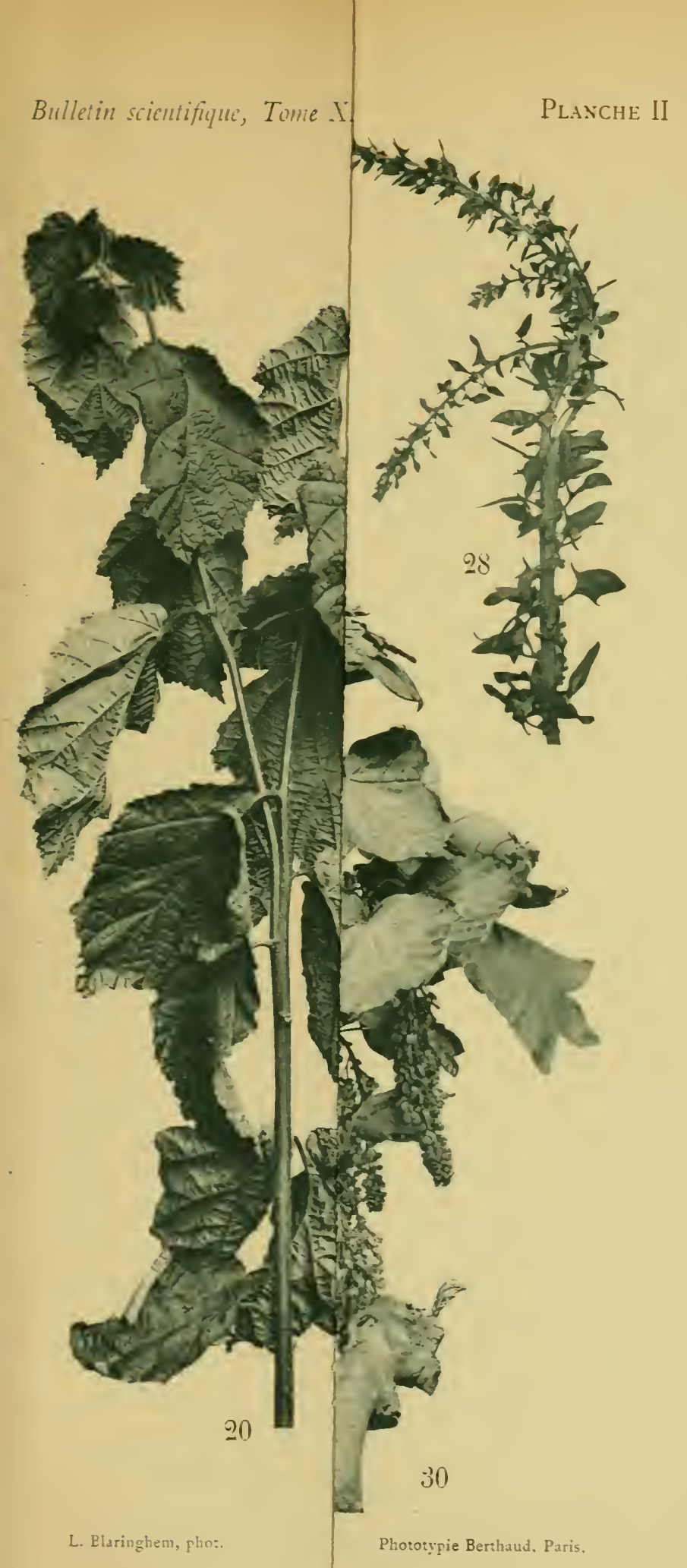




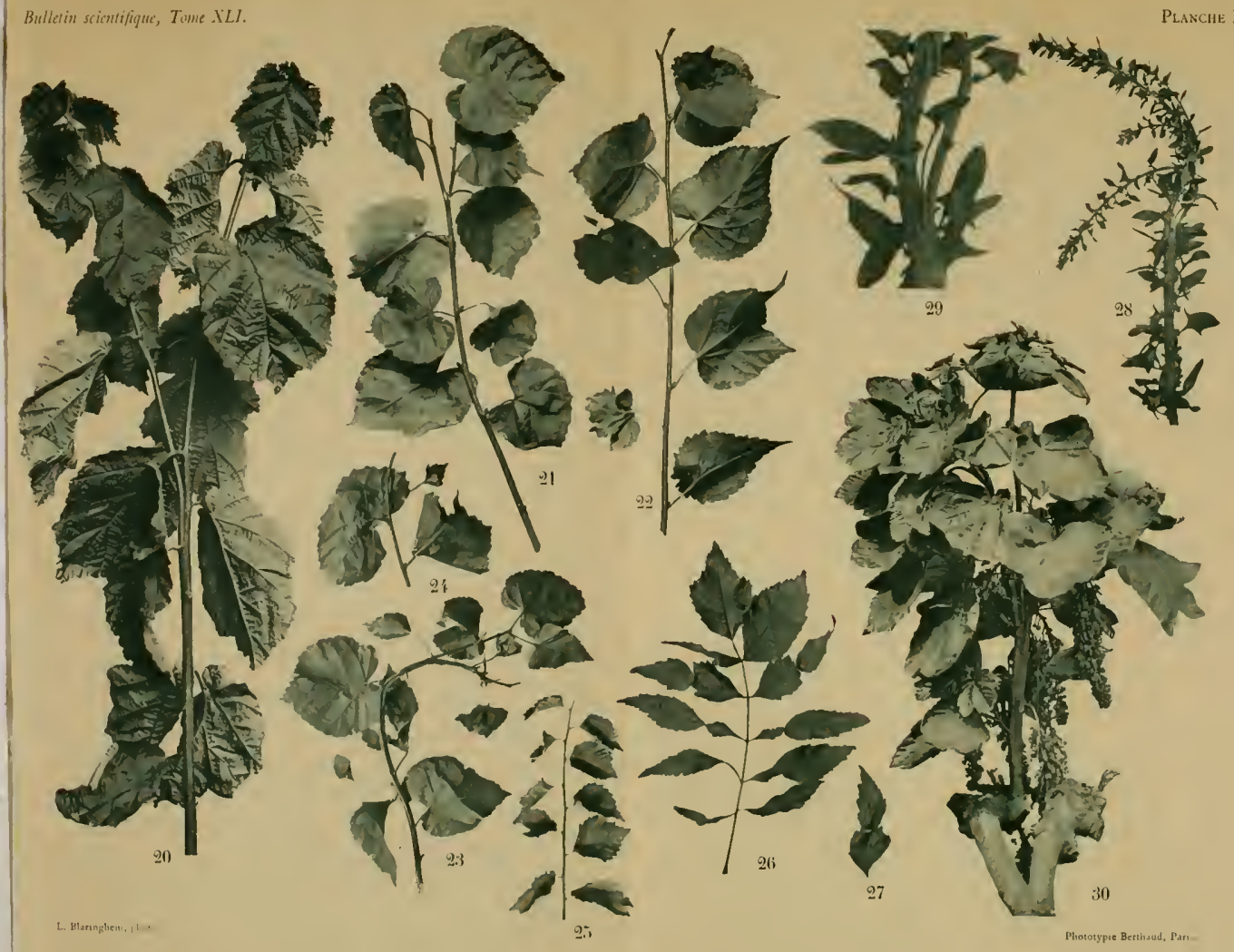

ANOMALIES DE TIGES ET DE FELILLES. 
PLANCHE III.

TIGES TORDUES DE MAÏS. 
Les figures 31-36 représentent des tiges tordues de Mä̈s de Pensylvanie; les figures 37-39 représentent des tiges tordues de Mcïs sucré tardif, Virmonin.

la torsion détermine le rapprochement des nœurls supérieurs de la tige de telle sorte que plusieur's fenilles sont insérées en des points très rapprochés. Tantôt la panicule est complètement libre (fig. 31), tantôt plusieurs rameaux de la base de la panicule sont insérés à l'aisselle de feuilles plus ou moins ávortées (fig. 32, $33,37)$. La torsion entraine donc, comme la fasciation, la condensation des organes et mème la suture de feuilles voisines (fig. 36).

C'est à cette condensation qu'il faut attribuer les analogies d'aspeet que présentent certaines inflorescences terminales (fig. 34 ) avee les inflorescences latérales femelles du Maïs. La présence fréquente d'épillets mâles métamorphosés en épillets femelles, dans les cas très accentués de torsion (fig. 35), montre que l'analogie n'est point apparente mais réelle et se traduit par des modifications corrélatives des qualités physiologiques.

L'état de torsion provoque, comme l'état de fasciation, des métamorphoses plus on moins accentuées des feuilles et des fleurs. Outre les cas, déjả citis de suture de fenilles et de faseie des rameaux de la panienle, il faut signaler l'avortement partiel des feuilles qui ne présentent plus de distinction nette eutre la gaine et le limbe (fig. 32.2), on la clisparition de la nervure centrale du limbe (fig. 3I) ou encore l'anomalie, non décrite encore mais très fréquente dans mes cultures de lignées tératologiques de Maïs, de la division du limbe en petites langnettes latérales (feuille de gauche de la figure 35 et feuille de droite de la figure 34 ). 
Bulletin scientifique, Tome XL PLAxche III

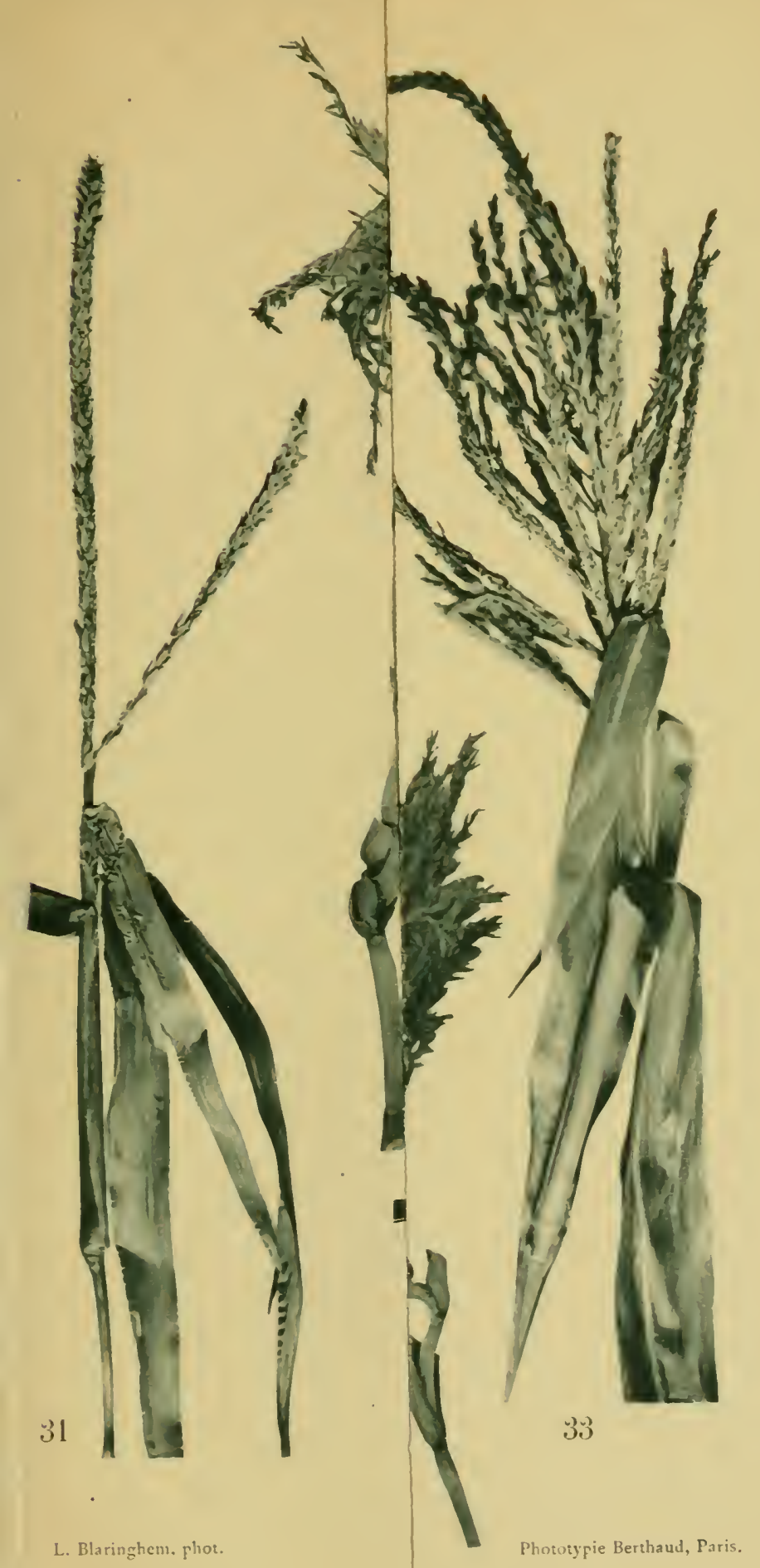




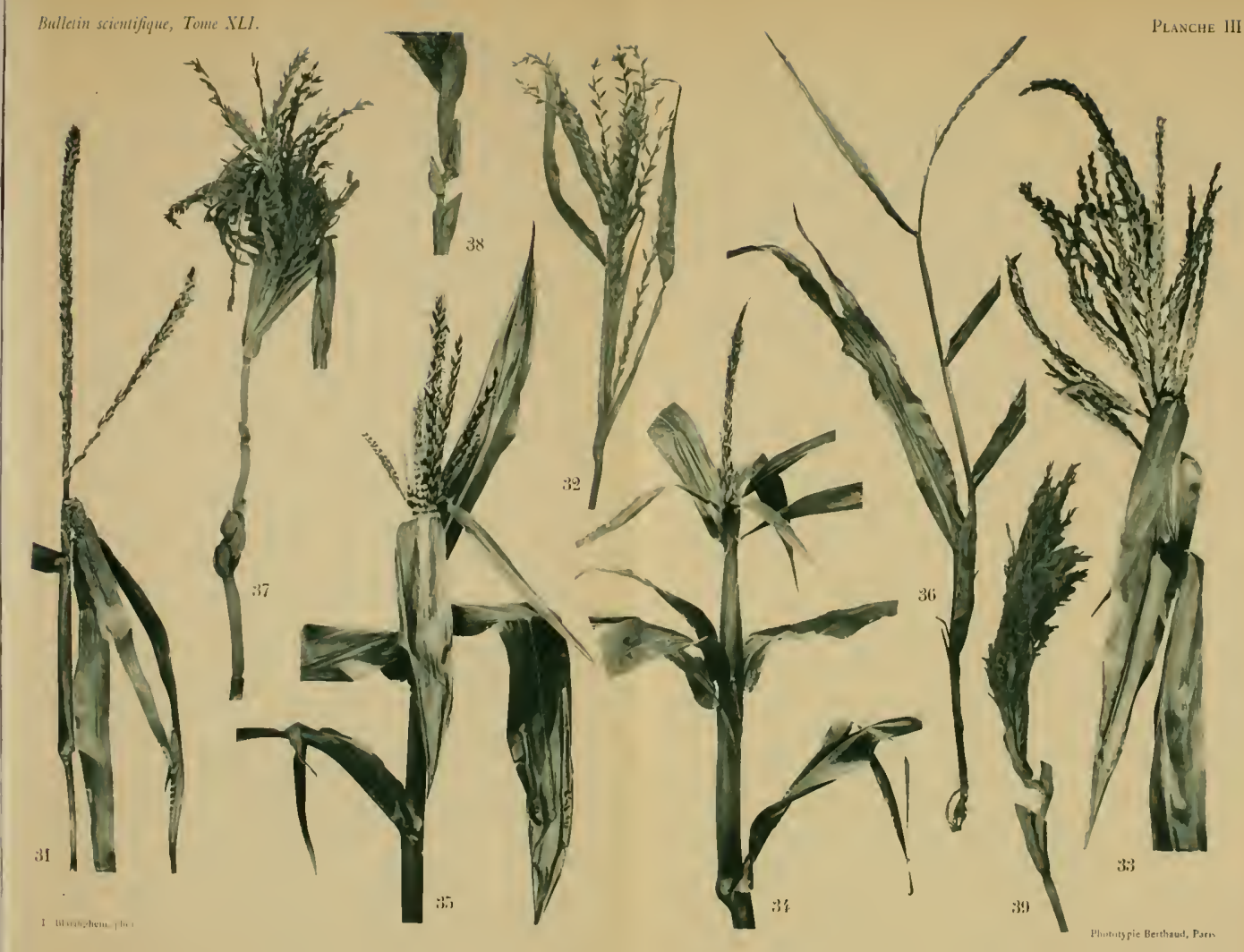

TIGES TORDUFS DE MAIIS. 
PLANCHE IV.

MAÏS A FEUILLES TUBULEEES ET ANOMALIES DU FRUIT DE SARRASIN. 
Les anomalies représentées par les figures 40 et 41 ont été observées sur le Maïs de Pensylvanie tératologique.

I es anomalies représentées par les figures $42-45$ ont été observées sur la variété instable de Mä̈s à feuilles tubulées.

Les anomalies représentées par la figure 46 sur une plante anormale de l'espèce élémentaire nouvelle Zea Mays praecox.

Le cas le plus fréquent dans les cultures et aussi le moins visible est présenté par les figures 40 et 46. Les bords de la gaîne de la feuille sont seuls soudés, le limbe normal s'étale dans un plan. La suture se fait de très bonne heure et le tube qu'elle forme continue à croître avec l'allongement de l'axe; il en résulte un plissement de la gaîne tout le long de la génératrice de moindre résistance. On aperçoit, sur la figure 40 , les lèvres du plissement qui ne seraient pas visibles si les bords de la gaîne ètaient libres car, dans ce dernier cas, ils glissent l'un sur l'autre en restant étroitement accolés. Parfois aussi, il n'y a point de plissement et l'extrémité ouverte du tube est arrondie; les deux tiers sont bordés par la ligule, et l'autre tiers (fig. 46) est formé par une membrane mince, continue quoique échancrée, couverte de nombreux poils.

L'anomalie présentée par la figure 41 est extrêmement rare; je ne l'ai observée que deux fois dans des lots différents de la variété instable à feuilles tubulées. Elle frappe les yeux à longue distance et n'a cependant point été signalée jusqu'ici.

L'étude des inflorescences représentẻes par les photographies $42-45$ est très suggestive. Elle montre l'avortement complet ou partiel des panicules enfermées dans les feuilles tubulées (fig. 45, 44 et 42) et explique les difficultés que présente la fixation complite de la variété à feuilles tubulées née dans mes cultures. Les individus les plus anormaux sont stériles.

L'association des feuilles tubulées avec d'autres anomalies de végétation est visible sur la figure 45 qui représente, à la fois, une tige tordue et une feuille tubulée pourvue de deux nervures principales; de même les figures 40 et 46 montrent la suture des bords des gaines, la fascie des axes et des rameaux des panicules et li métamorphose des épillets mâles en épillets femelles. La figure 43 représente un cas de feuille tubulée de Maïs résultant de la sulure de deux feuilles voisines et insérées au même nœud. Sur la même tige, la feuille inférieure offre la subdivision du limbe en lobes latéraux.

Fig. 47. - Fruit de Polygonum Fagopymum à 2 carpelles.

Fig. 48. - Fruit de Polygonum Fagopyrum à 3 carpelles.

Fig. 49. - Fruit de Polygonum Fagopyrum à 4 carpelles.

Fig. 50. - Fruit de Polygonum Fagopyrum à 6 carpelles.

Ces fruits ont été récoltés sur la même grappe florale fasciée de Sarrasin après la section des tiges au ras du sol. 
Iletin scicntifique, Tome XLI.

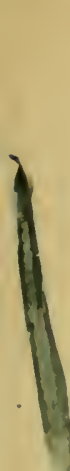

1
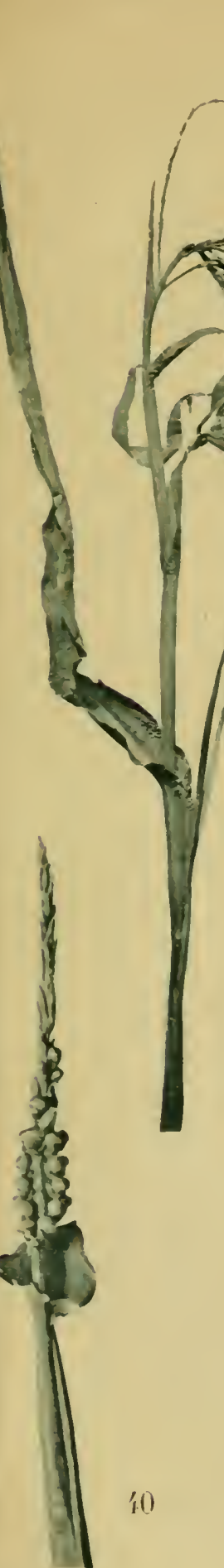

Hlaringhem. phot.

\section{Plaiche IV}
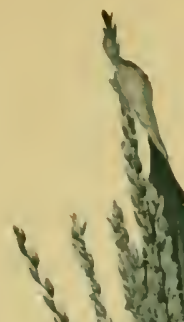

$-x_{4}$,

Nify

is $\operatorname{cts}^{2}$

in

yiy

iti
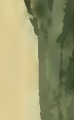

1 


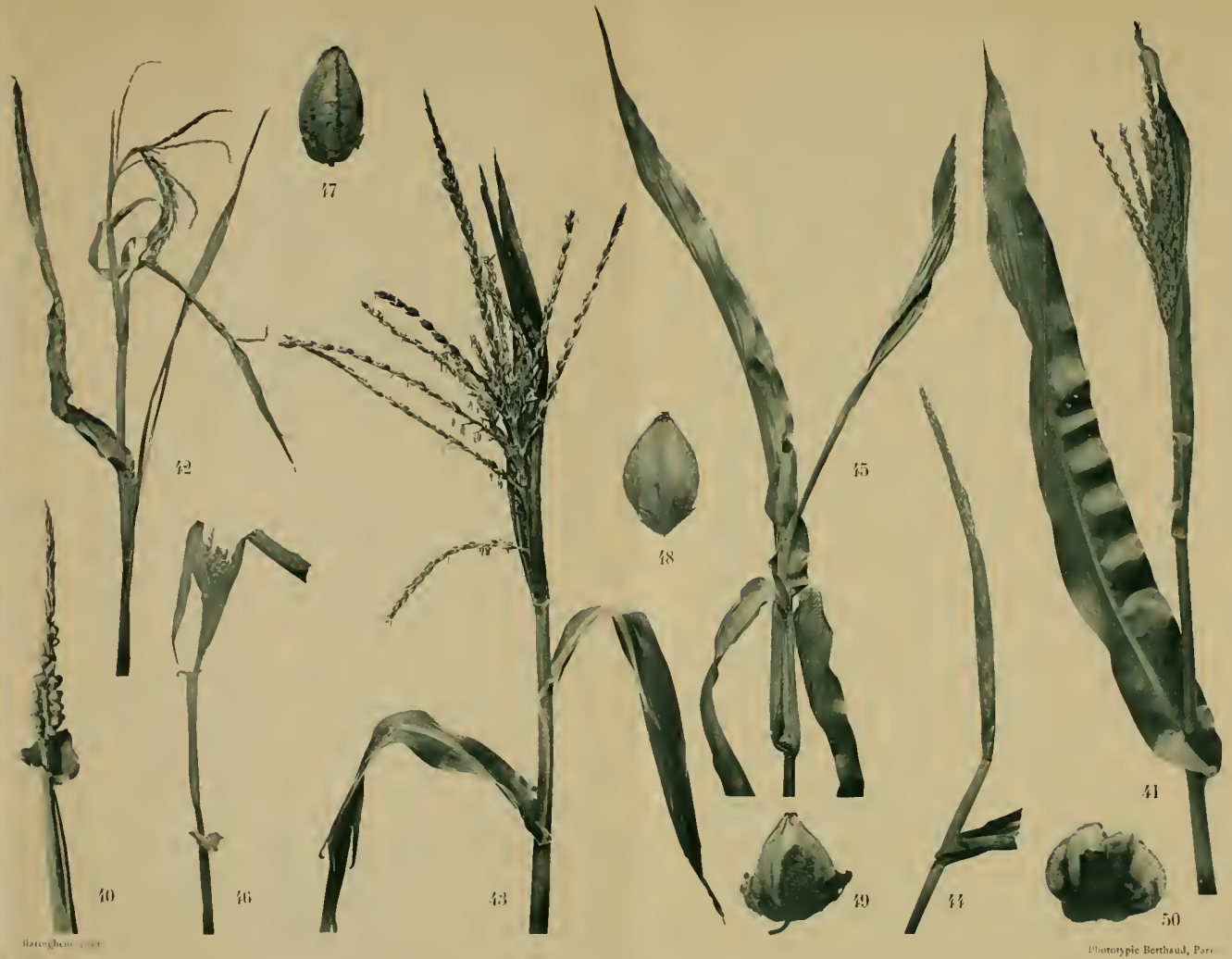

MAS A FECILLES TLBCLEES (Fig ill a iii)

1:T ANOMALJIS DL IRLIT DI: SARRASIN (Figures 47 a 50 ). 


\section{PLANCHE V.}

YAÏS A PORT PLEUREUR ET ANOULLIES DES ÉPILLETS DE LA PANICLLE. 
Fig. 51. - Panicule de Maïs de Pensylvanie normal au début de la floraison.

Fig. 52. - Panicule de Mä̈s à port pleureur photogiaphiée le mème jour que la panicule précédente, qui appartient à la série des plantes témoins. On aperçoit, à l'aisselle de la feuille inférieure, les extrémités des limbes des bractées qui enveloppent l'épi latéral.

Fig. .j.). - Panicule de Maïs à port pleureur en pleine floraison; une feuille bractée est développée à la base dı rameau inférieur.

Fìn. 5'ı. - Epi latéral femelle de la même variété, récoltẻ le même jour que la panicule précédente; le développement exagéré des limbes des bractées d'enveloppe, qui recouvrent les stigmates, rend difficile la fécondation des fleurs.

Fig. .5.)-5. - Portions de rameaux et épillets d'une inflorescence du type A. Les épillets sont mâles, mais leur's glumes sont partiellement métamorphosées et semblables á celles des épillets femelles. La déformation aflecte seulement les épillets sessiles.

Fig. "78-54. - Portions de rameaux de panicules déformées du type A remarquables parce qu'elles montrent l'association d'épillets mâles et femelles, quoique les glumes et glumelles de tous ces épillets aient subi une métamorphose complète.

Fig. (i). - Épillet femelle d'une panicule anormale de Maïs. Les deux fleurs femelles sont développées, et à chacune d'elles correspond un stigmate. Les glumes et les glumelles ont des caractères intermédiaires entre ceux des glumes mâles et ceux des glumes femelles normales. 


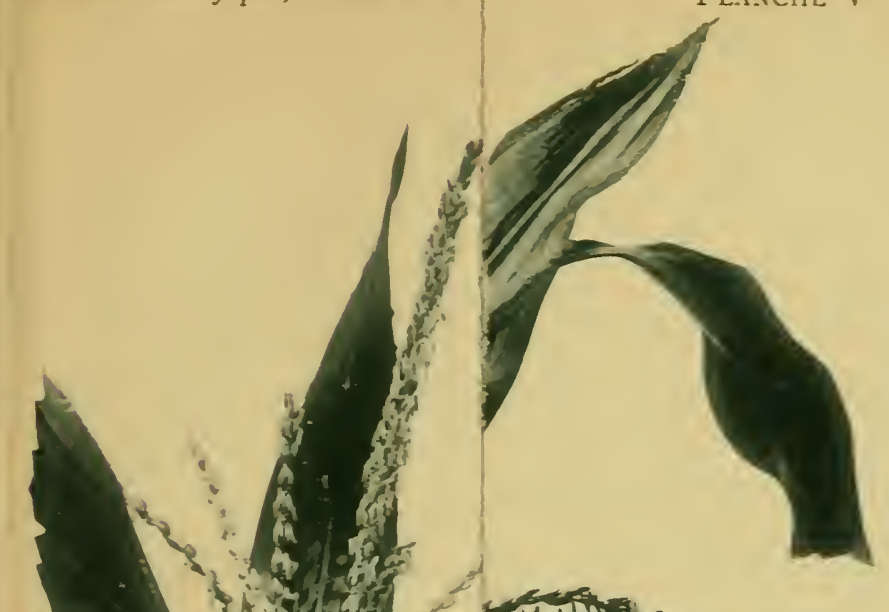




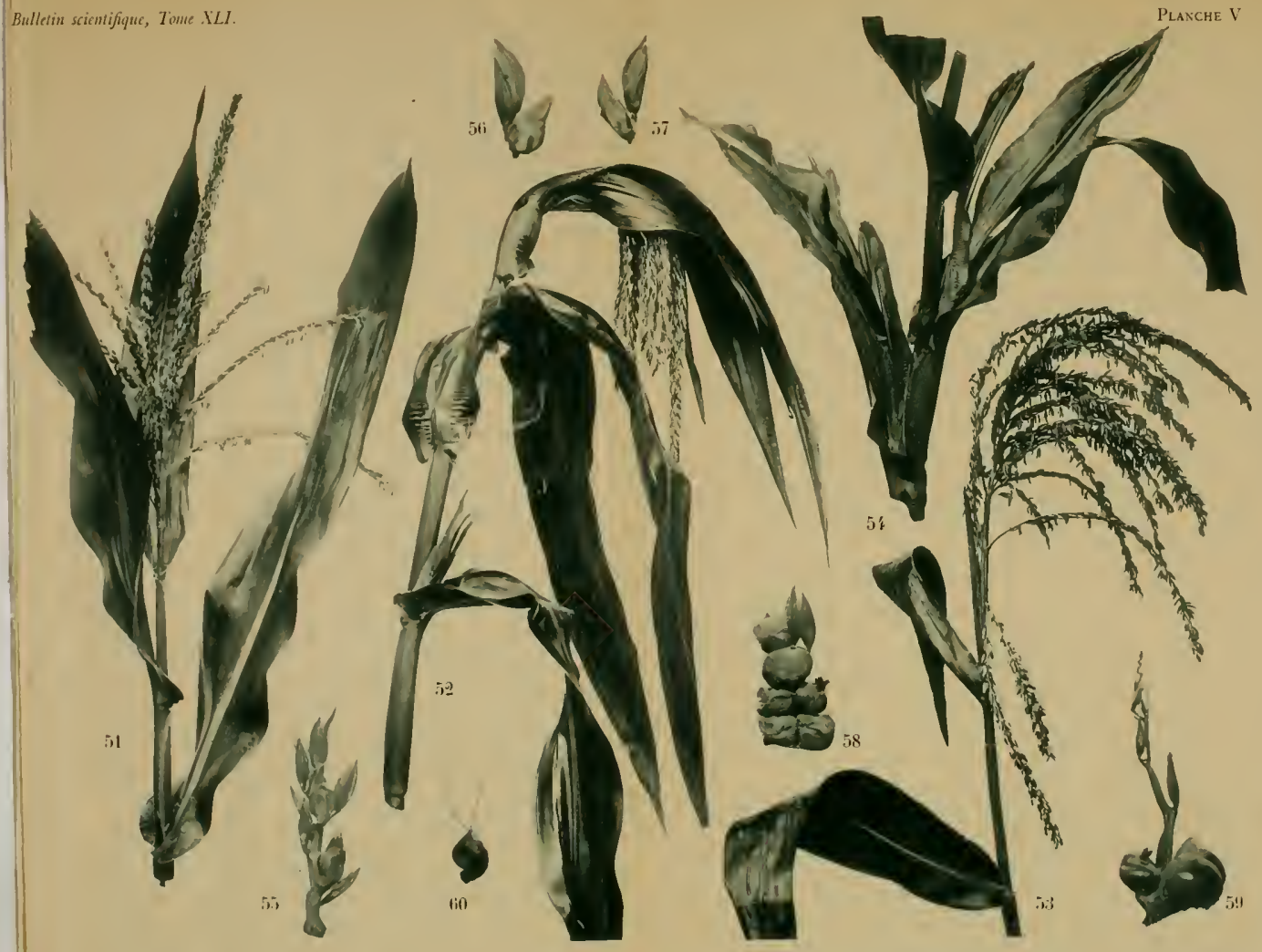

MAIS A PORT PLELRELR (Fig. DI-5i)

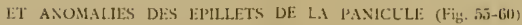




\title{
PLANCHE VI.
}

\author{
IAIIS TUNIQUÉ A ÉPIS «CHOL-FLEUR».
}

Fig. til. - Plante de la variété anomale $Z$ ea Muys tunicata à ćpis «Chou-fleur». La panicule présente des épillets màles métamorphosés soit en épillets femelles fertiles, soit en petits épis femelles non fertiles. Linflorence latérale, très épaisse, fait saillie hors des bractées d'enveloppe et oftre la ramification exagérée de l'axe; chaque rameau est un véritable épi ; l'épillet femelle est remplacé par un rachis couvert lui-mème d'épilletr femelles tuniqués et les enveloppes de l'épillet sont métamorphosées en bractées d'enveloppe d'épi. La tige de la plante est tordne comme il est facile de s'en apercevoir à la disposition spiralée des feuilles supérieures.

Fig. 62. - Panicule déformée de la mème variété. Les feuilles, quoique irrégulierement placées, sont moins rapprochées que dans le cas précédent et la torsion de la tige s'est accusée par la courbure de l'axe, favorisée par le poids considérable de l'inflorescence couverte d'épillets et d'ẻpis femelles.

Fig. (i3)-15.5. - Inflorescences observées sul le mème pied. La panicule (fig. 63) pst chargée de petits épis femelles analogues à celui que représente la figure 1 i4; l'inflorescence latérale (fig. 65) est ramifiée et complètement stérile.

Fig. (6)-iu. - Inflorescences latérales de la même variété dont la succession, dans l'ordre indiqué par les numéros des figures, correspond à une métamorphose croissante vers l'inflorescence « Chou-fleur 》 typique.

Les épis 66 et 67 sont les moins modifiès; les ramifications, enveloppées dans les bractées longues et épaisses, sont rẻgulièrement distribuées å la surface du rachis principal et occupent la place des épillets femelles des épis normaux; les ramifications sont aplaties, étalées dans un plan et imbriquées, comme le montre la figure 67 où on les a mis en évidence en enlevant une partie des bractées.

Aux figures 68 et 69 correspond une autre modification des inflorescences latérales. Après avoir' enlevé les bractées d'enveloppe principales qui r'ecouvrent l'épi tout entier, on observe une multitude de petites ramifications, couvertes elles-mèmes d'épillets femelles, imbriquées et distribuées sur toute la surface dı rachis; les bractées qui enveloppaient les ramifications sont disparues en totalité ou en partie. Elles sont encore visibles à l'extrémité de l'épi.

Enfin l'anomalie est developpée à son maximum sur l'épi représentẻ par' la figure 70 . Les ramifications inférieures sont totalement dépourvues de bractées d'enveloppe propres et ne sont plus aplaties: elles constituent des masses charnues de forme pyramidale, et, chacune d'elles est la réduction a une taille 
moindre de l'inflorescence totale représentée par la figure 68 . Il faut en faire l'examen microscopique pour isoler les éléments qui la composent.

Il n'est pas rare d'observer des inflorescences qui sont constituées par le mélange des différents cas qui ont été examinés. Les figures 71, 72 et 73 offrent la réunion, sans termes de transition, des ramifications enveloppées dans des bractées longues et épaisses et d'autres complètement nues et ramifiées à l'extrême.

Enfin les inflorescences monstrueuses de la varièté de Maïs à épis « Chou-fieur » trahissent fréquemment leur état de fasciation. On peut s'en rendre compte en examinant les pédoncules des épis représentés par les figures 72 et 73. 

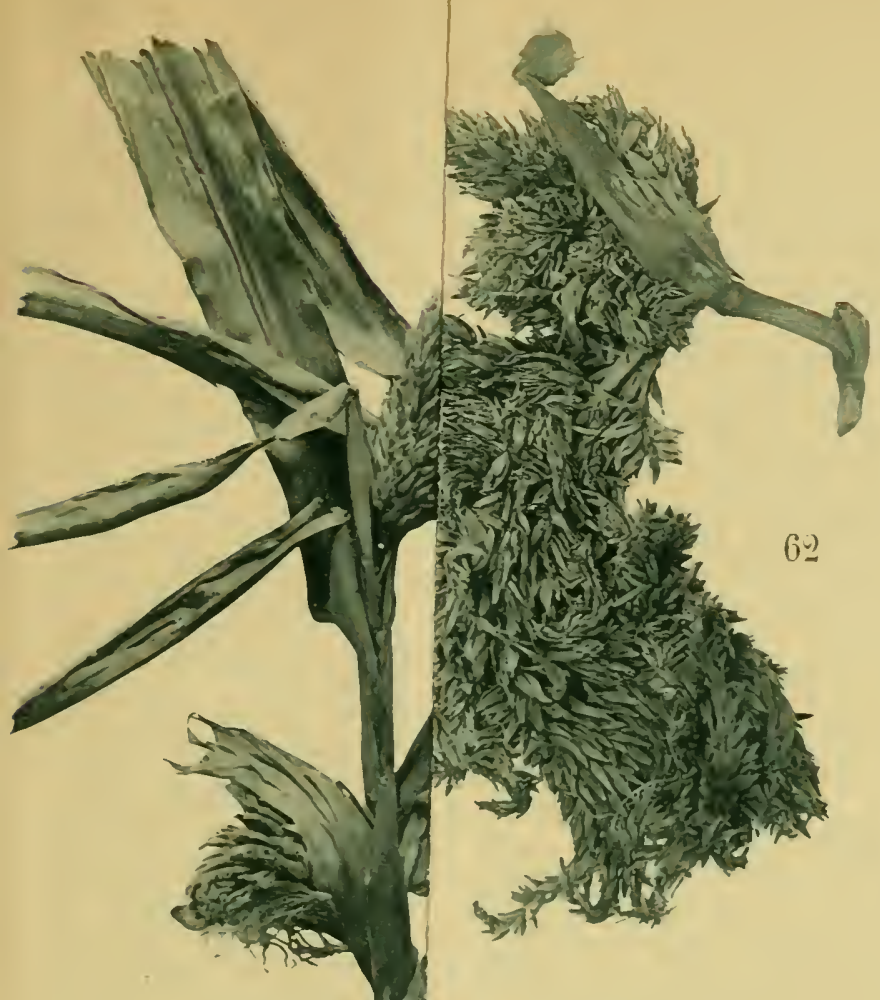

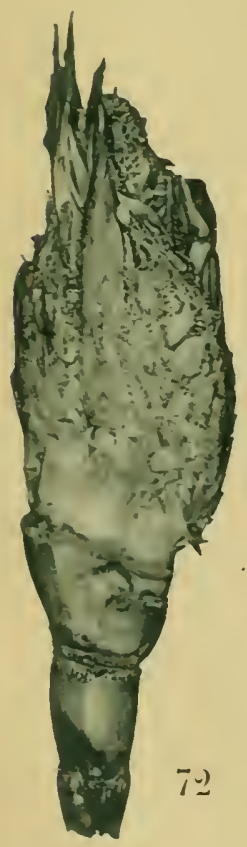

L. Blaringliem, phot.

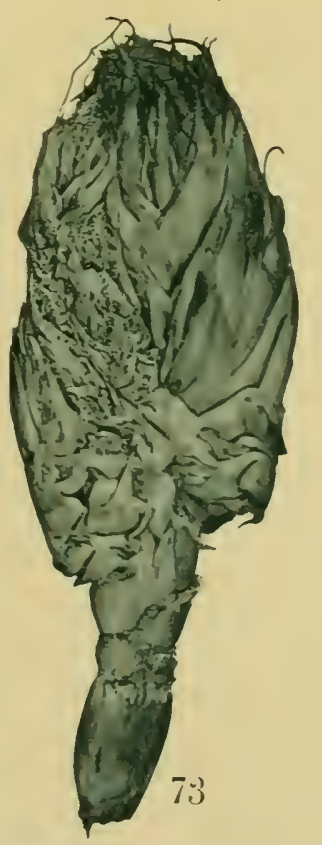

Phototypie Berthaud, Paris. 

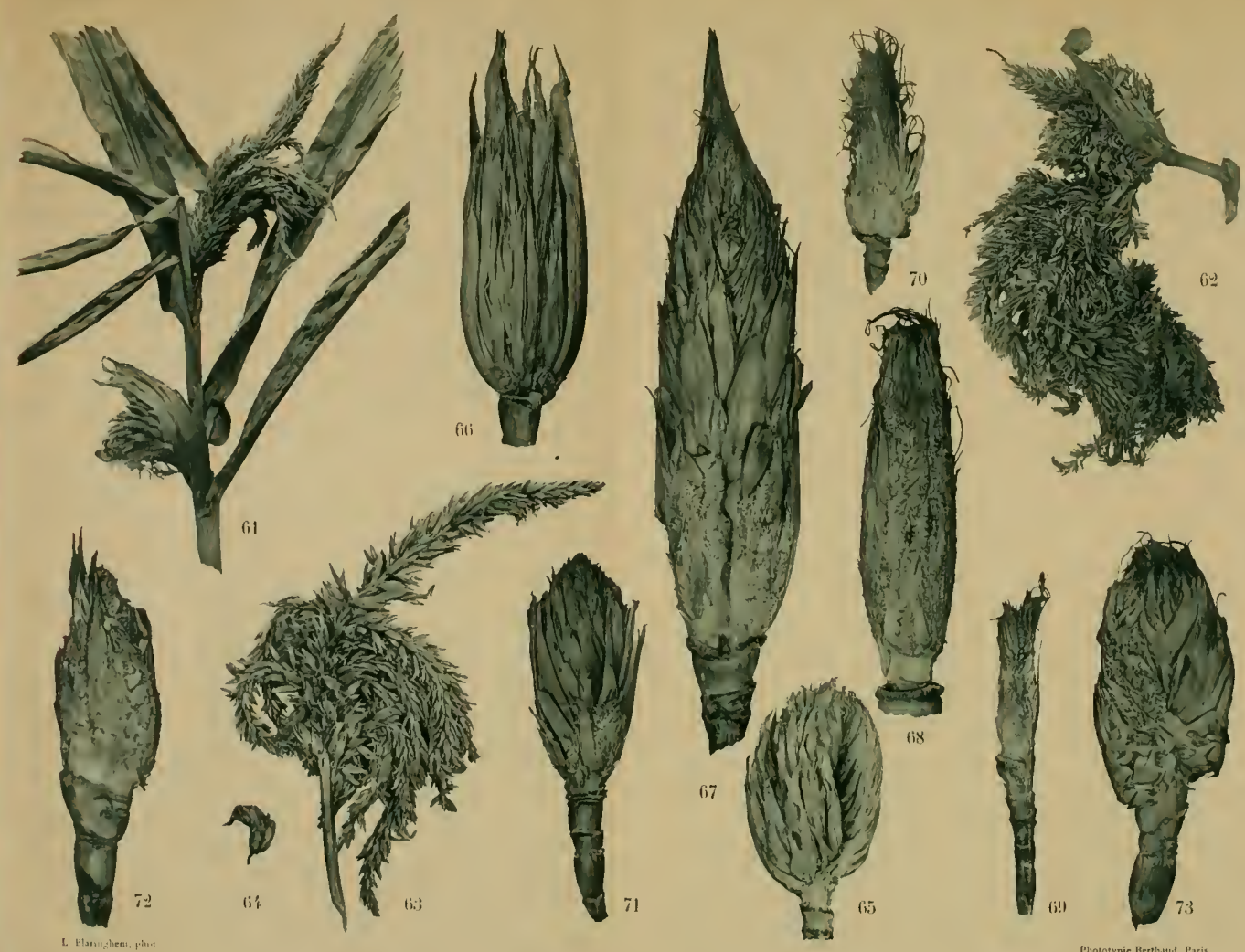

MAIS TLXIQLEE A EPIS "CHOU-FLEUR " 
PLANCHE VII.

ANOIJALIES DE GRAPPES FLORALES. 
Fig. 74-85. - Diverses anomalies provoquées sur Angelica silvestris.

Fig. 86. - - - -

Horderm distichum nutans.

Fig. 87. - $\quad$ - $-1 \quad$ - $\quad-\quad$ Avence sativa.

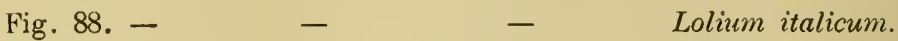

Fig. 89. - $\quad$ - $\quad$ - $\quad$ Enotherabiennis.

Ces figures sont destinées à montrer la dissociation ou la condensation des grappes, ou la substitution et le déplacement des parties sur les rejets développés après la seetion des tiges en périole de croissance rapide.

La dissociation des ombelles est visible sur les figures 74 et 75 ; la dissociation des épis sur la figure 86 ; la dissociation des panicules, sur la figure 87. L'ombelle, qui est une grappe condensíe dont les rameaux sont insérés aı même point de l'axe, est étalée dans le sens de la hauteur ; l'épi, d'ordinaire unique sur la tige, est remplacé par deux épis insérés en des points différents (tige médiane de la figure 86); la panicule de l'Avoine (tige de gauche de la figure 87), par deux panicules distinetes terminant un seul chaume. La dissociation d'une ombellule est représentée sur la figure 85 (en haut et à droite).

La condensation des ombelles entraîne la suture des rayons, des fleurs de l'ombellule et même des fruits (fig. 80-84) ou le rapprochement des épillets sur l'épi composé de Lolium (fig. 88). L'épi multiple de l'Orge (tige de droite de la figure 86) peut être regardé comme la condensation de plusieurs épis insérés à des hauteurs différentes sur le chaủme.

La substitution des parties est évidente sur la figure 76 ; le rejet de gauche porte une ombelle, grossie (fig. 77), comprenant une rosette de feuilles bractées, des ombellules et une tige tordue terminée par une ombelle normale. La figure 78 représente un phénomène analogue, et enfin, la figure 79 montre l'anomalie très curieuse de deux ombelles superposées et régulièrement placées à l'extrẻmité d'un même rejet. On peut regarder cette déformation comme résultant de la fascie des rayous centraux de l'ombelle inférieure, puis de la dissociation tardive et de la ramification régulière de cette portion de l'inflorescence.

La figure 89 correspond à un pied d'EEnothera biennis dont la tige fut coupée à 10 centimètres dı sol. Le rameau supérieur, développé au moment de la section, a donné des fleurs et des fruits normaux comme si la tige principale n'avait pas été enlevée; le rameau moyen montre le mélange de feuilles de rosettes, de feuilles caulinaires et de fruits. Le rameau inférieur porte, trés près de son insertion sur l'axe, un fruit mûr et normal; l'axe très court, porte ensuite plusieurs verticilles de feuilles dont l'ensemble constitue une rosette qui ne fleurira que l'année suivante. 


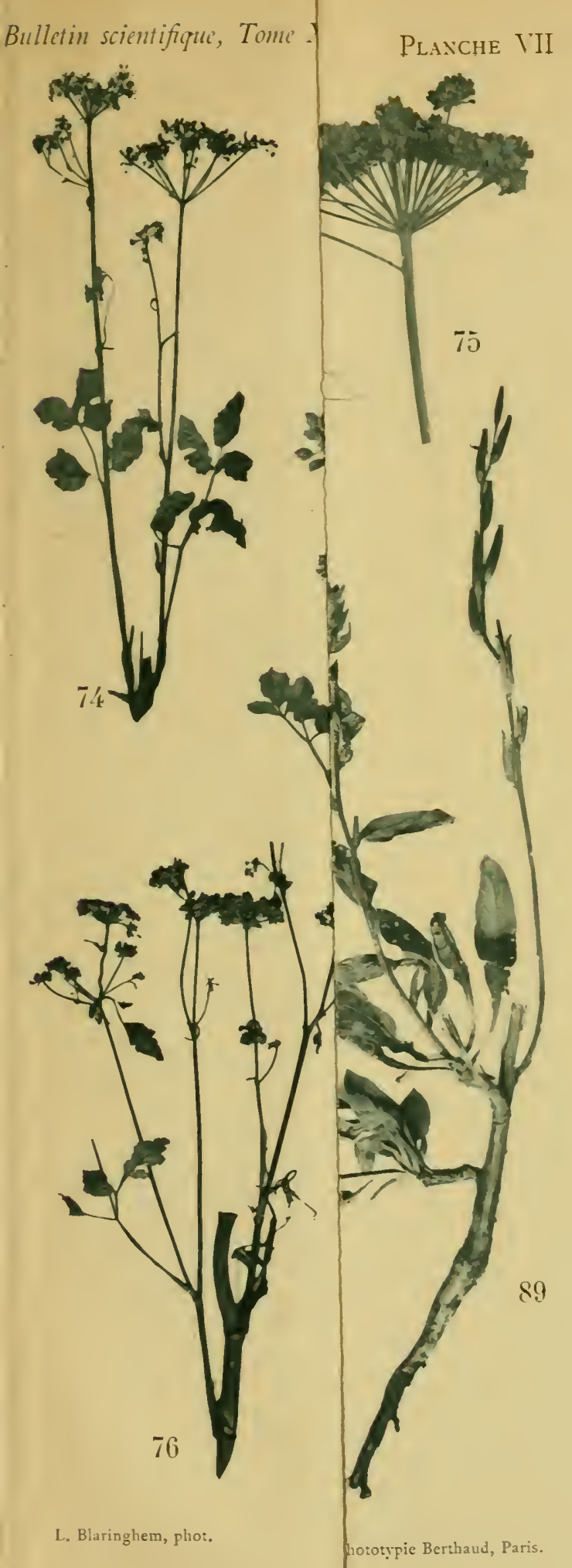




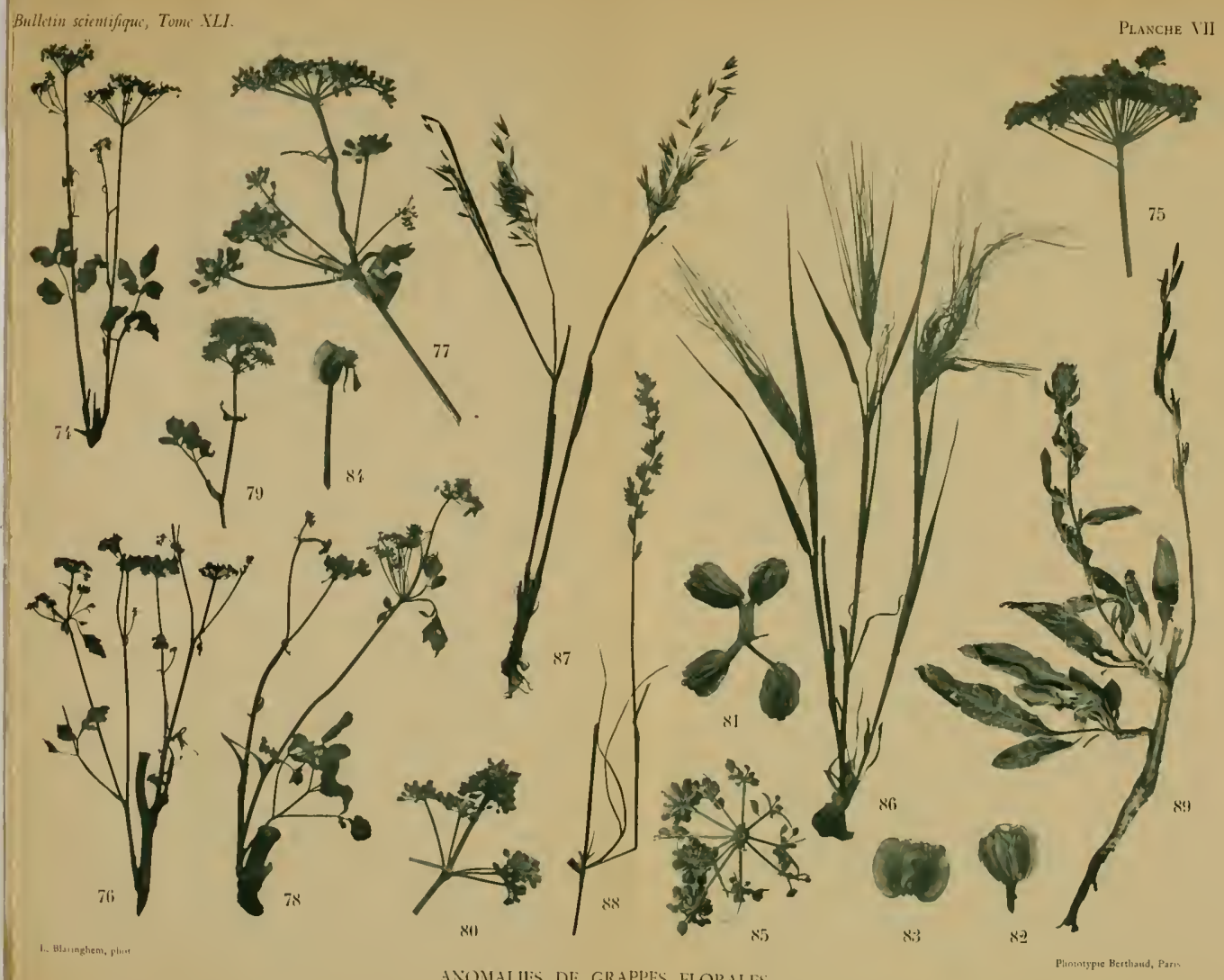

ANOMALIES DE GRAPPES FLORALES. 


\section{PLANCHE VIII.}

VARIETÉS NOUVELLES DE .YAÏ. 
Fig. 90. - Variété de Maïs Zea Mays pensylvanica Bonafous, origine des autres formes.

Fig. 91-94. - Variété nouvelle et stable Zea Mays pseudo-androgyna.

Fig. 95-97. - Variété nouvelle et instable de Maüs à épis dissociés.

Fig. 98. - Variété nouvelle et instable de Mcïs à épis ébréchés et à feuillage rouge.

Fig. 99. - Variété nouvelle et stable Zea Mays semi-praecox.

Fig. 100-104. - Espèce élémentaire nouvelle Zea Mays praecox.

Fig. 105. - Épi de Mä̈s de Pensylvanie montrant la métamorphose complète des épillets femelles en épillets mâles sans modification de forme des glumes et glumelles.

On peut observer sur les figures 91 et 95 l'aspect extérieur des épillets hermaphrodites; à droite de $\mathbf{a}$ et à gauche de $\mathbf{b}$, on aperçoit l'extrémité des étamines visibles surtout après l'enlèvement d'une rangée de graines. Les étamines restent souvent attachées au pédoncule des fruits (fig. 92 et 93 ); elles se développent même lorsque l'ovaire n'est point fécondé (fig. 94).

Les figures 101 à 104 montrent les particularités très curieuses des panicules de la variété instable Zea Mays praecox à glumellules métamorphosées en stigmates; on aperçoit les stigmates qui font saillie hors des glumes dı rameau de la panicule (fig. 101); ils correspondent à la métamorphose des deıx glımellules (fig. 102), ou d'une seule (fig. 103); il est beaucoup plus rare d'observer la même métamorphose sur l'une des glumelles (fig. 104). 
Bublctin sichotifigus:
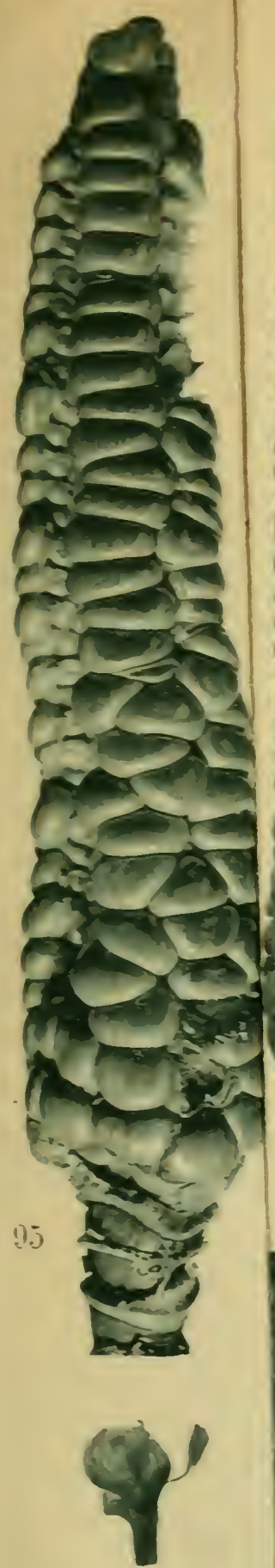

!1!
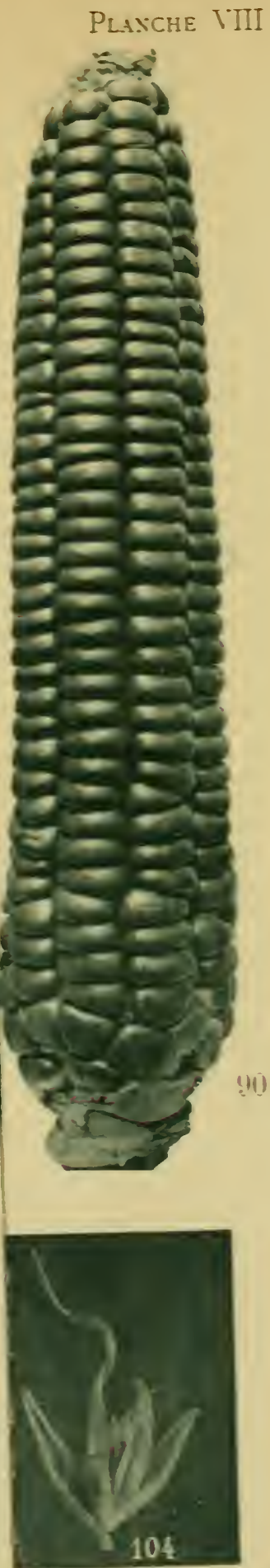

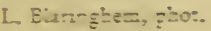


Bulldtin scientifique, Tont XLI.
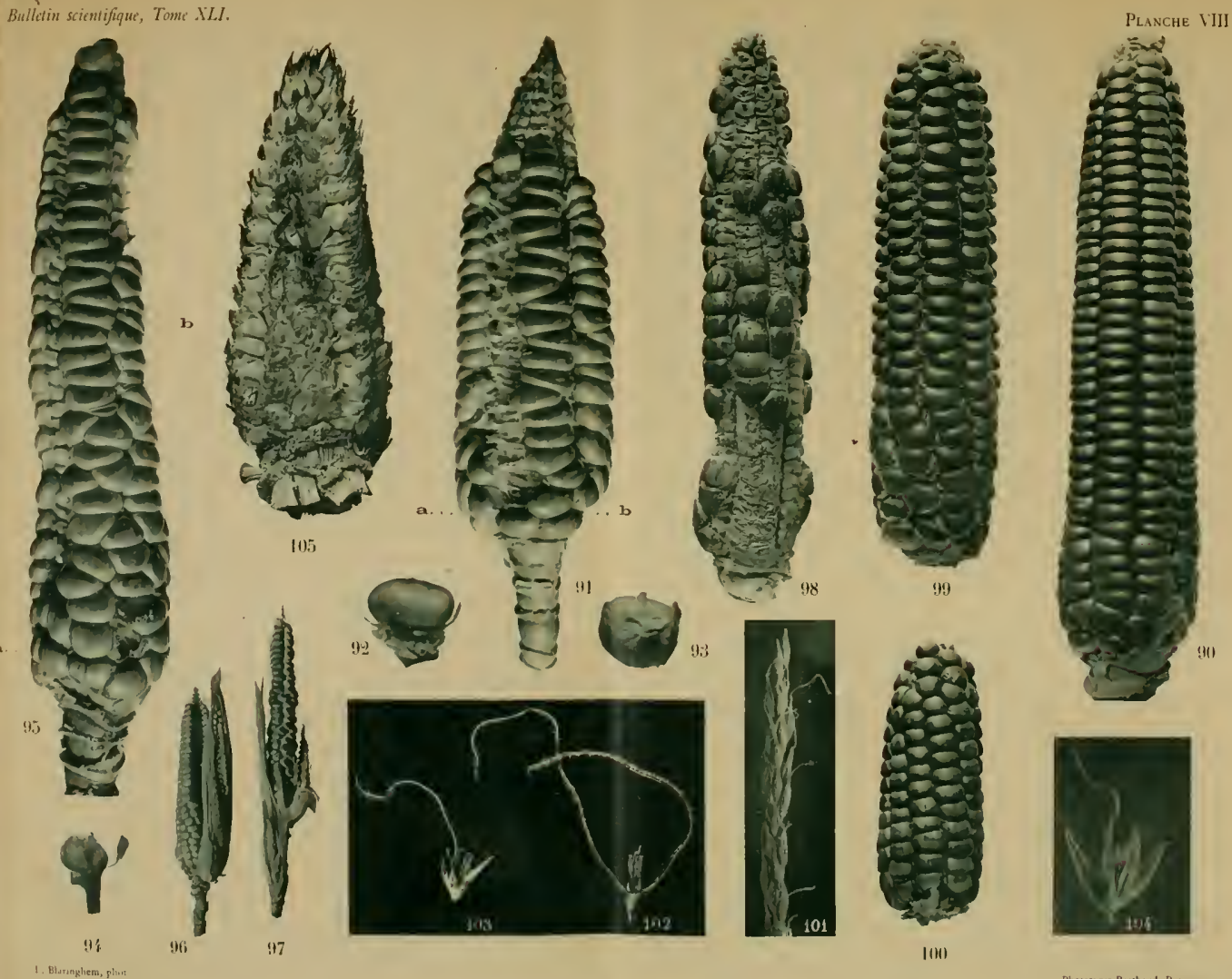

VARIETIS NOUTELLES DE MAISS. 
$x_{x \rightarrow 3}=x^{2}$

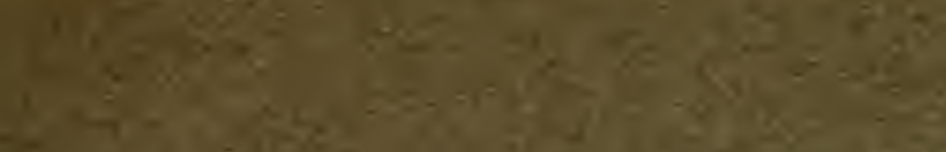

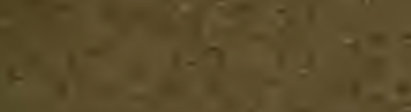

$+\frac{1}{8}, \frac{3}{3}=0$

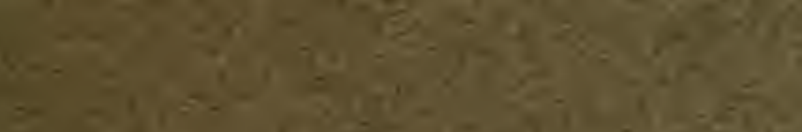

$\therefore: 405,15$

$8=9$

$$
\text { ing }
$$

to

sis is

G.

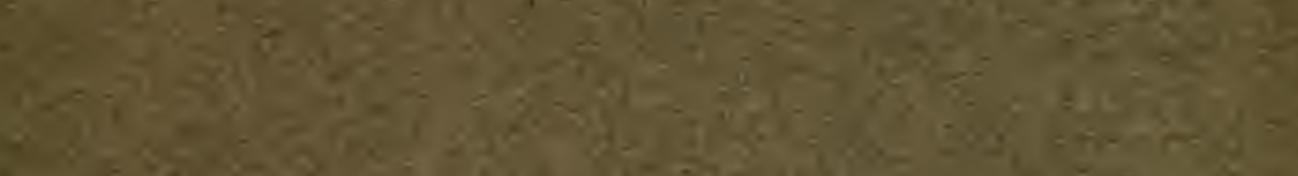

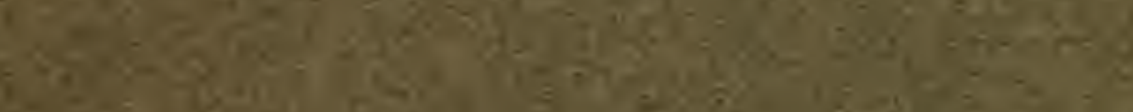

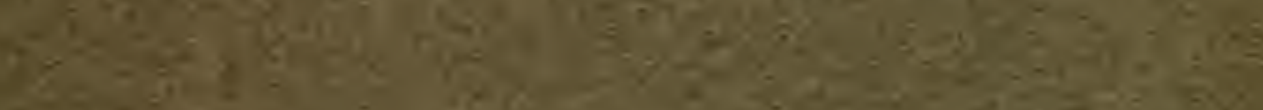

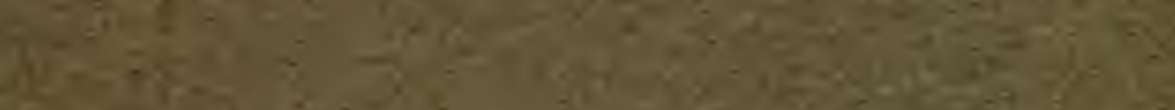

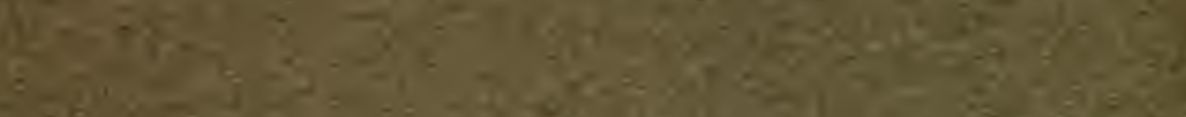

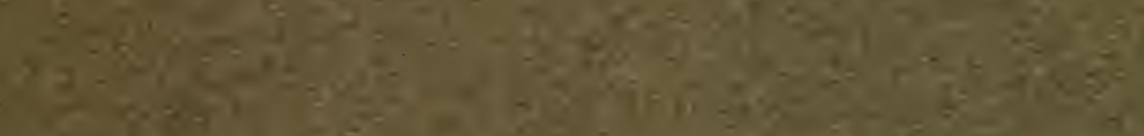
The

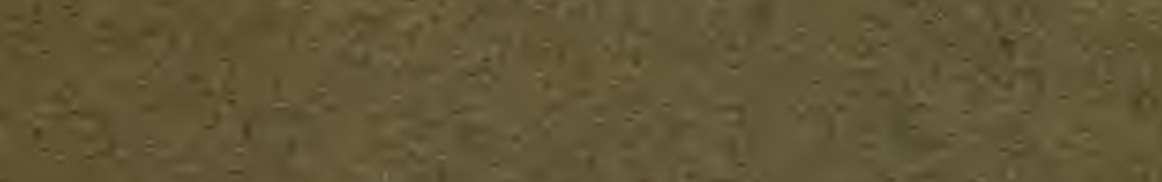
F)

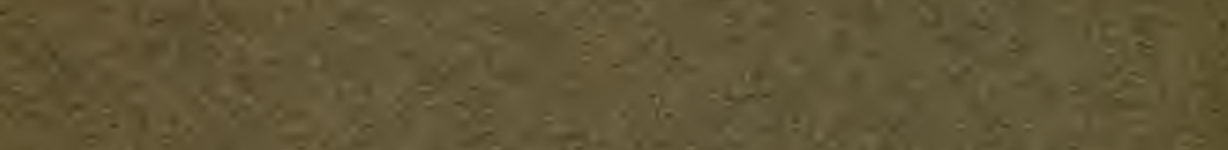

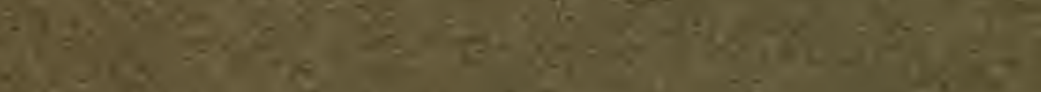

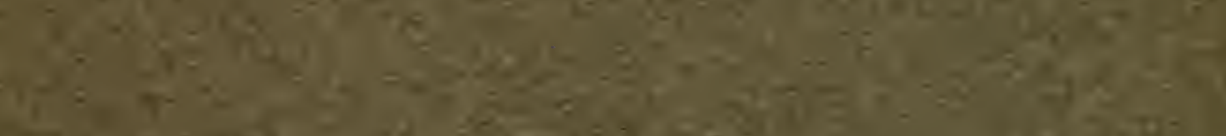

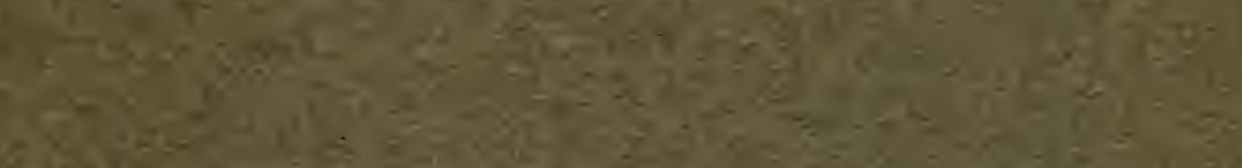
ax

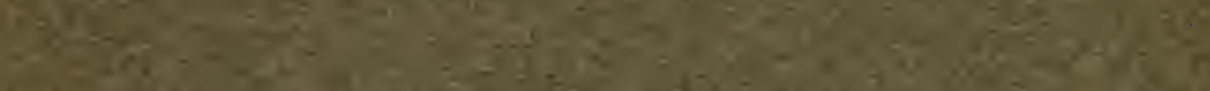

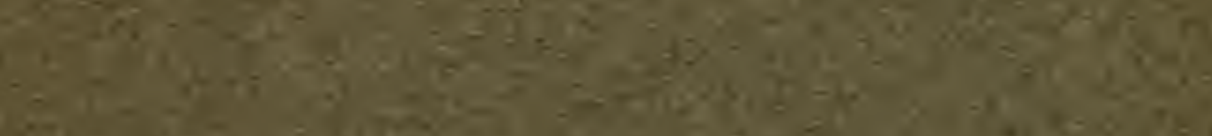

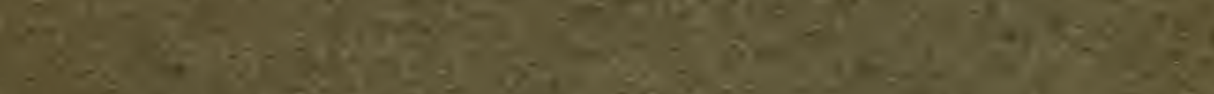

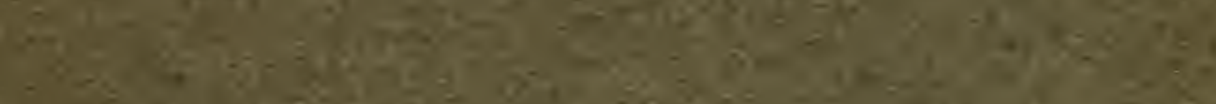

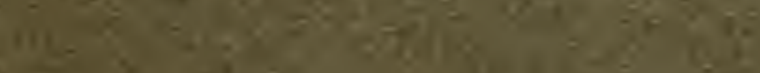




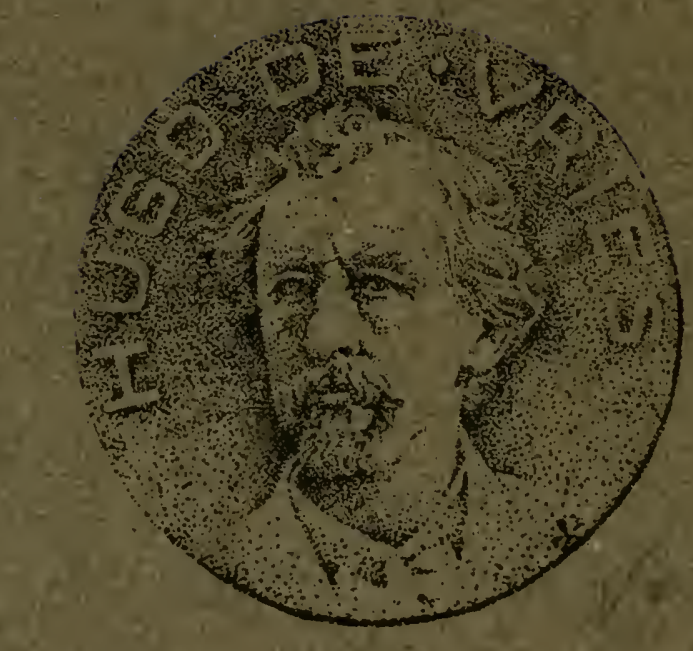

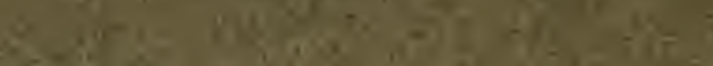

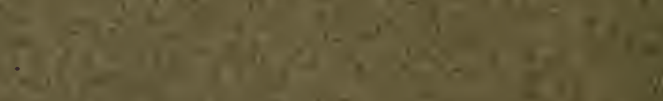




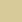





QL $34.24 j$ B B55

Blaringhem Louis/Mutation et traumatism

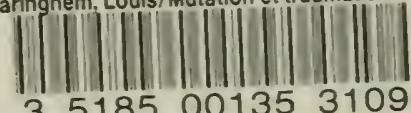

35185001353109 


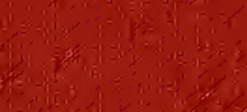

(8) 178

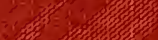

3. 00000

G.

6.8.

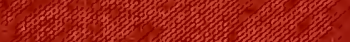

\begin{tabular}{|l|l|l|l|l}
\hline & & & \\
\hline
\end{tabular}

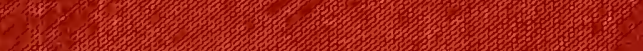

1.72

1.7.7.

7.

17,

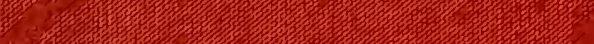

87 17 1

7.7.7.

107,

,

137

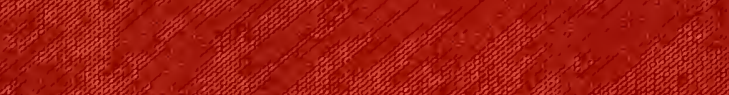

1.

3.

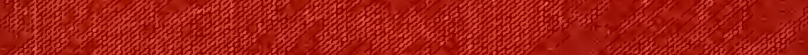

1010

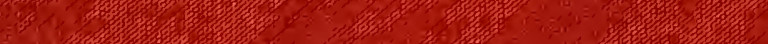
1. 30.

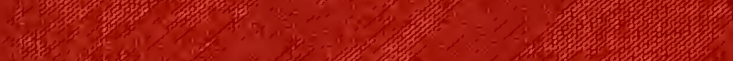

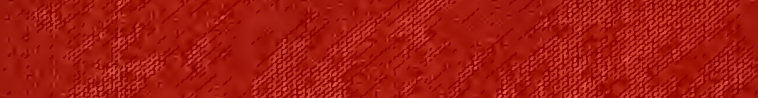

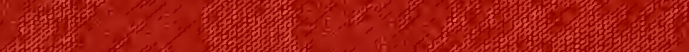

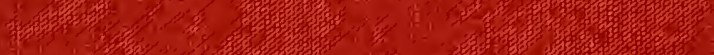
1, 3.

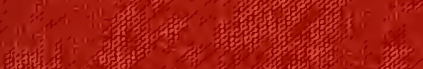
(y)
1.
(3)

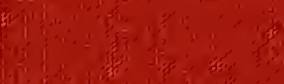

24

Q3

ard

得的

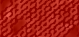

(1)

i 6 